\title{
INTERCULTURAL LANGUAGE TEACHING IN VIETNAMESE TERTIARY EFL CLASSES: A PARTICIPATORY ACTION RESEARCH STUDY
}

By

TRAN THI PHUONG THAO

\begin{abstract}
A thesis
submitted to Victoria University of Wellington in fulfilment of the requirements for the degree of Doctor of Philosophy in Applied Linguistics
\end{abstract}

Victoria University of Wellington, New Zealand 2020 


\section{STATEMENT OF AUTHORSHIP}

I, Tran Thi Phuong Thao, hereby certify that this thesis entitled

Intercultural Language Teaching in Vietnamese Tertiary EFL Classes: A

Participatory Action Research Study

submitted in fulfilment of the requirements for the degree of Doctor of Philosophy in Applied Linguistics issued by Victoria University of Wellington is my own work under the supervision of Associate Professor Jonathan Newton and Dr Corinne Seals.

This thesis has not been submitted for the award of any degree or diploma in any other institution. 


\section{DEDICATION}

Dedicated to my parents. Tran Duc Hoa and Nguyen Ngac Anh, for their love and trust an me, to my husband for understanding me and to my daughter for her wanderful company! 


\section{ACKNOWLEDGEMENTS}

I owe thanks to many people whose support is worth more than my gratitude.

First, I wish to express my endless gratitude to my primary supervisor, Associate Professor Jonathan Newton. Working under his supervision is the worthiest experience in my academic life I have ever had. I experienced many moments when I was academically motivated, appreciated, encouraged, independent, and most importantly enlightened by his wisdom and kindness. His supervision guided me to reach the best of myself. Second, I wish to express my wholehearted gratitude to my secondary supervisor, Dr Corinne Seals for her academic support and her enthusiasm to supervise me. Without her helping hands, especially in the critical times of my PhD journey, it would not have been possible for my thesis submission to be completed in time. I am proud to be their student. Third, my special gratitude goes to my examiners for their very helpful comments on my project.

I must thank the Vietnamese Ministry of Education and Training and Victoria University of Wellington (VUW) for funding my study. I am also thankful to the lecturers and staffs at the School of Linguistics and Applied Language Studies (LALS), especially Dr Jean Parkinson, Dr Patrick Coelho, Dr Le Nguyen, Janet Attrill, Bernie Hambleton, and the librarian Tony Quin for their assistance; Emily Greenbank and the advisers at VUW Student Learning, especially Kristen for their proofreading.

I am grateful to my participants for their time and cooperation. Their voluntary participation and interest in the research topic were amazing. I would like to pay my special regards to the University and School leaders, the lecturers and colleagues at my university in Vietnam for their consideration and facilitation before and during my study.

Many thanks go to all my PhD friends who supported me as member checkers, supporters, proofreaders and free drivers: Mrs. Bình, Mr. Tiến and his family, Chí Đức, Trang Bùi, Lộc Nguyễn, Mark Toomer, Anna Hoàng, Hoàng Phan, my office mates at VZ410: Muhammad Iwan Munandar, Paweena Jaruteerapan, Hằng Nguyễn, Erandi Kithulgoda, Brittany Hoback and Xin Chen, and many other friends at LALS. I would like to appreciate my friends: Loan Đỗ, Dung Nguyễn, and especially those at house 37B Devon Street: Thủy Trần, Thủy Bùi and Vân La for their sharing the turns of collecting our children from schools and the laughs we had together. My wholehearted gratitude goes to Mrs. Huyền Lê for her compassionate saving. She always encouraged me to grow my soul in Enlightened Wisdom of Compassion and Awakening. Thanks 
to this, I could successfully undertake my PhD journey. I also owed my Kiwi and my German friends who treated me very nicely in New Zealand.

My deepest gratitude goes to my parents and my brothers for their love and encouragement. I am deeply thankful to my parents in-law for their support and availability for helping me and my child. I sincerely want to thank my husband THANH-BINH NGUYỄN for his understanding of my PhD journey, which helps me feel calm. Finally, I love to express my appreciation to my daughter JOLIE NGUYỄN THẢO NGUYÊN who contributes greatly to my academic achievements by her wonderful company during my journey overseas since she was four years and three months. Her footsteps followed me to campus and all walks in Wellington regardless of any weather. She played by herself while I was studying and asked me about when I would submit the thesis. She flew with me for my data collection and conferences between Vietnam, New Zealand and Australia. She cheered me up by fun activities.

“Jolie đẹp xinh

Đôi mắt thông minh

Nụ cười lung linh

Chứa chan ân tình

Cùng mẹ chiến chinh, suốt cuộc hành trình."

(Pretty Jolie

Your smart eyes

Your loving smiles

Full of your care and love

Accompanying mom during her hard journey). 


\section{ABSTRACT}

In 2008, Vietnam introduced a new English language policy based on the Common European Framework of Reference (CEFR), and subsequently in 2014 adopted a Vietnamese version of this, referred to as CEFR-V. In adopting the CEFR-V, English language education in Vietnam has taken on a conception of English language proficiency in which intercultural competence (IC) is thoroughly integrated. Nevertheless, despite the emphasis of IC in national language policy, little research has dealt with how teachers can adopt interculturally informed pedagogy in their daily classroom practice, and specifically professional development and learning can be harnessed to increase teachers' capacity to adopt an intercultural stance in their teaching. This study aimed to redress this gap by investigating the process of adopting Intercultural Communicative Language Teaching (iCLT) practice in an English as a foreign language (EFL) course at a Vietnamese university.

The research deployed an interpretive, qualitative, case study approach and Participatory Action Research (PAR) to explore the nature of the teaching of culture by three tertiary EFL teachers at a Vietnamese university, and by the students in their classes. The data were collected from classroom observations, teacher interviews, and pre-workshop-one and postworkshop-two focus groups with students. The research included two phases.

The first phase of the study investigated the orientation to the teaching of culture in teaching materials and lessons taught by the teachers, and in their stated beliefs. Analysis of the three case study teachers showed that each of the teachers demonstrated both strengths and limitations regarding the teaching of culture in his/her stated perceptions and classroom practices. Cross-case analysis showed that the teaching of culture was intermittent and unplanned, and that the teachers held a static view of culture with little awareness of intercultural language teaching.

Drawing on these findings, the second phase of the research sought to develop a more principled engagement with culture by involving the case study teachers in two workshop cycles in which the teachers were introduced to principles and practical examples of intercultural language teaching and then implemented the redesigned intercultural-oriented lessons in the classroom teaching. The results drawn from classroom observation and interview 
data showed a positive impact of the workshops on the teachers' teaching practices, perceptions, and understanding of intercultural language teaching.

The study contributes to the growing body of scholarship on intercultural language teaching by showing how Vietnamese EFL tertiary teachers shifted from a cultural to an intercultural orientation through participating in an action research project. Accordingly, this study confirms the value of in-situ professional development for teachers. The study also shows how teachers, working from a set of intercultural teaching principles, can adopt an intercultural stance in their teaching even while working with existing teaching materials that contain little in the way of intercultural teaching affordances. 


\section{TABLE OF CONTENTS}

STATEMENT OF AUTHORSHIP .ii

DEDICATION ...iii

ACKNOWLEDGEMENTS . .. iv

ABSTRACT .vi

TABLE OF CONTENTS. viii

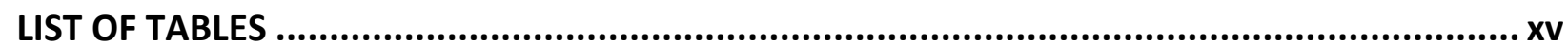

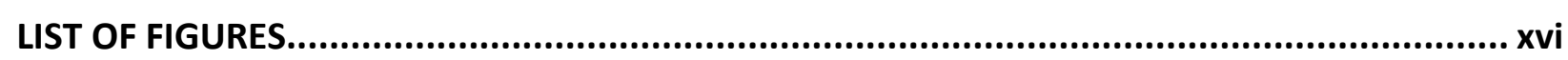

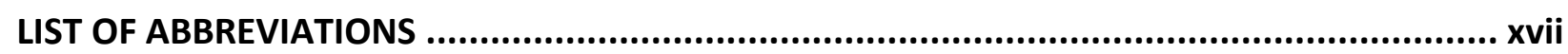

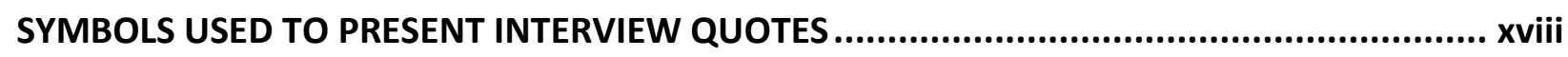

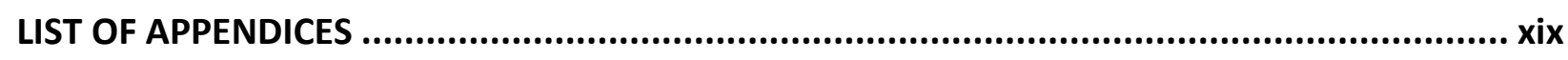

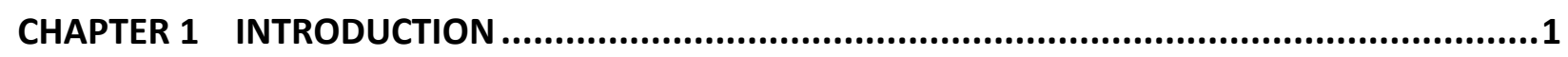

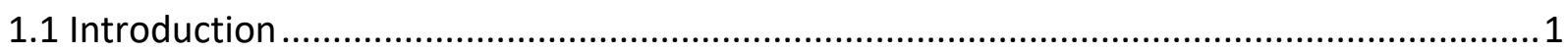

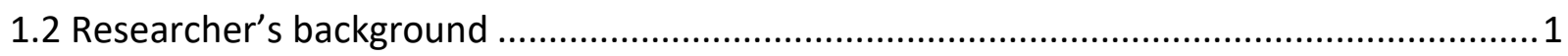

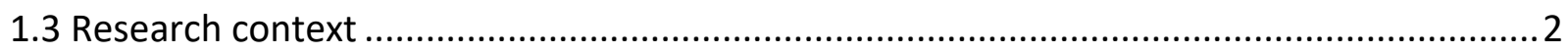

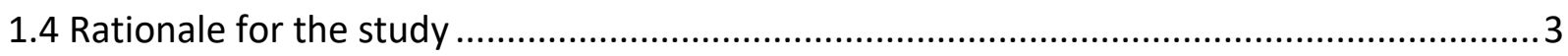

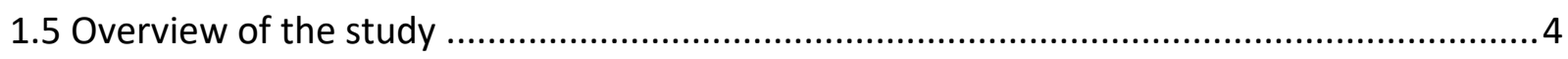

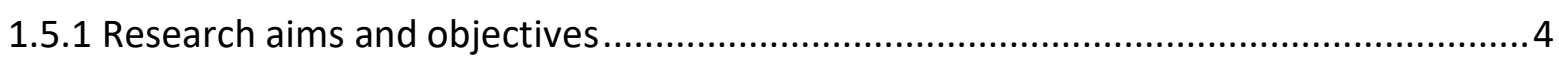

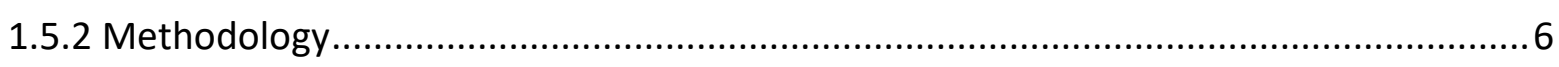

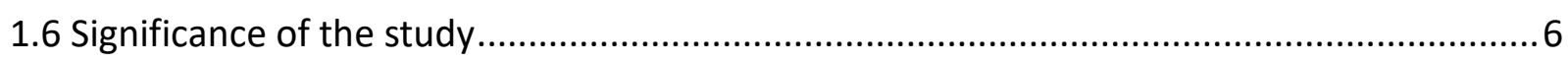

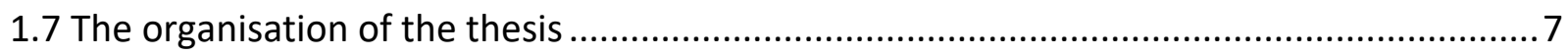

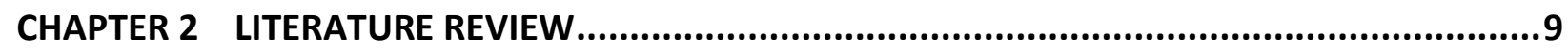

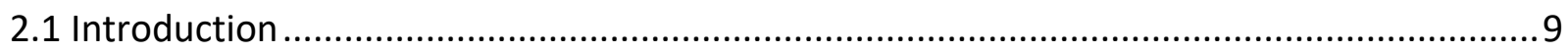

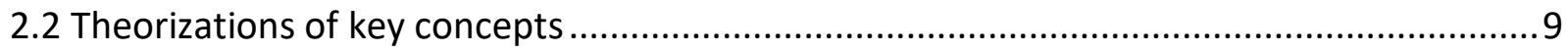

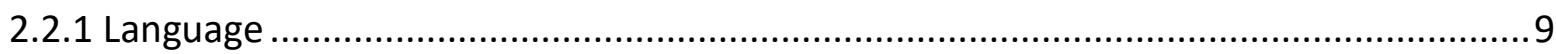

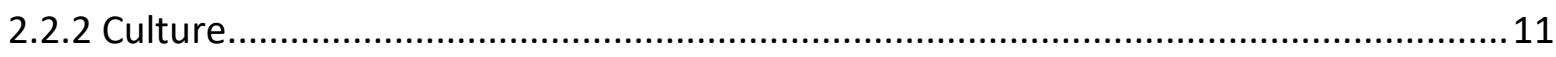

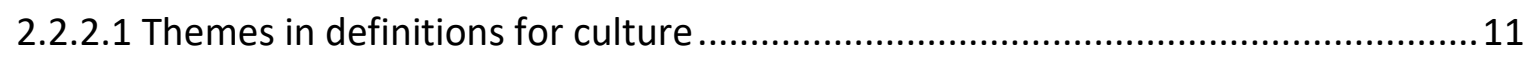


2.2.2.2 Approaches to culture in intercultural communication ....................................13

2.2.2.3 Modernist and postmodernist perspectives of culture .....................................15

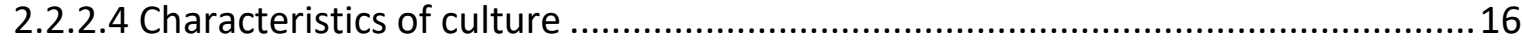

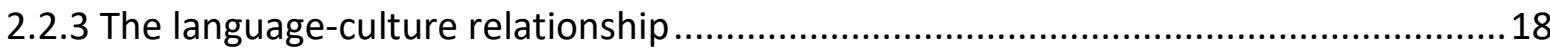

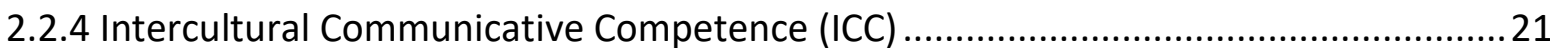

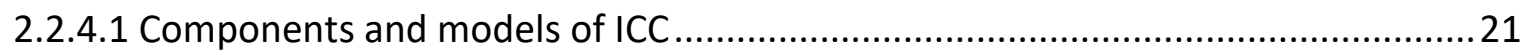

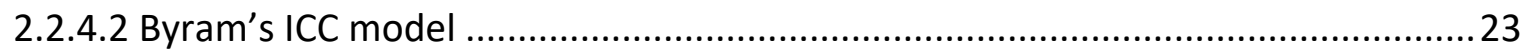

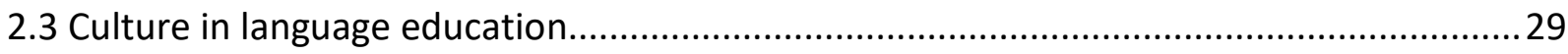

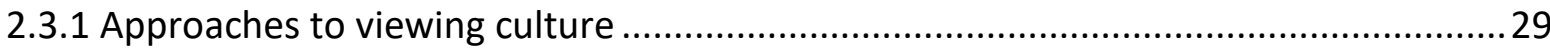

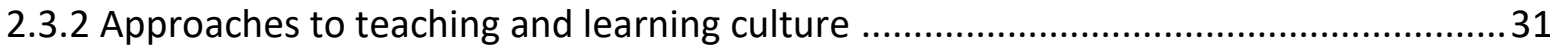

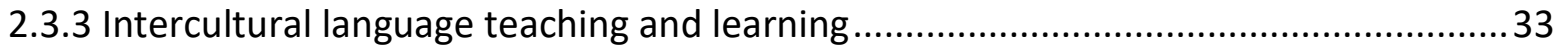

2.3.4 Teacher professional learning (TPL) in intercultural language teaching ....................42

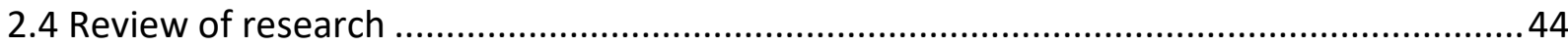

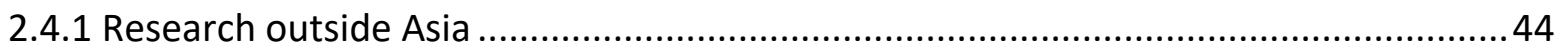

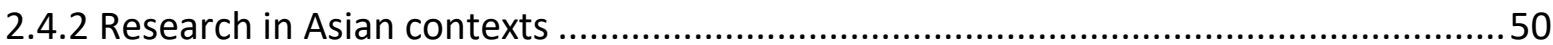

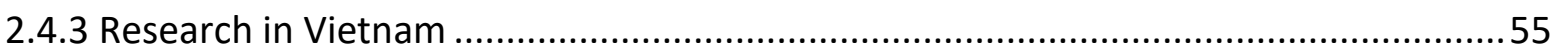

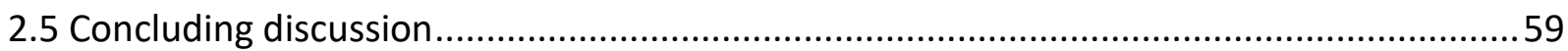

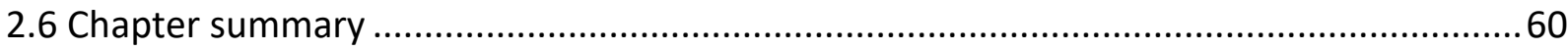

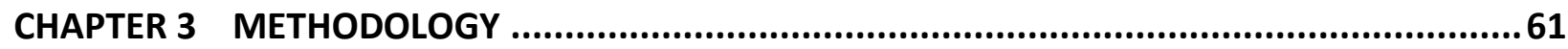

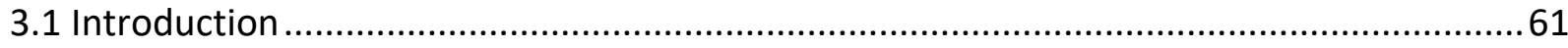

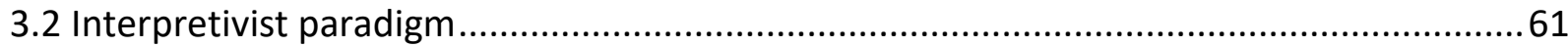

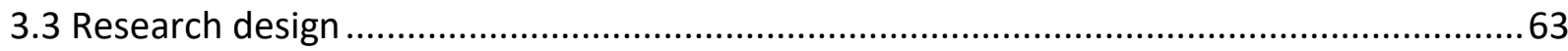

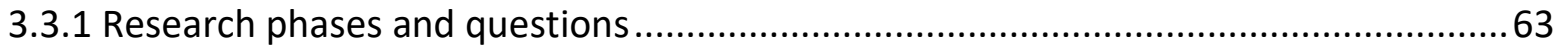

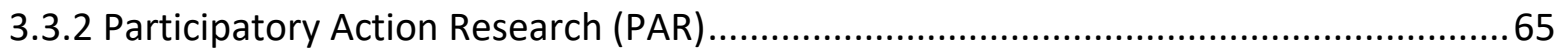

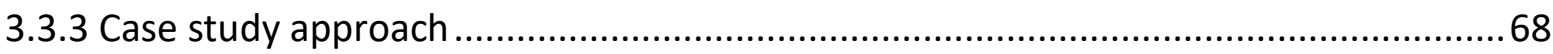

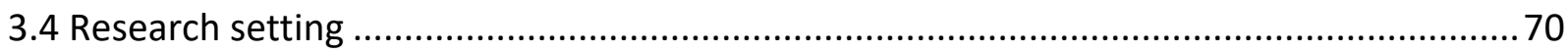

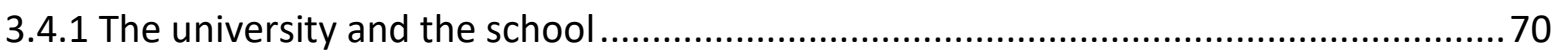




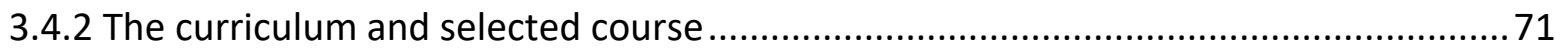

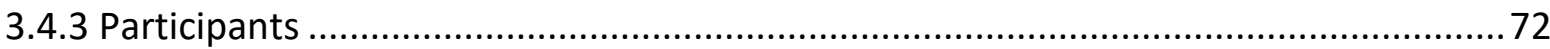

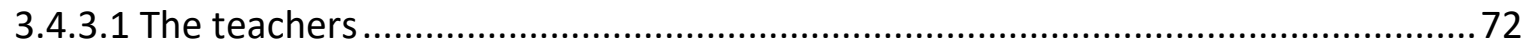

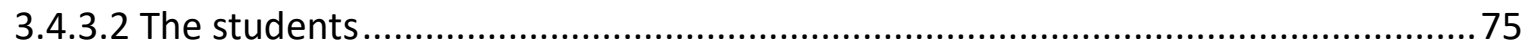

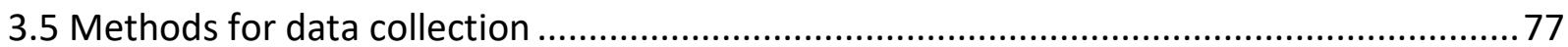

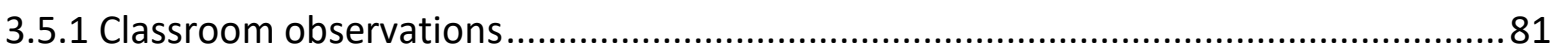

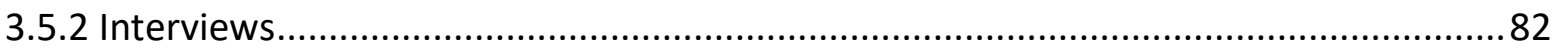

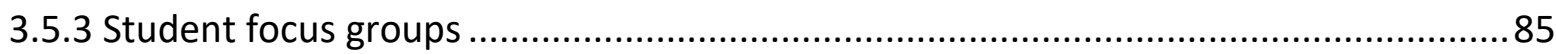

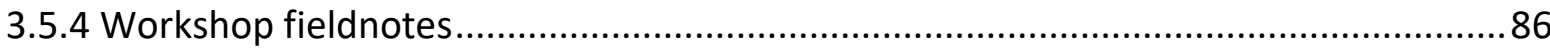

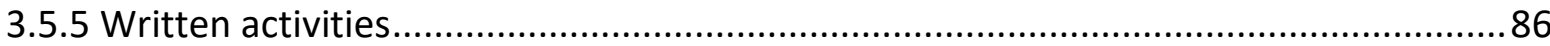

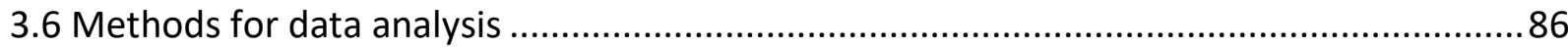

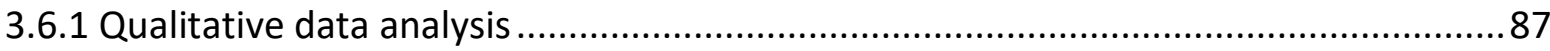

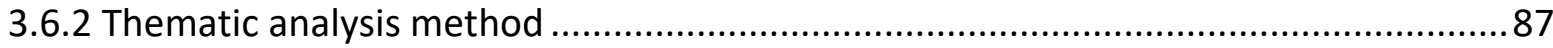

3.6.3 Theoretical frameworks for analysis and interpretations .......................................90

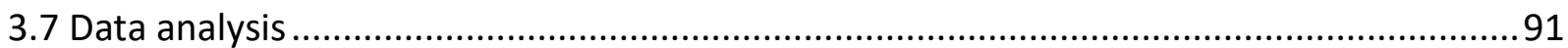

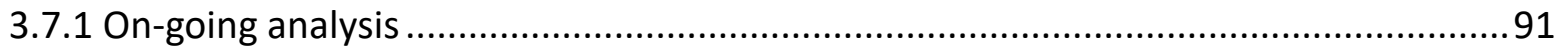

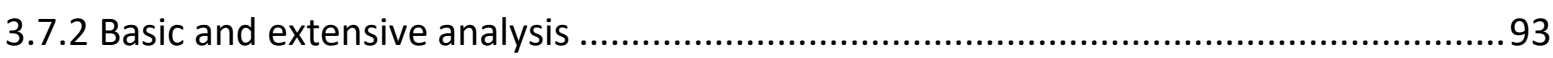

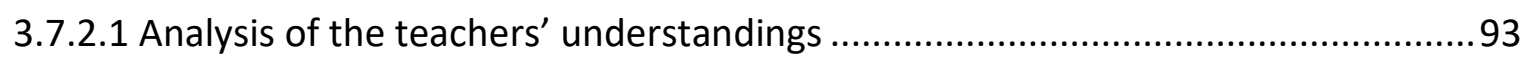

3.7.2.2 Analysis of the teachers' teaching practices ...................................................95

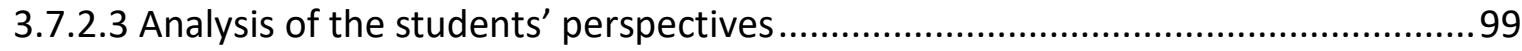

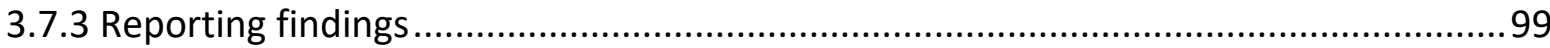

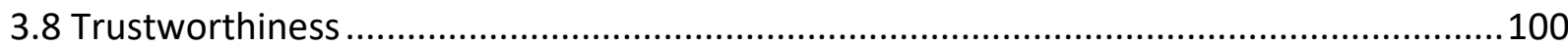

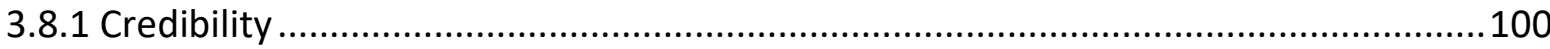

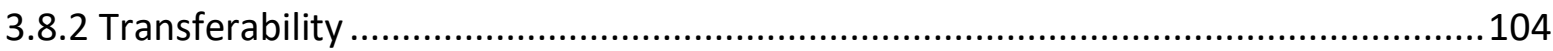

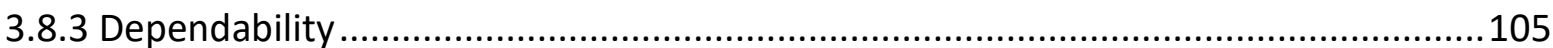

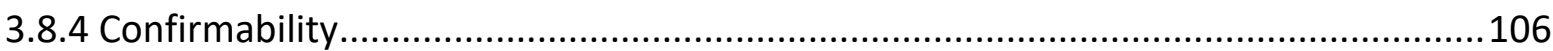

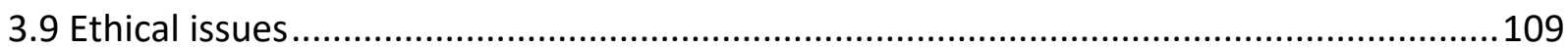




\section{CHAPTER 4 CURRENT ORIENTATION TO CULTURE: PHASE ONE FINDINGS AND DISCUSSION}

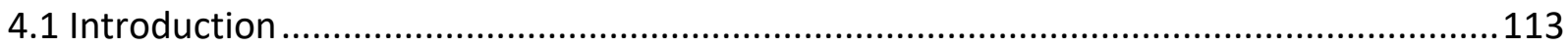

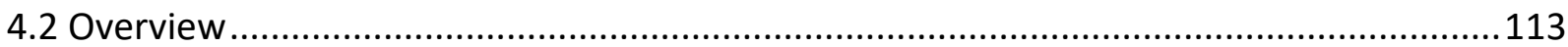

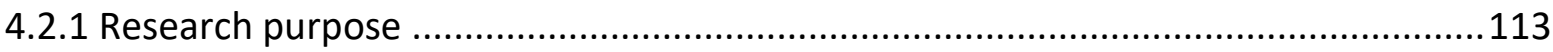

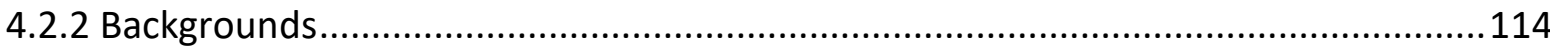

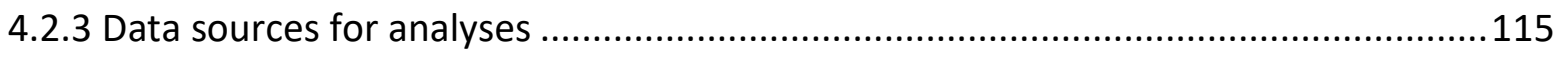

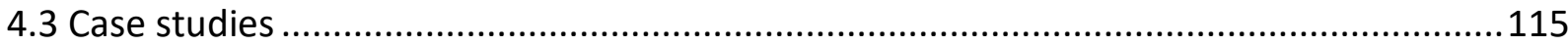

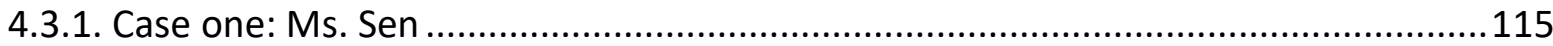

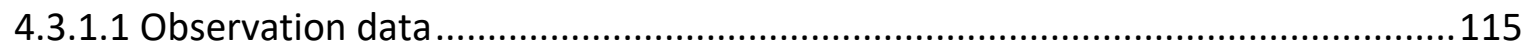

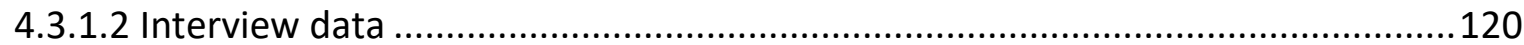

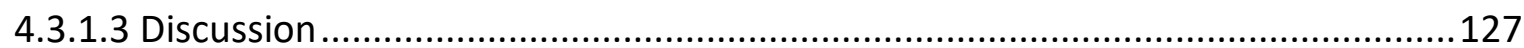

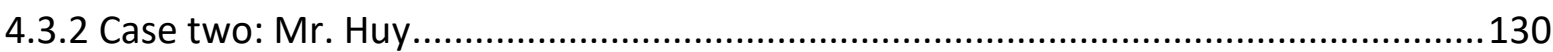

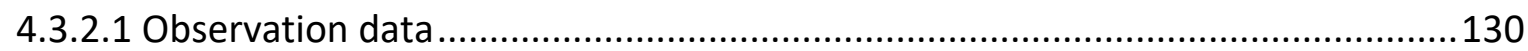

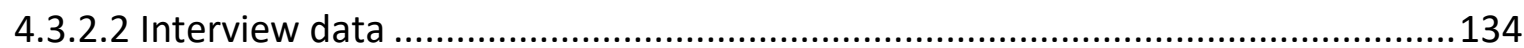

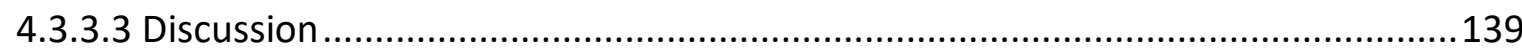

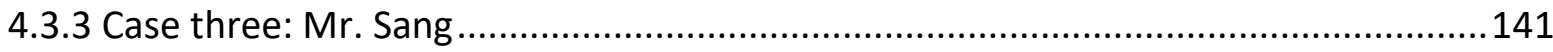

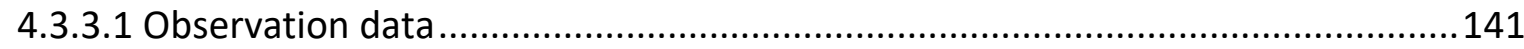

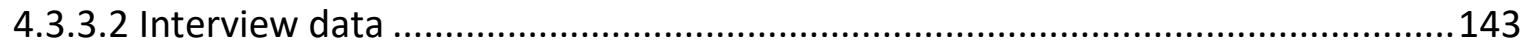

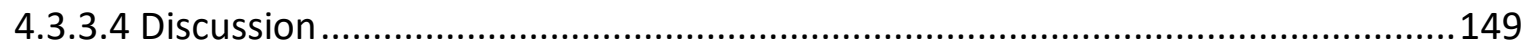

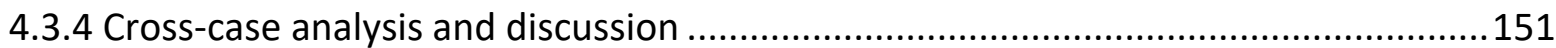

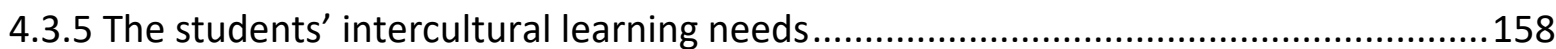

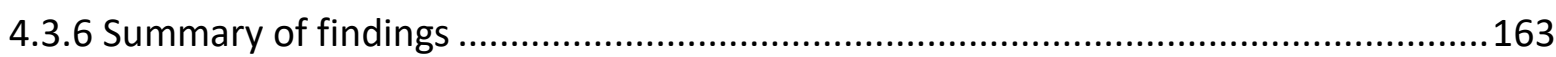

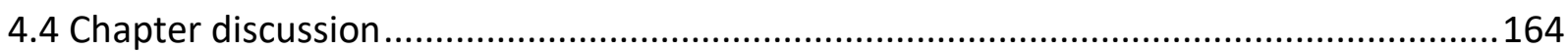

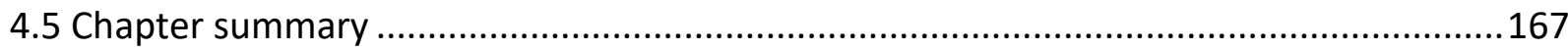




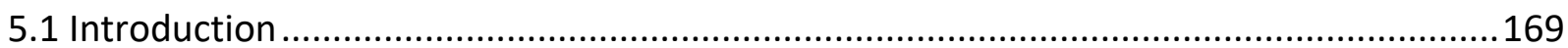

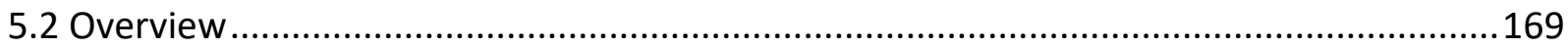

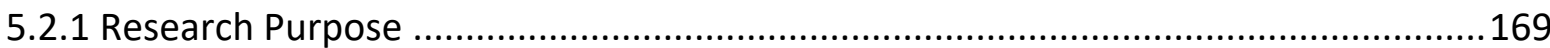

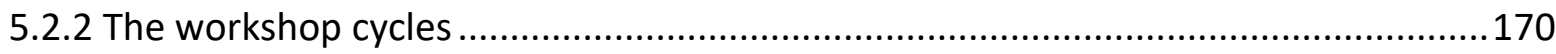

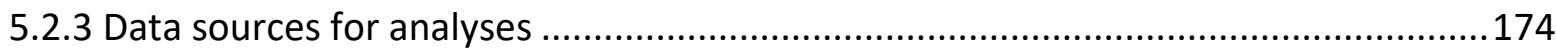

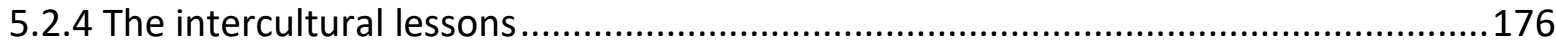

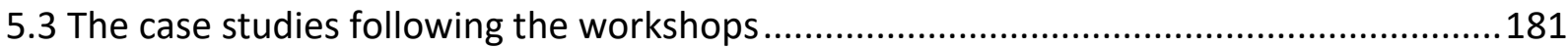

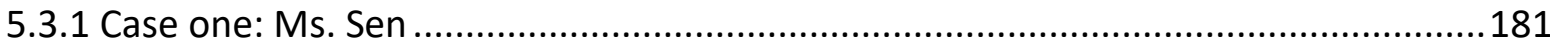

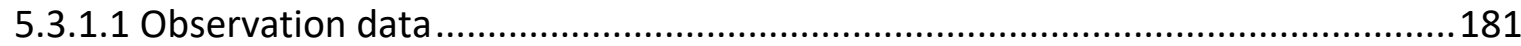

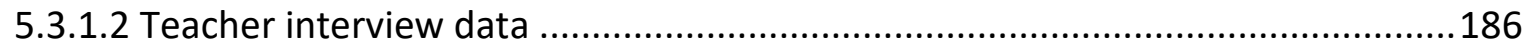

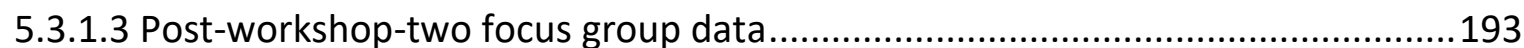

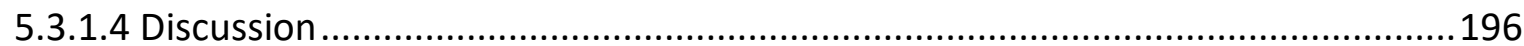

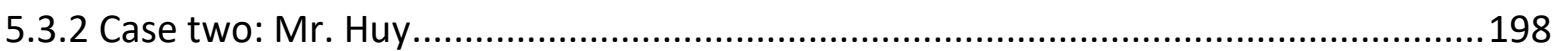

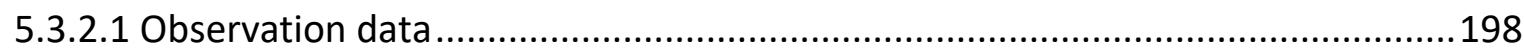

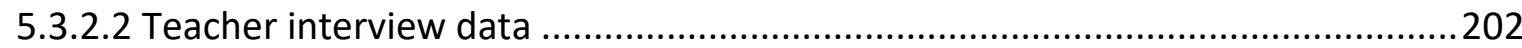

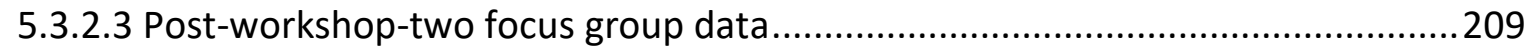

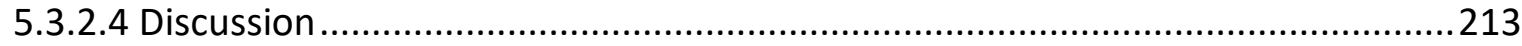

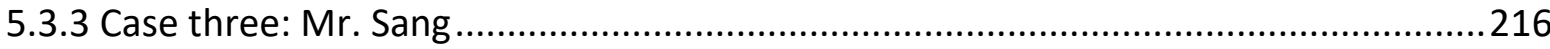

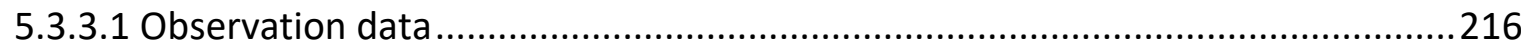

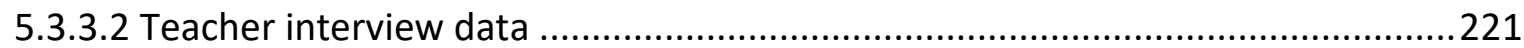

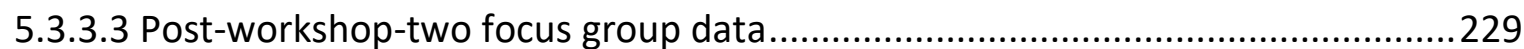

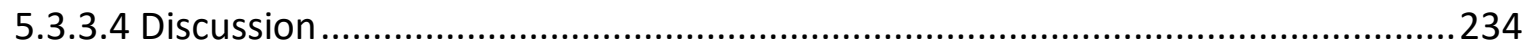

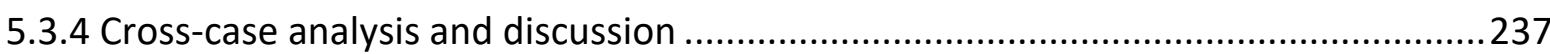

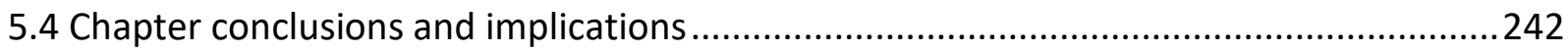

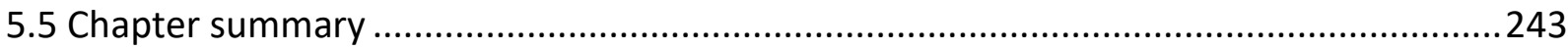




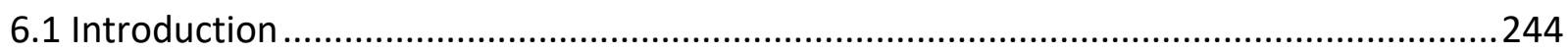

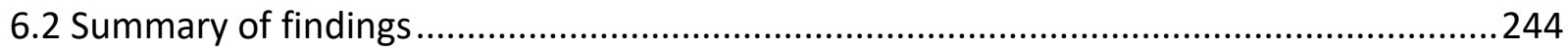

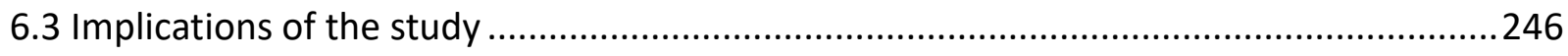

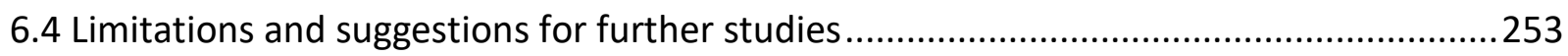

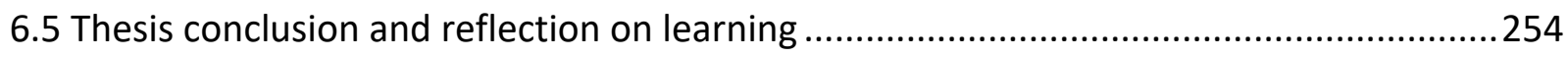

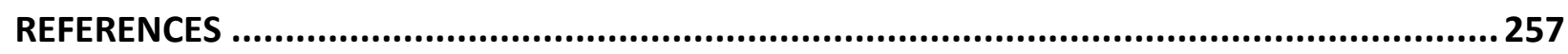

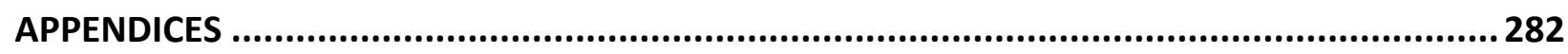

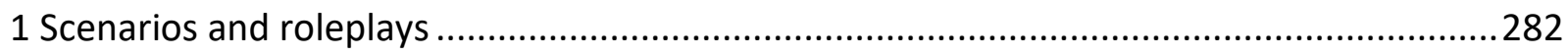

1.1 Scenario, roleplays and a conversation for modelling conversation analysis used in the

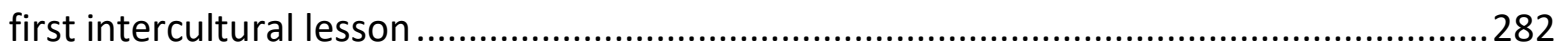

1.2 Scenario and roleplays used in the third intercultural lesson .....................................283

1.3 Teachers' co-constructed scenario and roleplays used in the fifth intercultural lesson

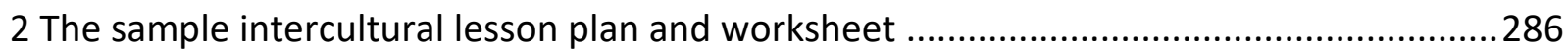

2.1 Lesson plan for the first intercultural lesson following the first workshop..................286

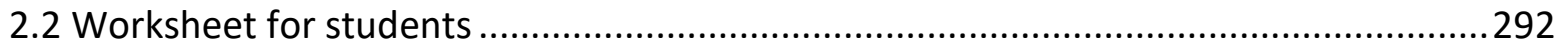

3. Textbook materials for the intercultural lessons following the workshops.......................296

3.1 Textbook materials for the first intercultural lesson ............................................296

3.2 Textbook materials for the third intercultural lesson ...............................................299

3.3 Textbook materials for the fifth intercultural lesson.................................................302

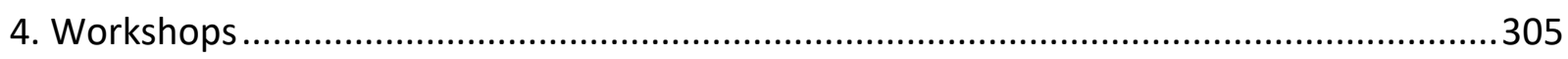

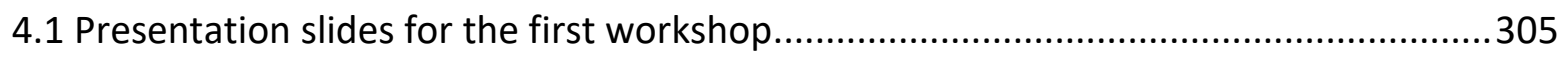

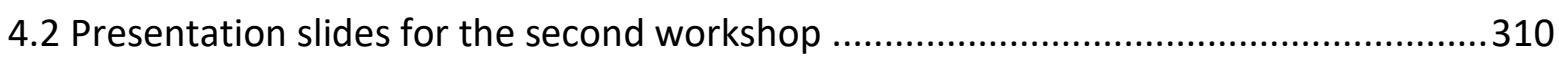

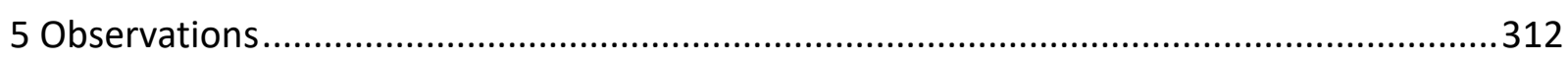

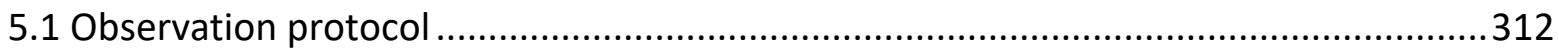

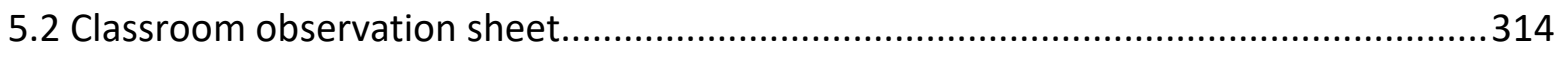


6. Written activity for students

7 Approval of Human Ethics Committee (VUW) 


\section{LIST OF TABLES}

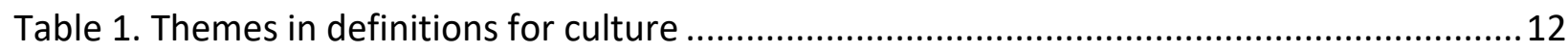

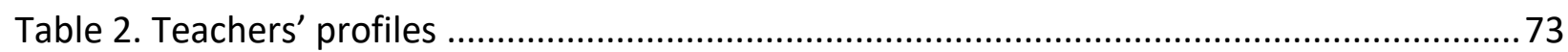

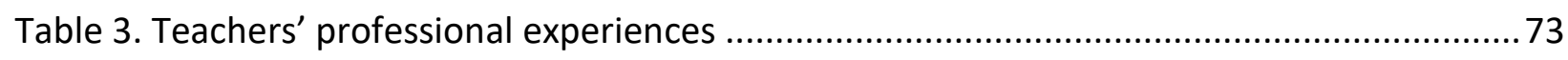

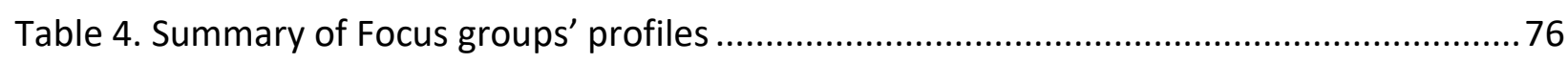

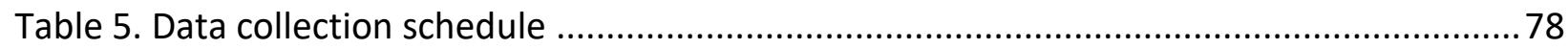

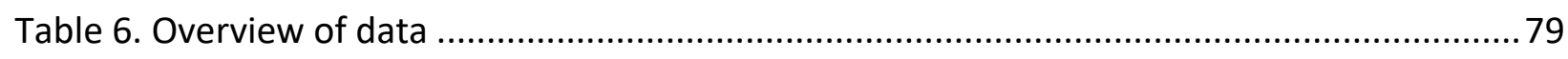

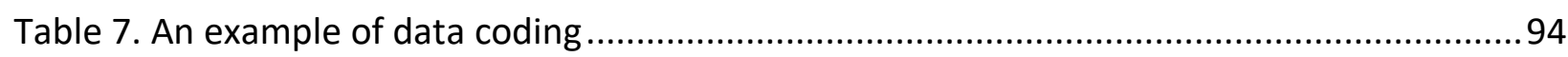

Table 8. Example of description of teacher classroom performances .....................................96

Table 9. Example of analysis of how teacher addressed culture ..........................................97

Table 10. Criteria and the strategies to enhance trustworthiness ........................................100

Table 11. Specifics about the pre-workshop observed lessons .............................................114

Table 12. Culture teaching in Ms. Sen's Phase One lessons .................................................120

Table 13. Culture teaching in Mr. Huy's Phase One lessons ................................................133

Table 14. Culture teaching in Mr. Sang' s Phase One lessons...............................................142

Table 15. Culture in teachers' teaching practices in Phase One .............................................151

Table 16. Culture in teachers' stated perceptions in Phase One ...........................................152

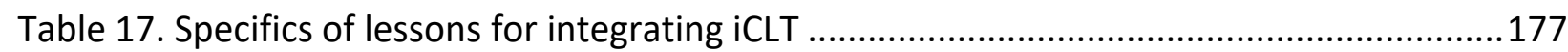

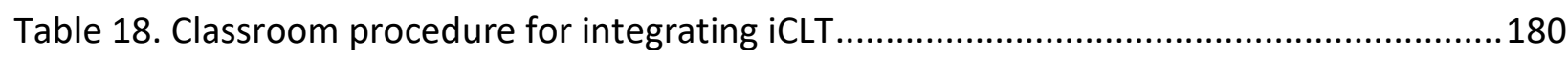

Table 19. Teachers' perceived opportunities for IcLL in the intercultural lessons ....................238

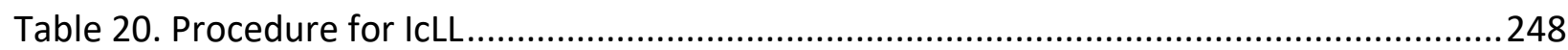




\section{LIST OF FIGURES}

Figure 1. Points of articulation between language and culture ............................................. 19

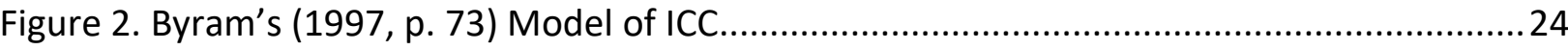

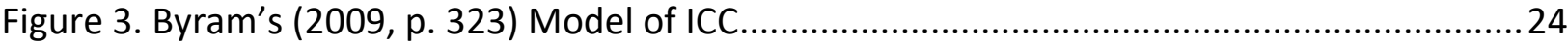

Figure 4. Interacting processes of intercultural pedagogy ................................................... 37

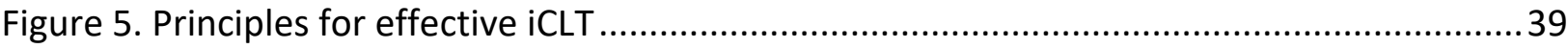

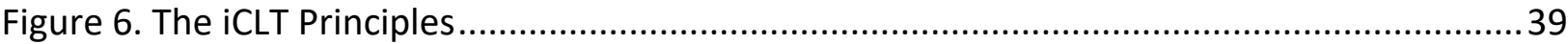

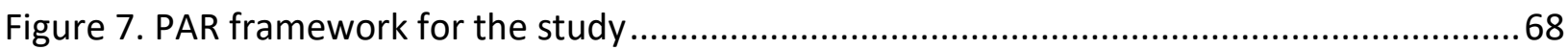

Figure 8. An example of the textbook's post-listening activity............................................... 72

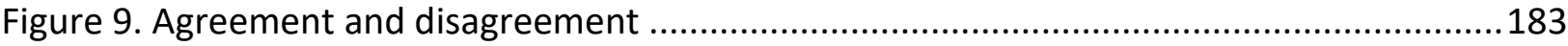




\section{LIST OF ABBREVIATIONS}

$A E$

BE

CC

CEFR

CLT

CoE

EFL

ELT

$\mathrm{FL}$

IC

ICC

ICLL

iCLT

IELTS

ITV

ITVs

Obs

PAR

$\mathrm{R}$

RCLCE

SR

Ss

T

TESOL Teaching English to speakers of other languages

TOEFL Test of English as a foreign language

TPL Teacher professional learning

Ts Teachers

USA
American English

British English

Communicative competence

Common European Framework of References for Languages

Communicative Language Teaching

Council of Europe

English as a foreign language

English language teaching

Foreign language

Intercultural competence

Intercultural communicative competence

Intercultural language learning

Intercultural communicative language teaching

International English language testing system

Interview

Interviews

Observations

Participatory action research

Researcher

Research Centre for Language and Culture Education

Stimulated Recall

Students

Teacher

The United States of America 


\section{SYMBOLS USED TO PRESENT INTERVIEW QUOTES}

" What is said by teachers or students

() English translation of Vietnamese answers

[ ] Researcher's explanations

... unfilled pause

[...] deleted text

/ / Phonetic transcription (International phonetic alphabet (IPA)) 


\section{LIST OF APPENDICES}

\section{Appendix 1: Scenarios and roleplays}

Appendix 1.1 Scenario, roleplays and a conversation for modelling conversation analysis used in the first intercultural lesson

Appendix 1.2 Scenario and roleplays used in the third intercultural lesson

Appendix 1.3 Teachers' co-constructed scenario and roleplays used the fifth intercultural lesson

Appendix 2: The sample intercultural lesson plan and worksheet

Appendix 2.1 Lesson plan for the first intercultural lesson following the first workshop

Appendix 2.2 Worksheet for students

Appendix 3: textbook materials for the intercultural lessons

Appendix 3.1 Textbook materials for the first intercultural lesson

Appendix 3.2 Textbook materials for the third intercultural lesson

Appendix 3.3 Textbook materials for the fifth intercultural lesson

Appendix 4: Workshops

Appendix 4.1 Workshop One presentation slides

Appendix 4.2 Workshop Two presentation slides

Appendix 5: Observations

Appendix 5.1 Observation protocol

Appendix 5.2 Classroom observation sheet

Appendix 6: Written activity for students

Appendix 7: Approval of Human Ethics Committee (VUW) 
This page is intentionally left blank 


\section{CHAPTER 1 INTRODUCTION}

\subsection{Introduction}

This study investigates the potential for fostering a more systematic engagement with culture in a tertiary English as a Foreign Language (EFL) course in the Vietnamese setting. This first chapter introduces the study including the researcher's background, research context, rationale for the study, overview and significance of the study, and finally the thesis organisation.

\subsection{Researcher's background}

I am an EFL lecturer in the School of Foreign Languages at a multidisciplinary university in the South of Vietnam where I completed my Bachelor's degree. It is a large university with a current training capacity of more than 45,000 students. English is taught in most of the training programs at this university. At the time I began the current research, I had roughly eleven years of teaching experience.

In my four-year Bachelor program, I learnt about culture in the last year. Culture was taught in subjects such as American culture and society and British culture and society. For example, in American culture and society, the content of culture included chapters about the USA's geography, political system, educational system, and holidays. This learning experience helped to build cultural knowledge particularly about the USA.

However, knowing cultural information about English speaking countries such as the USA did not help me to overcome my culture shock when subsequently I was in Australia doing my Master's degree in TESOL. During the first semester, I was not successful in communicating with people including the local English speakers and international students from China, Korea, Japan, and Iran. There were moments when I felt excluded from and found it hard to socialise with them. I judged the ways they dressed, spoke, and behaved.

One afternoon, feeling extremely isolated, I stood at the classroom balcony and was seen by my lecturer. She spoke to me about my cross-cultural encounters and we continued this discussion via emails and talks until I felt much more comfortable. Gradually, I changed my attitudes. For example, I found opportunities to talk with people without expecting them to produce a nativelike accent. I tried to be less judgemental and more open to difference. I learnt that intercultural communication skills, including open-mindedness and engaging with culture, are 
as important as language fluency when one is in situations that involve multicultural communication.

My learning experience as a foreign language (FL) learner and teacher motivates me to explore the intercultural dimension of FL learning. From my experience, I have an insight into the difficulties, expectations, and imaginations that EFL learners often have when learning a foreign language. I believe that FL teachers need to be aware of teaching language and culture in an integrated manner (Liddicoat, Papademetre, Scarino, \& Kohler, 2003; Byram, 2009). They need to have knowledge and skills to teach the intercultural dimension of FL learning (Bastos \& Araújo e Sá, 2015) in order to help learners to achieve both language and intercultural learning goals. It is for this reason that I undertook this research.

\subsection{Research context}

This section examines the research context of English language teaching and learning in Asia in general and in Vietnam in particular.

In Asia, intercultural communication has become diverse. According to Widodo, Wood, and Gupta (2017), English plays various roles, such as an official or semi-official language, a lingua franca, a medium of instruction, and a school subject, in many nations. Asian speakers of English interact with culturally diverse people locally and internationally (Widodo et al., 2017). Thus, communication in English between non-native speakers of English has become increasingly popular.

However, in reality, the native-speaker model has been dominant in English language teaching (ELT) in Asia with insufficient attention paid to the Asian multicultural and multilingual contexts (Kirkpatrick, Patkin, \& Jingjing, 2013; Widodo et al., 2017). As Chang (2011, pp. 191, 200, 201) argues, EFL education in Asia needs to emphasize non-native interactions and bi-directionality between non-native and native speakers of English in a globalised world.

In Vietnam, English has acquired a high status due to the economic renovation policy (Hoang, 2010). The Government Decree 1400/QD-TTg (Government, 2008, p. 4) emphasizes (1) constructing working environments which use FL (i.e., English) in units and offices, (2) making English ability a requirement for recruiting state officers, and (3) opening training courses for state officers and workers, particularly the young members, to improve their English. 
The importance of developing intercultural skills in EFL teaching and learning is advocated in the national language policy (L. Nguyen, 2015). In 2008 the government launched the National Project for Teaching and Learning of Foreign Languages in the National Educational System for the 2008-2020 Period (Government, 2008). This policy adopted the Common European Framework of Reference for Languages: Learning, Teaching and Assessment (CEFR) as a framework for FL teaching and learning at all levels of education nation-wide. The policy stated the objectives of (1) developing learners' ability to use English independently and confidently for studying and working in multicultural and multilingual integration contexts, and (2) making English communication ability a strength of nationals in serving national industrialisation and modernisation (Government , 2008, p. 1). Overall, with intercultural competences (i.e., intercultural skills and intercultural awareness) widely recognised in the CEFR (Council of Europe (COE), 2011), it is inevitable that FL teaching and learning in Vietnam will need to address intercultural competences along with the adaption of this framework.

In short, teaching and learning English in Vietnam needs to respond to the emphasis on intercultural skills in the national policies and to the important roles English plays in intercultural communication within and beyond the region.

\subsection{Rationale for the study}

Scholars have increasingly argued that, alongside linguistic and communicative competencies, FL education needs to address plurilingual, pluricultural, and intercultural dimensions of identity and language use, and global-mindedness (Behrnda \& Porzelt, 2012; Liddicoat, 2005; Newton, Yates, Shearn, \& Nowitzki, 2010). The call for greater inclusion of intercultural content is prominent in language teaching scholarship (Aubrey, 2009; Baker, 2008, 2016;; Phan, 2010; Ton \& Pham, 2010; T. T. Tran, 2010, 2013; Kirkpatrick, 2012; Marczak, 2013; Piątkowska, 2015). However, there have been mismatches between the call for greater inclusion of intercultural content in the scholarship and the reality of ELT in Vietnam. Teacher-centred teaching methods and exam-based curricula with a focus on grammar, reading, and vocabulary remain prevalent in Vietnamese ELT with little attention to developing students' intercultural skills (T. M. H. Nguyen, 2007; Hoang, 2010; Ho, 2009, 2011a, 2011b; H. T. Le, 2013; T. L. Nguyen, 2013; Doan, 2014; T. Q. Tran \& Dang, 2014; L. Nguyen, 2015; T. B. Nguyen, 2016).

Moreover, as Doan (2014) points out, the teaching and learning of culture in Vietnamese classes still adopts a monocentric orientation characterised by "the linearization of language 
and culture with the native speaker" (Doan, 2014, p. 90). He maintains that focusing on nativelike norms is no longer relevant for FL classes because of the increasing use of English as a lingua franca between non-native speakers of English.

One of the reasons for these gaps is that teachers are not aware of the value of inclusion of intercultural content in language teaching and have limited opportunities for professional development in this area. For instance, studies show that teachers are not well-informed about the inclusion of intercultural learning goals in the national policy (L. Nguyen, 2015) and professional workshops for Vietnamese EFL teachers have not focused on intercultural language teaching (T. L. Nguyen, 2013). While Vietnamese ELT scholarship has recognised the importance of teaching IC in tertiary EFL settings (T. M. H. Nguyen, 2007; T. Q. Tran \& Duong, 2015; T. Q. Tran \& Seepho, 2014; Trinh, 2014), little research has examined in-service teachers' professional learning development regarding teaching culture.

The above-mentioned shortcomings have been challenged by cultural diversity and the growth of English as an international language (Kirkpatrick, 2012; Doan, 2014). Due to these shortcomings, the EFL classroom reality does not correspond with the needs of graduates who wish to participate in multicultural working environments (Phan, 2010; Ton \& Pham, 2010) and the need for Vietnam to compete in the global economy (Doan, 2014). Accordingly, the current study examines the integration of intercultural content into the current Vietnamese tertiary EFL context. More specifically, it investigates the process of adopting intercultural language teaching practices in an EFL course at a university. The particular focus is on how a small group of teachers make sense of an intercultural perspective in both their understanding and their classroom practices.

\subsection{Overview of the study}

\subsubsection{Research aims and objectives}

This research aimed to investigate the integration of an intercultural stance in the tertiary EFL context in Vietnam. It focused on the teachers' ability to implement intercultural language teaching in their classes and reflect on this teaching experience. The research was conducted in two phases. Phase One explored the current orientation to culture at the chosen university. Phase Two investigated the experience of teachers and students as they worked with the newly-developed interculturally-oriented materials which were introduced to them in the workshop cycles. 


\section{Phase One objectives}

Phase One identified the fertility of the ground on which an intercultural stance was to be seeded in the second phase. This was done by first carrying out a document analysis, and by investigating the teaching practices and stated perceptions of three case study teachers. The analysis of these data identified factors that support and challenge a principled adoption of intercultural communicative language teaching approach (iCLT) in a typical Vietnamese tertiary EFL setting.

\section{Phase Two objectives}

Phase Two involved the teachers in two professional learning workshops and was expected to raise the teachers' awareness of iCLT and provide them with practical expertise to implement intercultural lessons and create their own intercultural lessons. Data was collected on how successfully the teachers implemented the intercultural lessons they had engaged with in the workshops and on their emerging understandings about iCLT. The outcomes of Phase Two included context-relevance recommendations for adopting iCLT and implications for professional development for teachers focused on intercultural language teaching in the Vietnamese context.

The research questions were formulated to address the research aims and objectives. The study's overarching question (RQ) was:

What is the potential for fostering a more systematic engagement with culture and intercultural learning in EFL classes at a university in Vietnam?

Each phase had its own specific question:

Phase 1: Current orientation to culture

1. What is the current practice and understandings of a small group of Vietnamese tertiary EFL teachers in relation to teaching culture?

\section{Phase 2: Intercultural orientation to culture}

2. What was the impact of the two intercultural language teaching and learning workshops on the orientation to culture in the teaching practices and emerging understandings of the case study teachers? 


\subsubsection{Methodology}

This study employed the interpretive qualitative case study approach (Chen, Shek \& Bu, 2011; Hua, 2016) and Participatory Action Research (Ragsdell, 2009; MacDonald, 2012; Bergold \& Thomas, 2012) as the research methods to address the research questions. Specifically, the study adopted a research cycle beginning with observing teachers' normal classroom teaching practices, and then tracking their understanding and classroom practices as they participated in two professional learning workshops on the topic of iCLT, and then applied their learning into their classroom practices after the workshops.

The study was conducted at a university in southern Vietnam during a fifteen-week semester. The teacher participants were three EFL tertiary teachers at that university. The student participants were the students of the three classes taught by these teachers.

The three main data collection methods used in this research included: video-recorded postworkshop classroom observations of the teachers' teaching, audio-recorded post-observation interviews with teachers, and pre-workshop-one focus group and post-workshop-two focus groups with students. I followed the process of qualitative data analysis suggested by Creswell (2012), Patton (2002), and Merriam and Tisdell (2016), and the thematic analysis method suggested by Braun and Clarke (2012) to analyse data.

\subsection{Significance of the study}

This research is of significance in several ways. First, the research findings provide insights into the current teaching approach to culture and the potential for adopting an intercultural stance in the Vietnamese tertiary EFL context in general and in the research site in particular, Second, the research provides implications that help to guide teacher professional learning development in teaching culture, which is under-researched in Vietnamese scholarship. More specifically, the research provided the case study teachers with the opportunity to participate in a collaborative action research learning model which involved awareness raising, transferring their learning into teaching practice, and reflecting on these dimensions. Insights into the teachers' beliefs, practice, and attitudes about teaching culture before and after their participation in this professional learning process can be useful not just for the teachers, but also for other stakeholders such as applied linguistics researchers, policy makers, curriculum designers, and teacher trainers. 
Third, the research can help to enrich options for developing intercultural learning content. The findings show how teachers were guided by intercultural language teaching principles to address students' intercultural skills despite a language-oriented and exam-based curriculum. In the same way, the larger TESOL community can use the approach taken to adopt an intercultural stance using the redesigned interculturally-oriented materials as a model for creating intercultural lessons.

Fourth, the research adds to the growing literature on teachers' perspectives regarding the process of adopting an intercultural stance. This is hoped to increase the understanding of the values and the challenges that teachers perceive and experience regarding their shift from a cultural to an intercultural stance.

Finally, the study addresses students' pressing need to better equip themselves with intercultural skills to engage in intercultural communication.

\subsection{The organisation of the thesis}

This thesis comprises six chapters. Chapter 1 introduces the research. Chapter 2 critically reviews the scholarship and research on key concepts that underpin the current study. This involves a review of (a) theoretical frameworks of culture and language and the relationship between them, (b) how culture has been dealt with in language education, and (c) research on iCLT with a focus on teachers' intercultural perspectives across teaching contexts. Chapter 3 describes the research methodology and justifications for using it. It provides details of the research paradigm, research design, methods for data collection and analysis, the conducted analysis, trustworthiness, and ethical issues. Chapter 4 and Chapter 5 report and discuss findings according to each phase. Chapter 4 deals with Phase One findings which relate to the current orientation to culture. Chapter 5 deals with Phase Two findings which relate to the teachers' adoption of iCLT and their stated perceptions about the experience of adopting an intercultural stance. Finally, chapter 6 is the conclusion which summarises the research findings, draws implications, discusses important limitations, and suggests further research directions, followed by my reflection on learning. 
This page is intentionally left blank 


\section{CHAPTER 2 LITERATURE REVIEW}

\subsection{Introduction}

This review addresses the main themes relevant to the topic of this research. It has three main sections that are intended to critically review scholarship and research on key concepts that underpin the current study. The first section is largely theoretically-oriented with discussion of theorizations of language, culture, and the relationship between them. The second main section examines how culture and intercultural competence have been addressed in language teaching. This section is largely focused on principled application of theory in language education. The third and final main section reviews empirical research on intercultural language teaching and learning with a particular focus on research on teachers' perspectives. This review is divided into research outside Asia, research inside Asia, and research in Vietnam.

\subsection{Theorizations of key concepts}

\subsubsection{Language}

This research is informed by Liddicoat and Scarino's (2013) integrated view of language and Kramsch's (2013) social semiotic view of language. Liddicoat and Scarino (2013) state that language is a multiple layered whole within which a structural system and a communication system provide elements and resource for social practice. From this perspective, language as social practice adds meaning and lived experience to structures and communication. Such an integrated view of language stands in stark contrast to traditional structural and communication-oriented views of language.

A structural view of language sees language as a set of linguistic structures and is learnt through formal instruction. Therefore, pedagogy concentrates on correct forms of grammar and underestimates the complexity of language use. A communication-oriented view of language considers language as a communicative system in which communication means using a combination of linguistic structures or grammar to express and transfer thoughts among people. Liddicoat and Scarino $(2013$, p. 13) critique this view, claiming that it simplifies the nature of communication because it sees communication as "the exchange of comprehensible and comprehended messages" but overlooks "voice, identity, and co-construction between participants, and the enactment of self through language." 
In contrast, a dynamic view of language treats language as social practice. That means language is the way that one participates in social life to express self, explore the world, present one's worldview, adapt, negotiate, and accommodate in social practices. This dynamic view recognises communication as "a creative, cultural act in its own right through which social groups constitute themselves" (Carey, in Liddicoat \& Scarino, 2013, p. 13). Instead of being a static system to be learned about, language interacts with individuals' interpretation and creation of meaning for their own communicative needs (Liddicoat \& Scarino, 2013). In this regard, Shohamy $(2006$, p. 5) describes the making and interpreting of meaning and communication as "open, dynamic, energetic, constantly evolving and personal." Teaching engages learners in analysing, discovering, and exploring language as a dynamic system, and noticing how meaning is made rather than limiting to the focus on using language to transfer knowledge (Liddicoat \& Scarino, 2013).

According to Wright (2015), language as a structural system and language as social practice reflect contrasting positions in the scientific tradition. Language as a structural system stands on objectivism which considers reality to exist objectively and to be understood and described in language. In contrast, language as social practice views language as constructed by the individuals through their lived experiences. From this perspective, language constructs and is constructed by reality (Wright).

Synthesizing the three main views of language above, Liddicoat and Scarino (2013) suggest that these views should be recognised as an integrated whole rather than alternatives. This integrated view of language aligns with Halualani's and Nakayama's (2010) broad view of communication and constructed view of culture. According to Halualani and Nakayama (2010), communication is shaped by the construction and intertwining of contextual meanings, social practices, structures and discourses and the discursive. Culture is considered as a larger social formation constructed by communicative meaning making. Additionally, Liddicoat's and Scarino's (2013) integrated view of language is supported by Risager (2006) who advocates the sociocultural dimension of language. In Risager's words:

Linguistic practice is always cultural, in the sense that it is in itself a form of cultural (meaningful) practice, and because it is imbedded in a larger cultural (meaningful) context on which it leaves its own mark (p. 3).

In addition to Liddicoat and Scarino's (2013) integrated view of language, this current study adopts Kramsch's (2013) social semiotic view of language which contends that the notion of 
language goes beyond an arbitrary system of linguistic forms. Kramsch $(2013$, p. 62) defines language as "a coherent system for the making of meaning." She further elaborates that:

Without language and other symbolic systems, the habits, beliefs, institutions, and monuments that we call culture would be just observable realities, not cultural phenomena. To become culture, they have to have meaning. It's the meaning that we give to foods, gardens and ways of life that constitute culture (p. 62).

The above quote suggests that language is the meanings that people give to a cultural reality and that language and culture are closely related to each other.

In short, Liddicoat and Scarino's (2013) integrated view of language emphasizes the function of language and the active roles of language users. Kramsch's (2013) social semiotic view of language emphasizes the ways in which language gives meaning to reality. These two views of language inform this current study's position that learning a foreign language is not seen as replacing learners' identity with the identity of the target language and culture. Instead, the learners' own culture interacts with the target culture across time and space, fostering learners' process of meaning making itself (Kramsch).

\subsubsection{Culture}

Marczak (2013) contends that the intercultural orientation to FL education requires an inclusive understanding of culture. The concept of culture has been examined across disciplines including anthropology, linguistics, sociology, psychology, and communication (DeCapua \& Wintergerst, 2016), ethnography, cultural studies (Corbett, 2003), and intercultural communication (Díaz \& Dasli, 2017; Hua, 2018). These disciplines are considered as complementary (Díaz \& Dasli, 2017) or tributary to FL education (Corbett, 2003) in terms of the key theories and methods they share despite their different foci (Hua, 2018). In the following section, this review examines four main culture themes: themes in definitions for culture, the approaches to viewing culture in intercultural communication, the modernist and postmodernist perspectives on culture, and the characteristics of culture.

\subsubsection{Themes in definitions for culture}

To distil the nature of culture, scholars have analysed definitions of culture. Faulkner, Baldwin, Lindsey and Hecht (2006, pp. 29-30) identify seven themes analysed from over 300 such definitions, which are structure/pattern, function, process, product, refinement, power or ideology, and group-membership. These themes are summarised in Table 1. 
Table 1. Themes in definitions for culture

Adapted from Faulkner et al. (2006, pp. 29-30)

\begin{tabular}{ll}
\hline Themes & Focuses of definitions \\
\hline Structure/pattern & $\begin{array}{l}\text { a system or framework of elements (e.g., ideas, behaviour, symbols, or } \\
\text { any combination of these or other elements) }\end{array}$ \\
\hline Function & a tool for achieving some end \\
\hline Process & the ongoing social construction of culture \\
\hline Product & artefacts (with or without deliberate symbolic intent) \\
\hline Refinement & a sense of individual or group cultivation to higher intellect or morality \\
\hline Power or ideology & group-based power (including postmodern and postcolonial definitions) \\
\hline Group-membership & a place or group of people, or a focus on belonging to such a place or \\
& group
\end{tabular}

First, the structure/pattern theme emphasizes the elements included in culture, seeing culture as fixed elements or a collection of elements. This type of definition holds the risk of essentialisation due to ignoring the differences within cultures and the dynamic nature of culture. Second, the functional definitions focus on outcomes (e.g., to adapt to the world, and express values) and so treat culture as purposive and intentional. Third, the process view sees culture as what happens, "something that occurs, rather than simply a set of elements such as structures or functions to be observed passively" (Faulkner et al., 2006, p. 41). It emphasizes people's processes of making sense of or constructing reality (Faulkner et al., 2006). Fourth, the product view emphasizes culture as artefacts and thus tends to be a more static view of cultures. Fifth, the refinement definitions emphasize culture as morality and intellectual development and thus share the active view of culture as process. Sixth, the culture as power or ideology definitions emphasize culture as a more holistic concept that includes structure, functions, process, and products. Finally, the group-membership definitions frame culture as group membership (Hecht, Baldwin, \& Faulkner, 2006).

According to Hecht et al. (2006), the above types of definition embrace different paradigms. These scholars maintain that structure and/or function-focused definitions are positivist or neopositivist as culture is considered as predictable objective variables. On the other hand, process-focused definitions that treat culture as communicative and social processes adopt an 
interpretivist stance. Power-focused definitions adopt a critical position to address the question of whose power culture serves.

Baldwin, Faulkner and Hecht (2006) and Faulkner et al. (2006) acknowledge that cultures and the conceptualisations of culture are actively shifting, contesting, overlapping, and discursive, and that any single definition or summary of definitions of culture obscures the dynamic nature of culture. As a result, it is worth being aware of diverse themes in definitions for culture. From Faulkner et al.'s (2006) categorisation and Hecht et al.'s (2006) discussion above, it seems clear that culture is a complex notion and that a single definition of culture is both unattainable and undesirable. This plurality of components of culture provides a rich resource for exploring culture in the language classroom and in relation to language and communication.

\subsubsection{Approaches to culture in intercultural communication}

Hua (2018) identifies four approaches to viewing culture in intercultural communication: compositional, interpretive, action, and critical.

The compositional approach views culture as made up of visible components such as behaviours, appearances, ways of doing things, and tacit or invisible components such as values, beliefs, attitudes, and assumptions (Hua, 2018). For example, culture has been metaphorically modelled as an onion (Trompenaars \& Hampden-Turner, 1998), and an iceberg with three layers (Ting-Toomey \& Chung, 2005). The compositional approach relies on a crosscultural comparative paradigm which has been widely critiqued as essentialist, reductionist and prone to over-generalization and stereotypes (Hua, 2018). Such an approach fails to address national heterogeneity and cultural super-diversity. This approach can be equated with the element view of culture identified in Baldwin et al. (2006).

The interpretive approach emphasizes culture as semiotic (Hua, 2018). Culture consists of the acts of searching for meaning and making meaning. As Hua (2018) argues, the interpretive approach overcomes the reductionism of the compositional approach and captures the bond between culture and communication. Its focus is on the processes through which structural elements are constructed and re-constructed rather than static observable elements of culture including linguistic structures (Baldwin et al., 2006).

The action approach treats culture as a verb (Street, 1993). Culture is beyond static elements which are passively observed and discovered (Faulkner et al., 2006). It emphasizes culture as an evolving process and the roles of people in (co)creating culture as well as the role of culture in 
shaping human activities (Hua, 2018). According to Faulkner et al. (2006) and Hua (2018), central to this social constructionist view of culture is the idea that culture is the actively changing process of sense making or meaning making. People and groups not only make sense of their own experiences and behaviours of those who they interact with but also define and re-define themselves in dynamic processes of cultural meaning making (Faulkner et al., 2006).

The critical approach conceptualises culture as the creation of hierarchy through ideology, placing its emphasis on power (Baldwin, et al., 2006; Halualani \& Nakayama, 2010; D. Moon, 2010; Hua, 2018). As a site of ideological struggle, culture is a contested zone where different subjects and social entities compete for control and dominance of the meaning making process (Halualani \& Nakayama, 2010; D. Moon, 2010). Individuals actively participate in this process to produce and reproduce meanings. These authors argue that culture contributes to and is impacted by power and ideology. Understanding power differences between and within groups is important to interpret human activities (Hua, 2018). For instance, Halualani and Nakayama, (2010, p. 6) view culture as:

an assemblage of meanings and representations that are vested with or are reified and spoken via different power interests, most notably by dominant structures (nation-state and its arms, law and governance, institutions, the economy, and the media) and cultural groups themselves.

Culture does not rely on sharedness, for example, shared values, behaviours, and attitudes (D. Moon, 2010). Culture, as a zone of contestation embedded in power relations, has moved beyond culture as an unproblematically shared and comparatively static composition of reality. As D. Moon argues, culture as a site of ideological struggle offers a way of understanding the complexity of the global condition and the power and structural influences on intercultural communication processes. In general, the view of culture as power and ideology defines culture in relation to whom it serves rather than defining it in terms of what it comprises (Baldwin et al., 2006).

Hua's (2018) classification of approaches to viewing culture reveals the emerging themes identified in Baldwin et al. (2006). The compositional approach (Hua, 2018) sees culture as tacit and separate elements and thus reflects the theme of Structure/pattern described in Baldwin et al. (2006). In contrast, the interpretive and the action approaches (Hua, 2018) emphasize culture as process and humans' engagement in meaning making activities. These two approaches reflect Baldwin et al.'s (2006) themes of Process while the critical approach (Hua, 2018) maps onto the theme of power or ideology. 


\subsubsection{Modernist and postmodernist perspectives of culture}

Kramsch $(2006,2013,2014)$ distinguishes between modernist and postmodernist perspectives of culture. This distinction shares common ground with the framing of culture by Hua (2018) and Baldwin et al. (2006) as discussed above.

The modernist perspective offers two main ways of conceptualising culture: big C Culture and little c culture (Kramsch, 2006, 2013). Big C Culture emphasizes a humanistic concept of culture as national products, such as a country's literature, drama, arts, history, and institutions. From a humanistic view, Culture is equated with general knowledge of literature and arts. The sociolinguistic concept of culture, or little c culture, emphasizes social contexts of communication and interactions. Little c culture refers to everyday ways of life in the target country, particularly "the native speakers' way of behaving, eating, talking, dwelling, their customs, and their beliefs and values" (Kramsch, 2013, p. 66). As DeCapua and Wintergerst (2016) argue, little c culture is subjective culture as it focuses on "the day-to-day features that define a group" (p. 18). It is less visible (Peterson, 2004) and is the main focus of sociolinguistic and anthropological scholarship (Kramsch, 2006; House, 2008).

The modernist lens on culture has been critiqued on several grounds. Big C Culture is traditionally taught with standard national languages and focuses on the study of literature, art, history, and institutions. Such culture is considered instrumental in promoting the continuity of the target nation's values and heritages (Kramsch, 2013). However, Kramsch (2013, p. 66) also critiques little c culture, claiming that it focuses too much on national characteristics, lacks historical depth, and considers culture as monolithic. Such culture focuses on the target culture's ways of life (e.g., foods, celebrations, customs, and behaviours) which are typical and sometimes even stereotypical (Kramsch, 2013). Thus, in education, the emphasis is on teaching cross-cultural pragmatics and sociolinguistic appropriateness of language use and helping learners to adapt or temporarily adopt the foreign culture as their own (Kramsch, 2006, 2013). Consequently, Kramsch $(2013,2014)$ argues that the modernist lens on culture does not correspond to the current global reality in which English as a lingua franca challenges the supremacy of the native speaker and bounded speech communities.

A postmodernist lens on culture gives primacy to discourse and identity (Kramsch, 2006, 2013, 2014). Culture as Discourse (with a capital ' $D$ ') indicates the "ways of using language, or thinking, feeling, believing, valuing, and of acting that can be used to identify oneself as a member of a socially meaningful group or social network" (Gee, 1990, p. 143). The ways of 
using language and the meaning of culture in the form of language are continually negotiated and renegotiated through language; therefore, a view of culture as Discourse reveals the closer bond between language and thought (Kramsch, 2006, 2014). Kramsch (2013, p. 68) continues that Discourse culture is:

a dynamic discursive process, constructed and reconstructed in various ways by individuals who engage in struggles for symbolic meaning and for the control of subjectivities and interpretations of history.

As Discourse, culture is a social semiotic construction which is shaped by those who read it (Kramsch, 2013). Emphasizing the dynamic nature of culture as Discourse, Kramsch and Hua (2016) note that "culture is not given, static...but something one does" (p. 43). Second, culture is identity. This view of culture emphasizes the individual instead of collective dimension in one's agency, and power to take control over one's own destiny (Kramsch, 2006, p. 17). Kramsch (2006) adds that the power relation between speakers plays an important role in the creation of their socio-political identity in communication. Overall, the postmodernist lens on culture emphasizes the relationality and subjectivity of people who actively take various positions in a globalised world to make meaning within their discursive practices while it does not lose the historicity of local national speech communities (Kramsch, 2013).

In brief, the modernist lens views culture as objective and monolithic entities while the postmodernist lens emphasizes culture as "portable schemas" (Kramsch, 2014, p. 409) of the meaning making process and its subjectivity. Despite the different ways of viewing culture identified by scholars such as Baldwin et al. (2006), Hua (2018) and (Kramsch, 2006, 2013, 2014), the emerging insight is that on the one hand, culture is treated as monolithic, tacit, separate elements; on the other hand, it is the active meaning making process in which people play an active role. Given this complexity, it is not surprising that language teachers can struggle to accommodate a balanced approach to culture in their teaching. Thus, it is worth exploring the salient characteristics of culture.

\subsubsection{Characteristics of culture}

Apart from conceptualising culture in terms of themes and approaches, scholars have also attempted to distil its essential characteristics.

Perhaps the most recognised characteristic of culture is that it is dynamic, highly variable, and constantly changing (Street, 1993; Liddicoat et al., 2003; Faulkner et al., 2006; House, 2008; Kumaravadivelu, 2008; S. Liu, Zala, \& Cynthia, 2015; DeCapua \& Wintergerst, 2016; Jackson, 2014; 
Holliday, 2013). Street (1993) argues that culture is a dynamic process of meaning-making and has the attributes of a verb rather than a noun or an object. The important thing about culture is what culture does (S. Hall, 1997). At this point, Liddicoat et al. (2003) consider culture as sets of variable practices in which people engage to live their lives; it is continually created and recreated by participants in interactions. Liddicoat et al. (2003) maintain that culture is about actions and interactions when people use cultural frameworks to structure and make sense of their social worlds and communicate with others.

House (2008, p. 10) contends that there are no "pure cultures" because groups and individuals are continually destabilised by external influences and internal restructuring. According to Kumaravadivelu (2008), culture includes the past values and historical patterns as well as the present patterns which are still relevant, and patterns which are still in the process of being established. In addition, as he points out, conditions necessary for culture change such as migration, globalization, and information revolution always exist. Agreeing with this, Holliday (2013) states that small culture (e.g., family, school) formation happens all the time as we all construct and deal with realities in time and space. Moreover, according to Jackson (2014, p. 69), culture is a site of contestation among ideologies, and so is contested, fluid and mediated through discourse. Likewise, culture is a changing whole of multiple elements and diverse constituents as a result of humans responding to the environment (DeCapua \& Wintergerst, 2016, p. 15)

Moreover, culture is learnt. According to Samovar, Porter, and McDaniel (2009), culture learning is both formal and informal and lifelong through interactions, observations, and imitations. DeCapua and Wintergerst (2016) point out that individuals learn cultural patterns such as customs, conventions, values, behaviours, and worldviews. Cultural learning sources, which are termed cultural carriers by Samovar et al. (2009), are diverse: from family, community, teachers, proverbs, folk tales, media (Liu et al., 2015), parents' explicit instruction, heritage values, and from one's own exposure and observation (Marczak, 2013), and from members of groups through socialisation (Liddicoat et al., 2003). Hence, it can be concluded that culture learning occurs both consciously and subconsciously.

According to DeCapua and Wintergerst (2016), the outcome of enculturation is the development and evolution of individuals' beliefs, ways of behaving and living, attitudes, and values. These changing outcomes affect the meanings individuals assign to the world around them, and their interpretation of the world. Thus, language (verbal and non-verbal) plays an 
important role during enculturation. Similarly, language transmits culture from one to other generations (Samovar et al., 2008). The language forms and the messages conveyed in them provide cultural knowledge (Liddicoat et al., 2003; Marczak, 2013).

Furthermore, culture is shared because culture learning often involves interacting with many people and through many resources (Samovar et al., 2008). People within a group or community share general sets of cultural practices, cultural understandings, and communication contexts (Liddicoat et al., 2003) and based on such commonality, they are able to make sense of others' actions (Samovar et al., 2008).

Finally, culture is relative (Jackson, 2014). She states that culture is understood and discovered in relation to another culture because one may become unaware of his/her own cultural preconceptions until he/she encounters other ways of being and doing.

In brief, the diversity in approaches to culture indicates that culture is a fluid and elusive concept (Kumaravadivelu, 2008). Culture is not simply a combination of multiple parts. Instead it is a holistic whole in which when an aspect is touched, other aspects are affected (E. T. Hall, 1977). Culture is expansively understood as social practices and contesting ideologies.

Knowledge of different ways of viewing culture is useful as it draws attention to various aspects of human behaviour (Scollon, Scollon \& Jones, 2012) and is a requirement for an intercultural approach to language teaching and learning (Marczak, 2013) which is the subject of this thesis.

\subsubsection{The language-culture relationship}

This section outlines contemporary understandings of the relationship between language and culture, which, according to Kohler (2015, p. 17), inform intercultural language teaching and learning. The relationship between language and culture has been analysed and discussed by scholars such as Kramsch (1998), Crozet and Liddicoat (1999), Atkinson (2002), Damen (2003), Risager, (2006), Kumaravadivelu (2008), and Hua (2018).

According to Crozet and Liddicoat (1999), language and culture articulate each other at various levels as represented in Figure 1: 
Figure 1. Points of articulation between language and culture

(Crozet \& Liddicoat, 1999, p. 116)

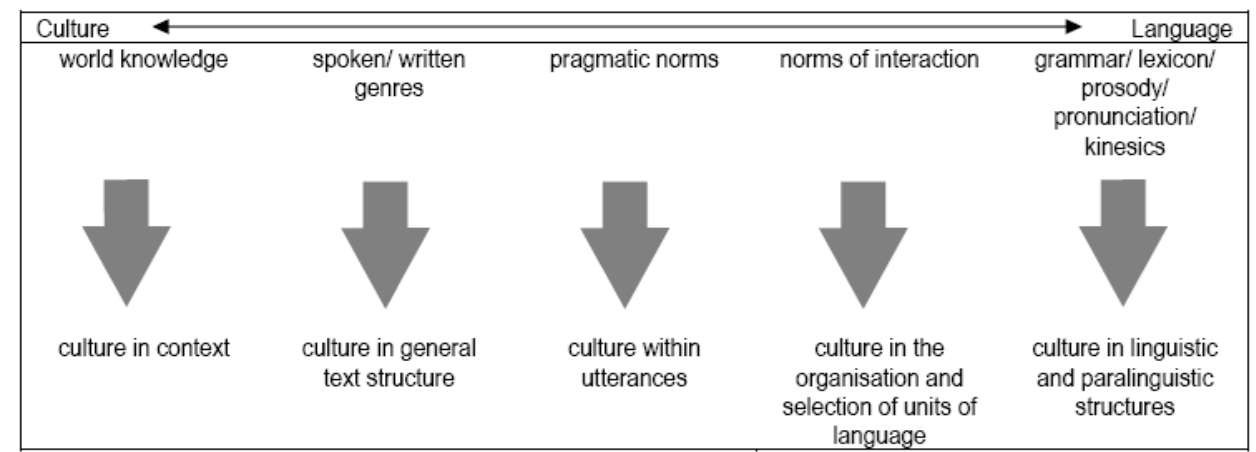

At the first point, culture relates to the sources and types of knowledge about the world (e.g., ways of life of a society) that individuals have. At this point, culture is contextual. The degree of articulation between language and culture increases at the next point, culture in general text structure, spoken and written genres. At this second point, culture shapes the features of spoken and written genres. For example, the way of writing a letter of request is different across cultures. Third, pragmatic norms refer to language use and particularly politeness. Fourth, norms of interaction refer to when and what is appropriate to say in conversation. Cultural pragmatic and interactional norms guide the choice of communication strategies to make sure that communication is polite and appropriate. Finally, culture is present in language structure in both verbal (e.g., grammar, vocabulary and pronunciation...) and non-verbal dimensions (e.g., physical contact and personal space). It follows that if cultural knowledge is embedded in all aspects of language, then culture can be addressed at multiple levels and stages of language learning.

Similarly but from a socio-cognitive perspective, Atkinson (2002, p. 528) identifies eight social dimensions of language which express culture:

- Politeness, identity and presentation of self;

- Perspective taking and contextualization cueing;

- Language-in-context;

- Turn-taking, participation structures and opportunity structures;

- Speech as an interactional accomplishment;

- Social indexicality; 
- Social knowledge of and participation in speech events, and sociolinguistic (including register) variation;

- The organization and addressivity of discourse.

These dimensions reveal the close bond between language and culture.

From a sociolinguistic perspective, Fishman (1985, 1986, 1991, as noted in Risager, 2006) identifies language as a part, an index, and a symbol of culture. Kramsch (1998) argues that language functions as expressing, embodying and symbolising cultural reality. Both Fishman (in Risager, 2006) and Kramsch (1998) emphasize the language-culture connectedness although they discuss different aspects of the relationship (Risager, 2006). As Risager notes, Kramsch's scholarship is based in socially and culturally oriented linguistic way of thinking while Fishman focuses on macro sociolinguistic and political perspectives.

The analysis of the language-culture relationship has led scholars to emphasize the inseparability of language and culture. However, this notion of inseparability has been challenged (Risager, 2006; Kumaravadivelu, 2008). For example, as Kumaravadivelu (2008) points out, the language-culture relationship is not linked inextricably. As he argues, if the language-culture relationship is inextricable,

then we would not be able to translate successfully from one language to another, nor would we be able to engage in any fruitful cross-cultural communication. Moreover, the emergence of World Englishes, with their amazing functionality and spread along with the rich body of creative literature in varieties such as Indian English and Nigerian English, proves, if any proof is needed, that culture and language are not irrevocably linked (p. 22).

The quote reveals that one language (i.e., English) can be embedded in different cultures, which according to Doan (2014) is the "localisation of the language" (p. 81). It also indicates the role of the speakers (e.g., Indian, Nigerian) in using that language (i.e., English) to create their own meaning. Agreeing with Kumaravadivelu, Risager (2006) critiques the simplified identification of the relationship as always inseparate, noting that the relationship is not inseparate all of the time.

To recap, the language-culture relationship has been shown to be multidimensional and complex in contemporary scholarship. Hua (2018) acknowledges that a comprehensive analysis of the structure of this complexity has not been well-addressed. But despite these gaps, 
language teaching cannot afford to ignore recognising and addressing this bond (Kumaravadivelu, 2008).

\subsubsection{Intercultural Communicative Competence (ICC)}

\subsubsection{Components and models of ICC}

Various terms have been used for ICC including: intercultural competence, intercultural sensitivity, and cross-cultural adaptation (Sinicrope, Norris, \& Watanabe, 2007), intercultural competences (Dervin, 2010), intercultural effectiveness (Spencer-Oatey \& Franklin, 2009), intercultural awareness and intercultural skills (CoE, 2001), and more recently, global competence and intercultural maturity (Griffiths, Wolfeld, Armon, Rios, \& Liu 2016; Hua, 2018).

Identifying ICC components and models is one of the key issues in studying ICC. ICC is comprised of multiple components (G. M. Chen, 2017). Spitzberg and Changnon (2009) identify five themes that emerge from over 300 common terms in models of interpersonal and intercultural competence: motivation, knowledge, skills, context, and outcome. The common components of ICC include the cognitive, affective and behavioural dimensions (G. M. Chen, 2014). These three dimensions are extended in to include an ethical dimension (Dai \& Chen, 2015, p. 108). This ethical dimension involves respect, sincerity, tolerance, and responsibility and regulates interactions intertwined in the earlier three dimensions.

Spitzberg and Changnon (2009) distinguish five types of model:

- Compositional models specify components of ICC but miss the conditional relations among components. The common components are motivational factors i.e., attitudes, skills, and knowledge; and cognitive and behavioural factors

- Co-orientation models incorporate interactions between components but are weak in addressing how these interactions develop.

- Developmental models address the progress and evolutionary nature of interactions and relationships. For example, Bennett's (1993) Developmental Model of Intercultural Sensitivity (DMIS) maps the development from ethnocentric stages to ethnorelative stages.

- Adaptational models emphasize one's adaptability during encounters but are still limited in specifying subcomponents of adaptability or the mutual adaptation of each stage.

- Causal path models indicate the specific causal relationships between different components and see ICC as a theoretical linear system. 
In terms of contexts, ICC models include general models, models for intercultural adaptation, models for education and training, and models for global communication (G. M. Chen, 2017). In general education, foreign language, and study abroad programs, as noted in Sinicrope et al., (2007), influential frameworks for conceptualizing and assessing IC include the models of Byram (1997), Risager (2007), Ruben's (1976) behavioral approach, Bennett's (1993) DMIS, Arasaratnam and Doerfel's (2005) Culture-Generic approach and Deardorff's (2006) process model of intercultural competence. Despite different focuses, these models share the common goal of seeking to describe the skills, dispositions, and processes involved in intercultural competence and especially in the ability to engage effectively in intercultural communication.

To take one example, Deardorff's process model of intercultural competence (2006, p. 256, 2008, p. 36) outlines the process of acquiring intercultural competence and the interplay of attitudes, knowledge, group of skills (observing, evaluating, analysing and relating) and acquired outcomes (i.e., adaptability, flexibility, empathy, effective communication and appropriate behaviours in intercultural encounters). This model is designed to aid the development of context-specific assessment indicators for intercultural competence. A limitation of the model as acknowledged by Deardorff is that it relies solely on the opinions of experts who participated in her study $(2008$, p. 40).

The models listed above originate from different disciplines and each model of ICC has its own focus, strengths, and limitations. Such theoretical diversity highlights the multifaceted nature of the construct of intercultural competence scholarship and an overall lack of interdisciplinary unity or consensus (Dervin, 2010, 2016; Deardorff, 2008). Discussing this scholarship from an interdisciplinary position, Dervin (2010) presents a critical account of the assumptions behind conceptualisations of intercultural competence. More recently, he has adopted a critical stance on IC, noting the dynamic contested nature of the construct and how it is continuing to evolve (2016).

The lack of consensus and the complexity in the intercultural scholarship inevitably challenges FL teachers in coping with the concept of ICC and addressing it in their teaching. Therefore, a framework that helps to guide teaching, training and research is crucial for them. This insight informs my upcoming examination of Byram's (1997) ICC model, which "is located firmly in the context of teaching and learning of foreign language in schools" (Spencer-Oatey \& Franklin, 2009, p. 67). It is the most influential ICC framework in language education (Behrnda \& Porzelt, 2012; Dervin, 2010), and is the framework adopted in the current study. 


\subsubsection{Byram's ICC model}

Byram's (1997, 2008, 2009) ICC model incorporates an intercultural dimension into communicative competence (see Figure 2 and Figure 3). This model transcends the assumption of native speaker competence which is implicit in the communicative competence (CC) model which has been widely influential in language education. The CC model includes the four pillars of linguistic competence, strategic competence, sociocultural competence and actional competence, and discourse competence (Celce-Murcia, 2008). Because sociocultural competence is equated with the speaker's pragmatic knowledge which is mainly concerned with knowledge of the life, traditions, history and literature of the target language community and one's living experience from being a member of the target language group (Celce-Murcia, 2008 , p. 46), it does not cover the same ground as intercultural competence. The CC model pays attention to both learners' knowledge of language and their ability to use the language being learnt (Byram, 1997; Alamri, 2018) and is concerned with both functional and structural aspects of language (Littlewood, 1981, in Manoliu, 2012). However, it has produced ways of teaching and learning languages in which culture has been marginalised (Dervin \& Liddicoat, 2013).

Byam's ICC model takes an educational focus including objectives, locations of learning, and roles of teacher and learner, and assessment. ICC targets the competencies of intercultural speakers, and as such, steps beyond the CC model. In teaching philosophy, it expands the kinds of competencies that foreign language teaching seeks to develop in learners in the way that realises the role of foreign language education in citizenship education. In teaching methodology, it explicitly addresses intercultural competence. The model aligns with the design of intercultural content developed in this thesis in that it shifted from the focus on native-like sociolinguistic competence to learners' self- reflections and making meaning from such reflections (Dervin, Paatela-Nieminen, Kuoppala, \& Riitaoja, 2012). In other words, Byram's ICC model presents an argument against the "tendency to retain the native speaker as a model for the learner" (Byram, 1997, p. 10). 
Figure 2. Byram's (1997, p. 73) Model of ICC

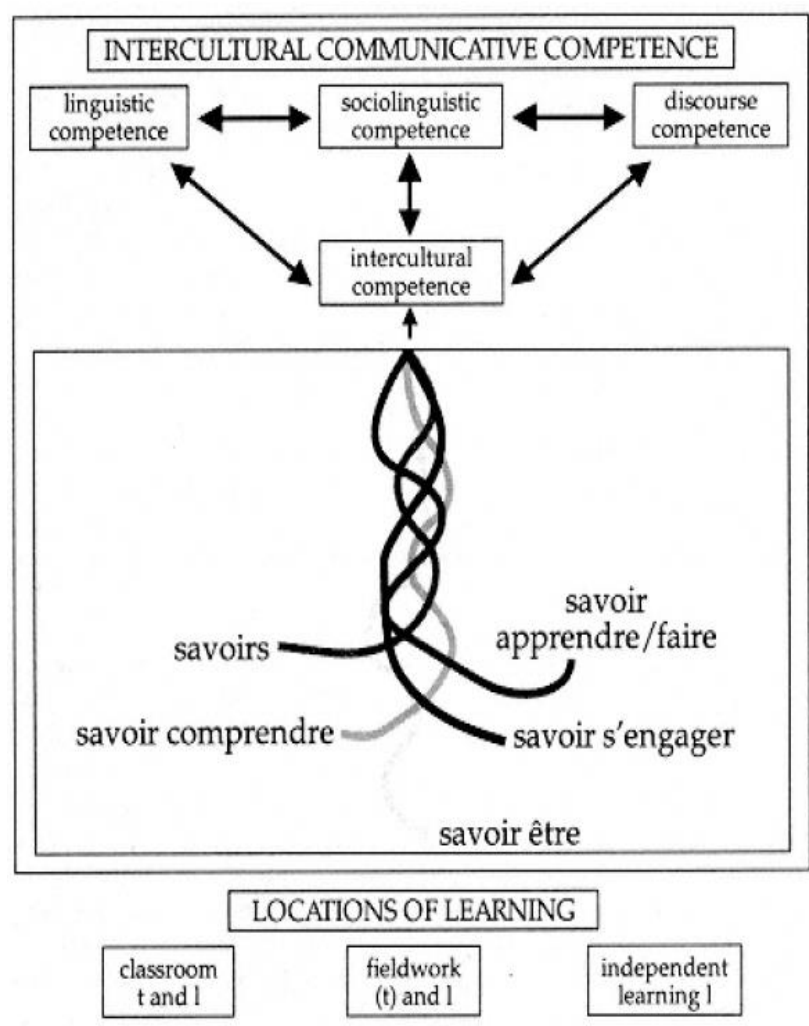

Figure 3. Byram's (2009, p. 323) Model of ICC

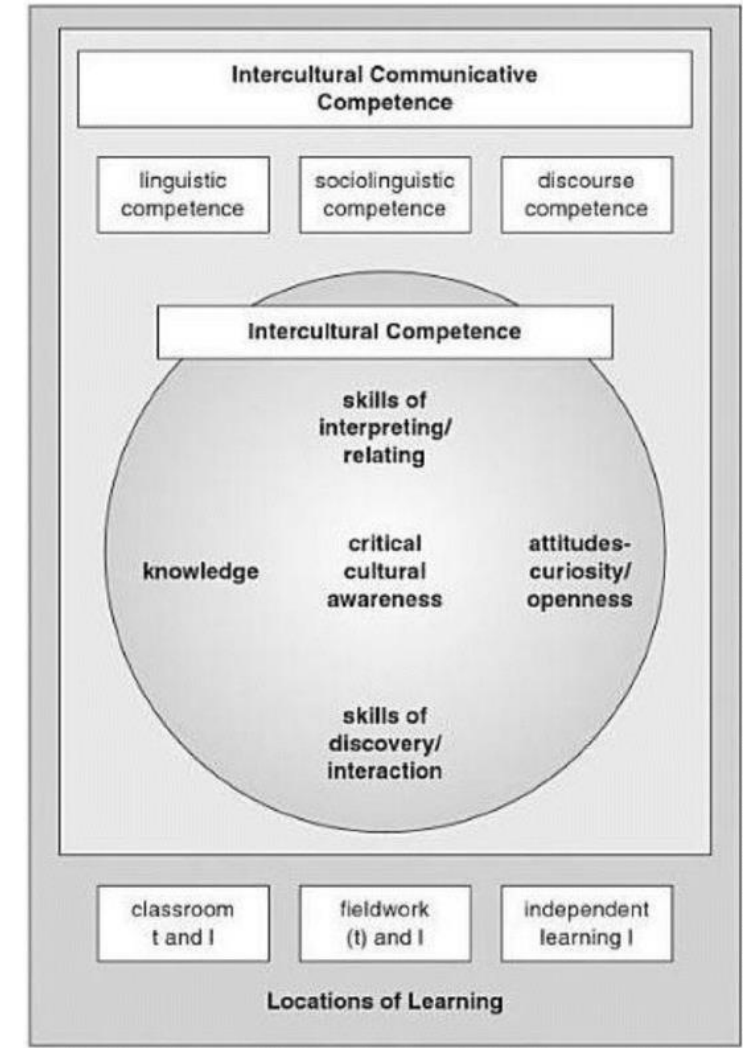


In Byram (1997), the ICC model composes four types of competence: linguistic, sociolinguistic, discourse, and intercultural competence (IC). IC is described in terms of five savoirs (knowings) corresponding to attitudes, knowledge, skills and critical cultural awareness. Specifically:

- Savoir être (Attitudes) refers to the ability to relativize self and value others by ones' curiosity, openness, and readiness to suspend (dis)beliefs and judgements about one's own and other cultures. One needs to decentre, bringing his/her pre-acquired beliefs/values to be openly analysed, challenged, and reflected with respect to others' meanings, values and beliefs (Byram, 1997). Attitudes, particularly genuine curiosity and openness, which are contrasted with those of business and tourist profit make intercultural discovery and interaction easier (Byram, 2008).

- Savoir (Knowledge) covers four categories: knowledge about (1) other cultures, (2) self, (3) others, and (4) interaction processes of individual and societal in communication. First, knowledge about other cultures involves declarative knowledge about daily life, values, beliefs, conventions, interpersonal relations, body language (Byram, 1997). This cultural-specific knowledge is important in that it is often not familiar to learners' previous experiences and they may be distorted by learners' stereotypes (CoE, 2001). Second, knowledge of self is that about one's own country's social groups and cultures. Normally acquired through formal education, this type is often refined, remains conscious, some unconscious, taken for granted, and unanalysed but strongly influences how one is likely to handle interaction in intercultural encounters. The third type involves knowledge similar to the second type but of the interlocutors and is relational in nature. The fourth type, fundamental to successful interaction but not acquired automatically, relates to knowledge about the social cultural processes which shape identity formation and ways of acting (Byram, 1997). With this savoir, the notion of cultural knowledge is stretched beyond the traditional focus on cultural facts about the target country (Newton et al., 2010). To use the above-mentioned knowledge sources, learners need the skills of interpreting and relating.

- Savoir comprendre means the ability to interpret and relate. That is to interpret documents or events from other cultures and relate them to documents or events of one's own. Examples of this skill include identifying allusions, connotations, and 
ethnocentric values; handling dysfunctions, contradictions; identifying unresolvable issues which often remain difficult for people from another culture to recognise (Byram, 1997).

- Savoir apprendre or savoir faire refers to the skills of discovering and interacting. Discovering is concerned with (a) recognising and acquiring new/significant knowledge of a culture and cultural practices and (b) drawing out their meanings and relationship to other knowledge both in documents and interactions. Interacting is concerned with applying the above-mentioned knowledge, attitudes, and combined skills to manage communication and interactions i.e., managing real constraints and dysfunctions, establishing relationships, and mediating (Byram, 1997).

- Savoir s'engager (Critical cultural awareness / political education) describes the ability to evaluate critically from explicit criteria, perspectives, practices and products in one's own and other's cultures (Byram, 1997).

Byram (2009) re-positioned critical cultural awareness to the centre of the ICC model to emphasize the crucial educational dimension of IC and the link between IC development and intercultural citizenship education (Byram, 2008, 2009). Liddicoat and Scarino (2013, p. 50) interpret this critical component as:

the capacity for critical cultural awareness that includes investigating and understanding one's own ideological perspective in communication and engaging with others on the basis of this perspective. It is also derived from interpreting and understanding the ideological perspectives of others.

As a dimension of ICC, critical cultural awareness means being able to evaluate human's thoughts and activities from multiple perspectives (G. M. Chen, 2017). Likewise, according to Félix-Brasdefer (2017), with critical cultural awareness, the intercultural speaker is seen as a world citizen with understanding of global issues and the ability to engage in critical discussion and evaluation about one's own and other's cultures.

In brief, according to Byram's ICC model (1997, 2009), in addition to CC (linguistic, sociolinguistic, and discourse), the intercultural speaker needs IC. IC is conceptualised as the ability to adopt relativised attitudes towards cultural differences and has a range of intercultural knowledge, skills, and high awareness of one's self to self-engage with the other in intercultural communication in a profound and critical manner. 
However, Byram's model is not without its critiques. Some scholars have offered suggestions for making the model more useable and comprehensive (Liddicoat et al., 2003; Sercu, 2004; Risager, 2007; Houghton, 2010, 2013; Sharifian, 2012; Liddicoat \& Scarino, 2013; Hoff, 2014).

The first type of critique has focused on the theoretical separation between communicative components and intercultural components in the model. According to Liddicoat et al. (2003), Byram's model weakly articulated the relationship between intercultural elements and other components of language competence. Liddicoat et al. (2003) continue that the influences among components are assumed but not operationalized in the model. Similarly, scholars at the University of South Australia (Research Centre for Language and Culture Education (RCLCE), 2007), maintain that Byram's model did not sufficiently address the important ways that language and culture affect each other, and how students make sense of this relation. The relationship among communicative and intercultural components in the ICC models is important. As McConachy and Liddicoat (2016) argue, the absence of dealing with this relationship makes it difficult to conceptualise the role of language in intercultural mediation. McConachy and Liddicoat (2016) contend that intercultural mediation is an important interpretive activity which relies on analysing language to probe the culture frames that shape the interpretation of pragmatic acts in each culture and across cultures. Moreover, McConachy (2018) adds that the absence of dealing with the relation among the communicative and intercultural components in ICC models may lead to the view that IC is something to be developed after $\mathrm{CC}$ has reached a certain level, rather than alongside each other. Byram (2009) acknowledged these kinds of critique, stating that his model is a list model for simplification for guiding teaching, planning, and assessment.

Scholars recommend expanding Byram's ICC model in some ways. First, Sercu (2004, p. 77) bases her framework for IC assessment on Byram's model but integrates subcomponents of culture-specific and culture-general knowledge and metacognitive strategies. Sercu (2004) discusses Byram's model in association with the four dimensions of the notion of competence in educational theory (i.e., domain-specific knowledge, cognitive strategies, metacognitive strategies, and affective characteristics). As a result, she argues that Byram's model addresses the knowledge, cognitive strategies, and affective characteristics well, but 
is silent on metacognitive strategies, defined as the knowledge and beliefs involved in students' self- regulating mechanism to plan, monitor, and evaluate their learning process. Liddicoat and Scarino (2013, p. 50) suggest that Byram's model should emphasize both reflection on action and on learning to put a stronger focus on educational dimensions in the model. They argue that meta-awareness, or the ability to elaborate and analyse awareness to make the intercultural speaker not only a participant but also an analyser in interactions, is a fundamental aspect of IC. Also looking at savoir (knowledge), Sharifian (2012) suggests that meta-cultural competence should be added. Sharifian (2012) explains that meta-cultural competence is the understanding that one language may be used to encode several systems of cultural conceptualisation.

Furthermore, Houghton (2010, 2013) adds the dimension of students' "knowing to become" namely savoir se transformer. Houghton (2010, p. 224) contends that this savoir draws on students' identity and self-development - their knowing how to make choices selectively as a result of their critical evaluation of self and others through interactions. In contrast to the other savoirs which focus on knowledge and the world, this sixth savoir emphasizes the role of oneself in how one changes (i.e., defines and redefines oneself) and decides how one wants to become, using one's critical awareness through self-reflection (Houghton, 2010). By savoir se transformer, Houghton (2010, p. 225) argues that the links of dependency or interdependency among the competences in Byram's ICC model become more explicit and comprehensive to teachers.

A second critique concerns the matter of nationalism (Risager, 2007) and over-emphasis on harmony and agreement in the model (Hoff, 2014). For instance, Risager (pp. 233-234) comments that the model lacks a global perspective with the intercultural speaker in Byram's model socially limited to an I-You relationship, thus neglecting a mediating role between different people or group. A third critique involves the relationship between self and otherness indicated in the model (Hoff, 2014). Discussing Byram's model in the light of Bildung theories, Hoff (2014) argues that savoir être indicates an unbalanced relationship between the intercultural speaker (self) and the counterpart speaker (the other). According to Hoff (2014), the model does not recognise conflicts, ambiguity, and differences which are considered both as a challenge and potential for successful dialogue between self and other in intercultural encounters. From Hoff's (2014) point of view, savoir être implies that the 
other's cultural values and presuppositions should be more valued than those of the intercultural speaker.

In brief, the critiques and recommendations for Byram's $(1997,2009)$ ICC model claim that it underplays the relationship between language and culture components in the model. This reflects the challenge of achieving one all-agreed framework that can avoid all pitfalls. Therefore, Byram (2009) suggests teachers' flexibility in using specific theories or models. The value of Byram's ICC model has been widely recognised. First, it reflects an exploratory approach to learning (Newton et al., 2010), and binds language learning with education for citizenship and democracy (Hoff, 2014). Second, it has been very influential (Sercu, 2004; Behrnda \& Porzelt, 2012), the most elaborated (RCLCE, 2007), and one of the major models of ICC and its assessment in language education and research (Sinicrope et al., 2007). Moreover, it is the most thorough and clearly articulated model (Newton et al., 2010), containing both linguistic and intercultural parts (Risager, 2007). It is and will be considered as the cornerstone in the field (Díaz \& Dasli, 2017).

Relating to Vietnamese tertiary EFL context, Byram's model is relevant in important ways. First, it is a comprehensive model of ICC which reflects the competencies (intercultural awareness, knowledge, attitudes and skills) emphasized in the CEFR which Vietnam has adopted. Second, the discrete aspects of ICC identified in the model provide an operational basis for setting standards on which to base teacher professional learning. Within the Vietnamese context, there is a need for theoretical frameworks capable of guiding teaching, training, and research.

\subsection{Culture in language education}

\subsubsection{Approaches to viewing culture}

In section 2.2.2.2, I discussed four approaches to viewing culture. Much of the scholarship drawn on there is from disciplines such as anthropology rather than from a language education perspective. Liddicoat and Scarino (2013) provide an alternative, though complementary, way of viewing culture with specific reference to language learning and teaching. They also identify four main approaches to culture, namely: culture as national attributes, culture as societal norms, culture as symbolic systems, and culture as practices. 
Culture as national attributes views culture as bounded to attributes of nation (e.g., literature, arts, and music) and geographical and political boundaries of groups (e.g., nation) and subgroups (e.g., minority and social classes within the nation). It is also referred to as high culture or the 'big C' Culture. Within this approach, learning about culture aims at mastering the artistic merits of the culture's literary work or valued texts because it sees culture as residing in texts (Crozet, Liddicoat, \& Bianco, 1999); Liddicoat, 2004; Liddicoat \& Scarino, 2013). However, as Crozet et al. (1999) point out, texts are not used to explore broader aspects of culture. Instead they are treated as cultural artefacts. Broad knowledge about various topics of a country such as history, geography, and organisations is considered crucial to understanding the target country's culture and society (Liddicoat \& Scarino, 2013).

A culture as societal norms approach is concerned with people and the cultural values associated with their actions and beliefs. Culture is described with reference to people's practices and the values that typify them. Teaching of culture typically includes topics such as politeness, (in)directness, and non-verbal communication. As Liddicoat and Scarino (2013) point out, this approach creates the risk of cultural stereotype formation since it treats FL learners as outsiders who observe and interpret others' actions and beliefs (Liddicoat \& Scarino, 2013).

Culture as symbolic systems conceptualises culture as a system of symbols (Liddicoat \& Scarino, 2013). Based on this symbolic system, people mutually construct, interpret, and communicate meanings in their daily life and interactions. Meanings are therefore shared, negotiated, context-sensitive, and highly variable. Culture is mediated and transmitted through symbols.

The fourth approach identified by Liddicoat and Scarino (2013) is culture as practices. This approach conceptualises culture as a framework which represents actions and understandings constructed by people (e.g., symbols, stories, rituals, and worldviews). People draw on these resources to construct and develop their course of action in response to changing circumstances in their lives. Liddicoat and Scarino note that according to this approach, cultures do not pre-determine people's practices, as people play a central active role in choosing what resources are relevant to their purposes of language use. Cultures are constantly made and re-made through people's lived experiences and actions (especially the 
way they use language). Culture is beyond inherent bodies of knowledge and values to be transmitted through generations.

On this basis, meanings are created in moments of interactions; therefore, meanings are fragmented, contradictory, and contested rather than simply shared. Because people's construction of meanings occurs in multiple groups in which they participate, cultural identities become dynamic, evolving, and fluid instead of being fixed (Liddicoat \& Scarino, 2013).

These four approaches reflect the static and dynamic views of culture as described in Liddicoat (2002). As Liddicoat et al. (2003) and Liddicoat and Scarino (2013) argue, the first three approaches (culture as national attributes, societal norms, and symbolic systems) reveal a static view of culture. These approaches treat culture as an unvarying synthesis of a discrete body of cultural information and consider learners as external observers of others' cultures. For example, the culture as societal norms approach emphasizes FL users' knowing what kind of behavioural manner or standard is expected of them in interactions. Teaching of culture typically includes topics such as politeness, (in)directness, and non-verbal communication, and so creates the risk of cultural stereotype formation (Liddicoat \& Scarino, 2013). By contrast, the fourth approach, culture as practices, reflects a dynamic view of culture since it addresses the complexity of culture and its relationship with humans (Liddicoat \& Scarino, 2013, p. 23), and emphasizes learners' ability to engage with culture and mediate between language and cultures (Liddicoat \& Scarino, 2013; Newton et al., 2010).

In brief, the literature reviewed highlights the multidimensional and complex nature of culture. Adopting this view of culture in this thesis, I will next study how culture has been interpreted and enacted in the context of language teaching and learning a foreign language.

\subsubsection{Approaches to teaching and learning culture}

How culture is interpreted and enacted in language teaching and learning has relied on reconceptualisation of culture, cultural competence and its role in language teaching (Crozet, Liddicoat, \& Bianco, 1999). The evolution of approaches and perspectives in which culture was interpreted and enacted in EFL teaching was outlined by scholars including 
Crozet et al. (1999), Newton et al. (2010), and Marczak (2013). The insight revealed from these works is that traditional teaching approaches fail to do justice to the complex, dynamic, and fluid nature of culture. Traditionally, culture teaching has limited itself to static dimensions such as a country's literature and civilisation in Grammar Translation Method; as formal aspects of life such as geography, material culture and lifestyle in Direct Method; as daily routine aspects in Audio-lingual Method (Marczak, 2013). The teaching of culture in these approaches was reduced to the focus on developing reading ability through understanding the target language's classical literature (i.e., in Grammar Translation Method) and declarative knowledge about the target country's national artefacts and formal aspects of life in the Direct Method (Marczak, 2013).

Kramsch (2006) points out that, the teaching and learning of culture shifted from a humanistic to a more pragmatic concept as way of life within Communicative Language Teaching (CLT) approach. Because CLT embraces communicative competence as the goal of language teaching (Celce-Murcia, 2008), it emphasizes that the language presented in classrooms should be authentic to reflect the dimension of language use in reality (Aguilar, 2008). This approach relies on the Communicative Competence model (as previously mentioned in section 2.2.4) which considers being culturally appropriate in communication with native speakers, or sociocultural competence, crucial for successful communication (Celce-Murcia, 2008, p. 46). Under the overall goal of developing communicative competence, the teaching of culture and its role in CLT is stated as follows:

\footnotetext{
If the goal of language instruction is communicative competence, language instruction must be integrated with cultural and cross-cultural instruction. General knowledge of the literature and other arts that are integral to the target culture should be part of language instruction as should basic knowledge of the history and geography associated with the target language community. The social structure of the culture should also be covered (e.g. family, kinship relations, child-rearing, courtship and marriage, gender roles) especially if the target culture differs in important ways from the learner's culture. Political and educational systems should be introduced as should the major religion(s) and holidays, celebrations, and important customs. These topics can all serve as content for language instruction with special focus on areas of cultural and interactional difference (Celce-Murcia, 2008, p. 51).
}

The above quote reveals CLT's emphasis on mastering knowledge of various aspects about the life of the country in which the target language is spoken. It becomes obvious that the 
learning of culture was simplified to adopting salient native-like sociocultural norms. In practice, CLT classrooms simply introduce students to sociolinguistic patterns related to particular speech acts through the use of authentic texts (Marczak, 2013), and particularly cultural knowledge about lifestyles and institutions in the target country (Corbett, 2003). It underestimates culture (Corbett, 2003), marginalises or even ignores learners' own culture (Alptekin, in Aguilar, 2008), and fails to recognise the heterogeneity of the target language society (Marczak, 2013).

The approaches reviewed above have shown their shortcomings. Given the importance of critical awareness about learners' own culture and the complex and fluid nature of culture, it is important to address the question of how culture can be adequately taught in the language classrooms. In response to this issue, scholars have increasingly examined intercultural perspectives on language teaching and identified intercultural orientation that can incorporate intercultural dimension into classrooms.

\subsubsection{Intercultural language teaching and learning}

Scholars' works have provided conceptualisations for the key concepts such as ICC (Byram, 1997, 2008, 2009; Deardorff, 2006; Risager, 2007), issues in conceptualising ICC (Wahyudi, 2016; G. M. Chen, 2017), rationale for an intercultural stance (Aguilar, 2008; Marczack, 2013), principles for intercultural language teaching and learning (Crozet \& Liddicoat, 1999; Liddicoat, 2002; Newton et al., 2010; Liddicoat \& Scarino, 2013; Witte, 2014 ), ICC assessments (Sercu, 2004; Fantini, 2012; Witte, 2014), intercultural language teachers (Sercu, Bandura, Castro, Davcheva, Laskaridou, Lundgren..., \& Ryan, 2005; Sercu, 2006; Marczack, 2013; Kohler, 2015). Drawing on this scholarship, this section outlines the core features which constitute an intercultural orientation in language teaching and describes the principles for Intercultural Language Learning (ICLL) and for Intercultural Communicative Language Teaching approach (iCLT).

\section{Features of the intercultural orientation in language teaching}

Liddicoat and Scarino (2013) coined the term intercultural orientation. According to Liddicoat and Scarino (2013), an intercultural orientation endeavours to emphasize the intercultural nature of language learning as an educational activity. Additionally, language learning provides a point of engagement with language and culture as inter-related meaning 
making systems to explore self, others, and the boundary between self and others to create an intercultural identity (Liddicoat, 2011).

Three key dimensions of an intercultural stance can be identified. First, an intercultural stance addresses culture beyond cultural information and native-like norms with the ultimate goals of developing learners' ICC. As Kramsch (1993) points out, ICC is the ability to take both an insider's and an outsider's view on one's own and others' language and culture or the ability to create a comfortable third place. This third place or third perspective (Kramsch, 1993, p. 201) metaphorically refers to a discourse process in which learners construct their personal meaning and identity during the process of learning the foreign language. Such meaning and identity are not expected to be the same as or imitation of their own culture or the target culture. In this discourse process, learners do not simply exchange cultural information nor consider culture as an object of study. Instead, they "relate, organise and realize meaning" (p. 11). Thus, through the interplay between language and culture in the classrooms, identities are constructed and evoked. Intercultural teaching and learning create interpersonal space to for learners to construct and reconstruct their own meaning and interpret it (p. 23). The intercultural outcome is the ability to understand oneself and others from one's own eyes and from the eyes of others. In Byram's words, ICC means "the ability to communicate and interact across cultural boundaries" (Byram, 1997, p. 7). Under the umbrella of ICC, learners become involved in a wide range of learning processes including probing, reflecting, comparing, connecting, interacting, experiential learning (Crozet \& Liddicoat, 1999; Newton et al., 2010), and mediating (Corbett, 2003; Liddicoat, 2014; McConachy \& Liddicoat, 2016). Moreover, developing ICC involves learners at multiple learning levels, which are cognitive, affective, behavioural, and critical awareness (Byram, 1997). Learners are engaged rather than excluded from their target language and culture to become interculturally competent speakers (Newton et al., 2010). Importantly, the intercultural orientation emphasizes learners' lifelong learning ability because ICC learning is considered as a lifelong process (Crozet \& Liddicoat, 1999; Byram, Gribkova \& Starkey, 2002; Marczak, 2013).

Second, the intercultural orientation establishes the equal importance between language and intercultural skills (e.g., understandings and mediation) and language ability (Liddicoat, 2002; Corbett, 2003; Newton et al., 2010; Newton, 2016). This orientation acknowledges 
the integrated nature of language and culture and addresses culture from all levels of language. Liddicoat (2002) contends that language learning is the most suitable place to address culture because language and culture articulate with each other at all levels. Language classes are sites for mining and developing the awareness of culture-in-language of students' lived experiences and of cultures of people present in classrooms (Newton et al., 2010). By addressing ICC alongside language, the intercultural approach does not negate nor completely replace previous teaching approaches (Corbett, 2003; Sercu, 2004).

Third, the intercultural orientation redefines the roles of teachers and learners (Crozet \& Liddicoat, 1999; Aguilar, 2008). The teachers' profile requires additional knowledge, new attitudes, competencies, and critical awareness (Aguilar, 2008). For example, in terms of attitude, teachers respect and appreciate the culture(s) students bring to class (Newton et al., 2010). Scholars such as Byram (1997, 2008), Corbett (2003), Damen (2003), Aguilar (2008), and Kohler (2015) emphasize teachers as intercultural mediators in classrooms who can guide, support, engage learners in cultural explorations and negotiations, and explore culture together with learners. Teachers create intercultural learning opportunities through their choices of texts (i.e., observation, analysis, comparing, interpretation and reflection) to draw learners' attention to linguistic and cultural content in their known language and culture and the new one. Through these processes, as Kohler (2015) argues, teachers help learners to build connection between the known language and culture and the new one. The best teachers are those who can make students see the connection between their own and other cultures regardless of their being native or non-native speakers of the target language rather than transmitting cultural information to students (Aguilar, 2008).

\section{Principles for Intercultural Language Learning}

Liddicoat et al. (2003) and Liddicoat (2008) developed an Intercultural Language Learning (ICLL) approach. According to these scholars, ICLL embraces the ideology that language and culture are co-constitutively related and considers culture study and language study as integrated and holistic. According to this approach, the concepts of language, culture, and learning are all central to language curriculum design. The authors argue:

Intercultural language learning involves developing with learners an understanding of their own language(s) and culture(s) in relation to an additional language and culture. It is a dialogue that allows for reaching a 
common ground for negotiation to take place, and where variable points of views are recognized, mediated and accepted (Liddicoat et al., 2003, p. 46).

Liddicoat et al. (2003, pp. 47-51) and Liddicoat (2008, p. 283) propose five principles of IcLL for curriculum design and classroom interactions. Liddicoat (2011, p. 840) note that these are not strictly principles of the intercultural but of teaching and learning in an intercultural pedagogy. The principles are summarised as follows:

\section{Active construction}

Learning involves learners making and re-making meanings through interactions and developing their own ways of responding to cultural and linguistic differences. Tasks that stimulate curiosity and challenge their existing knowledge are useful.

\section{Making connections}

Learning happens through interacting and comparing knowledge, experiences of language and cultures against new input.

\section{Social interaction}

Learning is social, interactive and interpersonal. Through every exchange of meaningful language, learners develop understanding about others. Such understanding is not given in advance but built up through social acts of discovering, negotiating, and creating in its unique social context.

\section{Reflection}

Learning involves working out/seeing one's own perspectives, becoming aware of the processes underlying thinking, knowing and learning through conscious awareness and reflection. Learners reflect on cultural differences in terms of what, how and why, and modify their intercultural behaviours. Learning is thus personal.

\section{Responsibility}

Learning depends on learners' attitudes and disposition toward learning. Learning involves learners' responsibility to respect others, develop sensitivity towards others, and contribute to the success of interaction as intercultural individual. 
These principles are translated into classroom as a four-component cycle of noticing, comparing, reflecting and interacting (Figure 4) (Liddicoat, 2008; Liddicoat, 2011; Liddicoat \& Scarino, 2013).

Figure 4. Interacting processes of intercultural pedagogy

Adapted from Liddicoat (2011, p. 841)

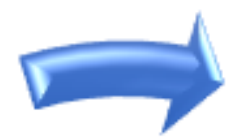

Noticing

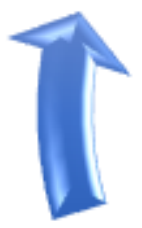

Interacting
Comparing

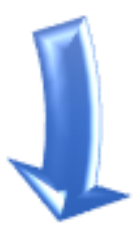

Reflecting

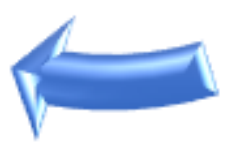

According to Liddicoat (2011, pp. 841- 842), first, when experiencing something new, it is fundamental for learners to notice the new cultural information. They seek to understand what it is in their own terms. On that level of experience, learners can perform cultural comparisons which involve identifying similarities and differences. Comparing involves not only the learners' background culture and the target culture but also what they already know and what they have noticed in the new input. These comparisons provide resources for reflection involving learners in interpreting their experiences. They make sense of experiences and create personal meanings from such experiences rather than emphasizing right or wrong conclusions. They are able to communicate these meanings, explore and reshape them in response to others.

\section{Intercultural Communicative Language Teaching}

Newton et al. (2010) coined the term Intercultural Communicative Language Teaching (iCLT). iCLT embraces an intercultural stance derived from the integrated nature of language 
and culture and highlights the dual focus on both the "intercultural" and the "communicative" in communication and pedagogy. iCLT takes the view that culture is negotiated by and belongs to individuals who participate in it; and that the relationship between group cultural membership and diversity of individual experience within cultures is dialectic. It aims to raise sensitivity to cultural differences and to develop the ability to navigate intercultural encounters. It thus emphasizes the importance of skills probing, reflecting, and comparing through engagement with language.

iCLT addresses culture in the ways that the earlier culture teaching approaches were limited in. First, while high culture (or big C Culture) focused on teaching information concerning artefacts (i.e., arts, traditions, and written texts), iCLT encourages learners to explore cultural artefacts, compare, and reflect the values laden in artefacts. Second, while culture as area studies focused on general salient knowledge that learners should know about a country, iCLT creates a link between such knowledge and learners' lived experiences for developing their growth of the cultural experiences of others. Third, iCLT challenges one's assumptions and emphasizes discovering the insights of the pre-constructed and subjective nature of stereotypes. Fourth, it focuses on culture explorations (of self and of culture) and comparison. Exploring self encourages learners to problematise the familiar - to look at their culture and language with new eyes - to understand their own language and culture better. Learners ponder how their use of language reflects their culture and how interactions reflect their language use. The purpose is to develop the ability to connect cultures rather than to create boundaries.

Hence, iCLT addresses culture explicitly. It does not require a new approach or method but "an explicit focus on interculturality into the communicative experiences available to learners" (Newton, 2016, p. 175). Such view is supported by scholars including Crozet and Liddicoat (1999), Corbett (2003), Sercu (2004), and Witte (2014) who argue that the intercultural stance expands the focus on CC towards developing ICC.

\section{Principles for Intercultural Communicative Language Teaching}

iCLT is built on the principles proposed in Newton et al. (2010) and Newton (2016). The six principles in Newton et al. (2010), are represented in Figure 5 below: 
Figure 5. Principles for effective iCLT

Source: Newton et al. (2010, p. 63)

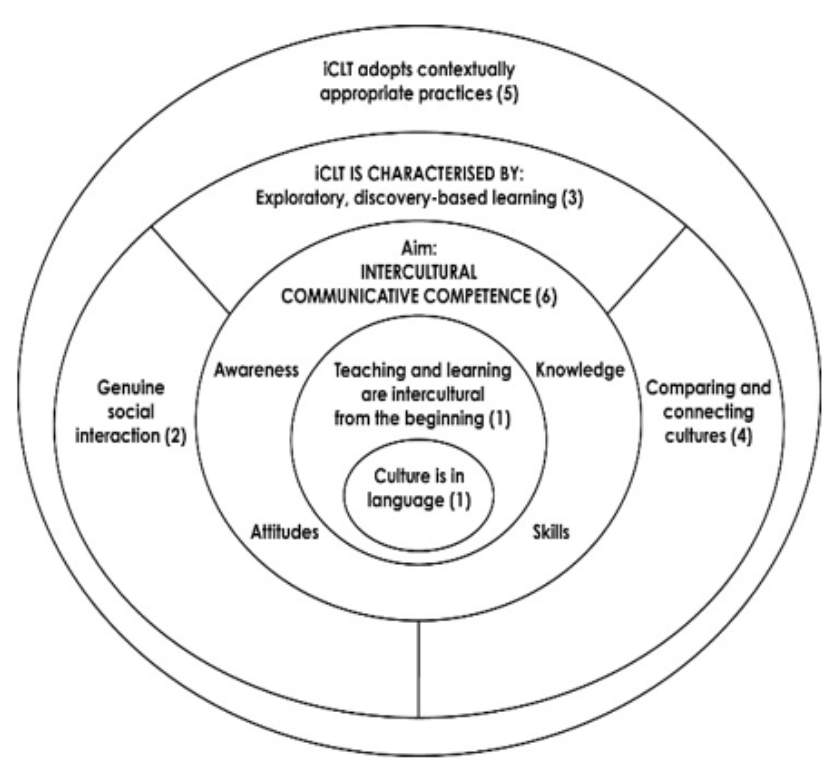

These principles are resequenced and expanded in the more recent set of principles in Newton (2016), which are represented in Figure 6:

Figure 6. The iCLT Principles

Source: Newton (2016, p. 165)

Principle 1. Mine the social context of learning

a. Use culturally responsive pedagogies to make the most of diversity in the classroom, school and community by recognizing and connecting to learners' home knowledge, languages and practices.

b. Expose learners to the diversity of world Englishes and raise awareness of English as an international language.

Principle 2. Focus on intercultural learning objectives

Foster and affirm intercultural learning achievements in tandem with linguistic and communicative achievements.

Principle 3. Adopt Intercultural classroom practices

Provide opportunities for learners to:

a. engage with culture in and around language from the beginning;

b. interact and communicate in the language;

c. explore, reflect on, compare and connect experiences, knowledge and understandings;

d. put learning into practice beyond the classroom, making choices and acting in interculturally informed ways.

Newton's (2016) principles are detailed as follows:

Principle 1. Mine the social context of learning 
Teachers and teaching activities value and connect learners' own linguistic and cultural backgrounds with the other cultural contexts in which learners socialise. The diversity learners bring to classrooms is considered as a resource for developing learners' knowledge about social groups, and social groups' products and practices in their own and other countries. Such resources promote an open-minded disposition to others. This general process of societal and individual interaction is fundamental to IC.

\section{Principle 2. Focus on intercultural learning objectives}

The goals of teaching embrace ICC rather than aiming solely at native-like norms.

\section{Principle 3. Adopt Intercultural classroom practices}

a. Engage learners with culture in and around language from the beginning iCLT builds on the integrated nature of the language and culture and focuses on addressing this relationship through learners' engagement with language from the start of the learning journey. Language and culture co-construct each other at all levels. Therefore, separating language and culture leads to stereotype and prejudice formation (Newton et al., 2010). This point is also shown in the words of Dellit (2005, p. 7):

Ignoring culture does not leave a vacant cultural space which can be filled in later. Rather, it leads to a cultural space which is filled in by uninformed and unanalysed assumptions.

b. Learners interact and communicate in the language

This principle emphasizes learners' experience of interactions through which students confront their assumptions and learn more about themselves and otherness. Learners explore linguistic and cultural boundaries, their own and others' cultural beliefs, values, attitudes, ways of talking, handling problems, and maintaining relationships. Discussion of cultural comparisons is encouraged.

c. Learners explore, reflect on, compare and connect experiences, knowledge and understandings

Teaching focuses on opportunities for learners to explore both overt (e.g., politeness forms) and less overt (e.g., the degree of tolerance for overlapping speech, the degree of indirectness) expressions of culture in language. Through exploring and experiences, learners reflect and construct knowledge about aspects of the target culture. 
d. Learners put learning into practice beyond the classroom, making choices and acting in interculturally informed ways.

This principle emphasizes learning beyond classrooms. Learners take active roles to act as interculturally competent citizens beyond the classrooms.

iCLT (Newton et al., 2010; Newton, 2016) reflects the theoretical scholarship and international trends in the practice of intercultural language teaching and learning. Developed to guide language teaching in New Zealand's multicultural context, it has been increasingly influential in research and practices both in New Zealand and other contexts. Scholars have drawn on the iCLT framework to examine teachers' beliefs and practices in language teaching and learning in New Zealand and beyond New Zealand. For example, Howard, Biebricher, Tolosa, Scott and East (2016) used it to analyse New Zealand school teachers' understandings against intercultural language teaching. Oranje (2016) used it to design the activities in the cultural portfolio project as a learning tool used in three secondary school language classes (i.e., German and French) in New Zealand. Kennedy (2016) explored the naturally arising opportunities for developing students' IC in Chinese as a foreign language classroom in a New Zealand high school against the iCLT principles. Ho (2011a, 2011b) and T. L. Nguyen (2013) used it to study university teachers' views and practices of teaching culture in the Vietnamese university EFL context.

The frameworks proposed by Liddicoat et al. (2003), Liddicoat (2008), Newton et al. (2010), and Newton (2016), inform the design of the intercultural learning content and analysis of teacher teaching and student learning in the current study. The two sets of ICLL and ICLT principles bring the integrated nature between language and culture to the heart of teaching and learning processes. These principles share a common concern for developing skills such as interpreting, comparing, relating, interacting, and reflecting. Especially, Newton's (2016) principles are relevant to the context of this current study because they were developed to guide the teaching of culture in English language classes rather than other languages and are concerned with an integrated view of skills teaching.

In brief, the theoretical frameworks above highlight the relevance of an intercultural stance in language teaching and learning. Next, I examine the issue of teacher professional learning in the field to shed light on effective professional learning that can improve teachers' teaching practices in relation to intercultural competence. 


\subsubsection{Teacher professional learning (TPL) in intercultural language teaching}

The concept of teacher professional learning (TPL) has been examined in scholarship using diverse terms including teacher development, teacher growth, teacher professional development (Manara, 2014). According to Manara (2014), the traditional view of TPL refers to the learning process of teachers acquiring and transferring their skills and knowledge to improve their teaching practice. Such view emphasizes the professional methods and knowledge that teachers are provided with for the purpose of promoting their classroom teaching effectiveness. However, as Manara (2014) argues, such scope is insufficient because teacher learning is complex and influenced by multiple systems of factors including the teacher, the school, and the learning activities or tasks (Opfer \& Pedder, 2011, p. 377). Realising this limitation, the sociocultural view of TPL, as Manara (2014) points out, focuses on teachers' understanding and making sense of their work and professional lives that involve other teacher-related factors. These factors comprise of teachers' interactions with multiple stakeholders (e.g., colleagues, students, administrators, and policy makers), teachers' own self-reflection on teaching, and other cultural and organisational factors (Manara, 2014; Bartell, 2005; Hwang, 2014). The sociocultural perspective of TPL is sensitive to the context of teacher learning and treats teachers as the key to effective TPL. Thus, the goal of TPL is not only to improve teachers' professional competencies required for their work but also to enhance teachers' active engagement in their professional growth.

Effective TPL has four characteristics as outlined by King and Newmann (2011). First, teachers focus on instructions and students' achievements in their own teaching context. Second, teachers have continuing opportunities for experiential learning of new content, i.e., learning through doing, getting feedback, and reflections. Third, teachers collaborate with peers and have access to support and expertise from both inside and outside experts. This means professional learning does not rely merely on outside experts and materials which are exclusive to their normal natural working context and collegial cooperation. Finally, teachers are able to impact on their own professional development process. In other words, teachers are able to add to their professional development by their own input, personal theories, and internalisation of learning. 
TPL plays an important role in enhancing teachers' implementation of intercultural dimension in their classroom practice. Many teachers are not well-prepared for intercultural language teaching and so the intercultural dimension is not sufficiently addressed in classrooms (Sercu, 2006; Garrido \& Aslvarez, 2006; Young \& Sachdev, 2011; Díaz, 2013; Conway \& Richards, 2016; Oranje \& Smith, 2018). Recognition of this gap has led to concerted efforts to equip language teachers with the necessary skills and dispositions to teach interculturally (e.g., RCLCE, 2007; Newton et al., 2010; Biebricher, East, Howard, and Tolosa, 2019). For this, Sercu (2006) recommends that TPL build on teachers' existing beliefs and teaching practices, including their beliefs about intercultural competence as a starting point for transforming teaching practice.

Research findings have shown that TPL can have a positive impact on teachers' willingness and capacity to teach for intercultural competence. For instance, Lázár (2011) found that teachers who took part in a formal training course that provided knowledge and practical techniques in teaching intercultural competence increased their effort to teach in ways that provided affordances for intercultural learning in their classrooms. In Sahin's and Yildirim's (2015) study, TPL encouraged teachers to self-reflect on their teaching, which initiated changes in their beliefs, and then changes in their teaching practice that were positive for intercultural learning. Other studies that have provided evidence of positive effects of TPL include Mahoney (2015), Feryok and Oranje (2015), Hepple, Alford, Henderson, Tangen, Hurwood, Alwi,...and Alwi (2017), Dimas (2016, 2019), and Maijala (2018). These studies are reviewed in the section 2.4 of this chapter.

In Vietnam, although the national language policy draws on the European Framework of Reference and emphasizes intercultural competence (Government, 2008), research on TPL in intercultural language teaching is limited. As far as I am aware, none of the studies in the Vietnamese context which I reviewed in section 2.4.3 investigated this topic except for the work of T. L. Nguyen (2013). One of his findings was that self-teaching was the participant teachers' main form of TPL due to little focus on the topic of culture in TPL programs that were available to them in their teaching context. T. L. Nguyen recommends that TPL in Vietnamese tertiary EFL context target raising teachers' awareness and supporting teachers' improvement in terms of theoretical understanding, methodological skills and skills to translate such pedagogical learning and their motivation in teaching culture into their 
classroom practice. According to T. L. Nguyen (p. 204), workshops and ongoing teacher training courses that introduce teachers with model techniques and improve their skills to develop intercultural learning materials are of paramount importance to meet their professional learning need and motivation. However, neither T. L. Nguyen (2013) or others have investigated how teachers actually engage in TPL within their current teaching setting in Vietnam. This could be attributed to the fact that, in reality, the current teaching and learning in Vietnam strongly emphasizes linguistic proficiency rather than intercultural competencies.

In brief, research has shown that appropriately structured and reflective TPL can provide an important opportunity for teachers to improve their understandings and skills for teaching intercultural competence. In this light, the current research created two repeated learning workshop cycles to introduce the participant teachers to the theoretical background of intercultural language teaching and to the ways in which intercultural teaching can be put into practice in the Vietnamese tertiary EFL classroom. Moreover, this research involved the participating teachers in translating their understanding into classroom practices and reflecting on their participation in the TPL.

\subsection{Review of research}

To serve the purpose of this current study, investigating the impacts of introducing an intercultural language teaching approach to teachers on their stated perceptions and teaching practices, this section focuses on studies concerning teachers' teaching practices and perspectives in relation to an intercultural stance, and teachers' professional learning in this regard. It first reviews the scholarship outside Asia, second the scholarship inside Asia, and finally the scholarship in Vietnam.

\subsubsection{Research outside Asia}

\section{Research on teachers' teaching practices and perspectives}

Sercu's studies (Sercu et al., 2005; Sercu, 2006; Sercu, 2007) provide a useful point of departure for discussing teachers' beliefs and practices of teaching culture across international contexts through a multi-country survey. The participant teachers in Sercu et al. (2005) included 427 teachers from seven countries (Belgium, Bulgaria, Greece, Mexico, 
Poland, Spain, and Sweden). Regarding an intercultural approach, Sercu et al. (2005, p. 10) identify two distinct profiles of FL teachers, namely, favourably disposed teachers and unfavourably disposed teachers. The main finding in Sercu et al. (2005) was that the majority of teachers were favourably disposed to addressing culture in language teaching. These teachers were found to consider language and culture equal in language teaching, display willingness towards the teaching of culture, and believe in the possibility for teaching culture in classes. However, these favourably disposed teachers were found not to actually practice teaching culture in reality. Sercu (2007) adds that the favourably disposed teachers taught cultural comparison more often than critical reflections and explorations. In comparison, the unfavourably disposed teachers were found not to believe in the positive effect, possibility, or aims of teaching culture (Sercu et al., 2005). Another finding in Sercu et al. (2005) was that time limitation and the teachers' overloaded curricula which focused on linguistic knowledge were the barriers to the teachers' practice of an intercultural approach. Based on Sercu et al. (2005) and Sercu (2007), recent studies have investigated teachers' perception regarding teaching culture in China (Han \& Song, 2011), Poland (Czura, 2016), and New Zealand (Oranje, 2016). Teachers' cognition regarding teaching culture has been also studied in the USA, the UK, and France (Young \& Sachdev, 2011), Canada (Dytynyshyn \& Collins, 2012), and Portugal (Bastos \& Araújo e Sá, 2015). For instance, teachers were found to approach culture as content (Young \& Sachdev, 2011) and as transnationality with emphasis on cultural adaptation and students' experiences across cultures (Dytynyshyn \& Collins, 2012). Bastos and Araújo e Sá (2015) found that teachers saw culture as a holistic interlinked affective and cognitive component which always develop dynamically.

In New Zealand, the strand of cultural knowledge in language learning is intended to support learners' effective communication in the nation's multicultural context (Newton et al., 2010). Recent research (East, 2012; Oranje \& Feryok, 2013; Feryok \& Oranje, 2015; Oranje \& Smith, 2018; Conway \& Richards, 2016; Howard et al., 2016; Tolosa, Biebricher, East, \& Howard, 2018; Howard, Tolosa, Biebricher, \& East, 2019; Biebricher et al., 2019) has increasingly scrutinised teachers' perspectives (e.g., cognitions, perceptions and understandings) and teaching practices. For instance, school teachers in New Zealand have been shown to teach culture infrequently and non-purposefully (Oranje \& Feryok, 2013) and to focus on cultural facts (East, 2012). They have been observed to struggle with 
incorporating an intercultural dimension in practice (Feryok \& Oranje, 2015); and demonstrate gaps in understanding an intercultural perspective against the theoretical scholarship on the topic (Conway \& Richards, 2016; Oranje \& Smith, 2018).

Biebricher et al. (2019) focused on the challenges that both native and non-native teachers of Mandarin encounter in addressing students' intercultural capability. The participants were two teachers. They had different backgrounds (a native and a non-native speaker), taught learners of different backgrounds (Pasifika and European/Asian), in two different New Zealand school contexts (socio-economic status, time allocation, students' familiar with target language culture). Nevertheless, the two teachers were found to struggle with the same challenges: fear of teaching stereotypes, uncertainty about the amount of language they used for the intercultural focus and a balance between language and culture learning. Biebricher et al. conclude that the teaching of culture seemed to have come at the cost of language learning. Therefore, Biebricher et al. (p. 14) argue that for greater integration of intercultural language teaching, one path could be that "all teachers undertake professional development that might help them to explore aspects of culture in and through the target language."

Howard et al. (2019) examined the effects of five generalist classroom teachers' integration of comparative intercultural explorations with year 7-8 students. The teachers were asked to attend two two-day workshops during a longitudinal research project to build their understanding of intercultural language teaching and explore pedagogical applications. Subsequent to each workshop, the teachers adopted a reflective inquiry approach. Data collection used questionnaire and interviews with teachers, lesson observations, teachers' written reflections, and student focus groups. The teachers were found to frame their inquiries based on Newton et al.'s (2010) iCLT principles to guide students' reflective discussions and critical explorations in the classroom. Additionally, Howard et al. found that the students achieved gains in cultural facts, noticing differences, openness to differences, comfort with differences. Overall, teachers are somewhat limited in their conceptualisation of teaching culture and their practice of intercultural language teaching culture in classes. Teachers are often not well-prepared nor aware of how to address the intercultural dimension in FL teaching. This situation reflects the need to develop in teachers what 
Biebricher et al. (2019, p. 3) term "an additional skill set" to guide students towards intercultural capability.

\section{Research on teacher professional learning in intercultural language teaching}

The scholarship outside Asia has also been concerned with teacher professional learning for teaching interculturally. Research has been conducted in many national contexts including Hungary (Lázár, 2011), Finland (Maijala, 2018), New Zealand (Feryok \& Oranje, 2015; Tolosa et al., 2018), Australia (Santoro, 2014; Mahoney, 2015; Hepple et al., 2017), and Colombia (Dimas, 2016, 2019).

In Europe, Lázár (2011) examined Hungarian pre-service teachers' beliefs about integrating ICC into language teaching and highlighted the powerful impact of a methodology-focused course, which played an awareness-raising function. This course, Methodology of Intercultural Communication Training, provided the participant teachers with theoretical knowledge and practical teaching skills for developing students' IC, and opportunities for them to talk about their own experiences, and to verbalize their reflections (Lázár, 2011). Data collection involved questionnaires, class observations, and semi-structured interviews. Results showed that the participant teachers who received formal training on cultural awareness and intercultural communication undertook the culture-related activities in classrooms more often than the participant teachers who had some experience of living overseas. In addition, the teachers, who took the training course, were found to make conscious effort to incorporate an intercultural dimension into their teaching.

Maijala (2018) studied pre-service FL teachers' reflections on their experience in culture teaching during their one-year teacher education programme at a Finnish university. Data were collected from 65 questionnaires and 10 interviews. One of the main findings was that the trainee teachers valued teachers' personal experiences in culture teaching. However, they were unsure of the amount of personal cultural experiences and the ways these can be integrated into their lessons. The author suggests that by involving pre-service teachers in reflecting on their personal cultural experiences and on their sharing such experiences with students in lessons, these teachers could be prepared for their future culture teaching. Similarly, in New Zealand, Tolosa et al. (2018) investigated the impact of teachers' inquiry and reflection on their own practices and on their beliefs of teaching and learning. They 
found that the participant teachers considerably shifted their view of teaching culture and focused more on cultural practices due to guided inquiry and reflection. The authors concluded that inquiry and reflection activities helped teachers to shift their practices towards developing students' ICC. Feryok and Oranje (2015) introduced the use of a cultural portfolio to a teacher of German in a New Zealand school and analysed the teacher's reflection on her use of the portfolios. The authors found that the case study teacher conceptualised the use of the portfolio as a form of internal formal assessment instead of a means to address culture interculturally.

Examination of the value of international experience in the development of pre-service teachers' ICC has been evident in the Australian scholarship. For example, Santoro (2014) studied the impact of an international trip on pre-service teachers' development. The fourteen Australian teachers went to India to live and teach for a month. During their trip, they taught English for primary school students in orphanages, and special needs schools, and took tourist trips at the weekend. Data collection was teacher interviews conducted two months after they returned to Australia. In the interviews, teachers self-reported and reflected about their overseas experiences. The key finding was that the teachers maintained postcolonial and neocolonial attitudes towards racial and cultural differences instead of understanding self and others.

Hepple et al. (2017) studied the effects of a structured immersion program on pre-service teachers' IC development. The participants were ten Australian student teachers. The program was carefully designed for building teachers' intercultural capability for global citizenship and Asia literacy in their final year of a teacher education course at a university in Australia. Specifically, the participants completed a two-week experiential learning trip in Malaysia. Prior to departure for Malaysia, they attended four formal briefing sessions that included topics such as cultural identities and processes, models of culture, intercultural communication, Asia literacy, and Bahasa Melayu. Data collection included (a) the participants' predeparture written rationale for joining the program, (b) the self-assessment survey of their IC, (c) their videoed reflective logs, and (d) interviews. It is worth noting that the interviews were conducted six months after their return to Australia to check the longterm impacts of the program (Hepple et al., 2017). In contrast to Santoro's (2014) finding, the teachers in Hepple et al.'s (2017) study were found to develop critical professional self- 
awareness regarding cultural diversity, build trust and intercultural understanding through intensive interaction with Malaysian peers, and become more culturally responsive during the experience overseas. Hepple et al. (2017) recommend that a structured short-term mobility experience be embedded within teacher education programs.

Mahoney (2015) investigated how teachers make sense of professional learning opportunities for teaching culture. In this study, teachers were introduced to a short online course that focused on two components: teachers' learning about teaching tasks which aim to foster students' ICC. Moreover, these teachers undertook the teaching tasks utilising Liddicoat et al. 's (2003) IcLL principles. One of the key findings in this study was that the teachers considered ICLL as an approach that complements other traditional cultural teaching approaches, develops higher-order thinking skills, creates awareness of context, and fosters appreciation of diversity.

In the Colombian context, Dimas $(2016,2019)$ involved teachers in discussing, implementing, and interpreting instructional frameworks for teaching culture with the aim of validating an instructional design for integrating ICC into language programs in a university in Colombia. This instructional design included four components: integration of communicative skills, emphasis on oral production, students' fieldwork research activities, and a product/project that aims at the consolidation of learning. Participants were six professors of five language faculties including English at the university. The participants were asked to implement the designed lesson plans. Prior to implementing the lessons, the participants attended orientation sessions in which they exchanged the thematic proposal and discussed the designed framework. Data collection involved the teachers' providing the annotated rationale for their decision-making process during teaching the lessons. The participants were found to perceive that the instructional design allowed them to fully develop language lessons and balance between textbook-based content and students' lived experiences. Additionally, they believed that the designed lessons developed students' critical thinking and inquiry strategies useful for their successful participation in workplaces. They acknowledged that working from lesson plans allowed them to implement the designed content more easily. As a result, Dimas (2019) calls for instructional designs that provide opportunities for integrating interculturality and involving learners as protagonists of learning. 
In summary, professional development for teachers towards teaching interculturally has become an important concern in the research outside Asia. Studies indicate the effectiveness of professional learning to foster teachers' understanding of and expertise in teaching culture as well as their ability to self-reflect on their cultural teaching and knowledge.

\subsubsection{Research in Asian contexts}

\section{Research on teachers' teaching practices and perspectives}

Similar to the scholarship outside Asia, research in many Asian countries, including Southeast Asian countries, China, and the Middle East has been highly concerned with teachers' teaching practices and perspectives.

In Indonesia, recent studies have explored teachers' perspectives and understandings (Gandana \& Graham, 2013; Gandana, 2015; Abdulrahman, Usu \& Tanipu, 2016; Siregar, 2016). Gandana and Graham (2013) provide insights into a case study teacher who struggled with contextual challenges in constructing her intercultural professional identity as an English language teacher. This teacher had to make instructional choices that did not align with her stated beliefs about teaching culture. Specifically, her stated challenges included a curriculum that embraced an over-simplified understanding of culture and language, limited teaching resources, and a hierarchical collegial relationship. Gandana (2015) studied three case study teachers' conceptualisations of culture and teaching culture, and intercultural competence in an Indonesian tertiary context. The teachers were found to view culture as concrete elements such as values, norms, beliefs and traditions, within a nation. Additionally, they were found to consider critical thinking skills to be crucial in the development of students' IC.

Abdulrahman et al. (2016) used multiple data sources to portray teachers' attitudes about integrating the teaching of culture. The findings were that the teachers supported teaching cultural objectives alongside language but had conflicts in prioritising between language teaching and culture teaching. Their reported constraints included their lack of cultural knowledge, time constraints, curriculum requirements, and linguistic-based textbooks. Indonesian teachers' perspectives were examined in association within the broader context of national language policy. Additionally, the multiple phase study of Siregar (2016) 
provided insights into (a) the essentialist view of culture ingrained in the national Indonesian language policy, (b) the potential for seeding an intercultural stance in the curriculum, and (c) the complexity of implementing an intercultural dimension in language classes. Siregar (2016) found that the essentialist view of culture in the top-down policy was matched by the teachers' essentialist beliefs about culture, and the detachment between language and culture in the curriculum design and classroom implementation. The abovementioned studies all highlight the increasing importance of the intercultural dimension and teachers' interest in integrating culture in the Indonesian context.

In Thailand, Cheewasukthaworn and Suwanarak (2017) examined teachers' understandings of teaching culture. They found that the sixteen participant teachers had a general grasp of ICC and did not fully recognise the importance of students' ICC in communication in English. The teachers were found to consider presenting cultural content to be the main way of teaching culture. Cheewasukthaworn and Suwanarak (2017) suggest that teacher education programs need to include ICC content to enhance Thai teachers' intercultural teaching perceptions and practices. Additionally, Thai scholarship (Baker, 2008; Laopongharn \& Sercombe, 2009) emphasizes developing students' understandings and awareness about Thai culture both inside and outside classrooms.

Little published research has been conducted in Laos, Malaysia, or Cambodia. Lim \& Keuk (2018), in the Cambodian context, used a sociocultural approach to analyse teachers' interview responses and documents from the classroom. He found that due to viewing English as a FL and their own limited cultural knowledge, the participant teachers did not aim to teach students' cultural knowledge and IC. They replaced teaching cultural content in textbooks by teaching test taking skills and knowledge of pragmatics.

Zhou (2011) and Tian (2013) investigated Chinese university teachers' perceptions and practices in teaching culture in their PhD theses. They both used large scale surveys followed by teacher interviews. In both studies, the main finding was that the teachers' perceived cultural teaching objectives reflected various aspects of an intercultural stance. The teachers' most commonly agreed-upon objective was to facilitate students' acquisition of cultural knowledge. Yet, in practice, their participant teachers used teacher-centred instruction most of the time. Both Zhou (2011) and Tian (2013) suggest an urgent need for 
teacher training programs, curricula, and materials that support teachers with cultural content and instructional methods so that they can teach towards intercultural objectives. According to Li's (2017) review of existing literature in China, the contemporary research (between 2000 and 2015) has focused on conceptualising and assessing ICC. Methodologically, the studies reviewed by Li (2017) mainly adopted Byram's (1997) ICC model and collected data through surveys. The large-scale survey studies (Gu, Meng \& Li, 2012; Gu, 2016) found that ICC assessment was recognised but not practiced by teachers. Gu et al. (2012) and Gu (2016) elaborated that the causes for this included teachers' lack of the following components: insights into ICC, teaching resources, and support from administrative educational policy. Similarly, the survey findings of Wang (2014) reveal that teachers gave little attention to teaching cultural knowledge and intercultural skills. Luk (2012) found that secondary school language teachers were uncertain of how and which sources of materials to teach despite their positive attitudes about teaching culture.

In the Taiwanese context, Cheng (2012) found that Taiwanese teachers' understandings of IC and cultural self-awareness did not play a part in their teaching practices. Moreover, Chao (2016) found that teachers' self-perceived ICC (e.g., personal capabilities) was inconsistent with their teaching practices (e.g., teaching objectives and strategies). In the Middle East (Iran and Saudi Arabia), scholars are highly interested examining teachers' perceptions and practices of intercultural teaching. Studies have reported the main finding that students' intercultural learning and teachers' roles in students' learning were perceived to be important. In the studies of Baleghizadeh and Moghadam (2013), Zare, Nemati, and Jafarian (2015), Banafsheh, Khosravi and Saidi (2016), Al-Amir (2017), and Estaji and Rahimi (2018), teachers demonstrated high awareness of addressing students' ICC but little teaching of culture in the classroom. These researchers called for supporting teachers with culturally-rich instructional materials and teacher-focused intercultural educational programs to increase both teachers' awareness of teaching ICC and the amount of classroom teaching of culture.

It appears that Asian teachers' perceptions have shown their realisation of the importance of addressing culture in language teaching, but their teaching practices are often not congruent with their realisation. In practice, they tend to either spend little time on teaching culture or merely transmit cultural knowledge or avoid teaching it altogether. This 
reflects a marginalised status of culture in reality in Asian teaching settings, as well as the urgent need to help teachers to increase the amount of teaching culture in their teaching practices.

\section{Research on intercultural teaching practices}

Apart from the focus on teachers' teaching practices and perspectives, Asian research has increasingly examined how to promote students' intercultural learning.

In Indonesia, Kusumaningputri and Widdodo (2018) suggest a classroom-based method to help teachers address culture effectively. The authors designed a model using digital photograph-mediated intercultural tasks to cultivate students' critical intercultural awareness. This model involves the participant students in several learning tasks which are in line with Byram's (1997) intercultural framework. In Kusumaningputri and Widdodo (2018), these tasks are: observations (searching for photos representing Anglophone/nonAnglophone countries and their own country); describing (identifying and presenting sociocultural dimensions embedded in these photos); and evaluating (comparing similarities and differences of these dimensions between the photos, realising their views about the represented social and cultural portrayals of the photos, and revisiting their views about the representations).

Taiwanese scholarship has investigated intercultural learning methods, such as the use of cultural portfolios (Su, 2011) and intercultural extracurricular designed activities (K. L. Liu, 2016). Su (2011) explored the effect of using cultural portfolios on Taiwanese tertiary students' cultural knowledge and stereotypes. The portfolio was designed to involve each student in the following components: researching resources, forming a hypothesis on the research topic, a self-reflection, a final written report, organising the portfolio, and a final presentation. Su's (2011) multiple data frames include questionnaires, students' oral and written reports, reflection interviews, and classroom observations. She found three major contributions of portfolio use to students' intercultural changes: (a) developing understandings of the target language cultures, (b) fostering critical thinking and cultural awareness about misconceptions and stereotypes, and (c) enhancing positive perceptions of constructing cultural knowledge and positive attitudes towards cultural learning. Altogether, these studies found evidence of students' improvement in aspects of ICC, such as awareness 
of personal misconceptions, intercultural knowledge, and relationship building skills. Moreover, these studies highlighted teachers' engagement in organising, and facilitating intercultural learning process.

There has been little published research on the topic of ICC in Korea. Yoon (2007) discussed the use of one conversation analysis method to teach culture in FL classes. She argues that what students formulate during their exchanges of talk while in communication regulates their social behaviours and that conversation analysis can present this intricate characteristic of culture and social action. As a result, she views conversation analysis as a valuable resource for teaching culture.

Japanese scholarship (Aubrey, 2009; Morita, 2013; McConachy, 2013; McConachy \& Liddicoat, 2016; McConachy, 2018) has explored the roles of pragmatics in intercultural learning. Aubrey (2009) and McConachy (2013) investigated the effect of students' engagement with pragmatics-based ideas and texts on their intercultural awareness. For example, McConachy (2013) aimed to develop students' intercultural awareness and interpretation of language through using textbook dialogues. The participants were a group of four Japanese tertiary EFL students, with an intermediate level of English. The author created a sequence of three analytical discussion tasks to guide students to explore the cultural dimension of apologising as a speech act in English. The three analytical discussion tasks included a meta-pragmatic focus, a discoursal focus, and an intercultural focus. The meta-pragmatic focus required students to analyse the feelings and intentions of the speakers by making connections between the language used and the communicative context. The discoursal focus required students to analyse the structure of the speech act and how it is negotiated within the dialogue. For the intercultural focus, students reflected on the act of apologising in Japanese and consider how apologising strategies in the given dialogue may be different and why. The students were expected to explore the ways in which apologies are structured in discourse and the language style differences compared to apologies in Japanese. Their discussions in the three analytical discussion tasks were audiorecorded and used for data analysis. Data analysis showed how the students constructed understandings and interpretations of language use, upon which they explored their own cultural assumptions. 
McConachy $(2013,2018)$ argues that teachers can create opportunities for intercultural learning by taking an interpretive orientation to existing learning resources. This interpretive orientation emphasizes the students' analysing of the language use, as well as their interpreting and evaluating aspects of language use in insightful ways. He continues that this interpretive process allows students to explore the influence of cultural assumptions on one's own perceptions. McConachy's (2018) interpretive approach to teaching ICC reveals the value of having learners explore the language-culture relationship in dialogues as a way of developing their intercultural perspectives.

In general, the scholarship outside and inside Asia has emphasized the importance of intercultural language teaching and learning, and the importance of teachers' professional development towards this pedagogy. One of the main findings across studies has been that teachers are not inclined to practise intercultural teaching regardless of their beliefs and teaching contexts. The most common reason appears to be a gap between teachers' understandings and practical skills, and a lack of familiarity with recent literature on intercultural language teaching. As a result, scholars have highlighted the need to help teachers to understand and become familiar with scholarship and evidence-based and principled practice through professional training.

\subsubsection{Research in Vietnam}

The scholarship in Vietnam falls into three broad types. The first type, literature study papers, includes T. M. H. Nguyen, (2007), Pham (2012), T. Q. Tran and Seepho (2014), Trinh (2014), T. Q. Tran and Duong (2015), and T. Nguyen (2017). These authors have endevoured to raise teachers' and related-stakeholders' awareness of the integration of culture into language teaching, and to highlight the importance of teaching IC.

The second type focuses on teachers' perspectives. This type includes the doctoral theses of T. L. Nguyen (2013), Trinh (2016), and T. B. Nguyen (2016). The critical ethnographic study of T. L. Nguyen (2013) found that teachers prioritised teaching language skills over culture and lacked relevant professional training and knowledge to teach and assess ICC. He additionally found that the national language policy which emphasized interculturality was not wellcommunicated to teachers, which partly explained teachers' neglecting culture in their beliefs and teaching practices. Additionally, T. L. Nguyen (2013) found that the participant 
teachers held a static view of teaching cultures, that is, in practice, they did not take an integrated view of teaching both language and culture, and so missed opportunities to teach critical cultural awareness. What the teachers did was to randomly explain certain cultural points in the textbook or provide cultural information (T. L. Nguyen, 2013). Overall, their culture teaching was what Byram (2009) termed “intermittent." Regarding teachers' perspectives, Trinh (2016) found that teachers had broad views of culture, i.e., culture embraces aspects of human life, and equated the role of teaching culture and language skills. However, they focused on transmitting cultural knowledge despite their use of various activities (lecture, quizzes and games, culture research, discussions, and dialogues) (Trinh, 2016). T. B. Nguyen (2016) found teachers to have vague and superficial understanding of the term IC. Congruent with such understanding was the teachers' exam-focused teaching style that neglects culture (T. B. Nguyen, 2016).

Other studies of the second type comprise Doan (2014), T. P.T. Tran (2014), T. Q. Tran and Dang (2014), Ho (2009, 2011a, 2011b), L. Nguyen (2015), L. Nguyen, Harvey, and Grant (2016), Vo (2017), Chau (2018), Chau and Truong (2018, 2019). For instance, Doan (2014) examined the teaching of culture in five tertiary English Teacher Education programs at five universities in the North, Centre and South of Vietnam. As he noted, these programs included five types of culture-focused course, namely British Culture and Civilisation, English Literature, American Culture and Civilisation, and American Literature, and in Cross-cultural Communication. The first four courses were compulsory while the last one was an elective. Analysing the objectives of culture teaching across these courses, he found culture teaching served to develop students' language skills (e.g., reading and oral presentation skills), and knowledge of literature and background knowledge of America and Britain. Nevertheless, results from interviews with eleven teachers showed that these teachers realised the status of English as a lingua franca and their responsibility to develop students' ability to communicate internationally rather than internalising English native-like cultures. Doan suggests that English teacher training programs should abandon a monocentric view and adopt a pluricentric view on culture teaching.

Contrary to Doan (2014), the teachers in V.C. Le (2015) were found to lack realisation of the shift from the traditional focus on cultural knowledge transmission and native-like model to the intercultural orientation. The teachers, in Tran and Dang's (2014) study, displayed a lack 
of congruence between their beliefs and practices of teaching culture. Recently, Chau (2018) explored 101 upper-secondary school teachers' concerns and expectations for integrating culture. In this study, data were collected through questionnaire survey and classroom observations. Chau (2018) found the key issues that teachers were concerned with include: learners' low language proficiency and learning motivation, lack of cultural orientation in coursebooks and curriculum, and teachers' lack of background of intercultural integration pedagogy. The teachers were also found to show high expectations for pedagogical training that enhanced their IC and intercultural integration. Chau and Truong (2019) found that teachers did not include intercultural objectives in their lessons and rarely conducted intercultural language activities in their teaching practices.

The third type of research, which involves empirical components, remains scant. Ho's doctoral thesis (2011b) and his published work (i.e., Ho, 2011a) were the studies of which I am aware that sought an innovative intercultural approach to students' ICC. He examined the curriculum, teachers' perceptions and classroom practices, and students' perceptions to look for evidence of teaching culture in the tertiary context before integrating an intercultural stance. Culture was found to be marginalised at all levels i.e., curriculum, in teachers' perceptions and practices, and students' perceptions. Particularly, similar to teachers in T. L. Nguyen (2013), in Ho (2011b), teachers' dependence on cultural topics and separating culture from language reflected a traditional teaching approach. The intercultural class in Ho's (2011a, 2011b) study adapted and applied the intercultural learning tasks which reflected an intercultural stance informed by Newton et al. (2010) and Liddicoat and Scarino (2013). As a result of the IC intervention, learners in the intervention group were found to increase in four components of IC: knowledge, attitudes, skills, and awareness. Especially, the students' awareness increased in five aspects which reflected five features of intercultural awareness (e.g., awareness of cultural similarities and differences, and of how to act appropriately in intercultural interactions). Ho used various data frames including pre and post-tests, reflective journals, case studies, self-evaluation questionnaires, and focusgroup interviews to triangulate his findings about the students' intercultural learning outcomes.

In another study by Truong and Tran (2014), the students were involved in learning activities intended to develop sets of intercultural skills while watching parts of the film in each 
lesson. These included observing, recognising, analysing cultural contents (e.g., what the native speakers in the film said and acts), practising language (e.g., listening and identifying verbal and non-verbal components in the film extract), and reflecting on self in target language and culture (e.g., acting out in front of the class and discussing this experience of acting). The authors found that students improved in cross-cultural knowledge and comparisons and became aware of their cultural stereotypes.

Important themes can be drawn from the Vietnamese scholarship. First, culture has a marginalised status in ELT. The curricula and students prioritise language skills in line with a native-like model (Ho, 2011a, 2011b). Teachers are unaware of the intercultural shift (V. C. Le, 2015). Teachers teach culture intermittently and do not acknowledge an integrated view of addressing culture (T. L. Nguyen, 2013). Teachers' beliefs and practices of teaching culture are often not aligned (Tran \& Dang, 2014; Trinh, 2016). There is a tension between monocentric and pluricentric view of teaching culture in teacher education programs (Doan, 2014). For example, in Ho (2011a, 2011b), teachers randomly taught cultural connotations and facts according to topics or based on their cultural experiences. In T. L. Nguyen (2013), teachers spent little time on culture and frequently missed opportunities to address the lesson content from cultural angles. Regarding official teaching materials, Trinh's (2016) analysis identifies the gap between how the cultural content was presented in Vietnamese tertiary English textbooks and the conceptualisations of cultural competence from an ICC perspective. In Chau and Truong (2019), the intercultural teaching was inferior to language teaching and was equated with cultural knowledge transmission. In brief, ELT in Vietnam has focused on form-instruction, placing a strong priority on linguistic proficiency rather than learners' ICC development.

The second theme is teachers' limited understandings and expertise to address culture in an interculturally-informed way. For instance, teachers considered students' low linguistic proficiency as a barrier to teaching culture (Ho, 2011a, 2011b) and had little knowledge and relevant professional training for the intercultural language teaching (T. L. Nguyen, 2013), vague and superficial understanding of IC (T. B. Nguyen, 2016). In V. C. Le (2015), teachers' teaching drew on their training experiences which mainly concerned British and American cultures and societies. 
Third, culture teaching has been hindered by various constraints. These include fixed nativelike model-oriented curricula (Ho, 2011a, 2011b), little direct intercultural exposure, time limitation for English subject, textbooks written by Vietnamese authors (D. C. Nguyen, 2013), and teachers' traditional teaching styles (Trinh, 2016). T. L. Nguyen (2013) also observes the constraints of fixed furniture arrangement in classrooms, big class size, shortage of culture-focused teaching input, insufficient professional training, and examoriented teaching style.

Fourth, similar to the scholarship outside and inside Asia, the Vietnamese scholarship has recognised the importance of integrating an intercultural dimension into language teaching and learning. However, to compare with the scholarship outside and inside Asia, very little research in Vietnam has addressed (a) teachers' knowledge and skills in guiding intercultural learning and developing materials for intercultural learning, and (b) teachers' implementation of intercultural language teaching and learning principles. This shortage does not seem to support the national language policy which recognises the importance of intercultural awareness in EFL education and the international integration throughout the country. This current research set out to fill this shortage.

\subsection{Concluding discussion}

This review reflects the complexity of culture, its relation to language, and the importance of addressing the intercultural dimension of FL learning. Research evidence across contexts has shown (a) teachers' realisation of the importance of teaching culture, (b) teachers' classroom-based applications of redesigned teaching activities (e.g., Su, 2011; McConachy, 2013; Kusumaningputri \& Widdodo, 2018), and (c) the positive impacts of professional learning on teachers' shifts towards their closeness to intercultural language teaching. Studies concerning teachers' professional learning for intercultural language teaching have focused on pre-service teacher training programs in which culture teaching was a designed or structured component of the teacher training program (e.g., Lázár, 2011; Hepple et al., 2017; Maijala, 2018). In addition, studies were conducted in school contexts in which exams are not present (e.g., Howard et al., 2016; Oranje, 2016). Thus, professional learning for teachers in EFL context where exams exist remains under-researched. In relation to these gaps, the current study addresses both in-service teacher professional learning and their 
classroom-based applications of redesigned teaching activities within their fixed curriculum. It seeks to increase understanding about teachers' perspectives and teaching practices in relation to in-situ professional learning on intercultural language teaching and learning.

\subsection{Chapter summary}

This chapter has reviewed scholarship concerning the key concepts on which this study is based: culture, language, the language-culture relationship, ICC, culture in language teaching and learning, and the research that focuses on an intercultural dimension in language teaching and learning. The review shows that culture is a multifaceted complex concept and that intercultural language teaching and learning with its focus on students' ICC has been increasingly emphasized. Previous studies indicate the need for research that addresses teachers' knowledge and practical skills for integrating intercultural language teaching and learning in their daily classroom practices. Drawing on the literature, this current study's argument is that it is high time ELT in Vietnam address teachers' theoretical understandings and practical expertise for a more principled engagement with culture in both the teachers' awareness and daily classroom practices. 


\section{CHAPTER 3 METHODOLOGY}

\subsection{Introduction}

This chapter outlines the research methodology of this study. First, the chapter begins with a discussion of the research paradigm that underpins the study. Second, the research design section introduces the research phases and RQs for each phase and justifies the use of Participatory Action Research and a case study approach in this study. The third section describes the research setting. The subsequent sections include strategies and methods for data collection, methods for data analysis followed by the conducted data analysis. The chapter concludes by discussing the issues of trustworthiness and ethical considerations.

\subsection{Interpretivist paradigm}

Paradigms can be understood as socially accepted frameworks of views, validated principles of conducting research, and ways of reaching solutions for the researched problems (Slawecki, 2018). Paradigms involve the system of basic philosophical assumptions underlying the practical activity of researchers (Slawecki, 2018). They are considered as widespread and desirable manners of doing research that come to light from various visions, approaches, traditions, ideas or concepts.

Paradigms include the pillars of ontology (assumptions about the nature of social reality or existence), epistemology (nature of scientific cognition and knowledge), and methodology (the corresponding derivative choices of ways to study a given phenomenon). Based on this structure, Guba and Lincoln (2005, as cited in Slawecki, 2018) categorised the five basic paradigms namely positivism, post-positivism, critical theory, constructivism, and participatory paradigm. Another classification by Burrell and Morgan (1985) distinguished functionalism, interpretivism, radical structuralism, and postmodernism. My study on intercultural language teaching and learning takes an interpretivist position which is also considered as the philosophical foundation that underpins qualitative research in social sciences (Y. Y. Chen, Shek, \& Bu, 2011). The interpretivist paradigm fits my study because it has been considered as one of the main paradigms used in studying culture and intercultural communication (Hua, 2016). Recently its value has increased as scholarship has shifted 
"away from differences between cultures and towards the question of how people construct and use culture to make sense of each other" (Holliday, 2016, p. 23).

In terms of studying culture, interpretivists can be contrasted with positivists (Chen et al., 2011). Whereas the former stands on subjectivity and relativity, the latter holds on objectivity. The latter views reality as external to and independent from the human mind, and that it is crucial to construct knowledge from studying the natural universal laws, and experimental methods instead of humans' interpretations (Slawecki, 2018; Willis, 2012). With regard to culture, these two paradigms have different assumptions. Specifically, the interpretive prism does not treat culture as fixed, measurable, and generalizable nor as isolated for research purposes (Hua, 2016). Hua (2016) maintains that the interpretive paradigm instead aims to study and interpret culture through its contexts and emphasizes detailed observations and descriptions rather than seeking to establishing generalisable causal relationships between culture and communicative behaviours or generalisation. In this light, I use classroom observations and interviews as the main forms of data collection. Interpretive ontology assumes that the nature of existence is socially constructed (Willis, 2012), and that the world does not exist independently of "the head process" (Kant, in Chen et al., 2011, p.130). The role of the individuals who perceive, participate in and experience reality is important. In other words, interpretivism embraces relativity and subjectivity about the nature of the social world and reality.

In accordance with its subjectivity and relativity about existence, interpretive epistemology contends that knowledge is constructed from humans' interpretation of the social world (Chen et al., 2011). Existence is explained in light of knowledge of how individuals interpret, organise and use their interpretations as well as the impact of their interpretations on their reality formation (Chen et al., 2011). It can be understood from this paradigm that how people feel, perceive, experience the world, and make sense of their experiences are the core dimensions of knowledge formation and learning. Therefore, individuals are at the centre of this process.

Guided by interpretive ontology, epistemology, and methodology, my study explores the current orientation to culture in a particular context (i.e., Vietnamese tertiary EFL classes) and how this orientation can be changed by examining how the teachers make sense of and 
teach culture in their EFL classes, and how they interpret their teaching experiences in this particular context.

Ontological and epistemological assumptions determine methodology (Slawecki, 2018). Guided by the interpretive paradigm, this current study employed the qualitative case study approach and Participatory Action Research as the research methods to address the research questions. Methodology refers to "a general approach to studying research subjects" (Chen et al., 2011, p. 135), or "a set of certain choices concerning the way in which a given phenomenon can be studied" (Slawecki, 2018, p. 14). Interpretive studies assume that during the process of interacting with the world around them, humans create and relate their own meanings; therefore, to understand the phenomena around them, it is crucial for researchers to access the meanings that people assign to these phenomena (Orlikowski \& Baroudi, 1991). Meanings are socially constructed and emphasized (Willis, 2012; Chen et al., 2011). Research focuses on searching for explanations of ways in which the world is constructed in the daily life activities of people (Slawecki, 2018). It demands the researcher's active engagement in the research context and process from which the meaning is created. Interpretive research is thus influenced and shaped by the world view and experiences of the researchers (Chen et al., 2011; Willis, 2012) and the participants (Slawecki, 2018). Hence, meanings are contextual (Willis, 2012). For these reasons, interpretive research makes more use of qualitative criteria (e.g., transferability and soundness) than quantitative criteria (e.g., reliability, validity, objectivity, and generalisability) (Chen et al., 2011). In this light, I use quality criteria (i.e., credibility, transferability, dependability, and confirmability) introduced by Guba (1981) to address the topic of research quality which I discuss in the section 3.8 of this chapter. To reflect the interpretive stance, I draw on principles of the participatory action research framework which is described after the following section on research phases and questions.

\subsection{Research design}

\subsubsection{Research phases and questions}

The purpose of this study is to explore the teaching practices and stated perceptions in terms of teaching culture of a small group of tertiary EFL teachers in a Vietnamese university. The focus is on how the teachers make sense of and adopt an intercultural 
perspective in their understandings and classroom practices. The research had two phases. Phase One examined the teachers' current orientation to culture. It involved observing their classroom teaching practices and exploring their views of culture and stated perceptions about teaching and learning in terms of culture.

Phase Two investigated the outcomes of developing and implementing an intercultural teaching innovation. This phase was comprised of two workshop cycles. Each cycle included the workshop, teachers' post-workshop teaching practices, and teacher interviews. The workshop cycles are detailed in chapter five.

The research questions are as follows:

\section{Overarching question:}

What is the potential for fostering a more systematic engagement with culture and intercultural learning in EFL classes at a university in Vietnam?

\section{Phase 1: Current orientation to culture}

1. What are the practices and perceptions of a small group of Vietnamese tertiary EFL teachers in relation to teaching culture?

1.1 How is culture addressed in the classroom teaching practices of three case study teachers at this university?

1.2 What are the case study teachers' attitudes and stated perceptions about teaching culture?

1.3 What are the students' perceptions of their cultural learning needs in EFL lessons?

\section{Phase 2: Intercultural orientation to culture}

2. What was the impact of the two intercultural language teaching and learning workshops on the current orientation to culture in the case study teachers' emerging understandings and classroom teaching practices?

2.1 How did the three case study teachers implement the interculturaloriented post-workshop lessons?

2.2 What were the three case study teachers' perceptions about the experience of teaching these lessons? 
2.3 What were the students' perceptions about their experience of learning these lessons?

\subsubsection{Participatory Action Research (PAR)}

The current study draws on principles of participatory action research (PAR). It did not treat PAR as its pure form due to the contextual constraints that included the case study teachers' busy teaching load, and the lack of teachers' professional training on the topic of intercultural language teaching.

PAR is a qualitative research methodology option (MacDonald, 2012), a subset of the interpretive approach and a strand of action research (Ragsdell, 2009). Different definitions of PAR tend to emphasize its three main components which are participation, action, and research. For example, Bergold and Thomas (2012) emphasize its cooperative dimension, in which researchers and professional practitioners collaborate to create knowledge, and the professional practitioners can either be studied or carry out the research under the support of the researchers.

Ragsdell (2009) and MacDonald (2012) emphasize the incentive to make positive practical changes and develop understandings. For example, PAR is:

a process that simultaneously aims to bring about change in organisational practices and to increase understanding of social science through researchers and organisational members working as partners in situations that are perceived problematic (Ragsdell, 2009, p. 568).

According to Wadsworth (1998, as cited in MacDonald, 2012 p. 38), PAR is:

followed by action and it is action that is researched, changed and re-researched within the research process by the participants, its purpose is to foster capacity, community development, empowerment, access, social justice and participation.

Emphasizing its dimension of improving practice, MacDonald (2012) contends that as a type of qualitative inquiry, PAR has the characteristics of being democratic, equitable, liberating, cooperative, and life- enhancing.

In addition to the synergy between improving practice and developing insights into practice, PAR values learning as a social process (Kemmis \& McTaggart, 2007) due to its position that knowledge creation is collective, active, reflective and contextual, rather than monolithic (MacDonald, 2012; Bergold \& Thomas, 2012; Tekin \& Kotaman, 2013). These scholars 
maintain that, in PAR, cooperation between the researcher and participants results in the increased awareness about each other and sharing of knowledge and experiences about the research issue. Knowledge production involves theory to practice, leading to new insights into both (Bergold \& Thomas, 2012). Moreover, through participatory engagement, participants are involved in decision making, action taking, and the reflection process, and they are gradually equipped with knowledge and skills during the research process (MacDonald, 2012; Bergold \& Thomas, 2012). PAR shares characteristics of collaborative research strategies in which the relationship between researcher and participants was crucial to the success of the research process (Louis \& Bartunek, 1992). Details of the collegial relationship and my role as both an insider and an outsider in the research project will be discussed in section 3.8.4 of this chapter. In other words, dynamic changes in the roles of participants and researcher and the improved empowerment of participants during the research process are two of the key advantages of PAR. This highlights its role in teachers' professional development, in addition to its roles in bringing about curriculum innovation in the educational context.

Furthermore, Bergold and Thomas (2012) maintain that the reflective dimension of learning can have various foci such as personal ways of re-acting, interactional relationships among the participants and the researcher, the research field, and the research process. Although the practical improvements and insights obtained by PAR as a form of action research are contextual, their benefits can be extended to people who are not involved in it because the dynamic structure of society still has consensus on key issues for relatively long periods (Tekin \& Kotaman, 2013).

Overall, the current study sought to investigate the affordances of adopting a more principled and systematic intercultural stance in the context of a university EFL program in Vietnam. This involved first developing a rich ethnographically-oriented description of the current practices and understandings of the teachers and the mandated teaching materials they used with respect to cultural content. This data provided the basis for identifying options for developing an intercultural stance.

Specifically, key stages in my study were informed by PAR and reflected the steps outlined by MacDonald (2012). These steps included preliminary preparation, the planning of actions, and reviewing. It is important to note that in the initial phase, I, as the researcher 
played a more directive role, but deliberately sought to create a collaborative community of professional practice with the group of teachers so that together we could co-construct the intercultural innovation that we were committed to. I (a) justified a set of personal assumptions about the teaching and learning of English in Vietnam by studying the literature, (b) reviewed several curricula used in Vietnamese universities, (c) developed the research proposal, (d) designed the intercultural content, and (e) composed the intercultural lesson plans (see appendix 2 for lesson plan for intercultural lesson one) based on the literature. I also studied the participating teachers and the research setting by reviewing their training program, current teaching materials, observing their teaching practices, and interviewing them in the first phase.

In the second phase, acting and reviewing, I organised the two workshop cycles on iCLT. These participatory cycles were considered to be professional opportunities for the teachers to learn, act, and reflect. Each cycle involved a workshop followed by classroom observations and interviews.

In short, the PAR process in this research comprised the following tasks:

1. classroom observation and curriculum review;

2. interviews with teachers (and students);

3. workshop with teachers to raise their awareness and to explore intercultural teaching materials;

4. observation of the materials being used

5. interviews with teachers;

6. and repeat steps 3-5 (with more teacher independence in task 3).

These key components are illustrated in Figure 1 and are further detailed in the research procedure and data collection sections. 
Figure 7. PAR framework for the study

\begin{tabular}{|l|}
\hline \multicolumn{1}{|c|}{$\begin{array}{c}\text { Planning and preparation } \\
\text { (Prior to data collection) }\end{array}$} \\
\hline Making and examining assumptions \\
\hline Reviewing the EFL culture course curriculum at three universities \\
\hline Developing research proposal \\
\hline Designing model intercultural lessons \\
\hline
\end{tabular}

\begin{tabular}{|l|l|}
\hline \multicolumn{2}{|c|}{$\begin{array}{l}\text { Investigating the research settings } \\
\text { (Phase One of data collection) }\end{array}$} \\
\hline Observations & Interviews with each teacher \\
\hline $\begin{array}{l}\text { The Ts taught as they usually did. } \\
\text { The researcher observed teachers' } \\
\text { teaching. }\end{array}$ & $\begin{array}{l}\text { About the observed lessons } \\
\text { About teachers' understandings (i.e., views } \\
\text { about culture, beliefs about teaching \& learning } \\
\text { in terms of culture) }\end{array}$ \\
\hline $\begin{array}{c}\text { Weeks 1-4 } \\
\text { (3 Obs/each teacher) }\end{array}$ & Week 4 \\
\hline
\end{tabular}

\begin{tabular}{|c|c|c|c|c|c|}
\hline \multicolumn{6}{|c|}{$\begin{array}{c}\text { Participatory cycles } \\
\text { (Phase Two of data collection) }\end{array}$} \\
\hline \multicolumn{3}{|c|}{ Workshop 1 Cycle } & \multicolumn{3}{|c|}{ Workshop 2 Cycle } \\
\hline Workshop & Observations & $\begin{array}{l}\text { Teacher } \\
\text { ITVs }\end{array}$ & Workshop & Observations & $\begin{array}{l}\text { Teacher } \\
\text { ITVs }\end{array}$ \\
\hline $\begin{array}{l}\text { Reflective } \\
\text { discussion (Ts) }\end{array}$ & $\begin{array}{l}\text { Transferring } \\
\text { workshop content } \\
\text { into individual } \\
\text { teaching (Ts) }\end{array}$ & $\begin{array}{l}\text { About the } \\
\text { designed } \\
\text { materials (R) }\end{array}$ & $\begin{array}{l}\text { Reflective } \\
\text { reflection (Ts) }\end{array}$ & $\begin{array}{l}\text { Transferring } \\
\text { workshop } \\
\text { content into } \\
\text { individual } \\
\text { teaching (Ts) }\end{array}$ & $\begin{array}{l}\text { About the co- } \\
\text { constructed } \\
\text { content (R) }\end{array}$ \\
\hline $\begin{array}{l}\text { Guided } \\
\text { discussion (Ts \& } \\
\text { R) }\end{array}$ & $\begin{array}{l}\text { Observing the } \\
\text { materials being } \\
\text { used in classes ( } R \text { ) }\end{array}$ & $\begin{array}{l}\text { Focusing on } \\
\text { teaching and } \\
\text { learning (R) }\end{array}$ & $\begin{array}{l}\text { Sharing } \\
\text { impressions } \\
\text { about teachers' } \\
\text { teaching }(\mathrm{R})\end{array}$ & $\begin{array}{l}\text { Observing the } \\
\text { materials } \\
\text { being used in } \\
\text { classes (R) }\end{array}$ & $\begin{array}{l}\text { Focusing on } \\
\text { teaching \& } \\
\text { learning }(R)\end{array}$ \\
\hline $\begin{array}{l}\text { Presentation of } \\
\text { theoretical } \\
\text { framework (R) }\end{array}$ & & & $\begin{array}{l}\text { Co-constructing } \\
\text { lesson plans (Ts) } \\
\text { Collective }\end{array}$ & & $\begin{array}{l}\text { Focusing on Ts' } \\
\text { cooperation (R) }\end{array}$ \\
\hline $\begin{array}{l}\text { Concluding } \\
\text { review (Ts \& R) }\end{array}$ & & & $\begin{array}{l}\text { discussion } \\
(T s \& R)\end{array}$ & & \\
\hline $\begin{array}{l}\text { Week } 4 \\
\text { (3 hours) }\end{array}$ & $\begin{array}{c}\text { Weeks 5-8 (3 } \\
\text { Obs/each teacher) }\end{array}$ & $\begin{array}{c}\text { Week } 9 \\
\text { (1 hr plus/each } \\
\text { teacher) }\end{array}$ & $\begin{array}{l}\text { Week } 10 \\
\text { ( } 2 \text { hours) }\end{array}$ & $\begin{array}{c}\text { Weeks 11- } 12 \\
\text { (2 Obs /each } \\
\text { teacher) }\end{array}$ & $\begin{array}{c}\text { Week } 14 \\
\text { (1 hr plus/each } \\
\text { teacher) }\end{array}$ \\
\hline
\end{tabular}

\subsubsection{Case study approach}

A case study is "an empirical inquiry that investigates a contemporary phenomenon in

depth and within its real-life context, especially when the boundaries between

phenomenon and context are not clearly evident" (Yin, 2009, p. 18). It can be also 
understood as "the intensive study of a single case where the purpose of that study is at least in part to shed light on a larger class of cases (a population)" (Gerring, 2007, p. 20). Under a PAR approach, each participating teacher in this research is treated as a case study. I intensively studied three case study teachers and their classes over a fifteen-week semester to obtain rich details about participants to develop in-depth understandings about the researched issue. One of the strengths of a case study approach is that it allows direct observation of events and values the perspectives of the people being studied (Yin, 2009). Moreover, case studies are advantageous for studying the particularity, complexity, and uniqueness of the phenomenon in particular important contexts; and intensive analysis of case studies can help with understanding the broader context to which the case belongs (Bassey, 1999). Multiple cases are considered more robust and compelling than a single case (Herriot \& Firestone, 1983; Yin, 2009), allowing explorations of differences within and between cases (Baxter \& Jack, 2008).

Common critiques of case study research include lack of generalisation (Yin, 2009; Dörnyei, 2007), length, risk of biases in findings (Merriam, 2001; Yin, 2009), and dependence on the researchers' integrity and research skills (Merriam, 2001).

The applicability of the criteria of generalisability in interpretive research has been debated (Duff, 2012). For example, case studies emphasize "uniqueness and particularization" and prioritise first understanding the cases themselves (Richards \& Morse, 2013, p. 79). Lincoln and Guba (1985, in Duff 2012, p. 51) use the term transferability instead of generalizability and argue that the audiences can determine the extent of connection, congruence between their own context and the context in case studies. Therefore, thick description of the context and participants (Duff, 2012), and the subtlety and the complexity of the case help to enhance transferability (Bassey, 1999).

In addition, subjectivity or lack of objectivity has been raised as an issue. The researcher, as the main data collection instrument and analyst, may bring his/her own perspectives or biases and ignore other perspectives (Duff, 2012; Hood, 2009; Merriam, 2001) However, an interpretive paradigm stresses the importance of socially constructed meanings and knowledge (Duff, 2012), including those of the researcher. 
Being aware of such critiques, I sought principles to increase the rigor of my research. For example, as suggested by Yin (2012), I used teacher case studies in combination with other research methods (student focus groups). I provided full details of the research process (e.g., decision making, analysing, and choice of participants), and triangulated different sources of data to see multifaceted views of the studied phenomenon (Duff, 2012; Hood, 2009; Merriam, 2011).

A case study approach allowed me to explore in-depth how each of the teachers (a) made sense of culture, (b) normally practiced teaching culture, (c) engaged in the repeated workshop cycles, (d) transferred the learnt content to create impact on their new teaching practices, and importantly (e) reflected on the whole experience of being involved in a collaborative self-improvement opportunity.

Such in-depth exploration increased my awareness of the participant teachers, who are my colleagues, with regards to their intercultural teaching awareness and professional development. I was able to develop knowledge about each case as much as possible through within-case analysis. I could also learn about the divergences and convergences across cases through cross-case comparisons and contrasts.

Moreover, in my research, the potential for introducing a more deliberate intercultural stance is explored from the teachers' perspectives rather than in a top-down manner. I involved the teachers in learning, acting and reflecting on the cultural content in their classrooms and on the intercultural lessons we created to make positive classroom-based changes. Focusing on the particularity of a small group of Vietnamese teachers enriches the international scholarship in this field by adding voices from Vietnam.

\subsection{Research setting}

\subsubsection{The university and the school}

The study took place at a public university in the South of Vietnam. This university operates under the guidelines of the Ministry of Education and Training. Since 2015, students have been recruited to the university based on their test performance results in the National High School Exam. This university is comprised of eighteen faculties and institutions, and various functional centres. The university offers diverse training programs including 97 
undergraduate, 34 postgraduate and thirteen doctoral programs. Approximately 9000 students enrol annually. Most of them are from the Mekong provinces.

Data collection took place at the School of Foreign Languages of the university. This school has three departments of English teaching, English study, and general English. The School offers Bachelor degrees in English teaching, and translation; and Master's degree in English teaching.

\subsubsection{The curriculum and selected course}

The training program for Bachelor degrees included 140 credit points comprised of three main areas of knowledge: general knowledge, basic knowledge, and advanced knowledge for the students' majors (Interpreters/Translators, and English Language Study). The curriculum aims to equip students with (1) career-oriented English proficiency, (2) sociocultural skills for working in multicultural integration contexts, and (3) professional knowledge relevant to students' future higher learning.

According to the Bachelor training program, culture is not an integral part in the courses of listening and speaking, reading, and writing. I chose to examine a listening and speaking course (intermediate level) and the materials used for this course due to the participating teachers' availability. This course took three credit points and was a compulsory course intended to provide students with basic knowledge for their majors. The course took 90 periods (70 periods for in-class study and 20 periods for self-study) within a 15-week semester including exam time. Normally, each class had 40 students, taught by one EFL lecturer at the school. The course objectives are for students to develop English listening and speaking skills, self-study skills and exam strategies, and cooperative and selfresponsible learning attitudes.

The teaching materials for this course involved the coursebook Listening Advantage 3 (Kenny \& Wada, 2009) intended for students of A2-B1 levels and its teacher's guide manual (Kenny, Wada, \& Sheils, 2010). The textbook has twelve units that cover a range of topics. Each unit is organised into a lesson A and a lesson B. Activities in each lesson A include: warm up, listening, further listening, language strategy, and talk-it-over. Activities in each lesson B include: before-you-listen, extended listening, conversation, phonetics/pronunciation, and try-it-out. Overall, the coursebook layout presents a 
dominant focus on listening practice. Figure 8 provides an example of the textbook postlistening activities (see appendix 4 for textbook's lessons).

Figure 8. An example of the textbook's post-listening activity

Source: Kenny and Wada (2009, p. 21)

\section{Talk li Over}

With a partner, practice making and

responding to friends' requests.

Can we have a party at your house?

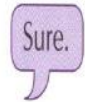

Will you pay for the food?

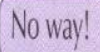

Seeing that the amount of (inter)cultural content and activities were limited in the current teaching materials, I studied the transcripts of the listening activities and the Language focus/strategies section in the coursebook units. I reached two important conclusions. First, the conversation transcripts contained paralinguistic content which could be exploited for intercultural learning. However, in my learning experience, transcripts are not usually used by teachers and learners. Second, the Language focus/strategies section lists language phrases for repeating politely, offering help, making requests, expressing ideas, checking for understanding, agreeing/disagreeing, giving advice, and apologising. This section is not usually emphasized and is often dropped by teachers due to constraints such as limited time and its lack of congruence with traditional teaching methods.

These two findings indicated that intercultural learning was not explicit in the current materials. One of the few places where it seems an intercultural foothold could be established is the explicit teaching of ICC and intercultural communication embedded in the Language focus/strategies section and the textbook-based conversations/talks.

\subsubsection{Participants}

\subsubsection{The teachers}

The study involved three teacher participants (one female and two males) in one department of the school. They are my colleagues. They were recruited on the criteria of (a) 
their academic qualifications and communication experiences, (b) their teaching responsibilities assigned by the department, and (c) their willingness and time availability to participate in the study. Pseudonyms Ms. Sen, Mr. Huy, and Mr. Sang were used to protect their confidentiality.

All the teachers completed their Bachelor of English Teacher Education at the same university where they are working. All took courses of American and British Culture and Society during the Bachelor program. Ms. Sen started her Bachelor's study before 1975 (the year of the national reunification) and completed it after 1975. She belongs to the very first generation of English teachers at the university. She studied her Master's degree in America in 2001. Mr. Sang completed his Bachelor's in 1992, and his Master's degree in Australia in 2009. Mr. Huy completed his Bachelor's in 1998 and Master's degree in Vietnam in 2008. All the teachers' Master's degrees were Education (M. Ed) and included culture-related courses. Their profiles and professional experiences are summarised in Table 2 and Table 3:

Table 2. Teachers' profiles

\begin{tabular}{|c|c|c|c|c|c|}
\hline \multirow[b]{2}{*}{ Teachers } & \multicolumn{2}{|c|}{ Qualifications } & \multirow{2}{*}{$\begin{array}{l}\text { Years of } \\
\text { service }\end{array}$} & \multirow{2}{*}{$\begin{array}{l}\text { Weekly teaching } \\
\text { periods }\end{array}$} & \multirow[t]{2}{*}{ Status } \\
\hline & Master's & Bachelor's & & & \\
\hline \multirow[t]{3}{*}{ Ms. Sen } & M.Ed & English Teacher & 39 & 12 & Retired \& invited \\
\hline & America, 2001 & Education & & & lecturer \\
\hline & & Vietnam, 1978 & & & \\
\hline \multirow[t]{3}{*}{ Mr. Huy } & M.Ed & English Teacher & 19 & 40 & Lecturer \\
\hline & Vietnam, 2008 & Education & & & \\
\hline & & Vietnam, 1998 & & & \\
\hline \multirow[t]{3}{*}{ Mr. Sang } & M.Ed & English Teacher & 29 & $6-10$ & Lecturer \\
\hline & Australia, 2009 & Education & & & \\
\hline & & Vietnam, 1992 & & & \\
\hline
\end{tabular}

Table 3. Teachers' professional experiences

\begin{tabular}{|c|c|c|c|c|}
\hline \multirow[t]{2}{*}{ Teachers } & \multicolumn{3}{|c|}{ Culture-related courses } & Communication experiences in \\
\hline & M.Ed & Bachelor's & Workshops & English \\
\hline
\end{tabular}




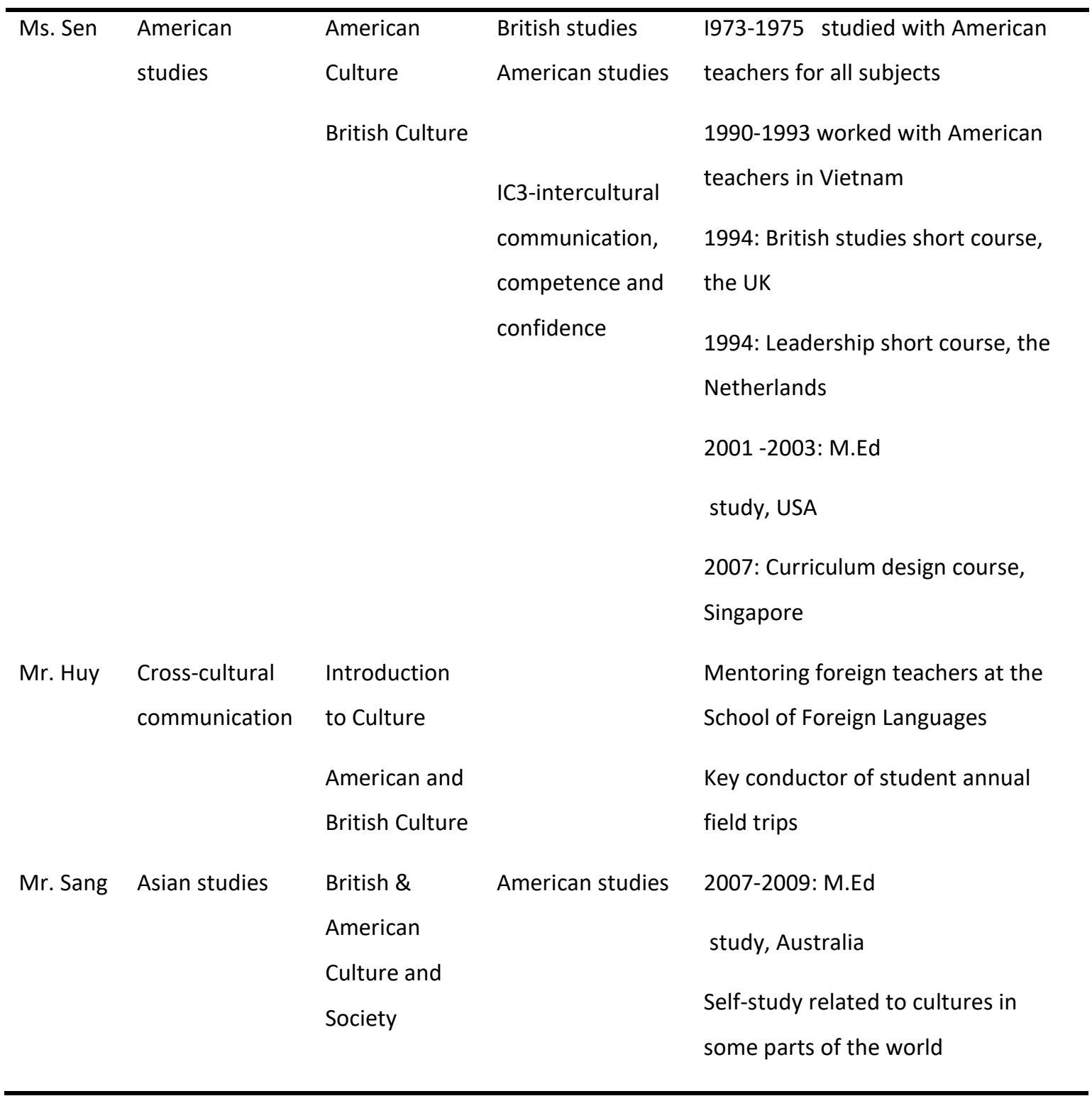

The teachers' self-reported profiles show that they have studied in multicultural education settings (especially Ms. Sen) and have mixed with culturally diverse groups of professionals during their careers. For example, taking a mentoring role for years, Mr. Huy has communicated with voluntary teachers and technicians from America, Australia, and Thailand.

The teachers' number of years of service ranges from 19 to 39 years. Ms. Sen had the longest time of service (39 years). Their teaching quota according to the university regulation was 360 periods per year. At the time of data collection, on average they taught fifteen and a half periods per week with Mr. Huy having the largest amount (40 periods). 
Apart from teaching, they also actively participated in professional conferences, workshops, and seminars in English teaching.

During the recruiting phase, at the beginning, I contacted Ms. Sen, Mr. Huy, and another teacher via emails, Skype, and phone calls while I was overseas in New Zealand. All of them agreed to participate in my project. However, due to the changes in the teachers' schedule and the student enrolment for the selected course, when I got back to Vietnam, the third teacher withdrew. Then, Mr. Sang was recruited by face to face contact, as we met in the school administrative office Vietnam. In our chat, Mr. Sang asked me about life and study in New Zealand and my research proposal. He expressed strong interest in the research proposal and immediately agreed to participate in the project.

All Ms. Sen, Mr. Huy, and Mr. Sang expressed interest in the topic of intercultural language teaching and learning. They arranged their schedules so that they could be available to participate in the project all the way through during the fifteen-week semester. They were informed in the information sheet and consent form that there would be classroom observations of their teaching practices and that they would attend interviews and take part in the workshop cycles.

\subsubsection{The students}

In addition to a focus on the teachers' teaching, this research also looked at students' selfreports on the experience of learning in the teachers' classes. When recruiting them, I came to each case study teacher's class and introduced my project and gave them the information sheet including Vietnamese translation.

\section{The students in the three classes}

The students were 18-23 years of age. Prior to university, they typically studied English for at least three years. They come from the Mekong Delta provinces and most of them had little contact with foreign speakers and cultures. All belonged to the same department as the teachers at the chosen university. They are training to be future interpreters and translators. Their English level is supposed to be A2-B1 for their second semester of the Bachelor program. At the time of data collection, they were in their first year and studied general subjects (e.g., National Defence Education, and physical education) and English skills (e.g., listening, speaking, reading, writing, and grammar) in the same classes. 


\section{Student focus groups}

I came to the class of each teacher and introduced my project to the whole class. Students looked positive. I told them that I would like to find five participants for group interviews and that if anyone was interested in, just let me know and stay behind. At the end of the class, interested students stayed behind and I gave them the consent form to read and sign.

Five students in each class were recruited for pre and post focus groups. Pseudonyms were used for them to protect confidentiality. None of them took extra English courses apart from their current university courses. Table 4 provides a summary of focus groups.

Table 4. Summary of Focus groups' profiles

\begin{tabular}{llll}
\hline Profiles & Focus Group One & Focus Group Two & Focus Group Three \\
\hline Men & Lieu & Ly & Thinh, Duy \\
\hline Women & Lien, Nghi, Lan, Thu & My, Ngoc, Hieu, Quyen & Diem, Nhu, Duyen \\
\hline Majors & English & Translation & English Study \\
\hline English & - A2-B1 & - A2-B1 & - A2-B1 \\
learning & - Over 5 years & - 3-5 years & - Over 5 years \\
experience & - Had studied with & - Had experience of & - Had studied with \\
& American & communicating with & American teachers \\
& teachers & English speakers & - Had communication \\
& & & experience of with \\
& & & English speakers \\
\hline Others & & & - Worked part-time \\
& & & - Took IELTS \& TOEFL \\
\hline
\end{tabular}

Each group is further detailed below.

Focus Group One studied in Ms. Sen's class and had four women (Lien, Nghi, Lan, and Thu), and one man (Lieu). Their major is English. They had studied listening and speaking with American teachers in the previous semester. All had studied English for more than five years.

Focus Group Two studied in Mr. Huy's class and had four women (My, Ngoc, Hieu, and Quyen) and one man (Ly). Their major is translation. Four of them noted that they had opportunities to communicate with English speakers in town and while travelling. These students had studied English for from three to five years.

Focus Group Three studied in Mr. Sang' s class and was comprised of three women (Diem, Nhu, and Duyen) and two men (Thinh and Duy). Their major is English. Diem had finished her Bachelor qualification in French Teacher Education. Nhu had a part time job at a coffee 
shop where the bosses were not Vietnamese. Duyen had overall score of 5.5 for IELTS and planned to migrate to Canada once getting an IELTS score of 6.5. Thinh had 575 for TOEFL in 2016 and used to be a teaching assistant at an English centre. All of them had studied English for more than five years. All students had chances to communicate with English speakers (e.g., in the previous semester's courses, travelling abroad, and talking with foreigners in town and at part-time jobs).

\subsection{Methods for data collection}

Prior to data collection, I was aware the data collection plan was shaped by the research questions and theoretical findings from my review of the literature during the research proposal development. This awareness helped me to focus on collecting data from each case study teacher about possible aspects of the studied topic such as the teachers' conceptualisations of culture, their beliefs about teaching and learning, and their teaching of culture before, during and after the two workshop cycles. However, I also approached the data collection context with the determination and curiosity to discover what was happening and why. For example, in addition to using observation sheets during classroom observations, I asked the teachers to explain specific teaching activities right after each lesson was finished. I took notes about the explanations and then added them to the observation sheet for that lesson.

Data were collected in two phases by multiple methods, which included classroom observations, teacher interviews, workshops, student focus groups, and students' written activities.

\section{Phase One}

Data collection for this phase was conducted in the first four weeks of the semester. It included (1) observations of the teachers' pre-workshop teaching practices, (2) postobservation interviewing with teachers, (3) focus groups with students (pre-focus groups), and (4) students' written activities (pre-written activity).

\section{Phase Two}

Data collection for this phase was conducted during the rest of the semester (from weeks four to fourteen). It included (1) workshop field notes, (2) classroom observations after each 
workshop, (3) post-observation interviews with teachers, (4) focus groups with students (post-focus group), and (5) students' written activities (post-written activity).

Table 5 summarises the chronological schedule of data collection for two phases. Table 6 summarises an overview of data:

Table 5. Data collection schedule

\begin{tabular}{|c|c|c|c|c|c|c|c|c|c|}
\hline Week 1 & 2 & 3 & 4 & 4 & $5-8$ & 9 & 10 & $11-12$ & $13-14$ \\
\hline \multicolumn{4}{|c|}{ Research Phase One } & \multicolumn{6}{|c|}{ Research Phase Two } \\
\hline \multicolumn{10}{|c|}{ Teacher data collection } \\
\hline \multicolumn{4}{|c|}{$\begin{array}{l}\text { Observations } \\
\qquad(\#=9)\end{array}$} & & $\begin{array}{l}\text { Observations } \\
(\#=9)\end{array}$ & & & $\begin{array}{l}\text { Observations } \\
(\#=6)\end{array}$ & \\
\hline T1 Obs 1 & T1 Obs 2 & T1 Obs 3 & & \multirow{3}{*}{$\begin{array}{c}\text { Workshop } \\
1\end{array}$} & $\mathrm{~T} 1 \times 3$ Obs & & \multirow{3}{*}{$\begin{array}{c}\text { Workshop } \\
2\end{array}$} & T1 $\times 2$ Obs & \\
\hline T2 Obs 1 & T2 Obs 2 & T2 Obs 3 & & & $\mathrm{~T} 2 \times 3 \mathrm{Obs}$ & & & $\mathrm{T} 2 \times 2 \mathrm{Obs}$ & \\
\hline \multirow[t]{2}{*}{ T3 Obs 1} & T3 Obs 1 & & T3 Obs 3 & & T3 $\times 3$ Obs & & & T3 $\times 2$ Obs & \\
\hline & & $\begin{array}{l}\text { ITVs } \\
(\#=3)\end{array}$ & & & & $\begin{array}{l}\text { ITVs } \\
(\#=3)\end{array}$ & & & $\begin{array}{l}\text { ITVs } \\
(\#=3)\end{array}$ \\
\hline \multicolumn{10}{|c|}{ Student data collection } \\
\hline $\begin{array}{l}\text { Pre- } \\
\text { written } \\
\text { activity } \\
\text { (three } \\
\text { classes) }\end{array}$ & & & & & & & & $\begin{array}{l}\text { Post- } \\
\text { written } \\
\text { activity } \\
\text { (three } \\
\text { classes) }\end{array}$ & \\
\hline & & $\begin{array}{l}\text { Pre- } \\
\text { focused } \\
\text { groups } \\
(\#=3)\end{array}$ & & & & & & \multicolumn{2}{|c|}{ Post-focused groups } \\
\hline
\end{tabular}


Table 6. Overview of data

\begin{tabular}{|c|c|c|c|c|c|}
\hline \multicolumn{2}{|c|}{ Collection methods } & \multirow{2}{*}{$\begin{array}{c}\text { Content } \\
\text { - Ts' normal teaching practices } \\
\text { (pre-workshop observation) }\end{array}$} & \multirow[b]{2}{*}{\begin{tabular}{l}
\multicolumn{1}{c}{ Size of data } \\
- 9 observations \\
(Lessons: 1A, 2A \& 2B) \\
(3 /each teacher). \\
- Two periods (100 \\
mins) - three \\
periods (150 \\
mins)/each \\
observation
\end{tabular}} & \multirow{2}{*}{\begin{tabular}{l}
\multicolumn{1}{c}{ Time } \\
Weeks \\
$1-4$
\end{tabular}} & \multirow[b]{2}{*}{ 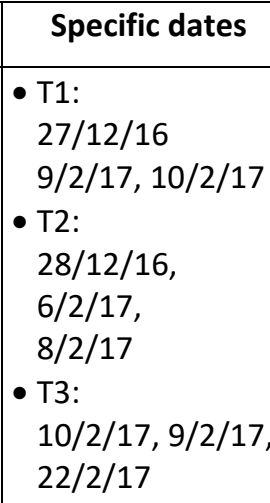 } \\
\hline \multirow{3}{*}{ 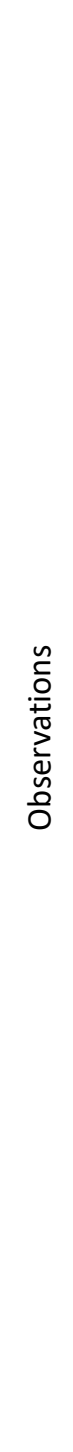 } & $\begin{array}{l}\text { Observation } \\
\text { Phase } 1\end{array}$ & & & & \\
\hline & $\begin{array}{l}\text { Observation } \\
\text { Phase } 2\end{array}$ & $\begin{array}{l}\text { - Ts' teaching practices after } \\
\text { workshop One using the } \\
\text { workshop content }\end{array}$ & $\begin{array}{l}\text { - } 9 \text { observations } \\
\text { (Lessons 4A, 6A \&7B) } \\
\text { (3 /each teacher). }\end{array}$ & 5- 8 & $\begin{array}{l}\text { - T1: } \\
\text { 27/2/17, 10/3/17, } \\
\text { 27/3/17 } \\
\text { - T2: } \\
\text { 23/2/17, 8/3/17, } \\
27 / 3 / 17 \\
\text { - T3: } \\
\text { 23/2/17, 9/3/17, } \\
23 / 3 / 17\end{array}$ \\
\hline & & $\begin{array}{l}\text { Ts' teaching practices after } \\
\text { workshop Two using group } \\
\text { lesson plans }\end{array}$ & $\begin{array}{l}\text { - } 6 \text { observations } \\
\text { (Lessons: 10A \& 12A) } \\
\text { ( } 2 \text { /each teacher) }\end{array}$ & $11-12$ & $\begin{array}{l}\bullet T 1: \\
\text { 11/4/17 } \\
\& 18 / 4 / 17 \\
\bullet T 2: \\
\text { 19/4/17 \& } \\
\text { 26/4/17 } \\
\bullet \text { T3: } \\
\text { 14/4/17 \& } \\
\text { 20/4/17 }\end{array}$ \\
\hline \multirow[t]{2}{*}{ 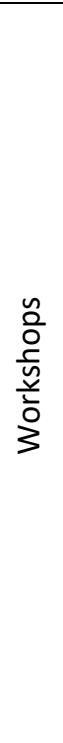 } & $\begin{array}{l}\text { Workshop } \\
\text { One }\end{array}$ & $\begin{array}{l}\text { 1. Ts' reflections on their } \\
\text { teaching and discussion } \\
\text { about the EFL learning } \\
\text { contexts in Vietnam and } \\
\text { beyond Vietnam } \\
\text { 2. Ts' discussion about the } \\
\text { intercultural lesson plans } \\
\text { 3. Ts' discussion about the } \\
\text { iCLT principles underlying } \\
\text { these lesson plans } \\
\text { 4. Ts' discussion about } \\
\text { adopting the workshop } \\
\text { content into their teaching } \\
\text { practices }\end{array}$ & $3 \mathrm{hrs} 5 \mathrm{mins}$ & 4 & $17 / 2 / 17$ \\
\hline & $\begin{array}{l}\text { Workshop } \\
\text { Two }\end{array}$ & $\begin{array}{l}\text { 1. Ts' reflections about their } \\
\text { teaching the lessons after } \\
\text { workshop One }\end{array}$ & $2 \mathrm{hrs}$ & 10 & $6 / 4 / 17$ \\
\hline
\end{tabular}




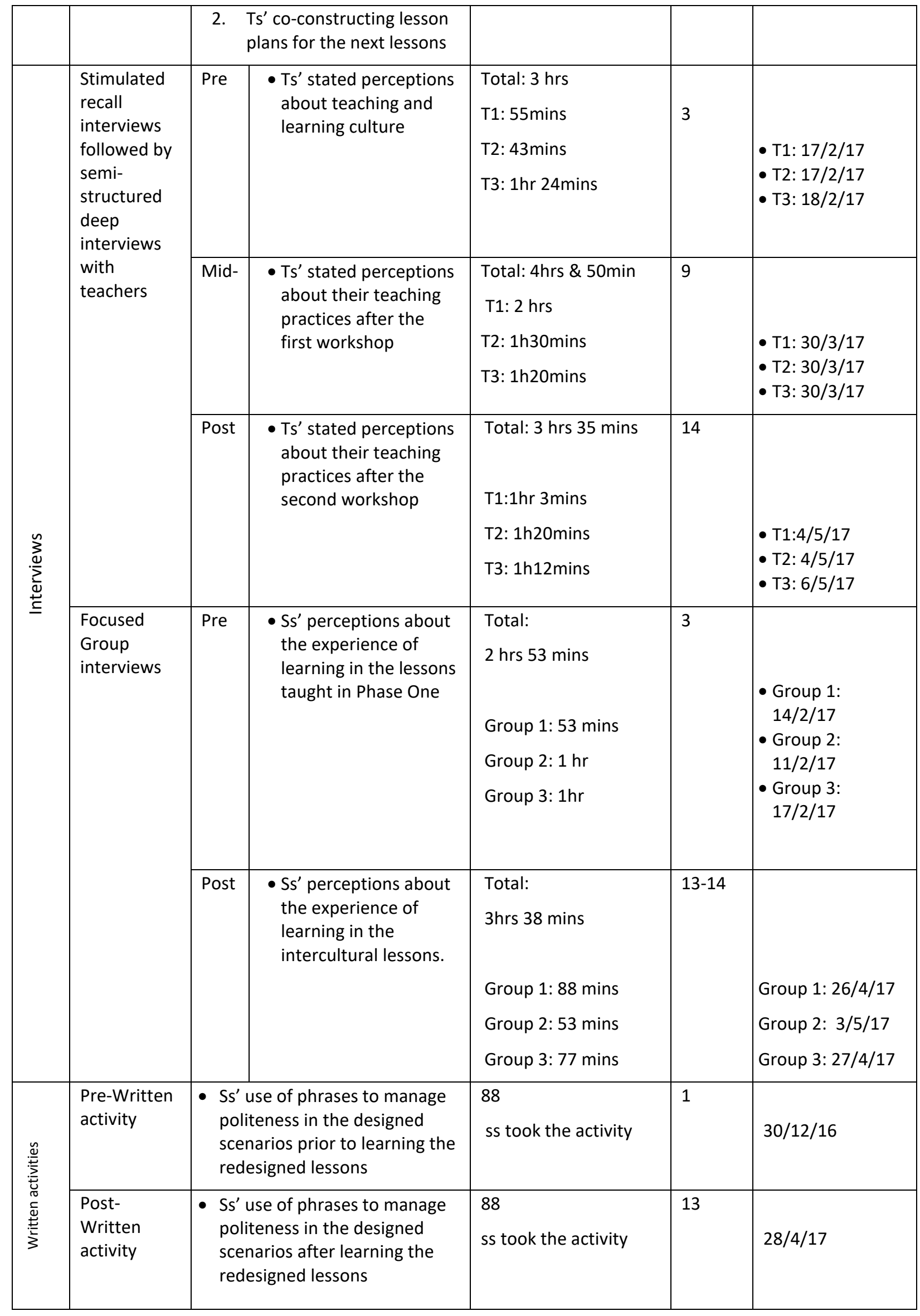




\subsubsection{Classroom observations}

The observations aimed to obtain rich, first-hand descriptive data about the teachers' teaching from an intercultural language teaching perspective to triangulate with data collected from other methods (e.g., interviews). According to Cowie (2009, p. 166), observation is defined as "the conscious noticing and detailed examination of participants' behaviour in a naturalistic setting" and is one of the most common methods in qualitative research. Observation is often used in conjunction with interviews for cross-checking of data against each method and for developing subsequent interviews (Merriam, 2001; Merriam \& Tisdell, 2016). Moreover, in-depth and multi-layered understandings about participants and contexts can be obtained through repeated observations (Mackey \& Gass, 2005).

Observations in the study were classroom-based and took place during two phases. There were 24 observations in total. Each observation varied from two periods (100 mins) to three periods (150mins).

Nine observations in the first research phase (pre-observations) explored the classroom processes with teachers' usual teaching practices to gain knowledge about the current settings and the participants prior to involving them in the innovation. Fifteen observations in Phase Two examined the classroom processes that occurred in the intercultural lessons. In both phases, the dual focus was the teachers' teaching practices and the student's participation in the lessons. My observations focused on each teacher's use of pedagogical activities to address culture in his/her own class. Observing student learning was in order to describe students' engagement in the pedagogical activities guided by teachers. The observations proceeded from an open observational approach to more structured observations once possible focused categories were identified.

The study employed overt and limited-participant observations. During observations, the researcher played the role of the outsider to explore the classroom practice. I took a limited-participant role, sitting quietly at the back of the classroom, taking notes without being purposefully involved in any classroom activities, and checking whether the camera was working properly. An observation sheet (appendix 5) that allowed flexibility was developed for me to take notes on a range of structured (i.e., predetermined) in combination with unstructured (explored) components which happened during lessons. In 
other words, my role was limited to observing, taking notes, and adjusting camera position where necessary.

Observed data were captured by video-recording and taking notes on observation sheets. These methods of capturing data are valuable in that the researcher can revisit the video audio resources (F. Liu \& Maitlis, 2010) and the written account of data (Merriam, 2001) after the fieldwork has been finished. One video-recording camera attached to a tripod was put at the back of the class at a convenient position to video teacher teaching and student learning.

\section{Strengthening observations}

Prior to the data collection period, the observation protocol, observation sheets, and observing skills were developed (appendix 5). An observation protocol identifies how observation is operationalised to ensure that intrusion is minimized, and the required data are obtained. All observations conducted in the research were for understanding classroom teaching and learning processes and had no other purposes.

To develop observational skills, I sought permission from a lecturer teaching the Skilled Migrant Program at VUW to observe her class for sixty minutes. I practiced observing and note taking using the designed observation sheet. This observation practice took place in mid-October 2016, two months before data collection. This practical opportunity increased my confidence and gave me reasons to revise the designed observation sheet which was too tightly structured at first. The lesson drawn from this practice was that classroom interactions are dynamic and various. For this reason, the final version of the observation sheet included both structured and unstructured components.

\subsubsection{Interviews}

The study employed individual teacher interviews and student focus group interviews.

\section{Individual teacher interviews}

Semi-structured deep interviews incorporating a stimulated recall (SR) component were chosen to obtain in-depth and broad data about teachers' perspectives (e.g., their making sense of teaching culture, decision making process, preparing teaching materials, cooperation, and teaching the lessons). Interviews with teachers were conducted 
individually in both research phases. Each teacher took part in three interviews during the study (pre, mid and post interviews). In both phases, each individual interview included SR at the beginning which was then followed by more in-depth questioning. During the indepth questioning, SR was also used where necessary to make sure that the interviewee remembered which activities and/or actions in the lessons were referred to at a particular point of the interview. There were nine interviews in total thorough the study.

An interview is a process in which a researcher and participant(s) engage in a conversation focused on questions related to a research study (Merriam \& Tisdell, 2016). As the dual purposes of the current research is to (1) understand teachers' making sense of intercultural language teaching and learning in terms of their mental processes and practice, and (2) students' stated perceptions about the experiences of learning in teachers' classes before and after the intervention was integrated, multiple interviews were employed to attain a full account of the phenomenon under investigation (Dörnyei, 2007). The researcher and participants can learn more about certain aspects because interviewing can be viewed as a learning event for both sides (Edwards \& Holland, 2013). Interviewing enables researchers to study what cannot be observed (e.g., mental processes or thoughts), and thus this method can reveal the interviewee's perspective (Merriam, 2001). This method allows exploration of the participants' meaning-making and interpretation of their answers (Kvale, 1996). Therefore, new knowledge can be produced and reconstructed through interactions within an interview.

All interviews were semi-structured (Merriam \& Tisdell, 2016). This form allowed flexibility to obtain data (Dörnyei, 2007; Richards, 2009). Semi-structured interviews also create more opportunities for clarification, and expressions of teachers' remarks thus making the teachers' voices more prevalent (Mangubhai, Marland, Dashwood, \& Son, 2004).

As guided by Dörnyei (2007), in alignment with the semi structured format, an interview guide was developed in advance (appendix 6). The guide included a set of core questions and the steps to carry out interviews. This ensures the researcher focuses on the research scope and standard steps during each interview, so interviews can happen in a manner that optimizes participants' comfort, openness, and richness as well as ensuring consistency of data across cases and groups. According to Richards (2009), the merits of an interview guide 
involve identifying key topics, developing unexpected directions, and flowing interactions. All interviews were audio-recorded and transcribed.

As Gass and Mackey (2016) argue, as a form of retrospective method in qualitative research, SR is used to uncover the interviewees' thought process by having them reflect retrospectively on what they did and think while on task. It captures the cognitive dimension of the participants' behaviours in classrooms, which is not easily achieved by means of observations alone (Gass \& Mackey, 2016). In this project, SR was included in interviews with teachers and students. The SR component in teacher interviews aimed at exploring the teachers' thinking underlying their specific teaching actions in the observed lessons whereas in student focus groups SR mainly aimed at increasing students' memory about the lessons to increase accuracy of their responses.

According to Gass and Mackey (2000), Mackey and Gass (2005), and Dörnyei (2007), video is one of the most common types of stimulus used in SR. In the current study, the classroom observations were video-recorded focusing on teachers' teaching and classroom procedures. These video recordings were shown to the participants (teachers and students) for the SR of each interview. Before the video recording of classroom observations was played, I reminded to the participants about the purposes of my research and explained to them the purpose of the SR and the interview.

The SR of each teacher interview proceeded in the following way. First, the teacher watched the recorded video of the lesson with me for about five minutes to generally remind him/her of which classroom observation he/she was watching. Next, he/she watched particular teaching episodes and stated his/her thoughts in relation to the episodes. The teacher was encouraged to replay any section that he/she wanted to see again. Either during or after viewing each episode, the teacher was asked open-ended questions such as what were you thinking at that time, why did you decide to do so, and how did you feel while teaching that point. After the teacher finished his/her answers to such questions, I moved to other questions which either emerged from their answers or was the question that I planned to ask them in depth. To take an example, in Ms. Sen's observed lessons after the first workshop, she visited each of the students individually during their speaking practice (the roleplay task). In the SR about lesson 7B (mid interview), she stated the reason behind her choice of teacher-individual student interaction as below: 
R: Why did you decide to come to individuals rather than pairing them, grouping them or teacherwhole class interaction?

Ms. Sen: I walked around the class and saw that many students were not on the right track, I changed, not teacher-whole class. At the beginning, I thought the task was not difficult. I assumed that they could do it; so later I came to each student to check and make sure they were on the right track.

R: What do you mean " on the right track"?

Ms. Sen: They do what they are supposed to do.

$[\ldots]$

R: Why do you think that closer relationship to teacher can help them to study or make them confident to ask you?

Ms. Sen: The more distance the worse it becomes because students dare not ask you. Many students don't ask questions in front of class but they will ask teacher if teacher comes to them.

\subsubsection{Student focus groups}

To investigate students' perspectives, focus-group interviews were undertaken. This method helps to attain insights about specific issues regarding groups of students' learning experiences. For this method, data are generated through group interactive discussions as students exchange ideas, share and hear from each other (Merriam \& Tisdell, 2016).

Three groups of students from three classes taught by the three teachers participated in pre and post focus group interviews. Each group consisted of five students including both males and females. They volunteered to participate. Three groups were interviewed twice i.e., pre and post. Pre focus group interviews (i.e., pre-workshop-one focus groups) were at the end of research Phase One to understand students' reflections after learning pre-workshop lessons (lessons 1A, 2A and 2B). Post focus group interviews (i.e., post-workshop-two focus groups) were at the end of research Phase Two to explore students' experiences of learning the intercultural-oriented lessons (lessons 4A, 6A, 7B, 10A, and 12A). In both phases, each focus group included SR prior to a more in-depth section. There were six focus group interviews in total in this study. 


\subsubsection{Workshop fieldnotes}

A workshop is an opportunity for enhancing teacher professional development; however, workshops about iCLT are not widely available to Vietnamese teachers. As noted in T. L. Nguyen (2013), professional learning workshops for Vietnamese EFL teachers have focused on other topics rather than intercultural competence teaching. I created two workshops in this research to guide the teachers to teach the selected lessons from an intercultural perspective. Both workshops took place in Phase Two at the teachers' convenience and were recorded. I also took notes about the workshops focusing on:

- The case study teachers' reflections on their existing teaching practices in terms of teaching culture and their discussions about the introduced content/materials (workshop one).

- Their reflection on their teaching using the first workshop content, their making decisions regarding using the redesigned intercultural content and their plans for teaching the last two lessons of the research (workshop two).

\subsubsection{Written activities}

The written activities (appendix 7) aimed to obtain information about the students' ability to manage politeness in communication in English before and after they experienced learning in the intercultural lessons. The activities asked students to give response to five given scenarios which focused on speech acts in English: making requests, complaints, (dis)agreeing, giving advice, and apologising. In Phase One, 88 students took the written activity in the first week of the semester. In Phase Two, they took the same written activity in week thirteen.

\subsection{Methods for data analysis}

I followed the process for qualitative data analysis (Patton, 2002; Dörnyei, 2007; Creswell, 2012; Merriam \& Tisdell, 2016). This section describes (a) the qualitative data analysis process, (b) the thematic analysis method which I adopted to analyse data, (c) the theoretical framework which informed my data interpretation, and (d) how I conducted the analysis. 


\subsubsection{Qualitative data analysis}

The process of qualitative data analysis is understood as the process of making meaning from data sources (Creswell, 2012) to explore emerging themes, patterns, concepts, insights, and understandings (Patton, 2002). According to Patton (2002), within this process, the researcher takes the integrated roles of the data collection instrument and the human tool for data analysis that starts during data collection.

Data analysis in this study was an iterative process with cyclical movements between the data collection and analysis stages, as well as within each stage (Dörnyei, 2007). It took place in three stages: on-going analysis, basic analysis, and intensive analysis as suggested by Merriam and Tisdell (2016).

\subsubsection{Thematic analysis method}

During each stage of data analysis, I followed the multiple steps of thematic analysis, which is "a method for systematically identifying, organizing, and offering insights into patterns of meanings or themes across data set" (Braun \& Clarke, 2012, p. 59). I adopted Braun and Clarke's (2012) approach because it is clearly described and suited my data set. It is sequential (with each step relying on the previous one), recursive (with the steps being revisited cyclically), and flexible (as some phases are interwoven). The six steps are described below:

Step one: Becoming familiar with the data

Initially the researcher needs to immerse himself/herself in the data by multiple readings/re-readings of the transcripts, listening/re-listening to the recorded audio, and watching videos. These repeated activities, combined with taking notes, allow the researcher to think analytically and critically about the data and to notice what is relevant to the research questions.

\section{Step two: Generating initial codes}

The researcher starts to generate initial codes by identifying, labelling, and interpreting segments of the raw transcribed text or data items. All the passages exemplifying similar content are assigned the same code; hence, coding is the act of indexing and categorizing blocks of data to create a conceptual structure of thematic ideas about it (Gibbs, 2007). Codes are created at different levels which are descriptive, semantic and interpretive (Braun 
\& Clarke, 2012), or categorical, analytical, and theoretical (Gibbs, 2007). Coding is also a recursive action because the created codes may develop during the coding process (Braun \& Clarke, 2012). That means recoding the earlier codes is possible until the data is fully coded and the data relevant for each code has been collated (Braun \& Clarke, 2012). The generated codes in this step allow the researcher to search for themes in the next step. It is worth noting that coding brings the researcher benefits. First, coding requires thorough reading of the data sources (Braun \& Clarke, 2012); as a result, it brings the researcher closer to the data. Second, as pointed out by Gibbs (2007, p. 40), "codes form a focus on thinking about the text and its interpretation" since the actual text is only one aspect of coding. Third, coding offers flexibility. The researcher can decide to code the entire data or only particular features of the data set. With the former option, the researcher creates the codes, and then explores themes depending on the data set. With the latter option, the researcher has particular questions in mind and looks for codes around these questions. In other words, coding can be more data-driven or more theory-driven. Moreover, in terms of technique, the researcher can code manually or use computer software program or file cards (Braun \& Clarke, 2012).

\section{Step three: Searching for themes}

This step entails searching for themes, a key concept in the data analysis of my research. First, a theme captures and unifies the nature or basis of the experience into a meaningful whole (Nowell, Norris, White, \& Moules, 2017, p. 8). Themes are "similar codes aggregated together to form a major idea in the database, they form a core element in qualitative analysis" (Creswell, 2012, p. 248). According to Braun and Clarke (2012), themes are regarded as significant when they capture meaningful features about the data in relation to the research question. Second, themes can be data-driven or theory-driven. That means themes are constructed inductively from the data set or deductively from theory (Nowell et al., 2017). Another way of identifying themes is ordinary themes, unexpected themes, hardto-classify themes, and major and minor themes (Creswell, 2012, pp. 248-249).

In searching for themes, the analysis develops to a broader and more abstract level (Braun \& Clarke, 2008; Creswell, 2012). The researcher reviews the codes, identifies their similar and different features. The researcher sorts the codes in the way that they reflect a broader meaningful pattern in the data to construct potential themes (Braun \& Clarke, 2012). The 
researcher also collates relevant coded extracts to support the identified theme(s) (Braun \& Clarke, 2008). In this phase the researcher can explore the relationships between themes and consider how they interconnect to reveal the whole story of the data. Hence, mind maps, Figures, tables are often used to help outline themes.

Braun and Clarke (2012) maintain that searching for themes is an active and flexible process because the researcher can make choices about how to construct themes. So, it is important for the researcher to be consistent in how he/she does this and to provide sufficient description of the decision-making process from collecting, organizing, coding, and analysing data (Nowell et al., 2017).

\section{Step four: Reviewing potential themes}

This step focuses on reviewing and refining the previously developed themes to confirm that the selected codes within themes are meaningfully coherent, and that distinctions between themes are clear in relation to the context of the whole data set. Braun and Clarke $(2008,2012)$ suggest that work in this phase goes through two reviewing levels. Level one requires the researcher to re-read and check the constructed themes against their supportive coded extracts to explore how the themes work within the data, for example, how a theme works within a single interview. The researcher can decide to split, combine or discard themes so that themes can better capture the meaning of the data and so that themes are well supported with relevant coded data. Level two considers the validity of individual themes in connection with the entire data set, for example, how a theme works across all the interviews. At the end of this phase, as pointed by Nowell et al. (2017), the researcher can reach a succinct set of themes that reflect the important features of the data set.

\section{Step five: Defining and naming themes}

This step involves the researcher further identifying the essence of individual themes. That is, what aspect of the data each theme captures, what story each theme tells about the data in relation to the research question(s), what the subthemes are if any, and how they interact within the thematic hierarchy. According to Braun and Clarke $(2008,2012)$, the researcher's work encompasses developing a deep analysis of each theme and identifying its scope. Specifically, the analysis should capture both the apparently-seen meaning and the implicitly 
latent meaning of the relevant extracts and tell readers why they are interesting. Hence, the analysis is not only descriptive but also conceptual and interpretive (Braun \& Clarke, 2012). In this phase, the researcher reaches a fine-grained set of themes and pinpoints what the themes are about and not about (Braun \& Clarke, 2008; Nowell et al., 2017).

Step six: Producing the report:

The report aims to tell a convincing, logical, and evidence-based story. Braun and Clarke $(2008,2012)$ emphasize that the analytic narrative should go beyond describing to making an argument in relation to the research question and the literature.

As can be seen, there are common correspondences between Merriam and Tisdell's (2016) analysis process and Braun and Clarke 's (2012) six step approach. Hence, for data analysis in my research, the step of familiarising myself with the data can be considered as correspondent with on-going analysis. The second and third steps (generating initial codes and searching for themes) can be considered as basic analysis, and the fourth and fifth steps (reviewing potential themes; and defining and naming themes) can be considered as intensive analysis.

\subsubsection{Theoretical frameworks for analysis and interpretations}

A theoretical framework includes the underlying concepts or theories that inform the study, and within this framework the study is oriented (Maxwell, 2013). It is within this stance that the researcher examines the research problem.

I formulated the research questions to examine the participant teachers' practices and understandings in terms of teaching and learning culture in EFL classes. Hence, this research relies on combined theoretical frameworks that address key concepts such as culture, language, and teaching and learning culture in foreign language classes. I critically considered views about culture using a range of scholarship including Kramsch (1993), Byram (1997, 2009), Corbett (2003), Aguilar (2008), Newton et al. (2010) Liddicoat and Scarino (2013), Newton (2016), and McConachy (2018) to interpret data and discuss findings. In addition, I adopted an interpretive stance (Hua, 2016) in exploring the research phenomenon to address the question of how the selected teachers made sense of and 
included culture in their daily teaching practices. The case study teachers' understandings and practices are interpreted through their context.

\subsection{Data analysis}

I conducted data analysis using three main sources of data for both research phases: teacher interviews, classroom observations, and student focus groups. Data from students' pre and post-written activities served to triangulate the main findings since many of students left the written activities unfinished. I applied the thematic analysis method (Braun \& Clark, 2012) across all sources of data used (i.e., interviews, observations and observation notes, and pre and post-focus groups) to analyse the data. The following section describes how I conducted the analysis.

\subsubsection{On-going analysis}

Taking the first step of Braun and Clark's (2012) approach, I familiarised myself with all data sources (audio-recorded interviews, audio-video classroom observations, field notes of classroom observations, audio-recorded workshops) through organising, summarising, transcribing, and translating the data.

Organising data

I organised the data sources according to the methods of collection (i.e., interviews, observations, workshops, written activities), the research phases (i.e., Phase One and Phase Two), and the types of data (i.e., audio recorded, video recorded, and written). Different organising methods help to store the data safely and to approach the data sources easily when using them. For example, all recorded interviews of each teacher were put in one folder. All folders of teacher interviews were put together under a bigger category named teacher interviews. This audio source of data was saved in multiple places to ensure its security.

\section{Summarising data}

I made initial summaries of the data (interviews, observations, recorded workshops) every time each kind was collected during data collection and during data analysis periods. For example, during the data collection period, after each interview in the first and the second phase, I summarised the interview based on the notes I had made during the interview. 
During subsequent data analysis, I listened to each interview again until I was fully familiar with it. While listening, I took detailed notes. These notes were utilised to compare and add to the initial summaries. By the end of summarising, I had made a second version of each summary to ensure it was accurate and concise.

For observational data, using the observation sheet, I summarised each observed lesson both in the form of text and of tabulated descriptions after I finished the observation. The initial tabulated form of each observed lesson was later extended with more details when I watched the recorded videos and listened to the interviews again.

For the workshop data, I applied the same method as with the interviews. All summaries were reported to my supervisor during regular work reports. Doing multiple summaries helped to increase familiarity with data sources and allowed iterative cycles of checking, comparing, and modifying sets of data summaries.

\section{Transcribing interviews}

I transcribed the teacher interviews and student focus group data during the data analysis stage. I intentionally transcribed fully what each participant said verbatim. The benefit of doing full transcription was that I captured the full picture of what was in the data and increased my familiarity with it. Before transcribing each source, I listened to it several times and took notes while listening.

I used NVIVO 11 to support my transcribing work. First, I imported the audio file to NVIVO 11 for access during data transcribing. Next, I played the selected audio file, typing it down while listening to it. By using NVIVO, I could enter the content, pause, forward, rewind, and skip back while transcribing. I could stop when having finished an entry, and automatically NVIVO added the ending time to the time span field and created a new transcript row. The created transcripts are automatically saved in NVIVO. To increase the safety of data storage, I also copied and stored the transcripts into Word documents in a safe drive in addition to the NVIVO storage. I checked spelling and content mistakes of the transcriptions and organised transcriptions according to each teacher and each focus group for each research phase. I then sent the transcripts to the participants for their cross-checking.

\section{Translating}


The interview protocol stated that the teachers could answer the interviews in either Vietnamese or English or both if they felt comfortable with it. For the pre-interviews and the final interviews, the teachers spoke mostly in Vietnamese, but in the mid interviews the teachers spoke in English most of the time. In the workshops and observed lessons, the teachers used both English and Vietnamese in their discussions.

Therefore, I did not translate all data; rather, I translated the transcribed texts quoted in the thesis into English for discussion. To ensure accuracy, I invited one EFL lecturer colleague to read through and check my translation.

\subsubsection{Basic and extensive analysis}

Basic and extensive analysis focused on:

- Analysis of the teachers' understandings

- Analysis of the teachers' teaching practices

- Analysis of students' perspectives

\subsubsection{Analysis of the teachers' understandings}

This analysis aims to explore the teachers' understandings about culture in both phases and particularly how they made sense of the intercultural lessons in the second phase to answer research sub-questions $1.1 ; 1.2 ;$ and 2.2. Data sources for this analysis included transcripts of three teacher interviews in Phase One, and six teacher interviews in Phase Two.

To begin, I read the interview scripts multiple times to gain a general sense of the data. With the research questions in mind, I identified and underlined words, phrases, and passages that were relevant to answer the research questions. I focused on the meaning of the underlined texts, based on the criteria that each segment must be comprehensible by itself and contain one idea or piece of information (Tesch, 1990). In order not to miss the contextual cues of the underlined segment, I often re-read the lines around it and the interview question I asked. I assigned the same code to all the underlined texts that revealed similar meaning. I reduced the number of codes by recoding the initial codes until codes had been collated (Braun \& Clarke, 2012) to create categories. I linked the substantial categories that exemplified the same ideas to construct themes (Nowell et al., 2017). To ensure the analysis was not only 
descriptive but also conceptual and interpretive, I reviewed and checked the constructed themes for each interview (Braun \& Clarke, 2012) noting whether:

- the supportive codes within themes were meaningfully coherent both in terms of their literal and latent meaning, if any;

- the name of each theme distinguished it from other themes within each interview;

- $\quad$ the theme revealed the data in relation to the research question(s); and

- I was consistent in using the same process to identify themes across interviews.

Table 7 provides an example of coding scheme using Ms. Sen's interview data when she answered the question "How do you think about the role of teaching culture in the English class?" in Phase One:

Table 7. An example of data coding

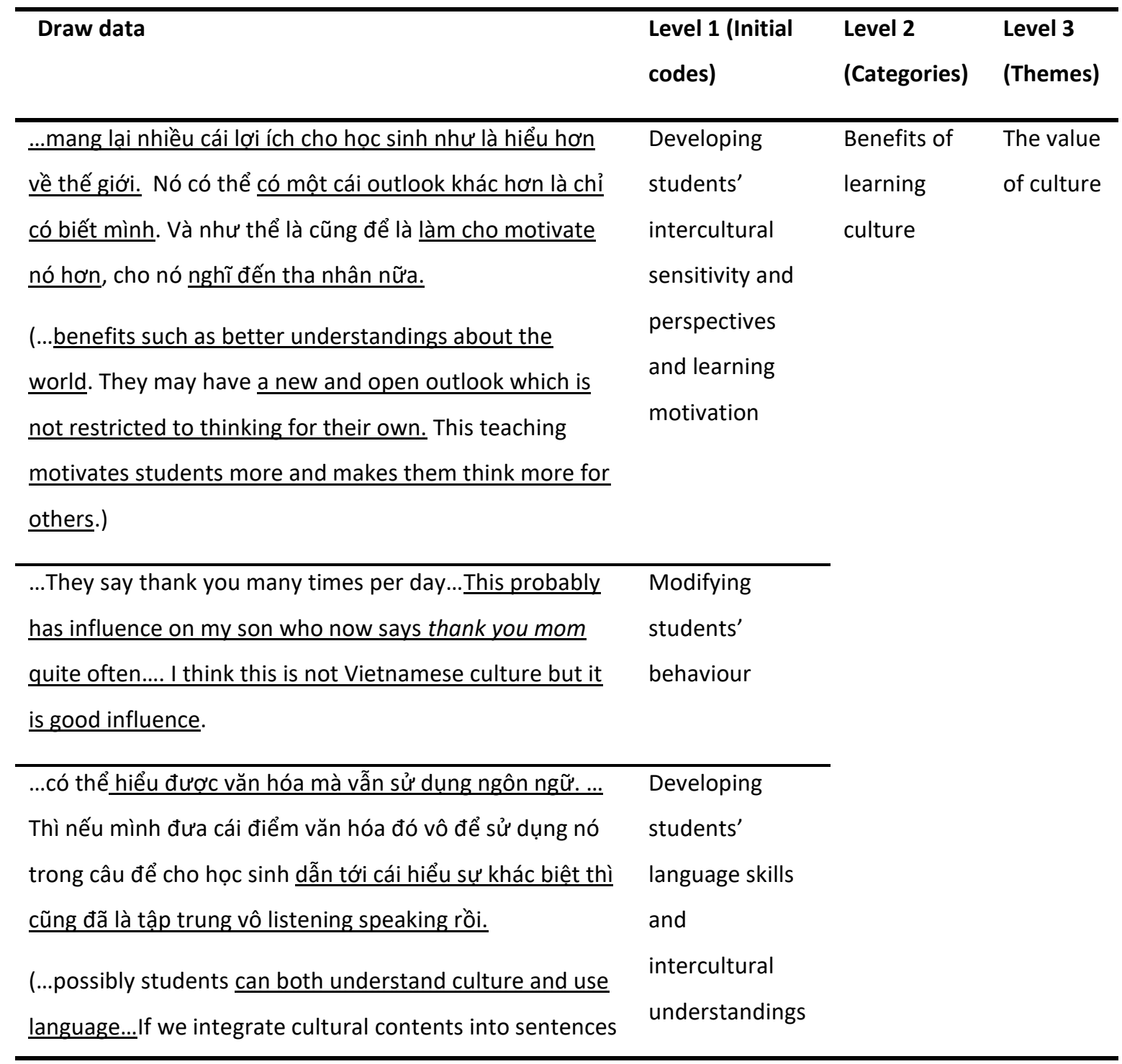


for students to use in their speaking and for themselves to discover cultural differences. This means we also focus on

listening speaking already.)

\subsubsection{Analysis of the teachers' teaching practices}

Analysis of the teachers' teaching practices in both phases included data sources from classroom observation notes, audio-video recordings of classroom observations, and teacher interviews. This analysis addressed research sub-questions 1.1 and 2.1. Post observation interviews included both stimulated recall and in-depth interview questions.

First, I watched the video-recorded lessons in full to become fully familiar with the data. With the research questions in mind, I paid more attention to the incidents in which the teacher(s) addressed culture in each recorded lesson. Second, I described these incidents in full including exactly what the teacher said and did. I counted the number of incidents of teaching culture for each lesson, and I added my comments next to the description of each lesson. Third, I compared each description with the observation notes and summaries of these notes. Fourth, to uncover the teachers' reasons and thoughts underlying the meaningful incidents in the teachers' teaching practices, I revisited the teacher interview transcripts and highlighted the parts where the teachers explained their teaching. Codes for these highlighted texts were previously made when I coded these transcripts. Therefore, I could easily add these codes and relevant direct extracts into the description of each lesson. I moved back and forth between sources of data. I analysed the entire observational data set; i.e., all the observed lessons (nine lessons in Phase One, nine lessons from postworkshop one plus six lessons from post-workshop two) in this manner. The outcome of this step was a set of full lesson descriptions that contained texts and tables plus the teacher's explanation about the meaningful incidents in each lesson. I developed a close engagement with the data that potentially revealed the pattern(s) of cultural content addressed in the lessons of each teacher and across all teachers.

Table 8 provides an example of analysis of teachers' classroom performances using data from Ms. Sen's third classroom observation in Phase One: 
Table 8. Example of description of teacher classroom performances

\begin{tabular}{|c|c|c|c|}
\hline \multicolumn{4}{|c|}{$\begin{array}{l}\text { Lesson 2B: Could you say that again, please? } \\
\text { Language strategy: Repeating politely }\end{array}$} \\
\hline \multicolumn{4}{|c|}{ Description of classroom performances } \\
\hline Tasks & Teacher's activities & Students' activities & $\begin{array}{l}\text { Addressing } \\
\text { culture }\end{array}$ \\
\hline $\begin{array}{l}\text { Listening to a } \\
\text { Japanese student } \\
\text { living in America } \\
\text { discuss about her } \\
\text { school }\end{array}$ & $\begin{array}{l}\text { Reviewed way of asking and saying time: (Ex: } 3: 15 \text { is said three } \\
\text { fifteen or a quarter after three) } \\
\text { Explained context of the listening task } \\
\text { Had Ss listened to the task } \\
\text { Explained "math" (AE) and "maths" (BE). } \\
\text { Mentioned the fact how Japanese in America maintain their } \\
\text { Japanese language } \\
\text { Compared this to Vietnamese overseas } \\
\text { Mentioned that "schools in Vietnam started at } 7 \text { am and students } \\
\text { got home for lunch and rest at noon while Japanese schools } \\
\text { started at 9am and students did not take a short nap at home. } \\
\text { This would be a disadvantage for Vietnamese students in future if } \\
\text { they worked for foreign companies that work through noon" }\end{array}$ & $\begin{array}{l}\text { Listened to and answered the teacher } \\
\text { Said the time in the textbook warm-up activity } \\
\text { Guessed about facts in school in Japan } \\
\text { Compared with those in Vietnam. } \\
\text { Listened and did the task (Gap filling, True/False } \\
\text { statements) } \\
\text { Summarised facts about Japanese school day in the } \\
\text { listening task and compared them to school day in Vietnam }\end{array}$ & $\begin{array}{l}\checkmark \\
\checkmark \\
\checkmark \\
\checkmark \\
\checkmark\end{array}$ \\
\hline $\begin{array}{l}\text { Listening to } \\
\text { conversation } \\
\text { strategy }\end{array}$ & $\begin{array}{l}\text { Explained people in America ask "Could you say that again, } \\
\text { please?" as in the title of the lesson } \\
\text { Explained conversation strategy (repeating politely) } \\
\text { Explained when English speakers say sorry } \\
\text { Had Ss listened to the task }\end{array}$ & $\begin{array}{l}\text { Listened with attention to when people said sorry and } \\
\text { numbered the phrases in the order they heard }\end{array}$ & $\checkmark$ \\
\hline $\begin{array}{l}\text { Recognising } \\
\text { similar sounding } \\
\text { words }\end{array}$ & Had Ss listened to the task & $\begin{array}{l}\text { Listened and circled the words they heard } \\
\text { In pairs, practiced saying the conversations again with } \\
\text { emphasis on sounding polite }\end{array}$ & \\
\hline
\end{tabular}


Table 9 provides an example of analysis of how culture was addressed using data from both Ms. Sen's third observation and pre-interview in Phase One.

Table 9. Example of analysis of how teacher addressed culture

\begin{tabular}{|c|c|c|c|c|c|}
\hline \multirow{2}{*}{\multicolumn{3}{|c|}{$\begin{array}{l}\text { What she did } \\
\text { (Observation data) } \\
\text { Meaningful incidents in the lesson }\end{array}$}} & \multicolumn{3}{|c|}{$\begin{array}{c}\text { What she explained } \\
\text { (Stimulated recall interview data }\end{array}$} \\
\hline & & & Reasons & Codes & Categories \\
\hline $\begin{array}{l}\text { Strategies used } \\
\text { to address } \\
\text { culture }\end{array}$ & $\begin{array}{l}\text { Telling cultural } \\
\text { facts } \\
\text { Comparing } \\
\text { cultural facts }\end{array}$ & $\begin{array}{l}\text { Mentioning the fact how the Japanese in } \\
\text { America maintain their Japanese language } \\
\text { Comparing facts in school in Japan with those in } \\
\text { Vietnam } \\
\text { Comparing how the Japanese in America maintain } \\
\text { their Japanese language to the Vietnamese } \\
\text { overseas. } \\
\text { Mentioning that "schools in Vietnam started at } 7 \text { am } \\
\text { and students got home for lunch and rest at noon } \\
\text { while Japanese schools started at 9am and students } \\
\text { did not take a short nap at home. } \\
\text { This would be a disadvantage for Vietnamese } \\
\text { students in future if they worked for foreign } \\
\text { companies that work through noon" }\end{array}$ & $\begin{array}{l}\text { Differences are more important to teach and learn because } \\
\text { differences have influence on comprehension. Similarities are } \\
\text { not significant and do not hinder comprehension therefore will } \\
\text { be ignored. Similarities do not affect students' behaviours or } \\
\text { attitudes. }\end{array}$ & $\begin{array}{l}\text { Comparing } \\
\text { cultural } \\
\text { differences and } \\
\text { similarities }\end{array}$ & $\begin{array}{l}\text { Raising cultural } \\
\text { awareness }\end{array}$ \\
\hline
\end{tabular}




\begin{tabular}{|c|c|c|c|c|}
\hline $\begin{array}{l}\text { Explaining } \\
\text { language use }\end{array}$ & $\begin{array}{l}\text { Explaining when people in America asked "Could } \\
\text { you say that again, please?" }\end{array}$ & $\begin{array}{l}\text { It is necessary to teach the embedded cultural content } \\
\text { embedded in this sentence to improve the students' language } \\
\text { skills.... Teacher wanted the students to be sure about how to } \\
\text { ask for full and focused repetition after learning the lesson. }\end{array}$ & $\begin{array}{l}\text { Cultural contents } \\
\text { embedded in } \\
\text { language }\end{array}$ & $\begin{array}{l}\text { Exploring } \\
\text { culture in } \\
\text { language }\end{array}$ \\
\hline & $\begin{array}{l}\text { Explaining conversation strategy (repeating politely) } \\
\text { Explained when English speakers say sorry }\end{array}$ & $\begin{array}{l}\text { To show politeness when responding to someone's asking for } \\
\text { repetition, students could begin with adding the word sorry } \\
\text { then add the repeated words. This was the strategy native } \\
\text { speakers of English used to respond to asking for repetition } \\
\text { politely }\end{array}$ & $\begin{array}{l}\text { Politeness } \\
\text { strategy }\end{array}$ & $\begin{array}{l}\text { Communication } \\
\text { strategy }\end{array}$ \\
\hline $\begin{array}{l}\text { Distinguishing } \\
\text { pronunciation } \\
\text { differences }\end{array}$ & Explaining "math" (AE) and "maths" (BE) & & & \\
\hline
\end{tabular}




\subsubsection{Analysis of the students' perspectives}

Analysis of students' perspectives answered RQ 1.3 and RQ 2.3 which aimed at understanding students' stated learning needs in terms of culture, and stated perceptions about learning in the intercultural-oriented lessons taught by the teachers. Because the current research focuses on teachers' perspectives, due to time and space limits, not all sources of data about students were used in the analysis. Therefore, although data collection involved the students' pre and post written activities, and students' pre and postfocus groups, analysis of student perspectives only used the students' pre and post-focus groups' transcripts. Student data analysis was conducted after the analysis of teacher interviews. I adopted the thematic analysis approach and generally followed the same process that I used for teacher interview analysis to code the student data.

When finishing coding all pre-focus groups and all post-focus groups, I reviewed and checked the constructed themes according to the research phases. Finally, I put them together according to research phases for reviewing to develop a sound and holistic understandings of the data.

\subsubsection{Reporting findings}

I reported findings according to the two research phases. Phase One findings are reported in Chapter 4 and Phase Two findings in Chapter 5. I chose the case study approach to present a full evidence-based story about each teacher's teaching practices and understandings. Each case story begins with how the teacher taught his/her lessons. The story progresses with how the teacher believed, perceived, made sense of, and reflected on his/her teaching practices. Chapter 4 treats the pre-focus group analysis as an independent part after the three teachers' stories are discussed. Chapter 5 treats the post-focus group analysis as a part of each teacher's story. These decisions were due to the nature of the findings about the students which are explained in Chapters 4 and 5 respectively. Each of these chapters comprises a cross-case discussion section where I study the divergences and convergences among the cases. Both chapters end with conclusions and implications drawn from the findings. 


\subsection{Trustworthiness}

Methods to enhance the analytical quality in qualitative research concern how to minimize potential threats that arise during analysis (Gibbs, 2007). To ensure qualitative research quality, researchers examine the rigour of qualitative findings, or trustworthiness (Anney, 2014). For this purpose, in my research, I applied the four quality criteria (i.e., credibility, transferability, dependability, and confirmability) introduced by Guba (1981), and later developed by Lincoln and Guba (1985). According to Krefting (1991) and Anney (2014), Guba's (1981) criteria model draws on the epistemological and philosophical bases of qualitative research. Anney (2014) also added that adopting the criteria of trustworthiness will increase genuineness of qualitative enquiry. To enhance these four criteria, I applied sets of strategies established in the literature which are outlined in detail in Guba (1981), Krefting (1991) and Anney (2014). Table 10 summarises the criteria and the strategies used in my study:

Table 10. Criteria and the strategies to enhance trustworthiness

\begin{tabular}{|l|l|}
\hline \multicolumn{1}{|c|}{ Quality criteria } & \multicolumn{1}{c|}{ Strategies } \\
\hline Credibility & - Prolonged engagement and persistent observation \\
& - Use of peer debriefing \\
& - Triangulation \\
& - Interview techniques \\
\hline Transferability & - Thick description \\
& - Purposeful sampling \\
\hline Dependability & - An audit trail \\
& - Code-recode strategy \\
& - Peer-examination \\
\hline Confirmability & - Audit strategy \\
& - Priangulation \\
&
\end{tabular}

\subsubsection{Credibility}

Credibility means the degree to which the research findings seem credible (Rallis \& Rossman, 2009), or the "truth value" (Lincoln \& Guba, 1985) or the confidence the researcher can establish on the correctness of the research interpretation (Anney, 2014). There are various strategies to ensure credibility. In my study I used prolonged engagement and persistent observation, peer debriefing, triangulation, and member checks. I will discuss each of the used strategies as follows: 


\section{Prolonged engagement}

Credibility can be enhanced by the researcher's engagement in the research context over a significant time period. This helps the researchers to avoid distorted data caused by their presence in the context (Guba, 1981) and thus to make sure that the participants act in a natural way (Mackey \& Mass, 2005). Moreover, the researcher has opportunities to test both his/her own and the participants' biases (Guba, 1981), and to establish trust with the participants (Anney, 2014). In addition to being a lecturer in the selected context, and a colleague of the participants, I spent more time learning about the context and the participants. During the six-month data collection period, I was extensively present in the School of Foreign Languages and the teachers' classrooms thorough most weeks to conduct classroom observations in all phases of the research.

Moreover, I also met the teachers in various environments. For example, I met them in both formal situations (in the classrooms, in the teachers' meeting room) and informal situations (at the teachers' houses, in the coffee shops) where the interviews and the workshops took place. I met them individually (for individual interviews, or short talks) or in a group (in workshops) and through phone calls and emails. According to Guba (1981) and Krefting (1991), these elements belong to the technique called persistent observation, which emphasizes various environments of interaction between the researcher and participants. Guba (1981) and Krefting (1991) maintain that different environments of collecting data helps me to justify my characterising of the context and the participants, and thus to enhance credibility.

My prolonged presence and persistent observation allowed me and the teachers to gain adequate understanding about the context and the participants and develop trust with each other as well as to learn from each other. All in all, these strategies helped me to have sufficient information about the context, the teachers, and for planning each of the data collection steps.

\section{Peer debriefing}

Peer debriefing involves the researcher interacting with other professionals to seek their scholarly support or guidance (e.g., their comments, feedback, perceptions, and critiques) (Guba, 1981; Anney, 2014). This allows researchers to have opportunities to test their 
growing insights (Guba, 1981). I regularly discussed theoretical and methodological issues with my supervisors. I discussed my challenges, decisions, and findings with other PhD students. I conducted a seminar to share with and seek feedback from my university colleagues in Vietnam. These various opportunities offered me diverse useful comments, guidance, and critiques, which expanded my perspectives and critical thinking about my emerging insights.

\section{Triangulation}

Triangulation is widely known as a powerful strategy to ensure qualitative research quality especially credibility (Guba, 1981; Krefting, 1991; Mackey \& Gass, 2005; Dörnyei, 2007; Rallis \& Rossman, 2009; Anney, 2014). It refers to the researcher cross-examining or cross checking for reducing bias and confirming the findings (Krefting, 1991; Anney, 2014). Krefting (1991) and Rallis and Rossman (2009) pinpoint the four common triangulation techniques which involve the use of (1) multiple data collection methods, (2) multiple data sources, (3) co-researchers to strengthen conclusions, and (4) different theories or perspectives.

I applied these four techniques. Data were collected using classroom observations, interviews, workshops, and focus groups. Each of these methods was repeated in each phase. To be specific, I conducted three observations per teacher to explore their current teaching practices in Phase One. I did three post-workshop one observations and two postworkshop two observations per teacher to explore how they taught the intercultural lessons under guidance and more independently. The dual workshops gathered data about the teachers' sense making processes in relation to an intercultural stance in their teaching practices. The pre and post-focus groups collected data that reflected the teachers' teaching from students' perspective.

In addition, data collection tools such as observation sheets and observation protocols, and interview guidelines were developed prior to data collection and modified for improvements during data collection. As a part of data collection instruments, I also practised observing and note-taking skills prior to data collection.

Analysis was based on assessing different data sources collected from different methods against each other. Specifically, classroom observation data were triangulated with post- 
observation interviews, field notes, and parts of the teachers' participatory discussions in the workshops.

\section{Member checks}

Member checks means including the voices of the participants in the interpretations and reports to eliminate the researcher's bias (Anney, 2014). For cross-checking with teachers, I sent the verbatim interview transcripts and summaries of lesson observations back to the teachers. For cross-checking with students, I sent the interview transcripts to one student from each group. They were invited to check whether the information was accurately transcribed and summarised before data analysis. Moreover, I also sent the teachers drafts of the research findings for comments.

Interview technique

Credibility can be enhanced during the interview process (Anney, 2014), particularly by reframing and repeating questions or expanding questions on different occasions (Krefting, 1991). In my interviews with teachers in the first phase, I tried not to mention technical terms such as intercultural competence and culture. I believed that avoiding using these technical terms helped to avoid answers based on social desirability - that is the participants responding with what they think is preferred (Krefting, 1991). The teachers were free to use any terms and languages (either English or Vietnamese or both) that they wanted.

In the post workshop interviews in Phase Two, I repeated questions by paraphrasing them several times to make sure that the teachers' answers were consistent. In cases of contradictory responses, I asked them for explanations and examples so that I understood the answers more. I used this interview method to create what Guba (1981) and Krefting (1991) called structural coherence, making sure there were no unexplained inconsistences between the data and their interpretations.

I drew on Barbour (2007)'s procedure for running student focus groups. I clearly explained to the students that attending the focus groups did not affect their assessment in any way. During focus groups, I did not use technical terms. 


\subsubsection{Transferability}

Transferability concerns the extent to which the findings are applicable or useful to theory, practice and future research (Lincoln \& Guba, 1985). Providing thick description of the researched context and using purposeful sampling helped to augment this quality.

For transferability, it is crucial to provide sufficient contextual details for the audience to make a judgement about the fittingness between the researched context and their own contexts to which the transfer of findings is possible (Guba, 1981; Anney, 2014). My study mainly aims to develop in-depth understandings about a small group of teachers' making sense of an intercultural stance, and their transfer of the intercultural teaching content into their practices. My study does not aim to generalise the findings. However, I provide detailed descriptions about the research problem, research context, and methodology to help readers to evaluate the study, make comparisons with, and relate to their own contexts (Guba, 1981).

Furthermore, I used a case study approach to tell the story about each case study teacher both in terms of their teaching practices and understandings during the research phases. I described their practices using the observational data and interview data obtained from workshop cycles. In addition to the interview data, I also used recorded data from workshops to track their discussions and reflections about their teaching and understandings. Data from focus groups were intended to provide further insights, from students' voices, about how the intercultural orientation was adopted by the teachers. By using rich data from multiple sources, data interpretation can unfold for readers to help them make sense of the findings.

Transferability is also addressed by my detailed description of the participants' background (in the section of participants of this chapter). The study involves a small number of teacher participants. However, full description of their demographic information reveals that these teachers shared typical characteristics with the many EFL teachers in the tertiary context in Vietnam. For example, they all had relevant EFL qualifications, taught homogeneous classes of students within a fixed curriculum, had a certain amount of intercultural communication experience, and had busy teaching schedules. According to Krefting (1991), clear description about the informants' background information can help readers to compare the described characteristics to assess how transferable the findings are. 


\subsubsection{Dependability}

Dependability means the degree to which (a) the research findings are consistent and reliable and (b) the research procedures are documented (K. Moon, Brewer, Januchowski-Hartley, Adams, \& Blackman, 2016). The key aspects of dependability involve the researcher's documentation of the research procedures (Krefting, 1991), and the participants' evaluation of the analysis (Anney, 2014). To establish dependability, I used methods to increase the transparency of reporting the research procedure, and the accuracy of data collection and interpretation.

First, the research procedures are documented in detail in this chapter to allow the audience to follow, audit, and critique the research process (K. Moon et al., 2016). During the data collection and analysis, I used what scholars (Guba, 1981; Anney, 2014) refer to as an audit trail. I created a diary notebook about what I did and reported my activities and decisions to supervisors every fortnight. For any significant decisions, I discussed with my supervisors and provided reasons to justify my decisions.

I conducted a code-recode procedure during the analysis period (Guba, 1981; Anney, 2014). Specifically, for observational data, first during my data collection, I summarised classroom observations of each teacher to share with my supervisor. Then, during data analysis, I watched the video again and summarised the lessons. These two steps allowed me to add and modify the lesson summaries and kept my thinking about the lessons active during the writing-up period. For the interview data, I coded the interview and left it there and recoded it after a few weeks. This sequence repeated during the data analysis period. This coding and re-coding sequence allowed comparisons of coded results and enhanced a deep level of engagement with data.

In addition, for peer examination (Anney, 2014), I discussed the research process and findings with my supervisors and at least two academic friends. I also used peer-debriefing for their checking and comments about the verbatim interview transcriptions, observation summaries, workshop summaries, and the findings. From these community discussions, I became more aware of perspectives that were different from my own perspective, and this informed the way I interpreted the data. 


\subsubsection{Confirmability}

Confirmability refers to the extent to which the results derived from the data can be corroborated by other researchers (Anney, 2014). To enhance this criterion, I used an audit strategy, triangulation (which were also mentioned earlier), and practiced reflexivity (Krefting, 1991).

Using the audit strategy, I made the full details of data on which I based my claims and interpretations (Mackey \& Gass, 2005) available to my supervisor especially during the progression of my data collection and analysis. These included reporting summaries of data, data coding and thematic categories. I also sent data transcripts and summaries back to my participants for checking before I analysed them. Then, I invited them to comment on my interpretation of data.

Similar to using an audit trail technique to ensure dependability, I created a field journal that included my notes about my thoughts, decision making, steps taken, and my emerging understandings during the research process to ensure confirmability. I was aware that qualitative inquiry is an instrument in data collection and analysis, and so my perspectives play a role in interpreting the final findings (Johnson \& Christensen, 2012). To address this, I will explain my roles during the project and present my background (e.g., perspectives, assumptions, and interests) in the following sections. Such reflective activities do not necessarily remove bias but do help explain how the researcher's positionality informs the research findings (K. Moon et al., 2016).

\section{The role of the researcher as an insider and outsider}

My roles changed throughout the PAR project. On the one hand, I played the role of an insider who shared a similar occupational status at the same teaching context with the case study teachers. I did not hold a leadership position which might have influenced on the participants. In this sense, I understood the case study teachers' interest in professional learning, gained trust from them, and increased cooperation during research process. According to Braithwaite, O'Neill, Rebane and Cockwill (2007), the insider who belongs to the same part of the community as the participants, can successfully engage fully with the local participants and can get them express their true thoughts and feelings. On the other hand, I was an outsider who had opportunities to make sense of the literature on the 
research topic and discuss what I learnt from the literature with my supervisors and my PhD peers. I wanted to share what I have learnt to the case study teachers, my colleagues, in form of workshops. Thus, I invited the them to participate in my research. Louis and Bartunek (1992, p. 4) maintain that, in collaborative research, the researcher being both an insider and outside as well as being aware of such combined roles serve several advantages. In my project, for example, for classroom observations, I stepped back from my insider role so that I could capture the teachers' classroom teaching practices without missing meaningful incidents happening during the observed lessons. For interviews, I sought to step back from my insider role and to adopt more of an outsider perspective in order to uncover the teachers' assumptions related to the issues I asked them about. In part, I was able to shift into this outside role through my new identity as a PhD candidate and researcher, and also through viewing classroom practice through the new perspectives I had obtained from extensive reading of the research literature and general scholarship on intercultural language education.

\section{The researcher's positionality}

Scholars (Merriam, 2001; Gibbs, 2007; Dörnyei, 2007) have emphasized the importance of the qualitative investigator acknowledging his/her position so the audience can identify potential researcher bias. Issues to address include the researcher's background, power relations, the nature of interaction with participants, preconception, and epistemology (Gibbs, 2007) to create an "open and honest narrative" (Dörnyei, 2007, p. 60). This section addresses my position in the study.

I have been an EFL lecturer for roughly eleven years at the same university with the teacher participants. All three participating teachers and I earned our Bachelor degrees in English Language Teacher Education in the same university. Three of us studied our Master's degrees in English-speaking countries (America and Australia), and in Vietnam. None of us were in a leadership position at the time of my project. I positioned myself as a researcher and a colleague of my participants. Moreover, as the project is informed by PAR, all of us shared openly and took ownership of the process during the second research phase when we developed intercultural lessons together in the workshops.

In relation to the research context, I am familiar with the university. However, I am aware that as a researcher, I should not take for granted what I have been familiar with. 
I am interested in the topic of teaching culture for Vietnamese EFL learners. During my research proposal development, I gradually developed my understandings of the topic and have learnt that terms such as culture, intercultural, and intercultural communicative competence are defined in various ways in the literature, and that there are many models of culture and ICC developed by scholars worldwide. Therefore, I became more cautious about using these technical terms with my participants as I believe these terms may mean different things to each teacher in a language teaching community.

Due to the above emerging understanding, during the interviews, I neither relied on my own understanding about culture, intercultural language teaching and learning, and intercultural competence nor assumed that I understood these topics broadly. On the contrary, I assumed that there would be more interesting things I could explore from the participants. Therefore, I neither took it for granted that I understood everything about what they said nor made any judgements about their perspectives and practices based on their data.

First, I used semi-structured interviews to allow using follow-up questions to ask the teachers for clarification and explanation. Second, for classroom observations, I played a limited-participation role. This allowed me to explore fully the natural ecology of the classroom including both teaching and learning processes. Third, for the workshops, I played a participatory role as I supported the teachers with the theoretical frameworks underlying intercultural language teaching and learning. However, before I introduced the theories, I involved the teachers in reflecting on their teaching context and experiences. Fourth, the repeated workshop cycles allowed exploration of how the teachers progressed in terms of intercultural language teaching. Moreover, when analysing the data, I provided sufficient quotes for codes and applied quality criteria to ensure the findings were based on the data. As can be seen, through each stage of the project, I have kept myself alert about my own positionality. Given that no researcher can absolutely remove research bias (Gibbs, 2007), my application of quality criteria (credibility, transferability, dependability, and confirmability) and inclusion of my positionality help strengthen the appropriateness of my interpretations of and reports on the data. 


\subsection{Ethical issues}

Research ethics refer to how the research was conducted ethically (Rallis \& Rossman, 2009). Ethical issues are crucial because qualitative research inevitably involves human beings' personal views (Dörnyei, 2007). This research addressed ethical issues at two overall levels, which were procedural ethics and ethics in practice (Rallis \& Rossman, 2009).

The research followed the ethical guidelines of VUW. Prior to data collection starting on 16/12/2016, the study was granted ethical approval (Number: 23103) from the Human Ethics Committee of Victoria University of Wellington on 12/10/2016 (Appendix 7). The Committee assessed and approved components such as consent forms and information sheets for teachers; consent forms and information sheets for students; the information sheet and the letter of request for the Head of the selected research site; interview guidelines, observation sheets and protocols, and examples of interview questions. These forms addressed issues such as protecting participants' confidentiality, privacy, data storage, consent, voluntariness, right to withdraw, and benefits. The questions and comments from the Committee were answered and responded to in order to make sure that I was aware of the ethical issues and would act in accordance with the ethical approval. The ethics approval including the above-mentioned components is important in that it raises the researcher's awareness about potential risks to participants and the steps to make sure that the research is conducted in an ethically appropriate manner. Also, it helps the researcher to achieve institutional credibility to enter the research site.

In addition to the above dimension of ethics, this research was guided by the ethical principles of qualitative research (Dörnyei, 2007) in terms of protection of participants, benefits to participants, storage of data, and informed consent.

\section{Protection of participants}

Firstly, I ensured that no mental or physical harm would affect the participants as a result of their participation in this research. For example, I obtained a permit from the Head of School to conduct data collection. With the permit from the Head, the participants had support to participate in my study. The participants were provided with detailed information about the research process as well as what would happen to the information 
they provided. The interviews and workshops were also conducted at places and times of their convenience.

To ensure voluntary participation and privacy, I sent the information sheet and the consent form to the teachers for them to read and left them time to decide about their participation three weeks before I met them. I was available to answer any questions from the teachers during their time of consideration. They understood that they could decide not to answer any question or to withdraw their participation at any time. For classroom observations, I took a limited-participant role and did not wish to disturb their classroom teaching performances.

For confidentiality, the identity of the participants was not disclosed to anyone. Their real names and their institution's name were not mentioned in any form. For instance, the interviews were conducted individually; the materials from the interviews were not controversial nor involved disclosure of sensitive information. Regarding confidentiality within the department, it is possible that other colleagues may read this thesis and may be able to identify who the three teacher participants were. However, the research is not about the teachers as such, and the data gathered is not in the least bit controversial or sensitive. The focus is only on the intercultural dimension of the EFL teaching in Vietnam and on the intercultural lessons I have designed for the teachers to use.

Another way to protect the participants was the secure storage of data. Access to data is limited to me and my supervisors. All collected data will be destroyed three years after the end of the research (approximately in October 2022).

\section{Benefits to participants}

The participants were informed that their participation in this project would bring them professional learning opportunities related to classroom teaching of culture, and they would also be given small gifts in appreciation for their time and effort. I shared with the teachers the recorded interviews and transcriptions for them to read.

The students were given a book in appreciation for their participation. More importantly, they were involved in intercultural learning opportunities that aimed to address their need for intercultural content in EFL lessons.

Informed consent 
The participants were recruited using the informed consent model. The consent form and information sheet adhered to VUW's Human Ethics Guidelines. After the Human Ethics Approval was granted, I sent the information sheets and the consent forms to the teachers to read and consider. I was in touch with them via email and phone calls to answer any of their questions or provide any additional information they required. Then, I met with them to explain the project a week before the data collection formally started. The written informed consent form was obtained from the Head of the School, the teachers, and the students.

\subsection{Chapter Summary}

This chapter has detailed the methods employed to conduct this study. The overall research purpose was to explore the potential for integrating an intercultural stance into the current teaching context, and the focus was on teachers teaching practices and understandings in terms of culture. This research took an interpretivist research paradigm and drew on a PAR framework to study the synergy between improving the case study teachers' teaching practices and developing their insights into their practices for teaching culture. To enhance the research rigor, multiple methods were used to collect data, strengthen research quality, and address ethical issues.

The next chapter will report and discuss the findings regarding the teachers' existing teaching practices and understandings about teaching culture. 
This page is intentionally left blank 


\section{CHAPTER 4 CURRENT ORIENTATION TO CULTURE: PHASE ONE FINDINGS AND DISCUSSION}

\subsection{Introduction}

This chapter reports and discusses the teaching practices and stated perceptions of the three case study teachers, as well as students' learning needs in terms of culture prior to the implementation of intercultural language teaching and learning in Phase Two. The chapter comprises four main sections: (1) overview of Phase One, (2) findings about the current orientation to culture, (3) conclusions and implications, and (4) chapter summary.

The first section includes the research purpose, background information about Phase One, and sources for data analysis. The second section presents the findings of each case study teacher according to observation data and interview data. Then, the differences and similarities across cases are drawn and discussed from cross-case analysis and discussion. This section also reports findings about students' learning cultural needs, followed by a summary of the Phase One findings. The third section focuses on chapter discussion, followed by a summary of the chapter.

\subsection{Overview}

\subsubsection{Research purpose}

Phase One studied the current orientation to culture. It explored how culture was evident in the case study teachers' observed lessons, their conceptualisations of culture, and beliefs about teaching and learning culture. Drawing on this information, I will identify potential affordances and gaps in the teachers' professional practices and understandings regarding teaching culture. The key components of Phase One included observing the teachers' preworkshop teaching practices, interviewing teachers after observations (pre-interviews), and students' self-reports about their learning needs in terms of culture. Phase One seeks answers to RQ1 as follows:

RQ1: What are the current practices and understandings of the three case study Vietnamese tertiary EFL teachers in relation to teaching culture? 
1.1 How is culture addressed in the classroom teaching practices of three case study teachers at this university?

1.2 What are the attitudes and stated perceptions about teaching culture of the case study teachers?

1.3 What are the students' perceptions of their cultural learning needs in EFL lessons?

\subsubsection{Backgrounds}

\section{The teachers}

The recruited teachers are my colleagues, who studied in the same university for their Bachelor degrees in English Language Teacher Education and became lecturers within the university after graduation. By the time of data collection, in 2017, they all had Master's degrees in English Language Teacher Education, having between 19 and 39 years of teaching experience. They volunteered to participate in my project on the basis of their availability and interest in the research topic. Their details were presented in the methodology chapter.

\section{The selected lessons for observations}

I explored the teachers' current teaching practices by observing them teaching three lessons at the beginning of the semester. Specifics about these lessons are summarised in Table 11:

Table 11. Specifics about the pre-workshop observed lessons

\begin{tabular}{|c|c|c|c|}
\hline \multicolumn{4}{|c|}{ Phase One: Pre-workshop observed lessons } \\
\hline Weeks & & $1-4$ & \\
\hline Lessons & $1^{\text {st }}$ & $2^{\text {nd }}$ & $3^{\text {rd }}$ \\
\hline Lesson titles & $\begin{array}{l}\text { 1A What kind of } \\
\text { computer? }\end{array}$ & 2A If I practice hard enough & $\begin{array}{l}\text { 2B Could you say that again, } \\
\text { please? }\end{array}$ \\
\hline Listening tasks & $\begin{array}{l}\text { - Talks about computers } \\
\text { - Conversations between } \\
\text { computer shoppers and } \\
\text { shop assistants }\end{array}$ & $\begin{array}{l}\text { - Talks about after-school } \\
\text { activities } \\
\text { - Conversations between } \\
\text { parents and children about } \\
\text { advertisements about after- } \\
\text { school lessons }\end{array}$ & $\begin{array}{l}\text { - A Japanese student living in } \\
\text { America discussing about } \\
\text { her school } \\
\text { - Similar sounding words } \\
\text { such as plays/place, } \\
\text { ice/eyes }\end{array}$ \\
\hline Speaking tasks & $\begin{array}{l}\text { - Comparing features of } \\
\text { computers }\end{array}$ & $\begin{array}{l}\text { - Speaking about the reasons } \\
\text { for doing something }\end{array}$ & $\begin{array}{l}\text {-Speaking about after- } \\
\text { school life of students }\end{array}$ \\
\hline $\begin{array}{l}\text { Language } \\
\text { strategies }\end{array}$ & Comparisons & Conditionals & Repeating politely \\
\hline $\begin{array}{l}\text { Observed \& video } \\
\text { recorded }\end{array}$ & $\checkmark$ & $\bar{\checkmark}$ & $\bar{\checkmark}$ \\
\hline Reported in thesis & $\checkmark$ & $\checkmark$ & $\checkmark$ \\
\hline
\end{tabular}




\section{Classroom locations and schedules}

All observations took place in either $\mathrm{C} 1$ or $\mathrm{D} 2$ building at the chosen university. $\mathrm{C} 1$ is in an old three-storey building close to the inner university road. The physical environment around the observed classroom was noisy due to being close to the walking path. The big TV screen in the classroom was not working properly during the data collection period due to technical maintenance. In contrast, D2 is a new building with better light, air, and good condition of technology assisted teaching such as TV screen and wifi. However, since teachers next door frequently used microphones in their classes, the observed classrooms were sometimes disturbed by the loud noise. Each class studied eight periods (45 - 50 minutes each) organised into three sessions per week.

\subsubsection{Data sources for analyses}

Findings about each case study teacher in Phase One draw on data from three classroom observations and a post-teaching interview with the teacher (the pre-interview). Findings about the students draw on data from the students taught by each teacher using each preworkshop-one focus group interview.

\subsection{Case studies}

\subsubsection{Case one: Ms. Sen}

Ms. Sen earned her Master's degree in America in 2001 and has 39 years of teaching experience. The courses she taught included all the four skills of English, American Culture and Society, and Cross-cultural Communication. She retired in 2010 but was still teaching as an invited lecturer at the same university. She shared that her teaching philosophy was that one should learn courtesy before literacy.

\subsubsection{Observation data}

Ms. Sen's class had fewer than twenty students, the smallest class size of the three case study teachers' classes. She perceived her class's English level as low. Her class was scheduled for three days: three periods on Tuesday mornings (8:50 am to 11:30 am) in C1 building, three on Wednesday afternoons (1:30 pm to 4:10 pm) and two on Friday mornings (7:00 am to 8:40 am), both in D1 building. Lesson observations with her were conducted on Tuesdays and Fridays. The current textbook used in Ms. Sen's (and also the other two 
teachers) observed lessons was Listening Advantage 3 (Kenny \& Wada, 2009). Each of the observed lessons is described below.

\section{Lesson one}

In this lesson, Ms. Sen focused entirely on students' speaking practices. First, Ms. Sen modelled asking questions about the lesson's computer topic, for example Do you have a laptop or desktop? Where do you use your laptop? What do you use your laptop for? And then students used the same modelled questions to talk with partners. Ms. Sen wrote all of their answers on the board. Finally, she instructed students to imagine that they were shoppers looking for new computers, and then asked them to talk in pairs about features of the computers they were looking for. The class ended earlier than scheduled time.

\section{Lesson two}

In this lesson, Ms. Sen focused on two textbook-based listening sections. For each section, she followed a three-stage teaching procedure: pre-listening, while-listening, and postlistening.

The first listening section has four talks in which each speaker talks about his/her afterschool activities. To begin, Ms. Sen instructed students to discuss the lesson topic Study after school, and a list of statements in the textbook-based warm-up activity. Then, she had students listen to the talks three times, take notes about what they heard, and do the listening activities that followed. For post-listening activities, Ms. Sen chose some phrases (e.g., twice a week) from the conversations and had students practice pronunciation using the phrases. In the post-listening activity, students used their notes to talk about what they heard. After that, students talked about their own after-school activities.

The second listening section included four conversations in which parents talk to their children about after-school lessons (i.e., cooking, language, painting, and sports). Prior to listening, Ms. Sen used the textbook-based activity to have students order the pictures. She then taught new words and had students listen to the talks. During students' listening, she usually stopped the recording to give additional information and explain some vocabulary items in each of the talks. 
After students finished listening to the first conversation, Ms. Sen mentioned that students in Vietnam are luckier than students in America because the former do not usually work part time and thus have more time for study while the latter usually have part time jobs. While students were listening to the second conversation, Ms. Sen paused the recording and explained some points in the conversation. For example, she explained that the word "hon" that the parents used in the conversation to call their children meant honey; and honey is a word of endearment used by native speakers in real life. Ms. Sen focused on the phrase "come on" from the listening and gave an example of when people in Britain usually say it. She then distinguished "soccer" from "football". For the third conversation, Ms. Sen showed students the difference in the pronunciation of "portrait" between AE and BE. After students finished listening to the fourth conversation, she presented words for addressing one's mother in English ("mother", "mom", and "mum"). She compared "má" (mother) in Vietnamese with "mom"/ "mum" in English. The lesson ended at this point.

\section{Lesson three}

Similar to the above lesson, Ms. Sen focused on the two textbook-based listening sections in this final lesson. The first listening section included three listening activities which were based on a conversation between Takako, a Japanese high school student whose family moved to the USA, and a school officer talking about a weekend Japanese school in the USA that Takako was interested in taking. The first listening activity asked students to fill in a passage with missing information. The second activity asked students to respond to six true or false statements. The third activity asked students to number the phrases in the order they were spoken.

Ms. Sen began the lesson by asking students to do the before-you-listen activity in the textbook, matching the times with how they are said in English. For example, "1:30" matched "half past one". Ms. Sen reviewed ways of saying the time in English and quickly compared with Vietnamese ways. Students then talked about what they did at what time the previous day using the simple past tense.

Next, Ms. Sen said: "Now we are going to listen about a Japanese school. Before, listening, I would like to tell you about Japanese people." She mentioned that when she was studying in the USA years ago, she knew that many Japanese people there attended Japanese 
weekend school to maintain their mother tongue while living in a foreign country. She then asked students to think about whether Vietnamese people were also aware of maintaining their own language overseas like the Japanese did. After eliciting answers from students, she asked them to predict what they were going to listen to. She asked them to share things they knew about school in Japan and compare with schools in Vietnam. She noted on the board that schools in Vietnam start at 7 am and that students go home for lunch and a short nap or rest, while Japanese schools start at 9 am and students stay at school without taking a short nap. She mentioned that the students' habit of taking a short nap at noon would be a disadvantage in the future if they worked for foreign companies where people only have a lunch break. At this point, she had students listen to the conversation between Takako and the school officer and complete the three listening activities. While students were listening, Ms. Sen explained that math is AE spelling and maths is BE spelling.

Next, Ms. Sen had students practice speaking. She put them in pairs (one took the role of a Japanese student and the other a Vietnamese student) to ask one another about their schools. I noted that students managed to do this task without difficulty and that many of them looked comfortable talking in English. While students were practicing, Ms. Sen visited pairs and joined some parts of their speaking. After that, she let students listen to the conversation and do the true/false activity on page 14 of the textbook.

After that, Ms. Sen asked students to order the phrases as they were spoken. She gave some explanations based on the lesson's title, Could you say that again please?. She explained that in American culture, speakers ask this question if they want other people to repeat the whole sentence not a focused part of sentence; therefore, if students hear such question in communication in English, they are supposed to repeat the whole sentence. She said:

“Trong văn hóa Mỹ, nếu mà các em nói Could you please say that again thì người ta lặp lại hết cả câu đó tại vì người ta đâu có biết các em hỏi chỗ nào. Còn nếu mình chỉ hỏi một phần trong câu hoặc một từ nào trong câu, thì các em phải dùng focused repetition."

(In American culture, if you say Could you please say that again, people will repeat the whole sentence because they do not know which part of the sentence you ask for repetition. If you only want to ask for repeating one part of the sentence or one certain word, you must use focused repetition strategy). 
Ms. Sen continued to explain that to ask for focused repetition only, English speakers used other strategies such as mentioning the unclear words or saying excuse me before the unclear words, both with a raising tone at the end. Therefore, she told students to add the word sorry before the repeated words to show politeness when responding. She made this clear to students that this was the strategy that native speakers of English used to respond politely to someone's asking for focused repetition. She further explained that sorry in such situations does not mean an apology. She demonstrated this by showing two different situations: one in which sorry means an apology and the other means politeness. She gave some more examples of asking for focused repetition.

In the second listening section, students listened to people asking and responding to focused repetition. This activity focused on minimal pairs such as plays and place, or eyes and ice. Ms. Sen asked students to listen and circle the correct words said by the speakers. She checked their answers and reviewed pronunciation of pairs of words. Finally, she ended the lesson by reminding students about the use of communication strategies she had explained earlier in the lesson.

\section{Summary of observation data}

In Ms. Sen's lessons, she focused on teaching the textbook-based listening activities. Each of her lessons unfolded with three main parts which were pre-listening, while-listening and post-listening. Her first lesson included speaking activities which involved students repeating the teacher's modelled questions to talk about the lesson topic. Her second lesson involved leading a discussion and vocabulary presentation as pre-listening activities. During listening, she distinguished AE from BE pronunciations, explained words' meanings (e.g., hon means honey) and the contexts in which words are used, and compared language (e.g., mom in English and má (mother) in Vietnamese). Similar to the second lesson, she explicitly taught cultural facts and new words before and during listening activities in the last lesson. Also, she compared language (e.g., ways of saying time) and cultural facts (school time in Vietnam and Japan) and explained communication strategies. The opportunities for teaching culture in her three lessons prior to the first workshop are summarised in Table 12: 
Table 12. Culture teaching in Ms. Sen's Phase One lessons

\begin{tabular}{|c|c|c|}
\hline Lessons & Kind of actions & Opportunities \\
\hline One & - Missing opportunities to address culture & None \\
\hline \multirow[t]{5}{*}{ Two } & $\begin{array}{l}\text { - Comparing information about students' taking part-time jobs while at } \\
\text { university }\end{array}$ & 1 \\
\hline & - Distinguishing vocabulary (i.e., football vs. soccer) & 1 \\
\hline & - Explaining context in which words are said (i.e., come on, hon) & 1 \\
\hline & $\begin{array}{l}\text { - Comparing words for expressing mother in English and Vietnamese said } \\
\text { (i.e., mom vs. má (mother)) }\end{array}$ & 1 \\
\hline & - Distinguishing AE and BE pronunciations (i.e., portrait) & 1 \\
\hline \multirow[t]{4}{*}{ Three } & $\begin{array}{l}\text { - Asking students to compare how they say time in English and Vietnamese } \\
\text { - Telling about how Japanese people maintain their language while in living } \\
\text { overseas }\end{array}$ & $\begin{array}{l}1 \\
1\end{array}$ \\
\hline & - Asking students to compare school time in Japan and Vietnam & 1 \\
\hline & - Distinguishing AE and BE spellings (i.e., math and maths) & 1 \\
\hline & $\begin{array}{l}\text { - Explaining communication strategies (i.e., when and how to ask for } \\
\text { repetition) }\end{array}$ & 1 \\
\hline Total & & 10 \\
\hline
\end{tabular}

Table 12 shows that in two of the three lessons, Ms. Sen created quite a few opportunities for teaching culture based on the culture content and specific words in the listening activities. These opportunities focused on providing cultural information, distinguishing $A E$ from BE pronunciations, and comparing cultural information and language. In the first lesson, she missed creating opportunities into the lesson topic i.e., computer. For instance, she could have created opportunities for students to compare how people in different places buy and sell computers.

\subsubsection{Interview data}

Analysis of Ms. Sen's pre-interview data identified her views of culture, and her beliefs about teaching and learning culture. The content analysis of this interview data revealed six main themes, as follows:

a. View of culture

b. Value of culture in language learning 

c. The roles of teachers
d. Constraints for teaching culture
e. Attitudes towards integrating culture
f. The amount of teaching culture in Ms. Sen's observed lessons

Each of these themes is discussed below:

\section{a. View of culture}

During the pre-interviews with the three teachers, I deliberately avoided using technical terms such as culture until the teachers mentioned it. I did this to create a natural conversation between the interviewee and researcher. On this topic of how teachers conceptualise culture, there were two strands to Ms. Sen's responses, which are reported as follows:

First, Ms. Sen viewed culture as the ways people do their activities or behave. She viewed that people's lifestyles distinguish people from one country from other countries. She quoted the definition "culture is the software of the mind":

\footnotetext{
"Cái định nghĩa mà cô thích đó là: "Culture is the software of the mind". Software là ... cái phần mềm nó chỉ có thể dùng hiệu quả cho một việc gì thôi. Chứ không thể dùng hết trong tất cả mọi trường hợp.... Cô dùng phần mềm Vietnamese software là gì, là ăn như thế nào, chào như thế nào, mặc như thế nào để cho người ta biết mình là người Việt." 1

(The definition I like best is Culture is the software of the mind. Software is the soft part which is effectively used for only one thing, not for all of cases. I used Vietnamese software...to mean how you (Vietnamese) eat, how you greet, how you wear clothes so that people can know you are Vietnamese).
}

Secondly, she maintained that cultural knowledge about a country is not accumulated automatically but it needs to be learnt to be acquired. She said:

“Có những cái không phải là mình sinh ra là mình biết về văn hóa mặc dù mình sinh ra và sống trong văn hóa đó. Cho nên văn hóa là phải học và phải học cả đời.”

(There are things about our own culture we don't know although we were born and lived in that culture. Thus, culture needs to be learnt and learnt for whole life).

\footnotetext{
${ }^{1}$ English translations are provided for Vietnamese interview responses.
} 
Ms. Sen's point of view above embraces three main points. First, culture is the outside surroundings in which one lives. This shows her static view of culture. Second, one should not take it for granted that he/she can automatically understand his /her own culture. Finally, learning about culture is necessary in one's life.

\section{b. Value of culture in language learning}

Ms. Sen believed that teaching culture is important for teachers and students. When asked about the role of culture in English learning, she said:

“Cô nghĩ là văn hoá rất quan trọng đối với cả người dạy và người học bởi vì học sinh sẽ hiểu hơn về cái ngôn ngữ mà họ dùng."

(I think culture is very important for both teachers and students because students will understand more about the language they use).

Ms. Sen spoke at length about the benefits of addressing culture in English classes. First, she elaborated that her cultural teaching aimed to foster students' learning motivation and cross-cultural understanding in several ways. Specifically, it was aimed to broaden students' world view, awareness about the outside world, awareness about differences, and their sense of sympathy about others. Its final result is that students become more sensible. Early in the pre-interview, she commented:

"Cô khai thác cho học sinh hiểu hơn cái văn hóa của mình và cái văn hóa của cái ngôn ngữ đang học. Qua đó cũng mang lại nhiều cái lợi ích cho học sinh như là hiểu hơn về thế giới. Nó có thể có một cái outlook khác hơn là chỉ có biết mình. Như thể là cũng để motivate nó hơn, để cho nó nghĩ đến tha nhân nữa hơn là chỉ nghĩ đến mình, không coi mình là số một. Cho nên cô cũng nhắc tới".

(I included cultural content for students to understand further about the culture of their own and of the target language they are learning. Through this, students get benefits such as better understanding about the world, a new and open worldview which is not restricted to thinking for their own sake This is to motivate students more and make them think more for others and not consider themselves number one. Thus, I mentioned culture).

The extract reveals Ms. Sen's belief that teaching students to understand one's own culture and the culture of other people is important for developing students' cross-cultural perspectives, cultural sensitivity, and learning motivations. This was also the reason motivating Ms. Sen to integrate culture in her teaching. This shows that Ms. Sen valued self- 
reflections in teaching and learning of culture, which is important for developing an intercultural orientation in classes.

Another advantage Ms. Sen speculated was that integrating culture develops students' language and cultural understanding simultaneously. She elaborated:

\footnotetext{
“Nếu giáo viên hiểu rõ như vậy thì đưa vào tình huống học sinh sử dụng...có thể hiểu được văn hóa mà vẫn sử dụng ngôn ngữ... để cho học sinh nói và ... hiểu sự khác biệt thì cũng đã là tập trung vô listening speaking rồi chứ đâu có ignore phần listening speaking."

(If teachers are clearly aware of the importance of teaching culture, just go ahead to integrate it into situations for students to learn...possibly students can both understand culture and use language...for students to talk about and discover cultural differences. This means we focus on listening speaking already, not ignore listening and speaking skills).
}

The above extract indicates Ms. Sen's belief that it is possible for students to develop listening and speaking skills alongside discovering culture by inserting cultural content into speaking and listening activities.

Additionally, Ms. Sen believed that teaching cultural comparisons helps students to understand other speakers and to be understood better while in communication. During watching the video replay for the first observed lesson, Ms. Sen insisted that she concentrated on cultural differences. The following extract shows her view about the potential for culture in her lesson clearly:

R: Ngay lúc đó mình có thể kết hợp gì để dạy văn hóa không?

Ms. Sen: ... Cô chỉ focus vô cái gì diferences thôi. Cái gì giống cô không dạy. Lý do nó không có hinder comprehension.

(R: At that time, could we integrate something to address culture?

Ms. Sen ...I only focus on differences. I don't teach what is similar. The reason is that similarities do not hinder comprehension).

By focusing on cultural differences, she was cross-culturally oriented. To support her point above, she gave an example of how she may create opportunities for cross-cultural comparisons: 
..." Cô làm cái so sánh... cho hai cái cột ra rồi một bên có sẵn thông tin rồi học sinh ngồi có thể làm pair work đến group work coi cái điểm khác biệt đó là cái gì, cái nào giống cái nào khác. Đến cái bước khó hơn là nói giống/khác như thế nào."

(...I have students compare... make two columns, one column contains cultural information. Students sit maybe in pairs, then in groups to consider what the difference is about, whịch is different, which is similar. Then to the next more difficult step, explaining how it is similar/different).

In the above extract, Ms. Sen said that she would guide students to compare culture from less to more difficult, i.e., from pointing out differences to explaining differences. This reveals Ms. Sen's experience in creating opportunities for students to learn in terms of culture.

In short, according to Ms. Sen, cultural learning can occur alongside language learning; and the essence of teaching culture is that it enhances students to become more open in life and more effective in communication.

\section{c. Roles of teachers}

Ms. Sen mentioned the roles of teachers when asked about the role of culture in EFL classes. She considered teachers to be crucial in teaching culture in various ways.

First, Ms. Sen emphasized teachers' awareness of addressing culture and their cultural knowledge. She maintained that it is this awareness and cultural knowledge that orients teachers towards choosing to focus on language or on a cultural dimension as the textbook does not usually indicate a clear focus on culture. This point is shown below:

“Nhiều khi giáo viên không nghĩ ra như vậy nên không có dạy cái điểm đó bởi vì người ta nghĩ cái focus của bài là vô speaking listening chứ không phải vô culture.

[...] Mà nếu giáo viên hiểu rõ như vậy thì đưa vào tình huống học sinh sử dụng.

[...] Nhưng mà nó đòi hỏi giáo viên phải có kiến thức về hai ngôn ngữ".

(Many times, because teachers don't realize such importance, they skip teaching cultural point. They think the focus is listening and speaking not culture.

[...]Teachers, if they realise the importance of teaching culture, they will integrate culture into situations for students to use it.

[...] But this requires teachers to have knowledge about the two languages). 
It is clear that, in Ms. Sen's opinion, teachers' realisation of the importance of teaching culture, and their knowledge of cultures and languages helped them to recognise what cultural elements to teach and how to create opportunities to teach them in each lesson.

Second, suggesting how teachers can create cultural learning opportunities in classes, Ms. Sen emphasized teachers' cultural experience and their ability to make use of such experience. She added:

“Nhưng đối với người không có đi nước ngoài, thì ..có thể dạy văn hóa được. Trong một nước nhưng khác vùng miền với nhau thì cũng thể hiện được nét văn hóa ở một số điểm nào đó. Hoặc chúng ta có phải mời, phỏng vấn những người đã đi học ở nước ngoài lâu,... hoặc mình có thể tận dụng các giáo viên hay chuyên gia nước ngoài ngay trường ngay tỉnh của mình".

(But for teachers who have not been to foreign countries, it is ... possible to teach culture. In the same nation, there always exist different regions that potentially represent certain cultural diversities. Or we have to invite and interview teachers who had long time studying overseas...or we can make use of foreign teachers or experts in our university and provinces).

As indicated from her answer, Ms. Sen believed that teachers' exposure to foreign culture is an advantage but not the only resource for teachers to rely on to teach culture. The important point she made is that teachers can make use of local and national cultural diversity which is present in classes. At this point, she was close to the value of an intercultural stance.

Finally, Ms. Sen considered teachers' self-exploratory learning to be important. From her perspective, teachers getting well-prepared for the lessons they are going to teach is an important step in helping students to learn culture. She mentioned teachers' self-learning:

“Giáo viên phải chuẩn bị trước ... Do đó là chúng ta khám phá từng ngày từng giờ. Đặc biệt là mình đi dạy từng cái buổi dạy là mình khám phá những điều thú vị về văn hóa của nước bạn, của cái nước trong giáo trình cũng như cái văn hóa của chính minh."

(Teachers have to prepare lessons in advance... therefore, we have to explore culture every day, every hour. Especially in every lesson, we explore interesting things about the target culture, the culture of the country represented in the textbook as well as about our own culture).

In sum, Ms. Sen's perception of teachers' roles revealed the four aspects in which teachers were generally considered important: teachers' cultural teaching awareness, cultural 
experience, ability to create learning opportunities for students, and ability to recognise and explore culture while planning lessons.

\section{d. Constraints for teaching culture}

Ms. Sen identified two types of constraints. First, she acknowledged that teachers' busy workloads reduced the amount of time that they can spend on lesson preparation. She gave example of her teaching hours per semester below:

“Khối lượng công việc quá nhiều, không có thời gian để chuẩn bị...7 buổi, một buổi 3 tiết đó em tính

đi. Thứ 7, chủ nhật, một ngày 8 tiết."

(So much workload, no time to prepare...seven classes per week at university, each class was three periods as you can count it, Saturday and Sunday, eight periods per day).

Second, she noted that teachers had difficulty in guiding students for effective intercultural communication due to students' experience with their first language and culture. This point was evident when she explained why cultural comparisons are important. She said:

"Nhắc học sinh là những câu như "How old are you? What is your salary? Why dont' you get married?" thì không được hỏi. Nhưng cũng khó cho học sinh bởi vì người ta hỏi ... những câu này là thể hiện sự quan tâm trong văn hóa Việt cho nên họ vẫn hỏi khi có người nước ngoài vô lớp. Cũng không dễ để dạy cho học sinh thay đổi ...cần có thời gian lắm."

(I reminded students not to ask questions such as “How old are you? What is your salary? Why don't you get married? But this is also hard for them because in our Vietnamese culture, people ask these questions to mean they care. Students keep asking foreigners these topics when they visit our class. Not easy to teach them to change...needs much time).

In the above response, Ms. Sen noted that students often apply cultural assumptions from Vietnamese to communication in English and that it can be a challenge to change these assumptions. From an intercultural perspective, these differences provide rich intercultural learning opportunities, but Ms. Sen's comment suggests she did not see the cultural differences in question in this light.

\section{e. Ms. Sen's attitudes towards integrating culture}

Ms. Sen showed positive attitudes towards integrating culture. She expressed her interest:

R: How much do you like teaching culture in your class? 
Ms. Sen: Uhm. How much? (She raised tone to emphasize). To me, very much.

R: How much are you willing to create opportunities for teaching cultural dimensions in your class?

Ms. Sen: Yes... I think it will be fun. Integrating cultural content will make a difference in class because the sequence of textbook-based activities looks boring. If we integrate cultural points, students talk more, understand more about culture. It definitely becomes more interesting and much better.

Ms. Sen believed that integrating culture adds fun to class and students' learning motivation.

\section{f. The amount of culture teaching in Ms. Sen's observed lessons}

Ms. Sen perceived that the amount of teaching culture in her observed lessons was insufficient. When asked about the amount of culture in the observed lessons, Ms. Sen commented:

“Not much... Những bài vừa rồi thì cô thấy cô dạy không có được nhiều về culture."

(Not much... in the last lessons, I knew I hadn't taught much about culture).

In summary, Ms. Sen viewed culture as specific ways of life which distinguish people of different countries. Through this prism, she highlighted the importance of teaching a cultural dimension in developing students' worldviews and sympathy, as well as the multiple roles that teachers play in this process. As Ms. Sen perceived, factors such as teachers' heavy teaching loads and students' cultural assumptions from their first language/culture were constraints for teaching students to communicate effectively with native English speakers. She expressed high interest in teaching culture although she acknowledged that the amount of culture addressed in her lessons was limited.

\subsubsection{Discussion}

Overall, Ms. Sen's teaching practices in Phase One closely followed the textbook-based sequence and focused on aspects of listening and speaking skills for each lesson. She also addressed cultural aspects of language use as they arose in the lesson input.

In terms of practices, Ms. Sen's teaching displayed a number of characteristics in terms of teaching culture. First, she created various opportunities and strategies for teaching cultural content that arose from the lesson input, despite her culturally homogeneous class. She taught culture through teaching language, for example, she explained differences between 
$\mathrm{AE}$ and $\mathrm{BE}$ spellings and pronunciations, and language use aspect. She talked about the cultural content embedded in the input and encouraged students' comparing and relating cultural information between the target culture and their own culture (in the final lesson). She included cultural comparisons between Vietnam and Japan related to school life instead of always focusing on cultural information about the USA. She integrated these incidents explicitly drawing on her cultural knowledge and lived experience of living in the USA during her Master's study. These incidents helped to enrich students' cultural learning in addition to finishing the textbook-based content and activities.

Second, she valued lived experience and paid attention to equipping students with skills and knowledge which she believed would be useful for their participation in future work. For example, her mentioning of differences between time frames in schools in Vietnam and in Japan may raise students' awareness of differences between school life in the two countries. With her explanations to students about the cultural content embedded in the textbook-based conversations, to some extent, she could enrich her lessons with cultural knowledge.

However, Ms. Sen's teaching practices have revealed room greater engagement with culture. First, her main emphasis was on native-like linguistic accuracy and cultural norms. Distinguishing AE from BE word spellings, pronunciation, and discussing cultural information about the USA implies the belief that understanding native-like norms is important and that she focused on the most powerful standardised form of language. Second, she tended to focus on transmitting cultural facts rather than encouraging students to construct their own cultural understandings and perspective. Third, her little attention to culture in the first lesson reveals that she did not regularly integrate culture. This suggests that her teaching of culture is dependent on the textbook-based lessons' topics.

In terms of beliefs about teaching and learning culture, Ms. Sen's reflections in the interview showed two points of positive alignment with an intercultural stance on language teaching. First, she recognised the value of engaging with cultural content. For example, she pointed out that (a) teaching and learning culture develops students' worldviews, sympathy and tolerance; (b) one's own culture and other people's cultures are important for developing students' intercultural perspectives and sensitivity; and (c) culture and language can be integrated alongside each other in students' speaking practices. She especially emphasized 
cultural comparisons and the ability to relate target culture to one's own personal cultural perspectives. These nuances of Ms. Sen's views about culture align with intercultural teaching values.

Second, she identified teacher roles that are congruent with an intercultural stance for teaching culture. The roles she proposed included teachers' awareness of teaching culture, ability to create opportunities for students to learn culture, and the ability to self-explore cultural content. These perceived roles showed that Ms. Sen did not show doubt due to not being a native English-speaking teacher regarding teaching culture to students.

However, Ms. Sen's views and beliefs about culture show limitations. First, she viewed culture as systems of specific ways of lifestyles which distinguished people between different countries. Thus, she put more weight on transmitting cultural facts about native English-speaking societies such as America and Britain and was dependent on the topics of textbook-based lessons. Second, Ms. Sen believed that cultural differences between students' first language/culture and the target language/culture are sources of constraints for students' cultural learning instead of useful resources for developing students' awareness of how one's own assumptions, beliefs and behaviour are culturally shaped.

It is apparent that there is a tension between her somewhat static or fixed conceptualisation of culture and her wish to help students develop intercultural competences. Her view of culture reveals a modernist lens which, according to Kramsch (2006, 2013), reduces culture to Big C Culture and small c culture. This was evident when she explained that culture is the software of the mind which is effectively used for people in one country. In her view, if someone mentions Vietnamese software, that person means how Vietnamese people eat, greet, and dress. Her view also coincides with culture as societal norms pointed out in Newton et al. (2010). A criticism of the societal norms in Newton et al. (2010, p. 44) is that this approach "too easily presents learners with stereotypes of the target culture and individuals within that culture."

That is to say that Ms. Sen equated culture to specific elements of culture. She saw culture as static etiquettes rather than as a process. As Liddicoat (2017) maintains, a static view of culture does not emphasize learning outcomes beyond native-like-standard proficiency. I argue that Ms. Sen's static view of culture would limit her approach to culture regarding 
helping her students to broaden their worldviews, sympathy and tolerance as she wished. This contradiction between her views and her aim suggests that an intercultural perspective could enhance her approach to culture.

To conclude, the following points can be made about her case. First, Ms. Sen's teaching practice created quite a few opportunities for addressing culture, although the opportunities created revealed a traditional knowledge transmission approach to culture (with ten cultural teaching incidents across the three lessons shown in Table 12). Second, she demonstrated high interest in integrating culture into her teaching. Her beliefs about teaching and learning culture showed both strengths and limitations. Ms. Sen's interest in teaching culture is an affordance for her to move forwards to an intercultural stance. However, her closeness to an intercultural stance was limited by her restricted view of culture as fixed national attributes and by her unfamiliarity with how to approach cultural differences as a starting point for intercultural language learning.

\subsubsection{Case two: Mr. Huy}

Mr. Huy completed his Master's degree in Teaching English (M.Ed) at the current university in 2008. By 2017, he had nineteen years of teaching experience. He often teaches skillbased and communication courses for various levels at his university. He is, moreover, in charge of mentoring both foreign English teachers at his school and the students' apprenticeship field trips every semester as well.

\subsubsection{Observation data}

Mr. Huy's class had forty students and was scheduled with two periods on Monday mornings (9:50 am to 11:30 am), three periods on Wednesday afternoons (1:30 pm to 4:10 pm), and two periods on Friday mornings (9:50 am to 11:30 am). Observations of his teaching were in his Wednesday classes in D1 building.

\section{Lesson one}

In this lesson, Mr. Huy focused on two textbook-based listening sections. He followed the pre-while-post teaching structure.

His pre-listening activities included teaching new words followed by a teacher-student discussion activity. First, to begin the lesson, Mr. Huy explained and modelled pronunciation 
of new words. He then had students ask and answer questions with each other using the textbook-based discussion activity. Specifically, students stated their opinion and explained if they agree or disagree with the statements in the discussion activity. Finally, he asked students to talk about their habits of using computers. He invited some students to talk in front of the class before the while-listening stage.

The first listening task had four talks. During the while-listening stage, students listened to the recordings and did the textbook's listening activities. Mr. Huy asked them to take notes and pay attention to the speakers' pronunciation in each of the talks. Mr. Huy checked students' answers and explained word forms and the intonation used in each talk. He explained that English speakers he met in Vietnam usually added the phrase I tell you at the end as in "the coffee is great, I tell you". Following this, students listened to the second listening section. They took notes and Mr. Huy corrected their answers.

For post-listening activities, Mr. Huy used roleplays for speaking practice. Students in pairs played the roles of a shop assistant and a customer buying and selling computers. After a few minutes, three pairs performed their conversations in front of the class. Finally, Mr. Huy reminded students that they had been involved in two main activities of the lesson, which were talking about their own habits of using computers and buying/selling computers at computer shops. At this point, the lesson ended.

\section{Lesson two}

Similar to the first lesson, in this lesson Mr. Huy focused on the two listening sections and followed the pre-while-post structure in lesson two. First, he reviewed vocabulary and had students make predictions about after-school activities in English-speaking countries, such as the USA, as pre-listening activities.

After that, Mr. Huy had students work on the first listening section. They listened to the recording in which four speakers talked about their after-school activities. Mr. Huy corrected students' answers and explained differences in $\mathrm{AE}$ and $\mathrm{BE}$ pronunciations of ballet (AE /bæ'leI/, BE /'bæles/). Mr. Huy then explained to students that foreign volunteers, whom he worked with in Vietnam, said that in their countries they often dance but do not sing karaoke at parties. He pointed out that in Vietnam, people often sing karaoke but do not dance at parties. While students were listening to the last talk, Mr. Huy paused the CD 
player and explained the phrase national exam. He asked students some questions about the Vietnamese national exam. By doing so, he showed some awareness that can be developed into an intercultural stance.

At the end of the first listening section, Mr. Huy asked students to talk in pairs about each other's after-school activities. He went around monitoring students' speaking practice. He joined a few pairs. I observed that students were doing a good job and that some pairs finished earlier than the rest of the class.

Next, Mr. Huy had students listen to the second listening section which includes conversations between parents and their children. Following this, Mr. Huy asked students to look at a list of incomplete conditional sentences in the textbook lesson and think of possible ways to complete them before they listened to the language focus listening activity. For example, "if I have a chance to go abroad for a year, then ..." He then got students to listen to the language focus activity twice and checked correct answers. Finally, students moved around to talk with new partners about their after-school activities. The class ended after students finished their speaking practices.

\section{Lesson three}

In this lesson, Mr. Huy mainly had students practice speaking about their after-school activities and taught the textbook-based listening section.

At the beginning of the lesson, Mr. Huy asked students to talk about their after-school activities using the prompts as follows:

Describe one activity you often do after school. You should say:

- How often you do it

- When you started doing it

- Why you liked it.

You should talk for two minutes.

Mr. Huy asked students to change partners during their speaking practice. By the end of this activity, three students performed their talks in front of the class. 
After that, Mr. Huy began to teach the listening section. First, he asked the class "What do you say when you want someone to repeat?" He played the CD and had students listen to the first section. He paused and taught new words (meanings and pronunciation) and explained the ways that people in the listening activity asked for repetition. Additionally, he told students that the annual school year in America is 40 weeks lasting from April this year to March the following year but in Vietnam it is from September to May. By explaining this, he focused on cross-cultural differences but in this case, he was not accurate because the school year in the USA starts around end of August to September and ends sometimes in May or June. Students gave and compared answers of the listening activity with friends. He had students ask and answer questions with each other about their school courses and schedules. To end the lesson, he invited some students to talk in front of the class.

\section{Summary of observation data}

To summarise, each of Mr. Huy's lessons focused on the textbook-based listening activities. Each of his lessons involved pre-listening, while-listening, and post-listening activities. His pre-listening activities involved vocabulary review or prediction activities. The whilelistening activities focused on having students complete the listening activities. During this, Mr. Huy provided cultural information, distinguished AE from BE pronunciations, and shared his lived experience with students. Table 13 summarises these opportunities in his lessons:

Table 13. Culture teaching in Mr. Huy's Phase One lessons

\begin{tabular}{llc}
\hline Lessons & \multicolumn{1}{c}{ Kind of actions } & Opportunities \\
\hline One & $\bullet$ Explaining the phrase / tell you & 1 \\
\hline Two & $\bullet$ Sharing experience about activities people do at parties & 1 \\
\hline & $\bullet$ Asking students about the Vietnamese national exam & 1 \\
& $\bullet$ Telling students about school terms in Vietnam and in America & 1 \\
\hline Three & & 1 \\
\hline Total & & 5 \\
\hline
\end{tabular}


As can be seen in the Table 13, there was limited amount of culture addressed in the first and third lessons.

\subsubsection{Interview data}

Analysis of Mr. Huy's pre-interview data identified his view of culture and his beliefs about teaching and learning culture. The content analysis of his interview data revealed five main themes as follows:
a. View of culture
b. Priority in language classes
c. Constraints for teaching culture
d. Mr. Huy's attitudes toward integrating culture
e. The amount of teaching culture in Mr. Huy's observed lessons

The following section details each of these themes.

\section{a. View of culture}

In the data, Mr. Huy conceptualised culture as ways of people's speaking, behaving and thinking. When asked about how he defined culture, he stated:

"Culture is the way of speaking such as uses of tone, voice, intonation, being straight or not, being patient or not, the knowledge about behaviours including gestures, events, activities, speech, and thoughts about certain things".

Mr. Huy viewed culture as the outer circle which contains language inside it. He said:

"Culture includes language. Language lies inside the overall term culture. Language includes grammar, and sounds, etc."

He did not explain his view further but mentioned that he learnt that language and culture are linked together from one English teaching workshop he attended a few years ago.

Mr. Huy viewed culture as components which include language, language use, and knowledge about people's ways of doing, behaving, and thinking. His definition of culture mentioned culture as the "way of speaking" and "the knowledge about".

\section{b. Priority in language classes}


This theme is presented according to two sub-themes: (1) focuses in language class and (2) the status of culture in class.

- Focuses in language class

Mr. Huy privileged language over culture in his language courses. He spoke about the status of language in his class:

"When I come to language class, I think the primary goal is to improve language, improve competence, not to improve the understanding about culture. So my main focus is to improve the language, the (language) competence."

It is clear from the above extract that language goals are prioritised over culture. This was reconfirmed when he talked about his focuses in class:

R: What did you focus on in your class?

Mr. Huy: Tại lớp này là lớp ngôn ngữ nên thầy quan trọng khả năng nói của sinh viên. Phần nghe, phần nói, thầy không bao giờ quên fluency và pronunciation trong lớp. Pronunciation cũng là một phần trong mảng ngôn ngữ."

R: Ngoài ra, thầy chú trọng thêm điều gì?

Mr. Huy: Thầy khuyến khích khả năng học ngoài lớp, lên mạng xem cái video clips, hướng cho tự học, tự nghe, khuyến khích gặp gỡ người nước ngoài...để tăng khả năng tự tin giao tiếp"

(Mr. Huy: because it is a language class, I consider speaking skill important. Listening, speaking, I never forget fluency and pronunciation in class. Pronunciation is an important part of language).

R: Apart from that, what else did you pay attention to?

Mr. Huy: I encouraged the ability to self-study outside class, watching online clips, guided self-study, self listening, encouraged them to meet foreigners...to increase their confidence in communication).

As can be seen, the focuses in Mr. Huy's class involved fostering aspects of listening and speaking skills and after-class self-study ability. There was an absence of focus on culture. Mr. Huy's reflection reveals that his teaching prioritised language goals and did not recognise culture. The status of culture in his lessons will be further explored next.

- The status of culture in class 
In the data, the teaching of culture was peripheral in several ways according to Mr. Huy's teaching reflection. Firstly, it was marginalised by the current curriculum. Mr. Huy stated that the existence of teaching culture in classes totally depends on teachers' interest since this dimension was neither compulsory nor assessed according to the curriculum. He said:

“Nếu không dạy về mảng văn hóa thì chắc cũng không ai nói gì vì người ta đặt nặng cái course có mục đích là improve listening speaking competence. Thêm được gì thì tốt hay không thêm người ta cũng không quan tâm. Đó không phải phần đánh giá, đó là tùy giáo viên.”

(If teachers do not teach cultural aspects, no one will complain because people heavily aim for improving listening speaking competence. Adding anything apart from language components is good but is not cared about. It is not assessed, and it depends on teachers).

Second, culture was marginalised in his classroom practices. Mr. Huy explained why he integrated culture into his lessons:

"Thầy nghĩ điểm khác biệt và gây hứng thú cho học trò, chỗ là mình giải thích chuyện đó, những cái experience đó mà mình đã kinh nghiệm qua. Cái đó mới là cái làm sinh động cho lớp, ...giúp cho học trò hiểu thêm và tự tin hơn."

(I think the difference is that teaching culture motivates students at the moment we explain our own real experience to them. This makes the class lively, ...helps them understand more and become more confident).

He added:

"Sometimes I explain about culture, just for students to understand and to know so that when they talk to foreigners they have knowledge, they understand differences between cultures; and I hope that they can speak well, become confident in that situation."

Mr. Huy's explanation above shows that culture was taught when he thought this teaching added to students' language learning, motivation, confidence in communication, and the classroom's positive atmosphere.

Third, if culture was taught, it was taught in an unprepared manner. Mr. Huy reported that he did not teach cultural content in a planned and principled manner. Instead, he based it on his teaching experience to teach culture. He reflected:

“Dạy lâu quá rồi thì làm theo kinh nghiệm chứ không phải lúc nào trong đầu cũng phải có principles... Thầy không take note. Trong bài của thầy, thầy cũng không take notes về dạy văn hóa chỗ nào. Lúc đó là do kinh nghiệm thôi, ...unprepared. mang tính kinh nghiệm...không prepare." 
(Teaching for many years, I based on experience instead of always having principles in mind...I didn't take any notes. In my lessons, I did not take any notes about any cultural aspects. Only based on my experience...unprepared, experience-based, ...unprepared).

Finally, Mr. Huy's explanation about why he shared his lived cultural experience was too focus on language goals. He explained:

“Dùng kinh nghiệm bên ngoài như một công cụ để phát triển kỹ năng nói chứ không dùng nó để dừng lại giải thích nhiều...vì cái goal là dạy ngôn ngữ."

(I used real-life experience as a tool to develop students' speaking skills not to provide more explanations ...because the goal is to teach language).

It was evident in Mr. Huy's beliefs that culture had a peripheral status in the curriculum, in teacher' classroom practices, and in the teacher's mind.

\section{c. Constraints for teaching culture}

When asked to explain his areas of teaching focus, Mr. Huy mentioned the current curriculum and teaching materials. He did not explicitly mention the constraints on teaching culture in the interview. However, analysis of Mr. Huy's opinion about the curriculum and teaching materials reveals that there were the two main constraints for teaching culture in the current teaching context.

First, the curriculum did not emphasize culture. Mr. Huy maintained that it is compulsory for teachers to focus on language according to the curriculum. He said:

“Trong syllabus design, cái tên gọi là môn ngôn ngữ, kỹ năng ngôn ngữ Nghe và nói. Vậy thì improve competence nghe và nói. Kỹ năng nghe cần improve là về main ideas, details, supra mental features để nghe được meaning. Về nói thì improve accuracy, fluency, pronunciation để cuối cùng là nói hiệu quả".

(Its name in the syllabus design defines it as a language subject, listening and speaking language skills. Hence, it means to improve competence of listening and speaking. Listening skills are about listening for main ideas, details, supra-mental features so that students can hear the meaning. Improving speaking includes accuracy, fluency, and pronunciation to speak effectively by the end).

Second, teaching materials contained little cultural content. Mr. Huy mentioned the absence of cultural components in the current textbook and teaching manuals when asked to comment on teaching materials: 
“Rõ ràng thấy được đây là một cuốn luyện kỹ năng.... các phần của bài không có phần nào về văn hóa nhưng các bài trong sách này có sự đa dạng.

[...] Manual...thường cung cấp kiến thức thôi...Ví dụ giúp giải thích một cái term nào đó."

(Obviously, this is a skill-focused textbook...there was not any part about culture but it has various topics.

[...] Usually, manuals ... only provide knowledge...For example, it helps to explain a certain (cultural) term).

It was evident from Mr. Huy's comment that language-focused course materials seemed to align with the language-oriented curriculum on which Mr. Huy based his decision to focus on language goals.

\section{d. Mr. Huy's attitude toward integrating culture}

The data showed that Mr. Huy had a degree of unwillingness to integrate culture. When asked about his willingness to integrate culture in his classes, Mr. Huy commented that:

“Ờ...willing hay không willing.. thì tôi nghĩ là một phần trong công việc nhưng nó không phải là goal chính nên nó sẽ mờ nhạt hơn. Mình giải thích thêm để mình phụ trợ phát triển ngôn ngữ. Nếu thầy nghĩ nó phát triển về ngôn ngữ, về sự tự tin thì thầy sẽ làm."

(Uh.. Willing or not... I think teaching culture is a part of my work but it is not the primary goal so it becomes blurred. I integrated explanation about culture to support students' language development. If I think that culture helps develop students' language and confidence, I will teach it).

\section{e. The amount of culture in Mr. Huy's observed lessons}

Mr. Huy perceived that culture was addressed to a limited extent and in an unprepared manner in his observed lessons. When asked about how he evaluated his lessons in terms of culture teaching, he commented:

$$
\text { "Unprepared" ... and "not much." }
$$

It is worth analysing how Mr. Huy perceived his students' proficiency levels to understand whether or not the limited extent of culture in his lessons was due to students' limited English level. In the following excerpt, Mr. Huy perceived that his class had good English ability and confidence. 
“Level và confidence của lớp này ... là khá cao so với những lớp thầy đang dạy. Khi mình đưa ra các hoạt động, cảm nhận là sinh viên rất hào hứng, get involved. Trên cảm nhận ban đầu đó, thầy cũng không ngại khi dùng tiếng Anh nhiều trong lớp".

(The level of English and confidence of this class was rather higher than other classes I am teaching. When organising learning activities, I felt that students were very enthusiastic and involved. I did not hesitate to use much English in my class based on my first perception).

It is clear that the limited amount of teaching culture in Mr. Huy's class was not due to students' limited English level.

In short, Mr. Huy viewed culture as ways of speaking and behaviours. Through this prism, he prioritised language goals, paid little attention to culture and demonstrated uncertain willingness to integrate culture. In his teaching reflection, his lessons focused on improving students' language and confidence.

\subsubsection{Discussion}

Overall, Mr. Huy's teaching practices and stated perception reveal a priority of language over culture.

Within his EFL lessons which focused on addressing textbook-based listening and speaking practice, his culture teaching consisted of (1) sharing his lived experience with students to explain the way English speakers speak and do things, and (2) providing cultural information. First, he was willing to share his lived experience with students. In the first lesson, he explained that English speakers usually add the phrase I tell you at the end of their utterance in conversations. In the second lesson, he told students about differences in party activities between Vietnam and other English-speaking countries. He said that he learnt such knowledge from communication with English speakers who he has worked with. As mentioned in his profile, Mr. Huy was in charge of mentoring foreign teachers and organising for students' annual apprenticeship field trips in his department. To some extent, his sharing shows that he recognised cultural content embedded in specific lessons and valued life learning engagement in addressing it within a fixed curriculum and languagefocused teaching materials. This could be seen as evidence of an intercultural stance in language teaching. 
Second, the nuance of teaching of culture reveals a focus on cultural information transmission. There were two out of five opportunities in the lessons in which he addressed cultural information (i.e., he asked students about the Vietnamese national exam; and told them about school terms in Vietnam and in America). These opportunities were limited to transmitting and exchanging cultural facts without drawing students' attention to comparing or relating them in relation to their cultural perspectives.

In terms of his stated perception, Mr. Huy's view of culture and beliefs about teaching culture did not align with an intercultural perspective. First, his conceptualisation of culture as ways of speaking and behaviours reflects culture as small c culture. Although he mentioned in the interview that language and culture are related, he did not provide explanations. Second, Mr. Huy considered developing students' language skills the ultimate goal in his lessons. As he elaborated in the interview, Mr. Huy chose to discuss culture when he believed it was useful to enhance students' learning motivation and language skills. He also said that his in-class explanations about culture were spontaneous and based on his teaching experience. This reveals his priority of language over culture in language teaching, which is at variance with an intercultural stance. In Corbett's $(2003$, p. 2) words:

"One key goal of an intercultural approach remains language development and improvement; however, this goal is wedded to the equally important aim of intercultural understanding and mediation."

In the above quote, it becomes clear that an intercultural stance considers language improvement and intercultural competence equally important. Such variance suggests that an intercultural approach to culture could enhance the status of culture both in Mr. Huy's teaching practices and beliefs because this approach deals with students' linguistic and intercultural competencies alongside each other.

In summary, Mr. Huy's lessons showed that he prioritised language practice goal over intercultural exploration goal although there was a positive alignment with an intercultural stance when he used lived experience to address cultural content embedded in the lesson input. His static view of culture and language-oriented teaching beliefs indicate the congruence between his teaching practice and pedagogical perspectives. 


\subsubsection{Case three: Mr. Sang}

Mr. Sang obtained his M.Ed from Australia in 2009 and had nineteen years of teaching experience by at the time of data collection. His teaching courses usually involved reading and communication skills. He had just taught the current course Language skills $2 A$ for the first time when I observed his class. He had fewer weekly teaching hours than Ms. Sen and Mr. Huy because he also had an administration role at the time of data collection.

\subsubsection{Observation data}

Mr. Sang's weekly class was scheduled on Wednesday mornings for two periods (9:50 am to 11:30 am), Thursday mornings for three periods (8:50 am to 11:30 pm), and Friday mornings for two periods (9:50 am to 11:30 am). Observations of his teaching involved the Thursday and Friday teaching in D1 building.

\section{Lesson one}

In this lesson, Mr. Sang focused on teaching the two textbook-based listening sections. First, Mr. Sang introduced the lesson's topic, using computers. He elicited new words and ideas from students. He had students listen to the first listening section, which has four talks. Students took notes while listening and gave answers to the listening activity. Mr. Sang explained aspects of the listening talks. For example, he explained the book report activity which was mentioned by one speaker in one talk. He said that book report is a type of assignment or task that students in Australia and other English-speaking countries usually do for assessment at university.

After that, Mr. Sang explained the second listening section to students. He got students to listen to it. Students took notes and gave answers to the listening activities. Finally, Mr. Sang summarised the content of this listening section and ended the lesson.

\section{Lesson two}

Mr. Sang focused on teaching the two listening sections as in the first lesson. The teaching actions involved his pre-teaching vocabulary and modelling questions, students talking in pairs about the lesson topic, students listening for correct answers, and the teacher explaining difficult words in the talks. There were no incidents of addressing cultural content. 


\section{Lesson three}

Similar to the previous lessons, this lesson mainly focused on the two listening sections and repeated the above steps. There were two opportunities where Mr. Sang explained the content of the listening activity. First, he explained the phrases freak ...out (in the sentence they are almost totally freaking out). He told the class that freak ...out is an informal phrase used as slang in daily English conversations. Second, he explained Takeshita, tea ceremony, and flower arranging in Japanese culture. He told students that tea ceremony and flower arranging are typical cultural activities in Japan.

\section{Summary of classroom observations}

Generally, the focus in each of Mr. Sang's lessons was language skills, especially listening skills. He adopted a pre-while-post listening structure in his lessons although post- listening activities were sometimes missed. In addition to teaching listening and speaking skills, he explained cultural information in the textbook materials during the first and the third lessons which are summarised in Table 14:

Table 14. Culture teaching in Mr. Sang' s Phase One lessons

\begin{tabular}{lllc}
\hline Lessons & \multicolumn{1}{c}{ Kind of actions } & Opportunities \\
\hline One & $\bullet$ & $\begin{array}{l}\text { Explaining cultural information (e.g., book report activity } \\
\text { in Australian universities) }\end{array}$ & 1 \\
\hline Two & $\bullet$ & Missing opportunities to addressed culture & None \\
\hline Three & $\bullet$ & Telling cultural information (e.g., Japanese tea ceremony & 1 \\
& & and flower arranging) & \\
\cline { 2 - 4 } & $\bullet$ & Explaining slang (e.g., freak...out) & 3 \\
\hline Total & &
\end{tabular}

Table 14 shows that opportunities for culture were limited and focused on cultural information in Mr. Sang's observed lessons prior to the first workshop. 


\subsubsection{Interview data}

Analysis of Mr. Sang's pre-interview identified his view of culture and his beliefs about teaching and learning culture. The content analysis of the interview revealed the following seven themes:
a. View of culture
b. Value of culture in language learning
c. Priorities in language class
d. Roles of teachers
e. Constraints for teaching culture
f. Mr. Sang's attitudes towards integrating culture
g. The amount of teaching culture in Mr. Sang's observed lessons

Each of the themes is analysed below.

\section{a. View of culture}

From Mr. Sang's point of view, culture is context-shaped and related to language. When asked to define culture, he explained at length:

“Culture không có rộng đâu mà cũng không nên rộng, là ngữ cảnh người ta sử dụng tiếng Anh ở những khu vực bản xứ. Người ta sử dụngở ngữ cảnh nào thì mình dùng mới đúng chứ. Cái đó là cái người ta muốn biết và cái làm giáo viên muốn biết.

Cái vấn đề tưởng là ngữ pháp nhưng rốt cuộc người dùng là dùng trong trường hợp nào đây và khi dùng thì ngữ điệu như thế nào. Ngữ điệu đó có nói lên được cái gì hay không hay dùng cùng ngữ điệu như nhau. Tại sao trong môt câu dài mà người ta nhấn ở từ thứ hai ở cùng câu đó thì hàm ý khác, nhấn ở từ thứ cuối thì hàm ý khác.Cái chỗ use (emphasized voice) đó là cái chỗ ăn...ăn nhập với culture không tách ra. Hay ẩn dưới cái language use đó là culture chứ không là cái nào khác được. Cho nên không tách ra là vậy."

(Culture is not broad and does not need to be broad. It is the contexts in which native speakers use English in their country. We can only use English in a similar context as they use it. This is what people and teachers want to know.

Grammar seems to be the problem but eventually it does not. Native speakers use English in certain contexts and with certain kinds of intonation. Whether that intonation reveals something or not or with the same intonation all of the time... Why in the whole sentence people stress the second word to mean one meaning, the third word to mean other meaning, or the final word to mean other 
meanings. It's the language use (emphasized voice) that means culture cannot be apart from language. In other words, hidden behind language use is culture not something else that is not culture. So, they are not split up).

In the above excerpts, Mr. Sang emphasized several points. First, culture is about the context in which the target language is used by its native speakers. Second, discovering hidden contextual factors embedded in language use is crucial to understand meaning and culture, because context influences native speakers' language use (e.g., intonation, and stress patterns). Third, language learning means learning to use the target language in the same way that native speakers do.

\section{b. Value of culture in language learning}

Mr. Sang recognised the value of culture in various ways. First, he commented on the importance of culture in students' language development:

“...không có thể nào phát triển các kỹ năng ngôn ngữ ...mà bỏ qua các yếu tố về văn hóa. Cái này là do thầy đọc thầy biết [...]. Nếu muốn master được target language thì phải master được cái này càng nhiều càng tốt."

(From my reading I know that it is impossible to develop language skills if cultural components are ignored [...]. To master the target language, students have to master these components the more the better).

He added the necessity of teaching culture early:

“Không cần chờ tới năm cuối. Ngay từ năm nhất, tất cả hầu như các môn liên quan đến Tiếng Anh thì dạy được rồi."

(We) don't need to wait until the last year. Right at the beginning of their first year, teachers can teach cultural components in almost all English related courses).

It is evident in Mr. Sang's perception that culture is a crucial factor that should be integrated in language courses as soon as possible.

Second, Mr. Sang stated a number of benefits of teaching culture in English classes. First, he believed that inclusion of culture enhances language learning. This was implied in the following excerpt:

“Nếu anh là người học mà anh ở trong môi trường của văn hóa đó sẵn rồi, thì tốc độ anh đạt được ngôn ngữ đó sẽ nhanh hơn người cũng học như anh nhưng không ở môi trường đó. Điều này xác 
nhận là culture và language là không thể tách nhau. Cho nên nếu trong môi trường như hiện tại mình đang dạy thì mình phải đề cập càng nhiều càng tốt."

(As a learner, if you learn the target language in its cultural context, the speed for you to obtain that language will be faster than those learning the same language independently from its cultural context. This confirms that language and culture are not separated. So in our current teaching context, we have to include the more culture the better).

Another benefit Mr. Sang realised was that teaching cultural content enhances students' learning motivation. He stated:

"To non-major students if we can mention any cultural points ... even they are small, when we mention cultural points, it motivates non-majors. Major students, to some extent, if compared to non majors, are more motivated but we need to foster their motivation too."

\section{c. Priorities in language class}

This theme is presented according to two sub-themes, namely focuses in language class, and the status of culture in class. Each subtheme is detailed below

\section{- Focuses in classes}

Mr. Sang's self-reported teaching shows that the primary focus in class was teaching textbook-based language practice exercises. When asked about his lesson focus, he stated:

“Tập trung vô bài tập nghe ... và bài tập nói. Bài tập nghe thì tập trung vô họ nghe được cái gì, họ biết tới đâu. Bài tập nói thì họ có thực hiện được các chủ đề nói nhỏ hơn mà mình có thể gợi ý từ chủ đề hay không. Để họ về nhà tìm thông tin rồi vào lớp trình bày."

(I focus on listening exercises and speaking exercises. For listening, I focus on what students can hear, what they know. For speaking, I focus on whether they can talk about the topic and subtopics which I suggested. I let them search for information and then present it in class).

This focus on language skills was reinforced in the following excerpt:

R: Apart from the parts like listening speaking components, what do you aim for?

Mr. Sang: Mở rộng phần nghe. Cần nghe thêm ngoài những tài liệu các em đang có...Tìm nguồn nghe ...tất cả những cái gì liên quan đến listening. Điều này cũng dẫn đến hiệu quả là phát triển speaking.

[...] Nói nôm na là phải đủ input. 
(Mr. Sang: extend the listening part. Students need to practice listening to additional supplementary.... Seeking materials for listening practices...anything related to listening. This results in speaking development. [...] Simply speaking, sufficient input is necessary).

It is clear from the excerpt that culture was absent from Mr. Sang's lesson focus.

- The status of culture

Responses by Mr. Sang in the post-observation interview revealed a reluctance to teach culture. One reason he gave was that teaching culture is not suitable in his class due to students' low language level.

“Cái này nếu mình đề cập cho sinh viên nhiều quá thì người ta không hình dung ra, người ta cho là quá xa vời. Bởi vì sao, bởi vì người ta đang vật lộn với các cái skills... Cho nên người ta chưa muốn biết cái kia."

(If we mention too much about culture, students don't understand, they think it is too much above their level. Why, because they are struggling with language skills... So, they don't want to know about culture).

Second, culture was peripheral in the way that cultural content was taught on an unprepared basis. Mr. Sang mentioned this when he was asked about how he integrated culture:

“Không ghi chú...Có thể nhớ được vì (mỗi) bài cũng ngắn."

((I) did not take notes... (I) can remember them because each lesson was short).

In general, Mr. Sang's self-reported teaching revealed a limited attention to culture.

\section{d. Roles of teachers}

Mr. Sang's beliefs about the roles of teachers indicate a teacher-centred teaching style. First, he considered teachers as key decision makers who decide whether or not culture teaching is integrated in class. He maintained that the teachers' role is to explore cultural content embedded in each lesson, search for additional materials, and design or adjust tasks to meet students' needs and English levels. The following extracts illustrate these roles:

“Mình là người quyết lúc nào cho phù hợp...Giáo viên mà phát hiện thấy có...thì phải đưa vào [...].

Nếu sách thiếu thông tin hoặc manual không có thì phải tìm thêm.

[...] Không phải tự nhiên mà nó nằm trong cuốn sách được. Em phải design, tự em. 
[...] Người giảng viên trên lớp phải personalise lại cho phù hợp với người học...Người ta chỉ học cái người ta cần."

(We decide when it is suitable to integrate culture...If teachers recognize cultural content...they have to integrate it. If the book and manuals do not have enough information, just search for supplements.

[...] It is not already available in the textbook. You have to design it, by yourself.

[...] Lecturers have to personalize materials to adjust with learners... They only learn what they need).

Moreover, Mr. Sang believed that teachers' self-regulating their own learning is essential since teachers need to keep exploring culture and enriching their own cultural knowledge. Mr. Sang maintained:

“Mình không bao giờ quên giáo viên là một cái resource... Do đó giáo viên cần phải biết nhiều, hiểu nhiều, không được dừng lại.

[...] Em phải biết kiến thức văn hoá xã hội trước, trải nghiệm qua, có đọc thấy, có xem TV thấy...Kiến thức văn hóa của em nằm sẵn ở đó, em chỉ việc đưa vào lúc phù hợp nhất."

(We never forget teachers are resources...So teachers need to know and understand widely, can't stop learning.

[...] You must know sociocultural knowledge in advance, have experienced it, have read and watched it on TV.... Your cultural knowledge is already there, you only need to include it in your lessons when suitable).

From Mr. Sang's perspective, teaching culture relies heavily on the teachers' own cultural knowledge, and thus teachers have to become autonomous learners of cultural knowledge.

\section{e. Constraints for teaching culture}

Mr. Sang identified three constraints for teaching culture. First, he perceived that curriculum-related factors restricted room for teachers to include cultural aspects. As he said,

“...không có thể nào phát triển các kỹ năng ngôn ngữ mà bỏ qua các yếu tố về văn hóa ....Nhưng mà bây giờ trên lớp học, implication cho teaching như thế nào thì còn tùy vào chương trình dạy, textbook, thời gian dạy và học.... Người ta có thể không có đủ space hay làm việc đó." 
(...It is impossible to develop language skills if cultural components are ignored...But now for classroom practices, implications for this depend on curriculum, textbook, time allocated for teaching and learning... People may not have enough space for this integration).

Second, Mr. Sang acknowledged that addressing the cultural dimension is taxing and complicated because it requires diverse supplementary materials:

“...em phải có nhiều nguồn tài liệu trong tay...em chọn lọc ra theo mức độ từ dễ tới khó phù hợp với mức độ đầu vô hay là không. Đấy. Không phải tự nhiên mà nó nằm trong cuốn sách được. Em phải design, tự em....Em phải đảm bảo rich enough mới được [...] Khó, phức tạp hơn, công phu hơn, đầu tư nhiều hơn nữa.

(...you must have many sources of materials in hand... you have to filter them out. from easy to difficult to meet students' English entry level. That's it. It is not already available there in textbooks. You have to design it yourself....You have to ensure that materials are rich enough. [...] Difficult, more complicated, more hard-working, and more investment).

Another concern Mr. Sang raised during the interview was how teachers can assess student learning in terms of culture:

“Mình ... không theo lớp suốt mấy học phần sau. Do đó cũng không biết được thời gian sau học trò sẽ như thế nào. Không có gì đo được [...] cho nên mình không biết cảm nhận đó sẽ thay đổi họ như thế nào [...] để coi các hướng dẫn về văn hóa có thay đổi gì học sinh không."

(We ..don't follow the class when they move to higher courses. Hence, we don't know how they are after that. (Teachers) have no means to measure [...] so don't know how their cultural perception will change them in which way [...] don't know how our instructions change them).

It is obvious that Mr. Sang was uncertain about how teachers can track students' cultural learning in the long-term.

In short, the constraints mentioned by Mr. Sang indicate that teachers face difficulties in adapting the curriculum, adapting and designing learning materials, and assessing students' cultural learning.

\section{f. Mr. Sang's attitudes towards integrating culture}

Mr. Sang was concerned with the issue of time when asked about integrating culture:

R: How much are you willing to create opportunities for students to learn about culture or to expose to cultural learning? 
Mr. Sang: Whenever I have time in class no matter the textbook or curriculum I am using. Any time depending on time, syllabus, curriculum and the amount I have for every class..

The key concern was the amount of time he had in classes.

\section{g. The amount of teaching culture in Mr. Sang's observed lessons}

When asked what he thought about students' learning and the amount of teaching culture in his observed lessons, Mr. Sang acknowledged that his lessons addressed culture to a limited extent. He briefly commented "Chưa gọi là đủ” (Not considered to be enough). In Mr. Sang's opinion, culture is about the cultural contexts of native speakers' language use. He believed that teaching culture is important and requires multiple roles of teachers. However, in his self-report about his teaching practice during the pre-interview, language was treated as the priority and culture received little attention. He was concerned with teachers' ability to adapt, design learning materials, and assess students' cultural learning.

\subsubsection{Discussion}

Overall, Mr. Sang's teaching practice showed a domination of language teaching over culture teaching whereas his stated perception revealed his high interest in teaching culture in language classes.

Mr. Sang's observed lessons focused on the textbook-based language skills with more weight on the listening skills than the speaking skills. His teaching of culture in these lessons reflects a restricted amount of culture by introducing facts about the target language and culture. He explained cultural content once in the first and twice in the third lesson. In the first lesson, he explained university students' activities in Australia (i.e., book report). In the third lesson, he explained tea ceremonies and flower arranging in Japan, and slang freak...out used by English speakers in the textbook-based listening activity.

Regarding his stated perception, his conceptualisation of culture and pedagogical beliefs revealed both strengths and limitations. The strengths were that his overall beliefs showed high awareness of the value of teaching culture, and willingness to integrate culture in his classes. For instance, he emphasized the need for early inclusion of culture in the first year of the training program and the role of teaching culture in enhancing students' learning outcomes and motivation. These strengths contrast with the limited amount of culture 
addressed in his observed lessons. The mismatch between Mr. Sang's teaching practices and his beliefs was likely due to the constraints he perceived. These involved (a) the languagefocused curriculum and teaching resources that did not emphasize culture, (b) teachers' lack of theoretical and practical knowledge of how to design culture-focused learning materials and assess students' cultural learning outcomes, and (c) learners' linguistic proficiency.

Mr. Sang' s perspective was limited in that he considered culture as the context of language use in the life of native speakers. This implies the importance of acquiring native-like norms of behaviours. In the post-observation interview, when asked about the reasons for explaining book report and freak...out, he said:

“...Để sinh viên hiểu context bài nghe.” (For students to understand the listening activity context).

\section{[...] 'I explained slang because it is necessary in spoken English.'}

These explanations reveal his emphasis on understanding the context of communication and provide insights into the above-mentioned incidents of culture teaching in his lessons. This shows the alignment among his conceptualisation of culture, his beliefs for teaching culture, and his teaching of culture.

Another limitation is Mr. Sang's assumption that teaching culture is not compatible with students' low language level and that the two can be separated and dealt with separately. He showed his concern about students' struggling with improving language ability when he explained his lessons' focus in the interview. This assumption implies that teaching language is more urgent, which leads to a delay or exclusion of addressing the cultural dimension alongside language. Separating language and culture is opposed to an intercultural stance. As Dellit (2005, p. 7) pointed out:

"Ignoring culture does not leave a vacant cultural space which can be filled in later. Rather, it leads to a cultural space which is filled in by uninformed and unanalysed assumptions."

Failing to address culture alongside language results in serious uninformed cultural learning in students.

In brief, although Mr. Sang only sometimes addressed cultural knowledge, he showed high awareness of teaching culture and willingness to integrate culture in his EFL teaching. 


\subsubsection{Cross-case analysis and discussion}

This section discusses the uniqueness and similarities of the three teachers. The purpose is to develop insights into a current orientation to culture across the cases as evidenced by what the participating teachers did and thought. The following tables (Table 15 and Table 16) summarise teachers' teaching practices and conceptualisation of culture, and their beliefs about teaching and learning.

As in Table 15, Ms. Sen created the most opportunities and strategies for teaching cultural content. Mr. Huy provided more opportunities to address culture than Mr. Sang did (and he assumed that these opportunities would facilitate students' confidence in communication).

Table 15. Culture in teachers' teaching practices in Phase One

\begin{tabular}{|c|c|c|c|}
\hline Teachers & Ms. Sen & Mr. Huy & Mr. Sang \\
\hline Opportunities & 10 & 5 & 3 \\
\hline \multirow[t]{7}{*}{$\begin{array}{l}\text { Kind of } \\
\text { Actions }\end{array}$} & $\begin{array}{l}\text { - Distinguishing AE from BE } \\
\text { pronunciations (e.g., portrait, } \\
\text { maths) }\end{array}$ & $\begin{array}{l}\text { - Distinguishing AE from } \\
\text { BE pronunciations (e.g., } \\
\text { ballet) }\end{array}$ & \\
\hline & $\begin{array}{l}\text { - Telling and comparing cultural } \\
\text { facts }\end{array}$ & & $\begin{array}{l}\text { - Telling cultural facts (e.g., } \\
\text { tea ceremony, flower } \\
\text { arranging in Japan) }\end{array}$ \\
\hline & & & $\begin{array}{l}\text { - Explaining cultural facts } \\
\text { (e.g., book report) }\end{array}$ \\
\hline & $\begin{array}{l}\text { - Asking students to relate cultural } \\
\text { information between their own } \\
\text { country and the target country } \\
\text { (e.g., relate school hours in } \\
\text { Vietnam and Japan) }\end{array}$ & $\begin{array}{l}\text { - Asking students to relate } \\
\text { cultural information } \\
\text { between their own } \\
\text { country and the target } \\
\text { country (e.g., relate } \\
\text { national exam in } \\
\text { Vietnam and Japan) }\end{array}$ & \\
\hline & $\begin{array}{l}\text { - Explaining vocabulary } \\
\text { differences (e.g., football vs. } \\
\text { soccer) } \\
\text { - Explaining the context of } \\
\text { language use (e.g., come on, } \\
\text { hon, mom) }\end{array}$ & & $\begin{array}{l}\text { - Explaining slang (e.g., } \\
\text { freak...out) }\end{array}$ \\
\hline & $\begin{array}{l}\text { - Explaining communication } \\
\text { strategies (e.g., when and how } \\
\text { to ask for repetition) }\end{array}$ & & \\
\hline & & $\begin{array}{l}\text { - Sharing personal } \\
\text { communication } \\
\text { experiences (e.g., } \\
\text { activities people do at } \\
\text { parties) }\end{array}$ & \\
\hline
\end{tabular}


Table 16 below shows that each teacher emphasized different (inter)cultural skills. Only Mr. Sang emphasized discovering contextual factors embedded in language, and the teachers' skills to adopt, design learning materials, and assess students' learning outcomes. Ms. Sen appeared to demonstrate the highest extent of awareness about the value of culture among the three teachers. She was the most interested in integrating culture in EFL classes.

Table 16. Culture in teachers' stated perceptions in Phase One

\begin{tabular}{|c|c|c|c|}
\hline Teachers & Ms. Sen & Mr. Huy & Mr. Sang \\
\hline $\begin{array}{l}\text { Defining } \\
\text { culture }\end{array}$ & $\begin{array}{l}\text { - Ways native speakers do their } \\
\text { activities and behave (i.e., } \\
\text { Culture is the software of the } \\
\text { mind... I used Vietnamese } \\
\text { software...to mean how } \\
\text { Vietnamese eat, greet, and } \\
\text { dress so that people can } \\
\text { know you are Vietnamese) } \\
\text { (Ms. Sen's answer translated } \\
\text { from Vietnamese into } \\
\text { English) }\end{array}$ & $\begin{array}{l}\text { - Ways of how native speakers } \\
\text { say and do things (i.e., } \\
\text { Culture is the way of } \\
\text { speaking such as uses of } \\
\text { tone, voice, intonation, being } \\
\text { straight or not, being patient } \\
\text { or not, the knowledge about } \\
\text { behaviours including } \\
\text { gestures, events, activities, } \\
\text { speech, and thoughts about } \\
\text { certain things) (Mr. Huy's } \\
\text { answer in English) }\end{array}$ & $\begin{array}{l}\text { - Context of language use } \\
\text { (i.e., Contexts in which } \\
\text { the target language is } \\
\text { used by its native } \\
\text { speakers) (Mr. Sang's } \\
\text { answer translated from } \\
\text { Vietnamese into English) }\end{array}$ \\
\hline $\begin{array}{l}\text { Cultural } \\
\text { skills } \\
\text { emphasized }\end{array}$ & $\begin{array}{l}\text { - Comparing cultural } \\
\text { differences } \\
\text { - Developing worldviews }\end{array}$ & - Confidence in communication & $\begin{array}{l}\text { Discovering contextual } \\
\text { factors underlying what is } \\
\text { said }\end{array}$ \\
\hline $\begin{array}{l}\text { Roles of } \\
\text { teachers }\end{array}$ & $\begin{array}{l}\text { - Multiple roles (e.g., having } \\
\text { cultural knowledge; having } \\
\text { skills to explore culture and } \\
\text { create cultural learning } \\
\text { opportunities in class) }\end{array}$ & $\begin{array}{l}\text { - Recognising when cultural } \\
\text { teaching supports language } \\
\text { learning }\end{array}$ & $\begin{array}{l}\text { - Multiple roles (e.g., } \\
\text { creating cultural learning } \\
\text { tasks in class; becoming } \\
\text { autonomous learners of } \\
\text { cultural knowledge) }\end{array}$ \\
\hline Constraints & $\begin{array}{l}\text { - Teachers' busy teaching } \\
\text { schedule } \\
\text { - Students' first culture and } \\
\text { language }\end{array}$ & $\begin{array}{l}\text { - Language-oriented } \\
\text { curriculum } \\
\text { - Language-focused teaching } \\
\text { materials }\end{array}$ & $\begin{array}{l}\text { - Curriculum-related } \\
\text { factors } \\
\text { - lack of culture-focused } \\
\text { teaching materials } \\
\text { - Teachers' tracking } \\
\text { students' cultural } \\
\text { learning }\end{array}$ \\
\hline $\begin{array}{l}\text { Attitudes } \\
\text { towards } \\
\text { integrating } \\
\text { culture in } \\
\text { EFL classes }\end{array}$ & $\begin{array}{l}\text { - Have high interest and } \\
\text { readiness }\end{array}$ & $\begin{array}{l}\text { - Have a degree of } \\
\text { unwillingness }\end{array}$ & - Interest \\
\hline $\begin{array}{l}\text { Amount of } \\
\text { culture in } \\
\text { the } \\
\text { observed } \\
\text { lessons }\end{array}$ & $\begin{array}{l}\text { - } 10 \text { opportunities } \\
\text { Not much (Ms. Sen's comment } \\
\text { about her observed lessons) }\end{array}$ & $\begin{array}{l}\text { - } 5 \text { opportunities } \\
\text { Not much (Mr. Huy's } \\
\text { comment about his observed } \\
\text { lessons) }\end{array}$ & $\begin{array}{l}\text { - } 3 \text { opportunities } \\
\text { Not considered to be } \\
\text { enough (Vietnamese- } \\
\text { English translation of Mr. } \\
\text { Sang 's comment about his } \\
\text { observed lessons) }\end{array}$ \\
\hline
\end{tabular}


In the data, the three teachers demonstrated similarities in what they did and said about culture and teaching culture. The following themes reflect the areas in which teachers are similar:

a. The teachers' knowledge transmission approach to teaching culture

b. The teachers' static view of culture

c. The teachers' lack of awareness about intercultural language teaching

Each of these themes is elaborated and discussed below.

\section{a. The teachers' knowledge transmission approach to teaching culture}

The teachers applied a knowledge transmission approach to teaching culture in their classrooms. First, the amount of culture taught was inevitably reduced due to the teachers' priority of completing textbook-based content which entirely focused on language. Listening practices involved students recognising new words and pronunciation and giving correct answers. Post-listening speaking practice involved students summarising and/or re-telling the content of the listening tasks and roleplays.

Second, the teaching of culture focused on teachers providing cultural knowledge embedded in the lesson input. Teachers' actions were typically in the form of an incidental explanation of cultural information and distinguishing $A E$ from BE spellings and pronunciation during listening activities. A few chances for comparing and relating cultural information to students' own language and culture and explaining communication strategies were observed in Ms. Sen's third lesson.

Third, as evident in the observed lessons, the cultural knowledge provided by the teachers focused on the most symbolically dominant English-speaking countries (America, Australia, and Britain). Students' lived experience and learning needs were not recognised nor made use of in class. The teachers' focus on national attributes was unlikely to stimulate students' openness, flexibility, tolerance, or exploration of culture. According to Byram (2015, p. 52), emphasis on cultural knowledge about a certain nation presupposes that teachers of language $X$ will teach culture which is based on country $X$. This presupposition has been challenged by the new roles of English in intercultural communication (Sharifian, 2012; Johnson, 2014; Byram, 2015). These scholars maintain that linguistic proficiency 
supplemented with cultural knowledge about particular countries is not sufficient to function effectively in intercultural communications. More seriously, according to Kumaravadivelu (2008) and Gandana (2015), focusing on a national paradigm runs the risk of reinforcing stereotypes and essentialism.

Fourth, the teachers' dependence on textbook-based language input, their own communication experience, and their cultural knowledge reflects teacher-centredness. For example, in the third lesson, Ms. Sen explained facts about Japanese people from what she knew in American society since she studied her Master's degree in the USA. Mr. Sang, in the first lesson, explained the activity book report because he knew about this activity from his Master's study in Australia. Mr. Huy in the second lesson shared with students what he heard from foreign friends, whom he worked with in his English department.

Finally, the teaching of culture was unplanned, not alongside language learning, and without students' engagement either to add fun or variety to classroom routines. In the stimulated recall parts of the pre-interviews, all teachers stated that they gave cultural explanations based on their judgement of when this was needed. They reported that they did not plan in advance what and when to explain.

The teacher's priority of transmission of cultural knowledge and teacher-centredness are at odds with an intercultural perspective. Byram (2015) and Howard et al. (2016) contend that the intercultural perspective to language learning, with its focus on students' ICC, requires beyond cultural knowledge. Similarly, Aguilar (2008) argues that the intercultural perspective goes beyond an acquisition of native-like linguistic proficiency and cultural knowledge and behaviours. Aguilar also notes that because of this, teachers should not be limited to transmitting cultural knowledge and modelling linguistic forms. Instead, the teachers' key role is to develop in students the competence to see things through both their own eyes and the eyes of culturally-different others. That means developing the students' ability to relativize and make connections between their own and others' values, beliefs, and behaviours. To fulfil this role, according to Aguilar (2008), teachers need to encourage students' tolerance, and cooperation to build mutual understanding and develop students' autonomous learning skills. The degree of teachers' fulfilment of these roles varies according to each stage of learning (Corbett, 2003). Aguilar (2008) continues that, in reality, due to textbook and curriculum constraints, teachers are especially important as mediators 
who adapt and develop intercultural learning materials and share cultural experience. When students become more confident, teachers become advisors instead of a resource to allow more cultural explorations (Aguilar, 2008). Hence, it is argued in this research that the role of intercultural teachers challenges participating teachers' teacher-centredness.

The above point highlights the marginalised status of culture in the teachers' teaching practices. This finding is consistent with other studies. For example, in the Vietnamese university context, teachers' random teaching of cultural connotation and cultural facts embedded in lesson topics was observed in Ho (2011a), T. L. Nguyen (2013), V. C. Le (2015), and Trinh (2016). Similarly, the teaching of culture was found to be fact-oriented and topicdependent in Tran and Dang (2014) in FL centre settings, and in Chau and Truong (2018, 2019) in upper secondary school settings.

Beyond Vietnam, similar findings have been reported (East, 2012; Oranje \& Feryok, 2013; Mahoney, 2015; Biebricher et al., 2019; Zhou, 2011; Tian, 2013; Cheewasukthaworn \& Suwanarak, 2017; Estaji \& Rahimi, 2018). For example, Mahoney (2015) studied community language teachers' teaching of culture in the Australian context in the teaching of Chinese, Korean, and Arabic. Using the teachers' reflections, Mahoney (2015) found that the teachers mostly treated culture as societal norms and as high culture. These studies have shown that the reasons that prevent teachers from teaching culture include lack of time (Sercu et al., 2005; Abdulrahman et al., 2016; Ho, 2011b; Vo, 2017); teachers' lack of: awareness about national language policy (L. Nguyen, 2015), cultural knowledge (Abdulrahman et al., 2016; Lim \& Keuk, 2018), iCLT principles (Oranje \& Feryok, 2013; Howard et al., 2016), and skills and knowledge to guide students' intercultural learning (Conway \& Richards, 2016); language-oriented curriculum (Young \& Sachdev, 2011; Abdulrahman et al., 2016); and curricula that over-simplified culture and language (Gandana \& Graham, 2013).

In this current study, the teachers' lack of attention to students' ICC and the teachercenteredness teaching style in classroom practices were likely due to two main factors. First, there was an absence of guidelines for addressing culture in the course's syllabus of the subject Language Skills $2 A$. Teaching ICC was not a compulsory part of teachers' daily teaching and assessment in this subject. Mr. Huy's comments in the pre-interview confirmed this reality. He said that if teachers do not teach cultural aspects, no one will complain because this subject aims for improving listening and speaking competence. The 
second factor was the teachers' conceptualisation of culture as comprised mainly of specific ways of lifestyles and behaviours. The following section further discusses the teachers' view of culture.

\section{b. The teachers' static view of culture}

Overall, the teachers' conceptualisation of culture reflects a modernist view of culture. According to Kramsch (2006, p. 13), the modernist approach to culture, known as little c or small culture, views culture as "the native speakers' ways of behaving, eating, talking, dwelling, their customs, their beliefs and values." Ms. Sen conceptualised culture as different ways of behaving and activities in people's lives in English-speaking countries. For Mr. Huy, culture means how people in a country say and do things, behave, and think. Mr. Sang considered culture to be the context of language use.

The little c approach with its emphasis on native-like norms has been widely criticized as "culturalism"(Liddicoat \& Scarino, 2013, p. 20), "monolithic, essentialised, and static" and "solid" (Liddicoat, 2017, p. 23) or "reductionist" and "stereotypical" (Diaz \& Dasli, 2017, p. 7). According to Liddicoat (2017), the static view of culture represents cultural differences on the basis of a fact-oriented static system without attention to people's engagement in linguistic and cultural diversity as resources for making meaning. The static view of culture does not emphasize learning outcomes beyond the idea of native-like-standard proficiency (Liddicoat, 2017). Similarly, Diaz and Dasli (2017) maintain that the essentialist view treats culture as a collection of independent factors that rule what one can and cannot do in given situations; therefore, adopting this view results in problems including stereotype formation. It can thus be concluded that the teachers' static conceptualisation of culture is not in line with features of an intercultural stance.

The teachers' static view of culture in this study reconfirms findings in previous studies in the Vietnamese EFL context. These include unpublished doctoral theses (Ho, 2011b; T. L. Nguyen, 2013; Trinh, 2016; T. B. Nguyen, 2016), and academic publications (Ho, 2011a; L. Nguyen et al., 2016). For example, in Ho's (2011a) study, nine out of twelve participating teachers viewed culture as small c culture which include "native speakers' manners, customs, beliefs, behaviours, moral values, habits, lifestyle" (p. 50). The other three teachers viewed culture as big C culture which includes "characteristics of a nation or 
particular features of an ethnic group" (ibid, p. 50). Teachers in L. Nguyen et al. (2016) conceptualised culture as concrete elements, products, and functions. Finally, teachers in Trinh (2016) viewed culture as aspects of human life such as manners, customs, lifestyles, values, behaviour, arts, music, and architectures. Overall, the case study teachers in this current study as well as the participating teachers in (Ho, 2011b; T. L. Nguyen, 2013; Trinh, 2016; T. B. Nguyen, 2016) were distant from an intercultural stance due to their static view of culture.

\section{c. The teachers' lack of awareness about intercultural language teaching}

The three teachers lacked awareness about intercultural language teaching in three main areas. First, they lacked attention to developing students' ICC in classroom practices. Data showed that they emphasized the idea of native-like linguistic competence. The two main ways of handling culture involved (a) the teachers' transmitting cultural information, and (b) distinguishing $A E$ from $B E$ pronunciations and word meanings.

Second, the teachers lacked awareness about intercultural language teaching in their pedagogical beliefs. An integrative view of addressing culture alongside language was absent across the three teachers. Ms. Sen thought that integrating culture added fun to classes. Mr. Huy expressed the view that teaching culture was not an obligatory task for teachers. Mr. Sang considered integrating culture when time in his lessons and schedule allowed him to do so. This finding was re-confirmed in the pre-interviews when all three teachers acknowledged the limited amount of teaching culture in their observed lessons.

Teachers not taking an integrative view of addressing culture in EFL classes has been found in Vietnamese tertiary settings (Ho, 2011a; L. Nguyen, 2015; Trinh, 2016). In these studies, although the participating teachers had different degrees of awareness of the importance of teaching culture, they seldom set goals for cultural learning in lessons. The case study teachers' lack of awareness about intercultural language teaching is contradictory to the emphasis of the teacher roles in an intercultural stance (Crozet \& Liddicoat, 1999; Aguilar, 2008; Kohler, 2015). Without such awareness, teachers are prevented from being able to guide students' in-class intercultural learning. International studies (Peiser \& Jones, 2014; Gandana, 2015; Oranje \& Smith, 2018) also found teachers not taking an integrative view of addressing culture. For example, in Peiser and Jones (2013, p. 387), the teachers' 
interpretations of intercultural understandings (which was one of the four key components of the National Curriculum revision in 2007 in England) and the way in which they translated these into practice were highly idiosyncratic and intuitive. Oranje \& Smith (2018) found that New Zealand school teachers were favourably disposed towards intercultural language teaching but did not practice teaching it in their classrooms.

Third, the three teachers held assumptions that were contradictory to iCLT principles. For example, Ms. Sen considered cultural differences in students' first languages/cultures as constraints for teachers in addressing culture. Mr. Huy thought that language goals are far more important than cultural goals. Mr. Sang believed that students with low language proficiency do not need or want cultural learning because they struggle with improving language fluency. According to the first principle of iCLT, language and culture are integrated from the beginning (Newton et al., 2010, p. 64). That means teachers can help learners to explore culture in language from an early stage of learning instead of delaying integrating culture until students have high language proficiency (Newton et al., 2010). The fifth principle of iCLT considers learners' cultural and linguistic backgrounds including their first language and culture as useful learning resources (Newton et al., 2010). In Mahoney's (2015, p. 90) words, iCLT “values students' home language and culture, and builds upon the prior knowledge they bring to classroom." Therefore, I argue that, with such assumptions, the case study teachers missed creating the opportunities for intercultural learning in their lessons.

In summary, the cross-case analysis identified and discussed the main differences and similarities across the cases. The teachers had more similarities than differences with all three teachers adopting a traditional stance to culture in teaching practices, holding a static view of culture with limited understandings about iCLT.

\subsubsection{The students' intercultural learning needs}

Analysis of pre-workshop-one student focus groups aimed to obtain insights into the students' experience of learning in the teachers' lessons to understand the students' intercultural learning needs.

During each of the pre-workshop-one student focus groups, I aimed to explore how students responded to the teachers' observed lessons in terms of learning culture. I avoided 
mentioning technical terms such as culture and intercultural content when asking the students questions. With this absence of the researcher's priming, in the data, none of the groups' answers or discussions mentioned learning of culture in the lessons they were taught. This showed the students' lack of awareness of the (inter)cultural dimension of learning although in the observed lessons, their teachers' integrated explanations related to the cultural content arose in the input.

Therefore, at the end of each pre-workshop-one focus group, I decided to provide some prompts. I asked questions such as Apart from the objectives of developing listeningspeaking, pronunciation, grammar, and vocabulary what do you think you need in your lessons? How were you taught in terms of culture in the lessons? In your opinion, what cultural content should be taught in class? Finally, students began to express opinions related to the (inter)cultural dimension of learning.

In the data, the major theme identified in each pre-workshop-one focus group is the students' stated beliefs about their (inter)cultural learning needs. The following section details this theme according to each group.

\section{Pre-workshop-one focus group One}

In the following excerpt, the pre-workshop-one focus group one discussed what culture means and why it is necessary to learn it:

Lien: [culture]về phong tục tập quán, thói quen sống cũng như ăn uống làm việc.

Lieu: Kến thức văn hóa tức là những cái gì người ta thích thì mình làm theo, cái gì ky. thì mình tránh ra. Students: nhập gia tùy tục .. đó trong giao tiếp mình có thể sử dụng vô để khi mình nói tự nhiên hơn.

Lan: Em nghĩ cách tiếp chuyện với người nước ngoài, ví dụ câu chào, câu .. goodbye hoặc là thank you là điều cần thiết để học nhất...vì nói nói lên cái cái sự tế nhị trong giao tiếp của mình.

(Lien: (Culture) is about traditional customs, habits of living as well as eating and working.

Lieu: Cultural knowledge means knowing to do what people like you to and avoid doing what people consider taboos.

Students altogether: In Rome do as the Romans do...in communication we can use cultural knowledge to speak more naturally. 
Lan: I think the way we converse with foreigners, for example, greetings, saying goodbye and thanks is the most important thing to learn...because it shows that you are considerate while in communication).

This discussion indicates two main points: the students' conceptualisation of culture and their emphasis on the importance of learning culture. First, the students considered culture as traditional customs, habits of living, eating, working, speaking, and expected manner of behaviour according to what native speakers value. Accordingly, cultural knowledge means knowing to be considerate while in communication with native speakers. This suggests that the students conceived of culture as societal norms and as small c culture which are categorized in Liddicoat and Scarino (2013). Second, they considered cultural learning to be important in the way that cultural knowledge (specifically knowledge of what to say and how to be considerate) provides an important means of enhancing successful communication. Overall, the first pre-focus group believed that cultural knowledge helps people to become more considerate in cross-cultural communication.

\section{Pre-workshop-one focus group Two}

Members of the pre-workshop-one focus group two had divergent opinions about whether or not cultural content should be added into their class. This was shown when they were asked: Apart from aiming to practice listening and speaking skills, what do you think is necessary to add into the lessons?

The following excerpt showed that students wanted to add cultural content in their class. They expressed:

Ly: Em muốn ...thêm nội dung về văn hóa. Khi được giải thích kỹ về văn hóa thì có nhiều kiến thức hơn và tự tin khi làm việc với người nước ngoài

My: Cũng cần thiết để hiểu biết về văn hóa của mình nữa.

(Ly: I want...to add content related to culture. When students are explained carefully about culture, they then have more knowledge and become confident when working with foreigners.

My: It is also necessary to know and understand our own culture).

On the contrary, other students were not aware of this dimension. Hieu and Quyen did not think culture is relevant to be added into lessons. They explained:

Hieu: Nếu dạy về văn hóa thì không đủ thời gian vì phải học hết content trong cuốn sách. 
Quyen: Em nghĩ chuyện dạy văn hóa của giáo viên không phải là mục đích chính vì chuyên ngành của chúng em là biên phiên dịch. Nếu gặp ngay vấn đề nào đó thì...lồng ghép một chút thôi chứ không phải là cái chính .. mà là phần phụ họa thôi.

(Hieu: If teachers teach culture, there won't be enough time because we have to finish all content in textbook.

Quyen: I think culture is not the main purpose because our major is translation and interpretation. If certain cultural content arises, then...teachers may integrate a little bit. This is not the main purpose, it is only supplementary part).

Hieu and Quyen were more concerned about the language dimension rather than the cultural dimension of learning.

Generally, not all students in this group were aware of or valued a cultural dimension of learning.

\section{Pre-workshop-one focus group Three}

In the pre-workshop-one focus group three, two main points emerged: the students' expression of what they need in terms of learning culture, and their perception about the cultural content in the teachers' observed lessons.

In the following extract, the students discussed how they have been taught about culture in the lessons:

R: How have you been taught about culture in class?

Thinh: Trong giờ học ít khi nào nói đến văn hóa. Hiện tại chưa đề cập nhiều về văn hóa trong lớp.

Nhu, Duyen, Diem (altogether): Chưa có nhiều trong lớp.

Duy: Chờ, có quá lâu để chờ đến bài có chủ đề nào đó để đề cập về văn hóa không? ví dụ năm bài mới có một bài để chờ đợi...

(Thinh: In the lessons, (we) rarely talked about culture. At present, (teacher) has not mentioned much about culture in class.

Nhu, Duyen, Diem (altogether): There was not much about culture in class.

Duy : Waiting, is it too long to wait for a lesson that has cultural content in it? For instance, cultural content is embedded in one in every five lessons). 
Their discussion about the lessons reveals that the amount of in-class cultural teaching and chances for cultural learning were limited. Duy complained that the textbook was poor in cultural content. His complaint implies his expectation to have more exposure to in-class cultural learning. Such an expectation was common within this focus group. As Thinh further stated:

Thinh: Em cho là văn hóa rất cần thiết. Học giao tiếp đương nhiên phải học văn hóa vì giao tiếp luôn đặt ra vấn đề về văn hóa.

(Thinh: I think cultural learning is crucial. Learning to communicate inherently includes learning about culture because issues related to culture always arise in communication.

Following this, the group expressed mixed ideas about the cultural content they perceived as necessary to be addressed in class:

R: In your opinion, what culture content should be taught in class?

Thinh: in my opion, the most important that should be taught is American culture because most of the things we learnt here is American, especially American accent.

Nhu: Em nghĩ nên dạy nhiều về cách ứng xử. Mình hiểu thêm về cách ứng xử để sau này có cơ hội hợp tác làm việc, học tập nhiều nơi mà không bị sốc văn hóa.

Diem: Em thấy học về văn hóa ảnh hưởng đến sự trưởng thành của mình rất nhiều. Mình biết về văn hóa càng nhiều nước càng tốt , khi sau này mình làm việc. Ví dụ sau này mình không chắc là đi làm cho Mỹ mà cho Thái Lan chẳng hạn. Mình cần nắm bắt được cách người Thái giao tiếp.

Duy: Em nghĩ giống Diem... không nhất thiết riêng một nước nào. Nếu biết nhiều nước thì làm việc được với nhiều người dễ dàng, đa dạng hơn.

(Nhu: I think, teachers should teach ways of behaviours. If we understand better about ways of behaviours, we can avoid cultural shock in future work and study in many places.

Diem: I see learning about culture influences my maturity a lot. The more countries' culture you understand about the better, for future work. For example, I am not sure I will work for America. I may work for Thailand instead. In that case, I need to master how Thai people communicate.

Duy: I agree with Diem...not necessary to focus on a certain country. If you know culture of more countries, you can work with diversity more easily).

Thinh preferred cultural content about America. Nhu emphasized learning about standardised behaviours in multicultural contexts. Diem seemed to have a more advanced view. She recognised the influence of learning about culture on one's personal maturity 
rather than emphasizing on native speakers' cultures. We can see here that Thinh's emphasis on the powerful standard form of language (i.e., American culture and accent) reveals his static view of culture. Except his case, other students' perception of cultural learning focused on (a) cultural diversity and (b) being equipped with intercultural skills to participate in multicultural studying and working contexts.

Drawing from their reflection on their learning in class, students in the third group showed awareness about the cultural dimension of learning. They expected more chances for inclass intercultural learning. They hoped intercultural learning would equip them with skills to successfully participate in a diversely multicultural working context.

In summary, students in the first and third pre-focus groups were of the opinion that more cultural content should be added into the lessons. Not all students in the second pre-focus group thought cultural learning was relevant for their major. The cultural content emphasized by all groups included culturally appropriate behaviours. This was because they aimed at being thought of as considerate and adaptable in multicultural working contexts in which they plan to participate in the future.

\subsubsection{Summary of findings}

Using within-case and cross-case analysis approaches, the above section has scrutinized culture in each teacher's teaching practices, conceptualisations, and pedagogical beliefs. The section also tracked students' intercultural learning needs which were evident in the pre-workshop-one focus groups after they learnt the lessons taught by the teachers.

The within-case analyses have revealed how each teacher addressed culture in his/her lessons, how he/she conceptualised culture and what beliefs he/she held for teaching and learning. First, their approach to teaching culture focused on cultural information transmission and revealed teacher-centeredness in each of the teachers' teaching practice. Second, the teachers' views of culture reflected a modernist perspective to culture. Third, the themes identified in each teacher's beliefs included values of culture, the roles of teachers, priorities in class, constraints for teaching culture, attitudes toward integrating culture, and amount of teaching culture. Discussion of the strengths and limitations in the teachers' practices, conceptualisations of culture, and their pedagogical beliefs indicate the relevance of introducing $\mathrm{iCLT}$ to the teachers. 
The cross-case analysis found that the teachers (a) practiced a knowledge transmission approach to teaching culture, (b) held a static view of culture, and (c) lacked awareness of an intercultural perspective on language teaching and learning.

Student-focus group data showed that most students wanted an intercultural dimension to be added into learning for the purpose of preparing themselves for future participation in cross/multi-cultural workplaces.

Final conclusions and implications of the above findings are now discussed.

\subsection{Chapter discussion}

The study findings suggest important implications for planning to adopt an intercultural stance into the current context. These include the limitations of the current orientation to culture and the affordances for the implementation of an intercultural orientation, particularly iCLT, in the subsequent phase.

\section{Limitations of the current orientation to culture}

First, the findings suggest that the current orientation to culture did not meet students' learning needs. Findings from classroom observations and pre-teacher interviews show that the traditional orientation to culture was dominant in the current teaching context. Specifically, this traditional orientation was characterised by the peripheral status of culture in comparison to a main focus on teaching language skills, and little attention to students' ICC. Culture was peripheral in that incidental cultural information transmission was the primary form of teaching. Lessons reflected teacher-centeredness and students' passiveness in acquiring cultural knowledge. On the contrary, findings from pre-workshop-one focus groups show that students expected their learning to be enriched with content on communication skills and multicultural knowledge necessary for them to participate in multicultural work environments. Hence, I argue that adopting an intercultural orientation guided by iCLT principles into the current teaching context is necessary to address students' ICC.

This claim is supported by scholarship. One pillar of iCLT is that it expands the focus on communicative competence towards developing students' ICC (Corbett, 2003; Sercu, 2004) and deals with culture more explicitly in the communicative experience available to learners 
(Newton, 2016, p. 175). Stated differently, iCLT supports and does not supplant language learning. While addressing students' ICC, intercultural learning involves learners in a wide range of skills such as noticing culture, exploring, comparing, reflecting, connecting, experiential learning (Crozet \& Liddicoat, 1999; Newton et al., 2010), mediating (Corbett, 2003; Liddicoat, 2014; McConachy \& Liddicoat, 2016), and interpreting (McConachy, 2018) to become interculturally-competent speakers (Newton et al., 2010).

Second, the case study teachers appeared to lack practical skills and knowledge which would enable them to address students' ICC within the fixed curriculum, particularly in language skill-based courses. The findings show the teachers' lack of awareness about an intercultural dimension and iCLT principles. As they stated, they taught culture on an unprepared and unplanned basis relying on their teaching experience, although they realised the value of culture in class. To address the contradiction between the case study teachers' current teaching practices and their appreciation of culture value, teachers need the professional knowledge, skills, and attitudes to address the goal of intercultural language teaching.

It is my contention therefore that the case study teachers need professional support to become intercultural teachers who can address culture in a principled manner. This support needs to be in line with the teachers' stated constraints, their professional aims, and gaps in their knowledge, fixed curriculum, limited teaching resources, and busy teaching schedules. To successfully guide students' intercultural language learning, teachers are required to take multiple roles such as intercultural mediators who are able to guide, support, and engage learners in cultural explorations and negotiations and create opportunities for these activities (Corbett, 2003; Damen, 2003).

The significance of professional learning on teachers' improved integration of intercultural teaching practice has been shown in studies by Lázár (2011), Peiser and Jones (2013), Mahoney (2015) and Tolosa et al. (2018). Lázár (2011) found that teachers who received training on cultural awareness and intercultural communication implemented meaningful classroom activities more frequently. Recently, Tolosa et al. (2018) found that teachers' critical inquiry and reflections on their practices enabled teachers' shift in their view of culture and application of intercultural language teaching into classrooms. Eventually, professional learning that introduces the case study teachers to a participatory learning 
model and a context-relevant lesson design model in the subsequent research phase is necessary for the teachers to fulfil their roles.

To summarise, the peripheral status of culture, absence of attention to foster students' ICC in classrooms, teacher-centeredness, teachers' lack of awareness about iCLT, and gaps in teachers' skills and knowledge seem to be the limitations rather than the strengths for adopting an intercultural stance at the current university. However, these gaps between the current teaching context and the literature on teaching culture provide incentives for the second phase of the current study to be implemented.

\section{Affordances}

It is worth noting a number of the teachers' strengths which can be considered as affordances for adopting an intercultural stance in the subsequent phase of this research. First, the case study teachers did not ignore culture completely in their practices. Second, the teachers' perceptions about their teaching acknowledged that their lessons were limited in addressing culture. Third, they realised the value of teaching culture. Fourth, the teachers had varying positive attitudes toward the integration of culture. Specifically, Ms. Sen had a strong interest. Mr. Huy considered integrating culture as long as this increased students' language improvement. Mr. Sang was eager to integrate culture anytime if time allows. Additionally, each of the teachers had his/her own strengths as portrayed in within-case discussions. For example, Ms. Sen did not show doubt about teaching culture due to not being a native speaker. Mr. Huy valued sharing lived communication experience.

In short, based on the Phase One findings, the overall implication for Phase Two is that adopting a more systematic and principled engagement with culture guided by iCLT principles is necessary for the current teaching context. Therefore, the key tasks aimed for Phase Two include developing the teachers' theoretical knowledge about the intercultural dimension of language teaching, particularly ICC, principles of $\mathrm{iCLT}$, and practical skills to implement and create their own intercultural lessons. 


\subsection{Chapter summary}

In summary, this chapter explored the current orientation to culture through three main sources of data: observations of teachers' teaching practices, post-observation teacher interviews, and student pre-workshop-one focus groups.

Data analysis identified a traditional orientation to culture in which culture took a peripheral role. Cultural information transmission and teacher-centeredness prevented the teachers from developing students' ICC although their pedagogical beliefs valued teaching culture. The findings indicate the gaps and affordances for adopting an intercultural stance. Drawing on the findings, my argument is that, to meet the students' intercultural learning needs as well as the case study teachers' wishes to help the students, the teachers need in-context professional learning that equips them with the necessary knowledge and skills to engage with culture more interculturally. In the next chapter, I show the teachers' emerging understandings and development towards an intercultural stance during the process of adopting intercultural language teaching in their current teaching context. 
This page is intentionally left blank 


\section{CHAPTER 5 IMPLEMENTING INTERCULTURAL LANGUAGE TEACHING AND LEARNING: PHASE TWO FINDINGS AND DISCUSSION}

\subsection{Introduction}

This chapter has a dual focus. The primary focus is to analyse and discuss the case study teachers' post-workshop teaching practices and stated perceptions about their intercultural teaching. The secondary focus is on the students' perceptions about the experiences of learning in the teachers' intercultural lessons.

The first section reviews the Phase Two research purpose, the workshop cycles, the intercultural lessons, and data sources for analyses. The second section presents the withincase and cross-case data. For each case, I first analyse each teacher's teaching practice, then the teacher's stated perceptions, and finally his/her students' perceptions of learning in the intercultural-oriented lessons. The final part of each case includes a within-case summary, and case discussion. The third section presents a cross-case analysis. Finally, the last section presents the conclusions and implications, followed by the chapter summary.

\subsection{Overview}

\subsubsection{Research Purpose}

Phase Two tracked the impact of integrating an intercultural orientation into the current teaching context. Specifically, it examined the impact of introducing the teachers to iCLT. The key components of the first workshop included introducing the teachers to an intercultural stance and providing them with a redesigned intercultural teaching sequence/model of an existing lesson. The second workshop involved the teachers reflecting on their teaching after workshop one and co-constructing their own intercultural lessons. Phase Two seeks answers to RQ2 as follows:

RQ2: What was the impact of the two professional learning workshops which introduced intercultural language teaching on the classroom teaching practices and emerging understandings of the case study teachers? 
2.1 How did the three case study teachers implement the intercultural-oriented post-workshop lessons?

2.2 What did the three case study teachers say about the experience of teaching these lessons?

2.3 What did the students say about their experience of learning these lessons?

\subsubsection{The workshop cycles}

Phase Two involved two workshop cycles with each workshop followed by observations of the teachers implementing the intercultural-oriented lessons (five in total for each teacher for both workshop cycles) and post-observation interview with each teacher (two individual interviews for each teacher for both workshop cycles). This section details each of the workshop cycles.

\section{Workshop One Cycle}

\section{The workshop}

This workshop began Phase Two and was conducted in the fourth week. It aimed to allow the teachers to explore together perspectives and approaches for intercultural language teaching and learning. (The workshop slides are provided in appendix 4.1). The workshop lasted for over three hours. Its activity agenda and content were: the teachers' reflective discussion, guided discussion of the materials, presentation of theoretical framework, and concluding review.

- Teachers' reflective discussion

This section took nearly 40 minutes. In this section I sought to facilitate the teachers' voicing of their perspectives, thus I played a minor facilitative role and mostly listened. To begin, the teachers were asked to describe how they would teach the upcoming lessons (lessons 4A, 6A and 7B). Second, they described what they had normally done in their teaching practices with regards to teaching culture. Third, they reflected on the current teaching practices of culture at university level. For this third content, they answered questions such as what are the strengths, constraints, and supportive factors for the teaching of culture, and what suggestions do you have to improve the current teaching practices. The teachers' responses indicated a range of constraints for teaching culture. For instance, in Mr. Sang's 
opinion, teachers were not confident in teaching cultural content because they could only rely on their personal lived experience and interest due to lack of resources and exposure to both Vietnamese and other cultures. Mr. Huy added that teachers lacked professional training for addressing culture. Following this, the teachers discussed the national and international contexts of learning and teaching English which included the roles of English and language teaching and learning.

- Guided discussion of the materials

This section took over an hour. In this section, I took a more supportive role by providing materials for the teachers to consider. These materials included (a) the redesigned model for intercultural content and the three pre-designed intercultural lesson plans, the handout and worksheet that could be used in these lesson plans, as well as the rationale for the lesson plans, and (b) presentation slides outlining the workshop agenda.

First, the teachers read the model lesson plans and asked questions that emerged during their reading. For example, Mr. Huy asked if the model lessons satisfy the priority of developing students' listening and speaking skill improvement. Second, the teachers discussed these questions: (1) What was your first impression about the model lessons?, (2) what do you notice about the guided activities in the post-listening part of each lesson?, and (3) what do you like and dislike about them? Next, drawing on relevant scholarship (which was mentioned in section 2.2 and 2.3 of chapter two), I guided the teachers to explore the materials. Before I started, I asked what the teachers thought were the principles underpinning the activities in the model lessons. For example, I guided the teachers to discuss the learning opportunities which the redesigned intercultural content aimed to provide students with, and the sequence of the intercultural learning components and language learning components shown in these lesson plans. Teachers discussed the theoretical framework that underpins the redesigned intercultural content. All the teachers noticed that the model lessons introduced some learning steps that were not evident in traditional teaching practices in terms of culture. They understood the underpinning principles of the lessons involved discovery learning, reflective teaching and learning, and language awareness raising.

- Presentation of theoretical framework 
This section took nearly 20 minutes. Following the guided discussion in the earlier section, I introduced the teachers to the theoretical framework that underpins the designed intercultural lessons. I focused on explaining the key concepts of concern which were: intercultural competence as defined in Byram's $(1997,2009)$ ICC model, intercultural language teaching and learning, and Newton et al.'s (2010) iCLT principles.

\section{- Concluding review}

This section lasted nearly 30 minutes and involved teachers' discussion of the answers to the following questions regarding the introduced materials: (1) What was the best point of iCLT in your opinion?, (2) what was new to you?, and (3) what kind of support and challenge do you think teachers might have if they applied intercultural language teaching? Finally, the teachers shared with each other the points they found useful from the workshop.

\section{Post-workshop classroom observations}

Following the workshop, each of the teachers implemented teaching three interculturaloriented lessons using the workshop content. The classroom observations took place between week five and week eight. Before each lesson, I supported the teachers by telephone. In class, I took a limited-participation role to observe the teaching practice of each teacher. The teachers did not observe each other.

\section{Post- observation teacher interviews}

In week nine, each teacher attended one individual semi-structure in-depth interview (within a week after their teaching) with the researcher. The interview lasted for around one hour and a half for each of the male teachers. The one with Ms. Sen was two hours. Each interview was conducted at the place of the teachers' convenience (i.e., either at his/her own house or at a coffee shop). Each interview began with a stimulated recall component in which the teacher watched sections of the video replay of his/her teaching the observed lessons. The purpose was to remind the teacher about his/her teaching and to explore his/her explanation about the teaching activities shown in the video replay. The stimulated recall component was subsequently followed by the semi-structure in-depth interview in which the teacher was asked about how they perceive the experience of teaching the intercultural lessons. Each teacher was asked questions such as: What aspect 
of the lesson do you like most? How do the introduced steps make sense to you after you have finished teaching the lessons? What kind of knowledge or expertise do you think you need in order to teach the redesiged lessons? Is it important to raise our students' awareness about whether or not they should consider revising their initial (cultural) hypothesis and why?

\section{Workshop Two Cycle}

\section{The workshop}

This workshop aimed to explore the issues that emerged during the teachers' intercultural teaching after the first workshop (e.g., what aspects of the lessons went well and what did not during their implementing the redesigned intercultural lesson plans; the teachers' comments on students' learning), and to engage the teachers in co-constructing a further set of intercultural lessons. The objectives were for the case study teachers to reflect on their intercultural teaching and cooperate to design the intercultural lessons which would be taught in the following weeks. The workshop was organised in week ten when all the teachers had finished teaching the three intercultural lessons and lasted for two hours (the workshop slides are provided in appendix 4.2). The workshop activities included teachers' reflective discussion and their co-construction of lesson plans.

\section{- Reflective discussion}

In this section, the teachers shared their experience of teaching the model intercultural lessons with each other. Specifically, they were encouraged to discuss the difficulties they had during their implementation of these lessons. Their discussion revealed issues related to the current curriculum foci and its teaching materials as well as the amount of teachers' preparation for teaching the intercultural lessons. For example, Mr. Huy was concerned with whether or not the long-term implementation of the intercultural lessons would be feasible as the current textbook did not serve to prioritise addressing intercultural dimension. Both Mr. Huy and Ms. Sen were concerned with the extra time spent on preparing the intercultural lessons if intercultural language teaching was to be adopted on a more regular basis. Accordingly, the teachers suggested teacher's flexibility in adopting the intercultural learning content in their current situation as in what Ms. Sen said:

"We don't need to adopt all intercultural skills in each lesson." 
- Co-construction of lesson plans

The main activity intended for this section was teachers' cooperation in order to create intercultural lessons of their own. The teachers were asked to cooperate to (a) discuss how they would teach the next two lessons in the textbook, (b) develop intercultural lesson plans to teach these lessons, and (c)arrange tasks for each other during the interim between these lessons. However, instead of creating their own intercultural lessons version or extending the model version, the teachers kept following the intercultural learning components (noticing, comparing, relating, and reflecting) and their implementation sequence as designed in the model intercultural lesson plans. What they discussed for each new lesson plan was articulating the scenarios and roleplays based on the topic of each lesson and outlining the key activities they would include in the lesson plans for each lesson.

\section{Post-workshop classroom observations}

Nearly a week (five days) after the workshop, the teachers implemented teaching their two co-constructed lesson plans. During the interim before each lesson, the teachers supported each other through emails and phone calls. In class, I took a limited-participation role to observe the teaching practices of each teacher. The teachers did not observe each other.

\section{Post-observation teacher interviews}

Each teacher attended an individual semi-structured in-depth interview within two weeks after their teaching. Each interview included stimulated recall and in-depth sections similar to the interviews in the first workshop cycle. Each interview lasted from one hour to one hour and a half. The teachers were asked questions such as: How did you feel while you together with your class were writing the hypothesis in this lesson? Was it different to previous lessons? What did you think about your students' roleplay performance? Did you feel more comfortable or pressured while using the group's lesson plans?

\subsubsection{Data sources for analyses}

Each teacher's teaching in Phase Two involved five lessons in total (three lessons after the first workshop and two lessons after the second workshop). Teaching in the three lessons after the first workshop was more guided as all teachers were asked to implement the intercultural lesson plans. For the analysis below of the teachers' teaching following the first 
workshop, I focus on the first and the third lessons because each lesson focused on a different kind of speech act. The first lesson was taught in week five, focusing on requests. The third lesson, in week eight, focused on agreement/disagreement. Due to space limitations, I chose not to describe the second lesson because it focused on the speech act of making requests, similar to the first lesson.

Teaching in the two lessons after the second workshop was intended to be more independent. The second workshop created chances for the teachers to discuss and coconstruct their own intercultural lessons for the two last observed lessons. However, they agreed with each other to adopt the same redesigned intercultural components as in the earlier lessons (making hypotheses, analysing and comparing conversations, revising hypotheses, and relating and reflecting). They co-constructed the scenarios and roleplays and agreed on these. In this way, the teachers applied the redesigned intercultural model I had given them instead of extending the model or creating a new one. For the analysis below of the teachers' teaching following the second workshop, I chose to focus on the fifth lesson taught in Week twelve because this was the last observed lesson in the research. The fourth lesson was not chosen because it was interrupted by unexpected power cuts during the lesson.

Each case includes description of the teacher's teaching, their perception about their teaching, and the students' perception of the experience of learning. Thus, each of the student post-focus groups is considered a part of the data for each case study. In summary, the cases each included:

- Observational data:

- $\quad$ The first and third lessons taught after workshop one

- $\quad$ The fifth lesson taught after workshop two

- Audio-recorded data:

- $\quad$ The teacher mid interview (post-workshop-one interview)

- The teacher final interview (post-workshop-two interview)

- $\quad$ The student post-focus group

Analyses aimed to respect the integrity of the case studies and of each lesson as a single organic unfolding event. Analyses also explored how the intercultural lessons unfolded and 
how intercultural growths or shifts were evident in each teacher. Moreover, thick description allowed triangulation across data sources.

\subsubsection{The intercultural lessons}

Five lessons in the current textbook were chosen for integrating intercultural language teaching (post-workshop teaching observations). This was because each of these lessons has a section on language focus/conversation strategies which presented a specific speech act. The speech acts included in these lessons were: making a request, agreeing/disagreeing, giving advice, and apologising. This seemed to be the most relevant place for developing an intercultural stance within the chosen listening and speaking course at the chosen university. In table 17, I summarise these five lessons' content, using the current textbook by Kenny and Wada (2009). 
Table 17. Specifics of lessons for integrating iCLT

\begin{tabular}{|c|c|c|c|c|c|}
\hline \multicolumn{6}{|c|}{ Phase two } \\
\hline Parts & \multicolumn{3}{|c|}{$\begin{array}{l}\text { Part one: } \\
\begin{array}{l}\text { Post-workshop-one lessons: re-designed by the } \\
\text { researcher }\end{array}\end{array}$} & \multicolumn{2}{|c|}{$\begin{array}{l}\text { Part two: } \\
\text { Post-workshop-two lessons: Co- } \\
\text { constructed by the teachers }\end{array}$} \\
\hline Weeks & \multicolumn{3}{|c|}{$5-8$} & \multicolumn{2}{|c|}{$11-12$} \\
\hline Lessons & $1^{\text {st }}$ & $2^{\text {nd }}$ & $3^{\text {rd }}$ & $4^{\text {th }}$ & $5^{\text {th }}$ \\
\hline Titles & $\begin{array}{l}\text { 4A: } \\
\text { Where is the } \\
\text { party? }\end{array}$ & $\begin{array}{l}\text { 6A: } \\
\text { Could you turn } \\
\text { down the music? }\end{array}$ & $\begin{array}{l}\text { 7B: } \\
\text { My online space }\end{array}$ & $\begin{array}{l}\text { 10A: } \\
\text { I recommend } \\
\text { plenty of rest }\end{array}$ & $\begin{array}{l}\text { 12A: } \\
\text { We're terribly } \\
\text { sorry about that }\end{array}$ \\
\hline $\begin{array}{l}\text { Listening } \\
\text { tasks }\end{array}$ & $\begin{array}{l}\text { - Talks about } \\
\text { parties } \\
\text { - Conversations } \\
\text { making service } \\
\text { request for } \\
\text { parties }\end{array}$ & $\begin{array}{l}\text { - Public } \\
\text { announcements } \\
\text { - Conversations: } \\
\text { people request } \\
\text { others to stop } \\
\text { doing something }\end{array}$ & $\begin{array}{l}\text { - A conversation } \\
\text { about online } \\
\text { service } \\
\text { - Stresses in } \\
\text { words such as } \\
\text { research, } \\
\text { contest. }\end{array}$ & $\begin{array}{l}\text { - Voice messages } \\
\text { predicting TV } \\
\text { medical experts } \\
\text { - Patients talking } \\
\text { to doctors about } \\
\text { their medical } \\
\text { problems }\end{array}$ & $\begin{array}{l}\text { - Talks about } \\
\text { places of travelling } \\
\text { - Conversations } \\
\text { about customer } \\
\text { services }\end{array}$ \\
\hline $\begin{array}{l}\text { Speaking } \\
\text { tasks }\end{array}$ & $\begin{array}{l}\text { - Making } \\
\text { request about } \\
\text { party }\end{array}$ & $\begin{array}{l}\text { - Requesting } \\
\text { people to follow } \\
\text { instructions }\end{array}$ & $\begin{array}{l}\text { - Taking about } \\
\text { cyber friends }\end{array}$ & $\begin{array}{l}\text { - Giving advice } \\
\text { about medical } \\
\text { problems }\end{array}$ & $\begin{array}{l}\text { - Making } \\
\text { complaints and } \\
\text { apology about } \\
\text { service situations }\end{array}$ \\
\hline $\begin{array}{l}\text { Language } \\
\text { strategies }\end{array}$ & $\begin{array}{l}\text { Making } \\
\text { requests }\end{array}$ & Making requests & $\begin{array}{l}\text { Agreeing/ } \\
\text { disagreeing }\end{array}$ & Giving advice & Apologizing \\
\hline $\begin{array}{l}\text { Observed } \\
\text { \& video } \\
\text { recorded }\end{array}$ & $\checkmark$ & $\checkmark$ & $\checkmark$ & $\checkmark$ & $\checkmark$ \\
\hline $\begin{array}{l}\text { Chosen to } \\
\text { analyze }\end{array}$ & $\checkmark$ & & $\checkmark$ & & $\checkmark$ \\
\hline
\end{tabular}

However, the content related to the given speech acts in the above five lessons solely focused on grammar. For example, in lesson $4 \mathrm{~A}$, the language focus for making a request includes "You can use Can I/Will you/Could we/May I + verb to make requests" and provides examples: "Can I have a drink? Will you get me a menu? Could we make a reservation? May I get some information?" (Kenny \& Wada, 2009, p. 21). Following the language focus/conversation strategies, there was no learning activity that potentially engage students with intercultural learning related to the speech act of making request. 
Therefore, on the basis of the five lessons above and the selected course (as described in Chapter 3), to address culture more explicitly, I developed a model of intercultural lesson which emphasizes the following intercultural skills: noticing, analysing, comparing, relating and reflecting. Specifically:

- Noticing skill involved students in (a) recognising one's own cultural assumptions and/or prejudices, (b) recognising what and how textbook-based conversations were said (e.g., the phrases that were used to convey politeness, to make conversations go smoothly, use of tone and stress and intonation in speech acts), (c) evaluating and exploring politeness, indirectness, and overall effectiveness of the conversations, and (d) discussing dimensions of conversational context such as degree of social distance.

- Comparing skill focused on comparing English and Vietnamese language styles and comparing students' roleplayed conversations and the textbook conversations.

- Relating skill involved students in sharing with friends about their previous communication experience and relating it to their own perspective.

- Reflecting skill involved students in drawing out their lessons/messages from the communication experiences and reflecting on their own perspective with respect to the cultural content embedded in the lesson input.

The redesigned intercultural content was intended to reflect the core principles of iCLT:

1. Mine the input for its cultural content

2. Encourage an exploratory, experiential, comparative, and reflective approach to culture in which learners (guided by teachers) construct intercultural perspectives

3. Develop awareness of how one's own assumptions, beliefs and behaviour are culturally shaped

4. Value intercultural learning goals alongside linguistic and communicative goals

The intercultural lesson model was designed with the purpose to enable the participants teachers to address the intercultural content embedded in the textbook lessons more explicitly alongside their teaching of listening and speaking skills. To successfully do this, in the workshops, the teachers were introduced to and discussed the rationale and theoretical framework (e.g., the iCLT principles) underpinning the intercultural skills included in the 
intercultural model lessons, and the classroom procedure for implementing these lessons in their upcoming observed teaching practices.

In terms of classroom procedure, at the start of each intercultural lesson, the teacher gives his/her class a communicative scenario and ask them to respond to it in English and in Vietnamese. Following this, the teacher asks the students to make cultural hypotheses about how the communication should be managed. For instance, at the start of lesson 4A, the teacher gives a scenario, which asks one person to make a request to achieve a communication purpose, to prompt the students' responses in both English and Vietnamese. Based on the students' responses, the teacher and students discuss how Vietnamese and English are used to make requests effectively. The outcome of this first stage is a cultural hypothesis related to the speech act being learnt.

Second, the teacher introduces his/her class to the communicative roleplay situations, which were based on the textbook lesson input (i.e., the lesson's audio conversations and its focused speech act) and asks the students to create a roleplay for each given situation in both English and Vietnamese for a point of comparison (e.g., how to request a change for reservations at a hotel). He/she then asks pairs of students to perform their roleplays. For example, in lesson 4A, at this second stage, the teacher has prepared a number of roleplays based on the lesson's topic (e.g., speakers make request for services such as booking a party room) and introduced these roleplays to the students. He/she can now organise the students into pairs to prepare their roles and then perform their roleplays in English for speaking practice. Following this, the teacher has his/her students listen to the textbook conversations for listening practice.

Third, the teacher guides the class to analyse the textbook conversations. For example, for lesson 4A, conversation analysis focuses on: (1) analysing the language (e.g., what phrases are used to make requests, what phrases make the analysed conversation go smoothly), intonation and pronunciation; (2) evaluating and exploring (e.g., the social context and relationship between speakers); (3) comparing the textbook conversations and the students' own roleplay conversations in terms of the way people make requests; (4) having the students think about their past experience in which they made requests or were requested to do things, and (5) having the students draw lessons from their past experience. By such analysis, the teacher guides the students towards noticing cultural content in the 
conversations. The students are also guided to review their past experience of using English and cultural beliefs about how people manage communication in English. They are further guided to relate the insights from such review to their initial hypotheses (cultural beliefs and experiences), critically reflecting on this, and finally revising or keeping their cultural hypotheses. Table 18 summarises the classroom procedure for the intercultural content in the intercultural lessons. A sample intercultural lesson plan is provided in the appendix 2.

Table 18. Classroom procedure for integrating iCLT

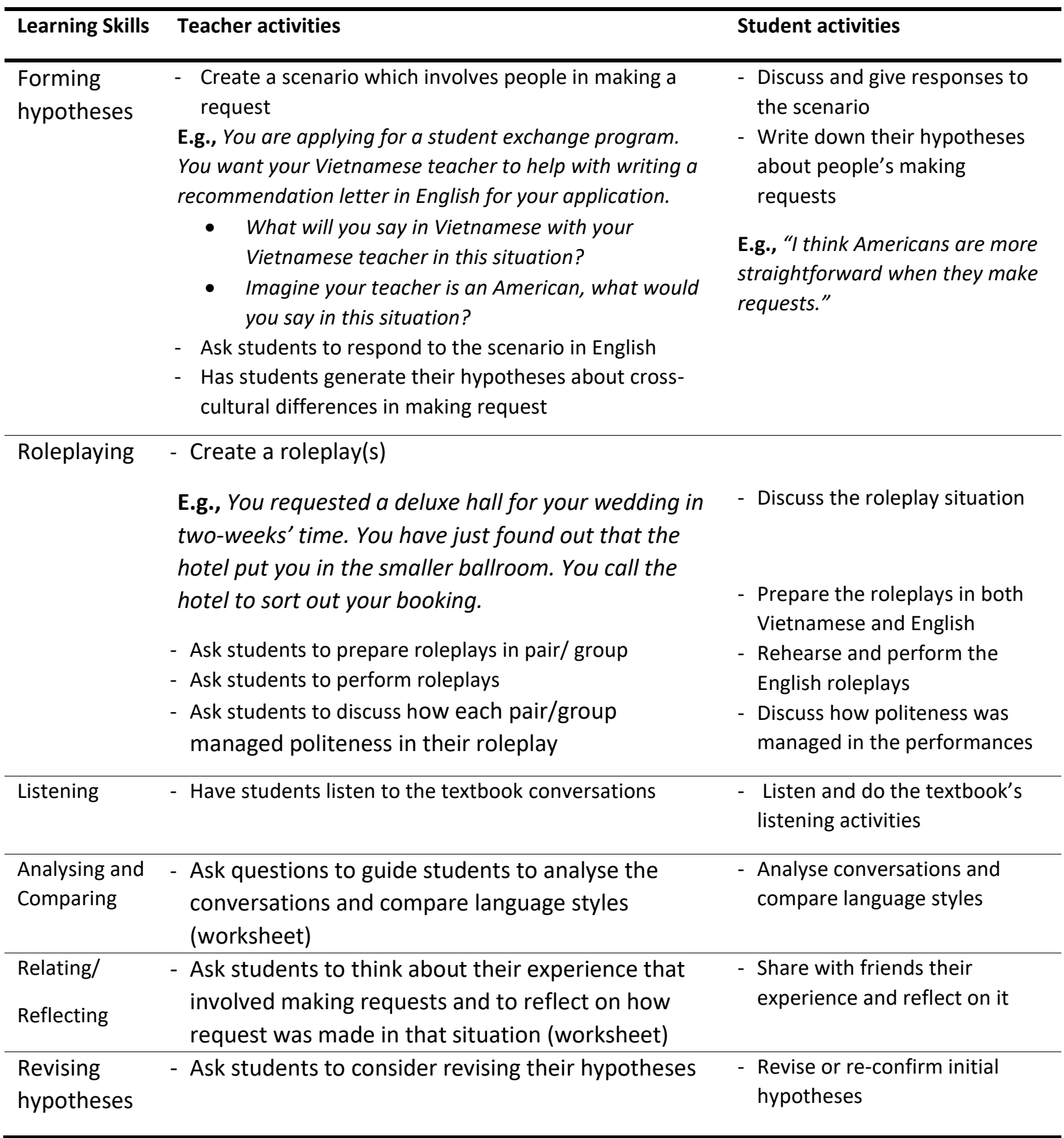




\subsection{The case studies following the workshops}

\subsubsection{Case one: Ms. Sen}

\subsubsection{Observation data}

\section{The first intercultural lesson}

At the beginning of Ms. Sen's first intercultural lesson following the first workshop, she asked the students to suggest different ways of responding in Vietnamese and English to a redesigned scenario (appendix 1.1).

The students responded with a lot of suggestions. She wrote on the board both their Vietnamese and English responses. Some examples were "Em có vài thắc mắc, Cô giúp em được không?" (I have some enquiries. Can you help me?), "Can you help me with a recommendation letter?"; "Do you have free time? Can you help me write a recommendation letter?" Ms. Sen and the students read through all the responses again. She asked them what the purpose of these sentences was and gave comments about these sentences. After that, Ms. Sen formed the hypothesis which was:

"Vietnamese and American are as polite as each other when making requests. But Americans are more direct than Vietnamese."

She asked the students to vote for the suggested hypothesis. They all agreed upon it.

Next, for the conversation analysis, Ms. Sen asked the students to think about factors that affect how Vietnamese make requests. She suggested dimensions such as relationship, familiarity between people, attitude, and context. After that, she introduced a conversation for modelling conversation analysis (Riddiford \& Newton, 2010, p. 23) which was about requesting a Friday off in a New Zealand workplace context (appendix 1.1). She modelled how to analyse this conversation. To continue, the teacher had the students listen to the textbook listening activities. She then asked them to analyse the conversations they already listened to. Students used conversation transcription during analysis.

Next, Ms. Sen guided the students to compare Vietnamese and English language styles as suggested in the worksheet (appendix 2.2). The students compared in terms of word use, intonation, and ways of addressing in the two languages. The class ended at this step as time was up. 
In the following class, Ms. Sen reminded the students about the last class. She emphasized the importance of making requests appropriately in real life. She wrote on the board phrases such as Could you/If you don't mind/Would you mind if...? She explained the terms politeness and (in)directness. She asked the student to finish the comparing task from the previous class. She invited some students to talk about their comparison of Vietnamese and English style differences. One student said that in English receptionists were more respectful and more polite to clients than those who are Vietnamese.

The lesson moved to the relating and reflecting tasks. Ms. Sen twice emphasized the importance of the ability to request appropriately in real communication. She guided the students to relate and reflect using the worksheet. She invited some students to share their own experiences in front of the class. For example, student Luan said once he asked foreigners that he met in his town to help him with English learning. He said, "Can you spend little time for us to practice speaking English?" He reflected that after Ms. Sen's lesson, he became aware that the phrase he used to request was polite, and now he thought it was a successful experience of using English. Another student, $\mathrm{T}$ also shared her communication experience. Once T was asked by foreigners, "Could you show me the direction to Ninh Kieu Quay?" She could not hear them well at first. She asked, "Can you please repeat that?" Now after Ms. Sen's lesson, she said that the way the foreigners asked her made her feel comfortable to give them the directions. The students then revised the earlier-formed hypothesis to the following:

"Foreigners are often polite and direct when they request."

When Ms. Sen asked them to explain further what they meant by "direct", her students clarified that it means "being straight to the point, not going around something else before reaching the point." They also said in English that foreigners are more direct than Vietnamese because they often go straight to the point instead of mentioning some other points before reaching the main point. For example, the sentence Can you repeat that? indicates directness in communication because the speaker is straight to their point of asking for a repetition.

After that, Ms. Sen discussed communicating in English and in Vietnamese, noting the importance of factors such as intonation, use of appropriate phrases, context, social status, 
in/directness, politeness, and age when communicating in English. She added that it is important to pay attention to speakers' social positions and adjust the use of pronouns when addressing people in communication with Vietnamese. Finally, she ended the lesson by saying "Mind your Ps and Qs in communication." She explained that they should use the word please (Ps) more often for good manner.

\section{The third intercultural lesson}

To begin, Ms. Sen showed pictures (Figure 9) to introduce the lesson's topic, online space and the lesson's language focus, agreement and disagreement.

Figure 9. Agreement and disagreement

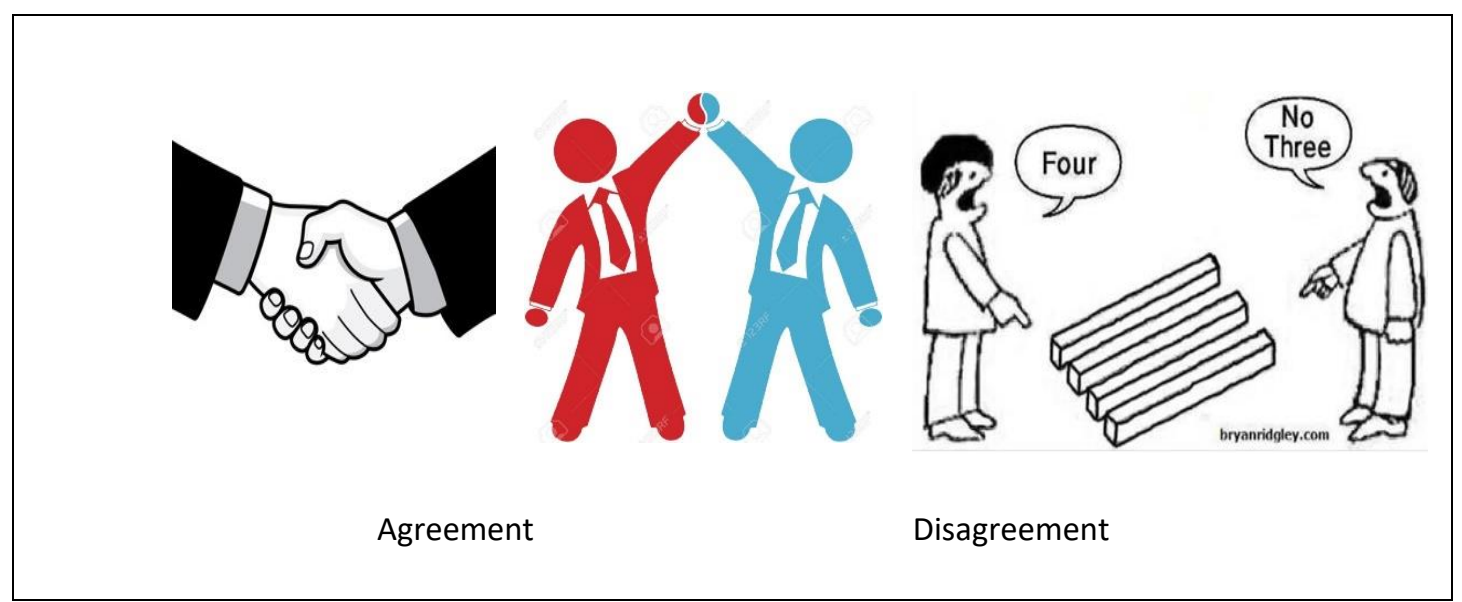

Ms. Sen asked questions in English such as: How do Vietnamese handle disagreement in conversations? How do English speakers handle disagreement in conversations? She explained that disagreement means looking at different perspectives and having different or opposite opinions to each other. She next showed a redesigned scenario and asked the questions that followed (appendix 1.2). Ms. Sen got many answers from students. Most of them respond: "I disagree", "Sorry, I don't agree." Ms. Sen asked the students to write their hypothesis, showed the pre-written hypothesis and asked the students to vote for it:

"I think Americans usually express their disagreement frankly when they have different or opposite opinions because they are individualistic."

Next, for speaking practice, Ms. Sen introduced and had the students do the redesigned roleplays (appendix 1.2). As the students discussed their roleplays, Ms. Sen visited each pair. As observed, creating roleplay conversation(s) took more time for the students than 
rehearsing them. Ms. Sen invited four pairs to perform. After speaking practice, she had the class listen to the textbook conversations and students gave correct answers to the listening activities immediately.

After speaking and listening practice, she guided the students to analyse the textbook conversations. Seeing that some of the students seemed unsure about terms used in the worksheet such as "direct", "indirect", "soften disagreement", Ms. Sen explained these terms again. She said that to be polite people use the phrases "I am afraid... or I don't think so" to express their disagreement indirectly. Ms. Sen asked students to share and explain their analysis. Ms. Sen asked them to refer back to their initial hypothesis. Then, she showed the pre-written revised hypothesis as follows:

\footnotetext{
"I see that the Americans in the conversation are willing to discuss about their disagreements with each other. They pay attention to the others' point of view instead of putting them down (e.g., "I see what you mean but..."). They use phrases to soften their disagreements and avoid conflicts ("I'm afraid...", "Oh yeah, sweetheart, Mmm...."). They also give reasons to support their opinion ("I think...", "to me...", "but I don't see..."). Understanding, and respecting other people's point of view, and politeness are emphasized. The speakers also show disagreement by reluctantly agreeing ("I can't disagree with anything you said here Mom")."
}

Students agreed with the revised hypothesis. Then, Ms. Sen wrote on the board phrases that indicated different degrees of disagreement. She also said, "in informal situations and with familiar people, they may say, 'Are you kidding me?'" and "to be indirect or soften disagreement, people may say, 'I don't think so' or 'I see what you mean but...'”. She further explained that parents used endearment terms to convey disagreement with children.

Next, Ms. Sen asked the students to make comparisons. They compared (a) their own English roleplayed conversation with the textbook-based conversations and (b) the Vietnamese with English styles of saying disagreement. She worked with individual students. Finally, Ms. Sen asked all students to talk about their experiences that involved their using English to express disagreement.

\section{The fifth intercultural lesson}

Ms. Sen was five minutes late for class. She entered the room and said sorry to the class. First, she said, "Today I came late, what did I say and why I said so?" Students answered, 
"You said I am sorry" and "because you did something wrong." This led the students to the lesson which focused on saying an apology.

Second, Ms. Sen asked how often the students get back to their hometowns and about the local transportation services. Most of them said that they use coaches. She explained that bus is American English and coach is British English. She showed a used coach ticket to the class and began to introduce a scenario (scenario 1, appendix 1.3). Many students gave responses in both Vietnamese and English. Ms. Sen let them speak as much as possible until no more responses were given. For example, students said: "Tôi xin lỗi vì đã phát trùng vé" (I am sorry for giving the same ticket), "Có sự nhầm lẫn gì ở đây, tôi sẽ kiểm tra lại” (There may be a mistake. I will check it), "I'm very sorry about this problem. I will fix it", "Sorry for my carelessness. I will change another ticket for you." Ms. Sen wrote all responses on the board. She asked them to read through and write down their thoughts about the responses. Students shared their thoughts and Ms. Sen wrote some of them on the board:

"I believe most English speakers usually apologize first, then fix the problem or correct their mistake."

"I think they say sorry and solve the problem right away."

"I think they accept their mistake quickly and correct their action."

Some students found it difficult to express their hypothesis in English and asked Ms. Sen for translation. Together they formed the following hypothesis on the board:

"I believe most native speakers of English apologize first and fix the problem. They don't give any explanation because they accept their mistakes and solve the problem right away. They're polite to customers."

Ms. Sen introduced the roleplays. She used real items to teach words useful for the roleplays such as plane ticket, economy class, business class, and boarding pass. She used pictures to teach the words motor, car buyer, car seller contract, and deluxe suit. The students read the roleplays (appendix 1.3). Students prepared and rehearsed the roleplays in pairs. Ms. Sen went around to monitor the class. Six pairs performed their roleplays. Following speaking practice, Ms. Sen had the class listen to the textbook conversations twice. Students did the listening activities quickly and correctly.

Next, Ms. Sen asked students to compare textbook conversations with their roleplay conversations in terms of politeness criteria. She suggested that they should think critically 
and comment on the phrases in the conversations. Consequently, the students revised their hypothesis. They explained the changes they made. Based on this, Ms. Sen wrote on the board and made sure it was exactly what the students meant as follows:

"I think most native speakers of English usually receive a complaint in a friendly, polite, formal and apologetic way in service situations. People apologize for the inconvenience they caused and offer compensation to fix the problem."

For the relating and reflecting tasks, Ms. Sen asked her students to follow the worksheet and share answers. At this point, the class ended.

\subsubsection{Teacher interview data}

The following themes arose from the mid and final interviews with Ms. Sen:

1. Values of the integrated intercultural teaching

2. Challenges of integrating intercultural teaching

3. Ms. Sen's attitudes toward adopting an intercultural orientation

4. Ms. Sen's perception about students' learning in intercultural lessons

Each theme will be detailed below:

\section{Value of the integrated intercultural teaching}

For this theme, Ms. Sen talked at length about the values of integrating intercultural content, using hypotheses, comparing conversations, relating and reflecting tasks.

\section{a. Integrating intercultural content}

First of all, when asked about her perceptions of teaching intercultural lessons, she emphasized the link between the redesigned intercultural content and students' involvement as follows:

"They are connected to make the lessons...all are connected, easy to understand, not difficult....I think activities in the lessons all engaged students because you write hypothesis and you ask them, they analyse conversations, they get involved, they relate they get involved, they revise they get involved.. all steps they have to get involved".

Ms. Sen gave a positive comment on integrating intercultural content: 
“Lồng ghếp các yếu tố đó vô, nó biết hơn ra về văn hóa. Cô nghĩ nếu không có dùng các steps đó... thì cái phần văn hóa sẽ rất là ít focus, học sinh không thấy rõ."

(Integrating the re-designed components helps students become more aware about culture. I think if I had not integrated these components, cultural dimension had been little focused, and students hadn't recognized cultural aspect clearly.)

In her view, the integration of intercultural content could engage students to a larger extent because it added more culture to the lesson. This enhanced students' awareness of various aspects of the cultural dimension.

Second, integrating intercultural content increased teachers' interest and awareness of teaching culture. She expressed her interest and growing familiarity with the innovation when she talked about the experience of participating in the research:

“Tới cái bài này thì cô thấy nó dễ hơn những cái bài đầu. Vì một là mình đã remember các steps. Hai nữa đây là cô thích, thích nó có đưa cái thực tế vô. Cái cảm giác của cô là hơi lo .... lo là điều mình dạy có giúp nó thay đổi hay không."

(Until this lesson, I found it easier than the previous intercultural lessons. First, I have remembered the redesigned steps. Second, I liked it as it brought the reality into classrooms. I was a bit concerned...concerned if what I taught helps to change my students.)

Ms. Sen's reflection of her participation in the research reveals her perceived professional gains and limitations. Her perceived gain was obvious when she reflected:

"This is good chance for me to get updated about theory and reflect what I used to teach. I used to focus on one side too much. That means not having taught students about the differences between our own and the foreign language and culture."

Here, she compared her own teaching style in the past with her recent intercultural teaching experience. Her emphasis on teaching both the target culture and one's own culture indicates her increased awareness of teaching cultural comparison from participating in this study.

Additionally, Ms. Sen highlighted the benefit of collegial co-operation in the second workshop cycle. She explained the value of sharing ideas and tightening collegial relationships during intercultural teaching integration:

“Cô nghĩ nó sẽ hay hơn bởi vì two minds are better than one... Cô thích cái share á ... Cô thấy vậy cũng là cái hay...vì ít ra mình có ngồi chung together. Nó active hơn, có close relationship hơn.” 
(I think it is more interesting because two minds are better than one... I like sharing. It is interesting...as at least we sit together. It is more active and closer relationship).

\section{b. Using hypotheses}

Ms. Sen perceived various benefits of using hypotheses to teach culture. First, she commented that the use of designed scenarios was helpful. She said:

"I think the scenario is helpful... it's good. It's like your routine when you talk to someone, you assume this person is like this like that but after talking to this person you say a..h...h right or wrong or uhm..uhm somewhere in between."

Second, Ms. Sen perceived that forming and revisiting hypotheses helps students to broaden and think critically about their own perspectives. She said:

“... if they can revise, it means they understand the lesson better... After analysing you see more aspects and draw conclusion whether...ah...it is true, we add more to it, or it is wrong. I think it is important. If they understand better, they can revise or change or write a new one."

Third, she noted that revising hypotheses was useful for students:

“Học sinh cần hiểu rõ sự khác biệt giữa forming initial hypothesis và revising hypothesis, tại sao mình phải revise nó. Trong đời sống hàng ngày mà nó nói chuyện nó nghe ai nói cái gì đó, nó cũng có kiểm chứng suy nghĩ cho nên cũng hay."

(Students need to distinguish clearly between forming initial hypothesis and revising hypothesis, and why they need to revise it. In daily communication, they hear people say something, they can revisit their thinking, so this is good too).

Interestingly, Ms. Sen commented in English on how the hypothesis component made her become aware of her role and focus on intercultural dimensions:

"...So you have to guide ...to make them understand why we have a hypothesis. After you analyse language you see why you have to revise it. It's good for me."

"It reminds you that you sticked to it. But if you don't have it, you ... don't go fine enough."

For Ms. Sen, the use of hypotheses helps students realize their own self in communication and enhances teachers' awareness of addressing culture in classes.

\section{c. Comparing conversations}


Ms. Sen thought that comparing conversation benefits students in many ways. Comparing develops students' critical thinking and problem-solving skills. She explained the reasons she liked comparing task in English below:

"Students see differences more clearly... I think it is easier for them to notice language differences... Develop critical thinking. When comparing students have to know both, seeing which is different. As a result, they have to know how to solve problems based on differences. For instance, they can do their way similar to what Vietnamese people normally do or they can change as Americans or they can adjust parts...; but at least they see differences in structures, language, and intonation... I find the redesigned component interesting at this point. Not until now have I recognised how interesting it is. Without following your method, I would have explained differences very quickly and not made a comparison table like this. If so, students could not understand cultural differences clearly as such."

Ms. Sen also perceived the comparing tasks as intercultural learning opportunities in which students explore, make sense of, and challenge their own perspectives. The following extract illustrates this:

R: What were you thinking when teaching comparing activity?

Ms. Sen: Cô thấy là thú vị lúc đó, học sinh...nói lên được cái ý của nó. Bây giờ trong cái bài này nó sẽ thấy là không phải như cái mình nghĩ. Đây cũng là một điều thú vị cho nó và cho người dạy... vì giúp nó hiểu được hơn hypothesis của mình, revising hypothesis là làm sao.

(Ms. Sen: I felt interested at that time because students expressed their ideas and recognized their thinking. Now in this lesson, they discovered that it is not the same as what they thought. This is interesting for both students and teachers because students understood more about their hypothesis and what it means to revise it).

In brief, the comparing tasks were seen by Ms. Sen as valued opportunities to develop various skills in students.

\section{d. Relating and reflecting tasks}

Ms. Sen explained the advantages of using relating and reflecting tasks. First, she said that these tasks are related to students' personal experiences, and by this, students found learning easy:

"Relating and reflecting was the part I like best because it relates to real life. This activity is the best activity of the lesson. Students have chance to say things that they can use expressions they learn from my lessons for real life....I think it is easy because it is about their own experience...They didn't invent it because things happened to them." 
Additionally, Ms. Sen perceived that relating and reflecting tasks encouraged students to make meaning from their experience because these tasks challenged their lived experience and traditional learning style. She elaborated this:

R: Is it easy or challenging for students to draw lessons from their own stories?

Ms. Sen: I don't think it's easy for Vietnamese students because they ...maybe... it becomes a habit that their mind was reluctant to think...because most of the time they were asked to memorise things and repeat. Now, they have to figure out something meaningful...it's difficult. It's not easy for them. In my experience these tasks challenge their traditional learning style.

In short, Ms. Sen emphasized how she now saw diverse benefits of the experience of intercultural teaching for both students and teachers.

\section{Challenges of integrating intercultural teaching}

For Ms. Sen, integrating intercultural teaching challenges teachers' intercultural communication experiences, intercultural knowledge and intercultural teaching skills. First, lack of intercultural communication opportunities affects teachers' confidence in teaching. She explained:

"Now not all teachers have opportunities to communicate with people from different cultures. This makes them not confident when they teach and explain culture differences. They only base on textbook to tell students. It is very challenging for teachers who have never been abroad."

Second, Ms. Sen maintained that intercultural teaching requires teachers' intercultural knowledge at multiple levels and intercultural teaching skills. When referring to her teaching of conversation analysis, she noted:

R: Was it easy or challenging for you to teach the analysing activity?

Ms. Sen: not very challenging because I have exposed to American culture and Vietnamese culture ...I think if you have no knowledge about culture it is not easy to analyse conversations and compare differences between cultures_because ...if you don't study more about this, you don't know how to explain differences between two cultures, it's not an easy thing.

R: Is it challenging for the native English teacher to guide students to do this step?

Ms. Sen: Yes. It is easy on their part of English because they live in that culture. But for the part of Vietnamese culture they have problem. In the same way, Vietname teachers know about Vietnamesse part but not much about the English culture or American culture. 
In Ms. Sen's view, teaching interculturally challenges teachers in several ways especially their intercultural knowledge and teaching skills. Her answers indicate that teachers' intercultural knowledge is more vital than teachers' being native or non-native speaker of English because it is intercultural knowledge that enables teachers to explain, analyse, and compare cultures.

\section{Ms. Sen's attitudes towards adopting an intercultural orientation}

In both interviews, Ms. Sen displayed a desire to adopt and to learn from adopting intercultural teaching in the future although she seemed selective. When asked about her willingness to use the innovation, she restated in English her desire and preference for relating/reflecting and comparing: to use Byram model to analyse this point

"Not from beginning to end, maybe reflecting, comparison... is the first step. The re-designed comparison is more detailed than what I used to. That's the new thing for me because when I teach I focus more on what American say, not on Vietnamese...I continue to use one hundred percent sure. I will analyze lesson plans more in detail... Reflecting and relating means you bring real life into your teaching. That is the part I am very pleased with."

Additionally, when Ms. Sen reflected on her participation in the research, she felt selfmotivated to adopt the innovation. She said in both Vietnamese and English:

“Cô thấy mình có trách nhiệm hơn. Dĩ nhiên có thích thú mình mới tham gia nhưng mà trong cái thích thú đó mình cũng có cái trách nhiệm hơn, đầu tư hơn, ... có đầu tư hơn mình mới học được nhiều hơn."

(I see I am more responsible. Of course my own interest makes me participate in the project but this also means more responsibility and investment. ...More investment enables more learning about the topic).

\section{$[\ldots]$}

"I reflect what I have done so far and what I should change in future... of course something new ... but now you have a chance to do it, so you want to continue because it is better or it makes you feel good about what you do or it makes students interested in."

Hence, participating in the research seemed to enhance her professional reflection and motivation.

\section{Ms. Sen's perception about students' learning in intercultural lessons}


In the first three lessons, (weeks five to eight), Ms. Sen's perception did not reveal students' active engagement. She said about their involvement in these lessons:

“I don't think they were active enough as I expected. The problem is for some students they didn't know what to do. They didn't use any expressions learned from the lessons. I feel that some were not very active."

In contrast, after the second workshop, Ms. Sen highlighted students' active engagement in the lessons (weeks ten to twelve). For example, while watching the video replay of students' analysing conversations in the fifth lesson, she noticed student's improvement:

R: Có thấy là buổi học này các bạn phân tích khá là tốt không?

Ms. Sen: Nó đỡ hơn mấy lần trước ...Giờ thì nó quen rồi, nó biết là so sánh phân tích làm sao...dễ hơn."

(R: Do you think that in this lesson students analysed pretty well?

Ms.Sen: They were better than previous times ...Now they got familiar, they knew how to compare and analyse...easier).

The following is another example of Ms. Sen's positive comment on students' revising hypotheses:

R: Cảm nhận của cô lúc cô cũng với lớp viết ra xong hypothesis này?

Ms Sen: Cô thấy vui hơn vì nó nói được một số câu. Có nghĩa là có những cái ý của nó nó nói lên được, ..nó cũng chú ý, cũng đóng góp ý kiến, hiểu bài hơn, nắm được hơn, trả lời được......Cô thấy dễ hơn vì nó thấy cái khác biệt giữa cách response của người Mỹ với người Việt... Nó viết được cái hypothesis rồi, thì bây giờ nó tự nhiên hơn.

(R: Your perception while writing this hypothesis with your class?

Ms. Sen: I felt happier as they could write some sentences. I mean they could express their own ideas...they also paid attention, contributed ideas, understood lessons more, mastered more, could answer...I felt easier because students saw differences in Americans and Vietnamese's responses ... They wrote hypothesis, so now they become more natural).

Moreover, Ms. Sen mentioned students' language improvement:

R: Cô cảm thấy như thế nào về khả năng nghe của học trò bữa đó?

Ms Sen: Nó cũng khá hơn đó, tại cô hỏi nó cũng trả lời được.

(R: How did you feel about students' listening skill that date? 
Ms Sen: They were better too because they could answer when I asked them.)

All the above incidents indicate a positive turn in Ms. Sen's perception about students' learning which progressed from passive to more engaged and improved toward the end of the research. It is also possible that the students' behaviours could also have actually changed some since they were getting more used to her using an intercultural teaching style by this point.

\subsubsection{Post-workshop-two focus group data}

In the focus groups, students' comments on the intercultural lessons conveyed their perceived positive perceptions of their learning outcomes in these lessons.

\section{Students' perceived learning outcomes}

First, students perceived that the intercultural lessons provided richness of speaking practice opportunities and speaking content. The following extracts, said in English by the students, illustrate this:

R: To compare with the non-observed lessons, in what way were the observed lessons different?

Nghi: We had chances to compare. The normal lessons strictly followed textbook.

Lan: I agree.

Lien: I agree.

Lan: Played roles

Thu: Make more conversations in the video lessons.

Lien: More on speaking skills, and more improved. I like this.

Nghi: Invited to speak more often, more speaking in front of the class.

Thu: Can talk about our experiences

Lieu: I like comparing ...this complements my own conversations. Teacher taught phrases that make conversations go smoothly.

Following the above extract, the group agreed that the teacher came to their desk and listened to their ideas, corrected their speaking style and their conversation, and gave her comments. This made their conversations better with richer ideas. Hence, the student selfreport indicates that the intercultural lessons fostered learner-centredness. 
In essence, students identified a range of speaking opportunities including responding to scenarios, creating and rehearsing roleplays, forming personal hypotheses, relating to personal experiences, sharing personal lessons, and discussing personal reflections.

Second, students' intercultural awareness was evident. They identified influential factors in intercultural communication below:

R: What should you pay attention to when you communicate in English with foreigners after you have learnt these lessons?

Lan: From now on when speaking English, we shouldn't translate word by word from Vietnamese to English...

(Nhu: agreed with Lan)

Nghi: At least we become aware that there are things that are considered impolite in other cultures but we think they are normal in our culture.

Thu: I must... think about ... emotions, gestures, facial expressions...because these make my conversation effective.

(Lien: agreed with Thu)

The students' reported learning outcomes of avoiding word-by-word translation, awareness of cross-cultural differences regarding politeness and of non-verbal components in intercultural communication are evident in the following extracts when Lien talked at length about how she found the lessons interesting and enlightening:

“...Một cái hay là hiểu được là cách thể hiện ý kiến giữa người Việt Nam và nước ngoài có nhiều khác biệt. Ví dụ nước ngoài rất chú ý cách dùng cụm từ tăng tính lịch sự (Can I..Could I, Will you). Họ muốn đưa lời khuyên thì đầu tiên họ đưa lời khuyên, sau đó kèm reason để thuyết phục để người nghe dễ chấp nhận hơn. Còn khi nói không đồng ý thì họ dùng các cụm từ giảm xung đột như I see what you mean but...Em thấy em hiểu hơn về cách nói cũng như sử dụng tiếng Anh nói chuyện với người nước ngoài.

Em thích phần chia sẻ kinh nghiệm nhất vì sau đó được đưa ra tình huống thực tế, áp dụng cấu trúc vô...hơn nữa. Được nghe các bạn chia sẻ kinh nghiệm của các bạn nên thú vị hơn. Nghe được nhận định từ nhiều phía rút ra nhiều bài học từ nhiều người dựa trên một chuyện”.

(It was interesting as I understood that the ways Vietnamese and foreigners express opinions are greatly different. For example, foreigners pay attention to phrases that indicate politeness such as Can I, Could I, Will you. When they give advice, they include reason to explain it to convince listeners. 
When disagreeing, they use phrases that minimize conflicts such as I see what you mean but...I see I better understand ways of speaking and using English to speak with foreigners.

I like sharing experience most because it is followed by a practical situation for us to apply language structures to talk about it... It is more interesting to listen to friends' sharing experience, more lessons and comments on one issue).

Lien's statement showed that she developed awareness about cross-cultural differences in language use regarding the specific learnt speech acts. This awareness goes beyond pragmatic knowledge because she critically compared cross-cultural language styles and personal perspectives.

In the end, when asked about the significance of the experience of the intercultural lessons, the students pointed to an integrated view of intercultural language learning. As Lien said and Nghi agreed then upon:

\footnotetext{
“Mình học ngoại ngữ đâu phải là chỉ học bốn kỹ năng ... mà cần ... biết cách phân tích một vấn đề nào đó, rút ra cho bản thân mình bài học. Vừa nhớ dai hơn, vừa có hiệu quả hơn khi giao tiếp, biết cách vận dụng những gì mình đã hoc."

(Learning foreign languages doesn't mean only four language skills... we need to know to analyze a certain problem, draw out lessons for ourselves. We can remember longer, become more effective in communication, knowing to use what we learnt).
}

Overall, post-focus group data analysis indicates students' positive learning experiences in both the language and intercultural parts. This confirms Ms. Sen's positive perception about students' learning.

In summary, Ms. Sen closely followed the pre-designed intercultural content and demonstrated interest and increased confidence and familiarity with the integrated orientation. Regarding students' learning, her comments were convergent with the students' comments. What was unique in her lessons was that (1) she often created chances to raise students' awareness about cross-cultural pragmatic differences by stressing dimensions of politeness and appropriateness in making the focused speech acts (requesting, dis/agreeing and apologizing), and (2) she made sure there was sufficient time for students to relate and reflect in all lessons, which reflects an intercultural orientation. 


\subsubsection{Discussion}

\section{Ms. Sen's teaching practices}

Ms. Sen's teaching practices in Phase Two supported the potential for adopting an intercultural orientation in the current context, as discussed below.

First, Ms. Sen's teaching practices in Phase Two addressed culture in a more principled and systematic manner than her teaching in Phase One. In all observed lessons Ms. Sen closely followed the pre-designed content which was intended to reflect principles of intercultural language teaching and learning as mentioned in the first section of this chapter. However, the extent to which each principle was evident varied. In the data, the following principles were more noticeable: value intercultural learning goals alongside linguistic and communicative goals; and encourage an exploratory, experiential, comparative, and reflective approach to culture in which the learners (guided by the teacher) construct intercultural perspectives.

- Value intercultural learning goals alongside linguistic and communicative goals

As an experienced teacher who had interest in and awareness of culture in teaching, Ms. Sen often raised students' awareness about cross-cultural pragmatic differences. In all lessons when guiding students to make hypotheses, Ms. Sen asked students to give responses in English and Vietnamese to given scenarios and wrote many responses on the board for students to compare and revisit during lessons. During the analysing tasks, she constantly emphasized the importance of politeness and appropriateness in English requests and disagreements. When guiding students to compare language styles, she suggested components such as age, social position, and relationship as factors that affect how people request and disagree in Vietnamese language (in the first lesson). Moreover, she explained and familiarised students with terms such as politeness and (in)direct (in the first and third lessons) hoping that they pay attention to their language use to achieve politeness and appropriateness while in communication. These teaching activities made use of the students' first language and culture to explore target language cultures and to draw the learners' attention to cross-cultural pragmatic sensitivity.

Intercultural learning in Ms. Sen's lessons seem to focus on raising students' awareness of politeness and appropriateness in communication and equipping them with relevant 
language to ensure these dimensions, but this also involved students in a more engaging learning style. Through her teaching, students' cross-cultural pragmatic sensitivity and language skills were perceived by the students to improve without either compromising the other. It is important to note that the current textbook and teaching materials did not prioritise learning of culture.

- Encourage an exploratory, experiential, comparative, and reflective approach to culture in which the learners (guided by the teacher) construct intercultural perspectives

Ms. Sen's teaching encouraged an exploratory and reflective approach to culture. She emphasized comparing responses in English and Vietnamese, made time for students to relate the input to their own lived stories and to draw lessons from these experiences. By so doing, students' lived experience was used for their speaking practice and reflection on culture. Relating and reflecting tasks were the parts that Ms. Sen most valued as mentioned in the previous analysis.

Second, Ms. Sen increased her confidence and flexibility in guiding the students. For example, in the first part of the first intercultural lesson following the workshop, she did not explain technical terms such as politeness, and indirectness which prevented the students from comparing language. However, in the second part of this lesson, she explained these terms and looked confident when doing so. In the third intercultural lesson, recognising students' confusion, Ms. Sen explained the terms direct, indirect, soften disagreement and then guided the students to revise/confirm their hypotheses.

\section{Ms. Sen's understandings}

Ms. Sen herself gradually constructed her professional understandings about an intercultural orientation during the research period.

First, she increased understandings about a principled intercultural orientation during the workshop cycles. For example, guiding the students to evaluate their hypotheses, Ms. Sen recognized the significance of helping students to critically understand their own perspective in intercultural communication. Being able to reflect on the self in intercultural communication is an important component of intercultural competence proposed in Byram's (2009) ICC model but unfortunately is usually ignored in teaching worldwide. 
As another illustration, Ms. Sen realised gaps in her previous teaching of culture. Specifically, Ms. Sen acknowledged that her teaching used to pay little attention to the students' first language and cultural identity. This reflective realization is significant because understandings about self and others are synergistically considered important in an intercultural stance.

Traditionally, many Vietnamese teachers and students prefer native over non-native teachers because they believe that the former have advantages over the latter with respect to language proficiency and teaching culture. However, Ms. Sen demonstrated a more advanced view showing that the teachers' intercultural knowledge and intercultural teaching skills are the key regardless of their being native or non-native speakers.

Moreover, the data showed how Ms. Sen's interest and open attitudes towards integrating culture developed. While in Phase One, Ms. Sen perceived that integrating culture adds fun to learning; in Phase Two, she came to understand how integrating culture brings life into classes. This makes the teacher feel more responsible and committed to addressing culture. In my opinion, feeling more responsible and committed is important because it is close to an integrated view of addressing culture alongside language in classes.

These emerging understandings reflects an intercultural stance in important ways. Specifically, they emphasize sensitivity to one's own and others' cultures and languages, abandoning a one-sided focus on teaching native cultural norms, and envisioning characteristics of interculturally competent teachers.

In conclusion, the extent to which Ms. Sen's teaching addressed culture, her growing awareness and understandings about intercultural teaching, her reinforced positive interest, and her shifting perspective can be regarded as positive outcomes of adopting an intercultural stance in her current context.

\subsubsection{Case two: Mr. Huy}

\subsubsection{Observation data}

\section{The first intercultural lesson}

Mr. Huy first activated the students' existing knowledge related to the lesson's topic. He asked them about their party experiences, kinds of party, places, timing, and party services 
in Vietnam. He also shared his personal experiences of attending parties with foreigners and how to book venues for parties. Then, Mr. Huy had students discuss how to request changes for party services at hotels and restaurants.

Second, Mr. Huy introduced the roleplays (appendix 1.1) and used pictures to teach words such as a deluxe hall, a grandball hall, a barbecue, and have a cancellation. He asked students to relate the roleplay topic to similar situations that they may encounter in their future workplaces. Students worked in pairs to prepare for and rehearse roleplays. Mr. Huy had students change their partners three times during these activities. Students performed their English roleplays in front of the class. Mr. Huy asked the audience to take notes about the language phrases used to make requests in the performances and give comments on the degree of in/directness and politeness of the phrases.

Third, Mr. Huy introduced to the class the redesigned scenario (appendix 1.1). He asked students to discuss the scenario and answer the questions that followed. Mr. Huy did not ask students to form a hypothesis.

Next, Mr. Huy modelled how to analyse a conversation using the model conversation (appendix 1.1). After he had the students listen to this conversation, they analysed it in terms of language, pronunciation, context, in/directness, politeness, and effectiveness.

The lesson continued with Mr. Huy having students listen to the textbook conversations. He then followed the worksheet (appendix 2.2) to guide them to analyse these conversations while they were listening. He and students analysed the conversations together.

Following this, Mr. Huy asked students to compare conversations. However, he spent little time explaining this task. The students looked confused. Similarly, for the relating and reflecting tasks, Mr. Huy let students follow the worksheet's instructions. He allowed little time for students to share their reflections with each other. At this point, the class ended.

\section{The third intercultural lesson}

Similar to Ms. Sen, Mr. Huy began the lesson by using pictures to introduce the lesson's topic, online space, and language focus, agreement/disagreement. Mr. Huy asked questions about the way Vietnamese normally express disagreement. Most of the students answered that Vietnamese often keep quiet when disagreeing because they do not want to hurt the 
relationship. The following observation excerpt provides an example of the students' answers and the teacher-student interaction during the class discussion about their use of Vietnamese and their own experience with it:

Mr. Huy: How do you behave or what do you say when you disagree with people?

Student C: ...I still listen to them and say my opinion later. If I still feel unhappy, I still try to keep calm, and look for help from older people like teachers and parents.

Student H: I once kept silent, took a deep breath, and got away.

Second, Mr. Huy showed the redesigned scenario (appendix 1.2) and students volunteered to answer questions with confidence and eagerness. For example:

Mr. Huy: How do you think English speakers express disagreement with each other?

Students together: Direct, frank, strong voice, stressed on some vocabulary.

Mr. Huy: Why do you think so?

Students: They valued individualism.

Based on the students' responses, Mr. Huy asked them to think about how Americans disagree and to complete the following incomplete hypothesis:

"When Americans disagree with someone, they often

Next, Mr. Huy explained words monthly, allowance, anonymous, and disposable. He introduced the roleplay (appendix 1.2) and had the students prepare it. Mr. Huy had the students changed their partner three times. He monitored students' working and gave help. Two pairs were invited to perform their roleplays in front of the class.

After that, Mr. Huy had students listen to the textbook conversations three times. During listening, Mr. Huy had students complete the textbook listening activities. He explained pronunciation and translated some content. He told them that in the Vietnamese language, people usually use additional particles. He said that these are added words that do not have one accurate meaning but serve as lexical means to show speakers' politeness or friendliness. He also emphasized the necessity of understanding the language style of the other English speakers in communication. Also, during the listening task, Mr. Huy asked questions related to the conversations' content and had his students analyse the conversations. Similar to his first intercultural lesson, in this lesson, he encouraged the 
students not to look at the conversation transcription while analysing them. He asked the students to share their answers with each other.

When the conversation analysis was completed, the students followed the teacher's instruction to revisit their initial hypotheses. They were eager to share their revised hypotheses with each other. Two students shared with the whole class as follows:

"I think the people in the conversation express their disagreement politely and they were indirect. "

"I think people try to emphasize their reasons to persuade others. They also listen to other people's opinion. They respect the others' opinion and avoid conflict by using phrases such as "it's ok, calm down."

For the conversation comparison task, Mr. Huy instructed the students to follow the guided questions in the worksheet. He gave little explanation for this task. By now his students were getting familiar with the comparing task, so few instructions were needed.

By the end, Mr. Huy asked the students to tell their friends about their own experiences that had involved disagreement with others. He asked them to pay attention to the language they used to express disagreement. Finally, Mr. Huy asked the students about the lessons they learnt from their experiences.

\section{The fifth intercultural lesson}

To start with, Mr. Huy asked if the students had ever experienced the following situations:

1) Your booked transportation service picked you up at the wrong place;

2) The waiter/waitress brought you the food different from your order; and

3) You bought a product and recognised that it had a fault.

Later, Mr. Huy introduced the lesson's language focus which was about saying an apology. He had students discuss these situations, think about how native speakers of English apologise, and write down their hypotheses.

Next, similar to Ms. Sen, Mr. Huy taught words that students were going to hear in the textbook conversations and probably use in their roleplays. He explained the check-in procedure at airports using a supplementary audio-video clip. He explained words used in this clip such as business class, check-in counter, boarding pass, and boarding gate. After 
that, he introduced and explained the roleplays (appendix 1.3) and put the students in pairs to prepare their roleplays. For rehearsing roleplays, Mr. Huy asked students to come to the space in front of the class and let them choose new partner(s) whenever they finished talking with one partner. After that, Mr. Huy invited four pairs to perform their roleplays in front of the class. He asked the class to take notes and comment on these roleplays.

After the roleplays, Mr. Huy had the class listen to the textbook conversations twice and complete the textbook's listening activities. Then, he asked students to (1) analyse the textbook and their own roleplayed conversations, and (2) compare the English style between the textbook conversations and their own roleplayed conversations.

After the above listening, analysing and comparing tasks, Mr. Huy asked the class to reflect on how they apologised in their roleplays and to draw lessons they could learn from analysing the textbook conversations. Furthermore, he asked the class to speak to each other about their own life experience regarding using English to apologise. Mr. Huy then invited the four pairs of students, who had previously performed their roleplays in front of the class, to talk about their reflection.

Subsequently, Mr. Huy asked these four pairs if they wanted to add changes to their initial hypothesis which they had made earlier in the lesson. Finally, Mr. Huy asked the whole class to consider revising their initial hypothesis. Two students wrote their revised hypotheses on the board. Mr. Huy helped with correcting the spelling mistakes in these hypotheses. The lesson ended.

\subsubsection{Teacher interview data}

Mr. Huy talked mostly in English in both mid and final interviews. Based on the data from these interviews the themes that arose for his case are:

1. Culture in intercultural lessons and in traditional lessons

2. Value of the integrated intercultural teaching

3. Challenges of integrating intercultural teaching

4. Mr. Huy attitudes towards adopting an intercultural orientation

5. Mr. Huy's perception about the students' learning in the intercultural lessons

Each theme is detailed below: 


\section{Culture in intercultural lessons and traditional lessons}

He perceived different statuses of culture for the integrated intercultural lessons and the traditional lessons.

First, Mr. Huy emphasized the culture-oriented nature of the intercultural lessons and the language-focused nature of traditional skill-based language lessons. Culture learning was considered as the prioritised goal in intercultural lessons, but as an additional goal focusing on teaching moral values, in traditional lessons. Mr. Huy highlighted this difference in the mid interview:

\footnotetext{
"Uhm at first, I am a little bit surprised when we put the culture into the lesson as primary goal. We used to put the language skill and the language use as primary goal, so it's quite clear that students should improve listening and speaking, right? We don't have any goal, clear goal, and clear requirements to improve the students' cultural knowledge in the listening speaking class. So this made teachers when they come to class, they just think that ah "my job to improve listening speaking, and the culture job is for someone else". But now but with these intercultural lessons, culture becomes the primary goal, not the secondary goal."
}

and in the final interview:

"Traditionally, culture was not the primary goal of the lessons... At the end of the lesson, teachers included some moral teaching or compared different cultures. This was taken for granted. Working with you during this semester, building the intercultural-oriented steps together, I see that we can put culture as quite a clearly focused goal. For the first three intercultural lessons, I was not familiar, a bit slow. But I got more familiar by the last two lessons.

... Now we integrate culture into the lessons and treat it as first priority."

Second, Mr. Huy perceived that intercultural lessons addressed culture more systematically than traditional lessons rather than simply teaching morality. Mr. Huy reflected on the differences between culture in his routine lessons and in the observed intercultural lessons. He stated:

\footnotetext{
“Ngày xưa thầy cũng hay có chen vào kể những câu chuyện, kinh nghiệm, rút kinh nghiệm về sinh sống, học thuật, bản thân. Đó là chuyện đối nhân xử thế.

Thực ra cái bài lồng ghép về văn hóa cũng làm explicit những cái đối nhân xử thế thầy dạy thôi. Ý thầy nói như vầy: giáo viên đến lớp không đơn thuần dạy ngôn ngữ mà phải dạy văn hóa, dạy ăn ở cư xử,
} 
và đó là một phần của mở rộng bài học mà. Thì bây giờ, để làm vậy cách của em làm nó những steps có tính logic hơn"

(Previously, I also often inserted telling stories, my lived experiences, and drew lessons about living, study, and myself. These were moral behaviours.

Actually, the integrated intercultural lessons addressed moral behaviours more explicitly. I mean teachers must include teaching culture and moral behaviours in addition to teaching language; and this a part of broadening the lessons instead of simply teaching language. Now your re-designed lessons provided more logical steps to address it).

In his opinion, both types of lessons paid attention to teaching students how to behave and live as individuals in community. Yet, this aspect was compulsory in intercultural lessons while remaining an extended part in traditional lessons.

Third, Mr. Huy perceived that intercultural lessons addressed intercultural communicative skills, which are beyond morality teaching. More importantly, intercultural lessons addressed these skills without compromising language learning. When expressed his overall perception of the experience of teaching the intercultural lessons, he said in English:

"First, I can tell what I like ... with a model from ...defining hypothesis to relating, reflecting, and yes students can compare and contrast what they think with what the American, foreigners think and behave, so after that they can improve their thinking, improving their behaviour.

Second when I ask them to roleplay conversations together, they can improve their language, and speaking, Yes (Uhm) when I ask them to listen to some expressions about, you know, an aspect of culture like disagreement, they can improve the language they use."

As can be seen, Mr. Huy considered that culture received a more central and explicit status alongside language in intercultural lessons than in traditional lessons.

\section{Value of the integrated intercultural teaching}

Mr. Huy highlighted the value of the redesigned intercultural content in the intercultural lessons. First, Mr. Huy perceived that the roleplays facilitated students' independent thinking and speaking. In his Phase One teaching practices, Mr. Huy used roleplays as a postlistening activity for students to practice speaking. This was not similar to the sequence in the pre-designed intercultural lesson plans in which the roleplays were intended for the students to do prior to their listening and analysing activity. In the mid interview, when asked about the influences of this change on his class, Mr. Huy commented as follows: 
R: in the observed lessons, we asked students to do the roleplay before they listened, so what did you think about this?

Mr. Huy: I think this new change is interesting.

My principle for listening previously is giving students input and they give output. I ask them to listen, and from the listening they take some phrases from it ... then they do the output. But here in the vice versa direction, they themselves think about what they speak first, then they listen and compare. Sometimes I think it's interesting, it's fine.

I don't give them any input I don't give them any idea about how to solve the problem, they have to think about how to solve the problem. They are the one who think about how to solve the problems...They create the language; they use the language by themselves.

... Students can write down or speak out what they think, not just imitate what they listened.

In the same vein, in the final interview, Mr. Huy added that the use of the roleplays enhanced students' awareness about the language they produced:

“... thời gian mà nó làm roleplay, nó prepare đó thì nó gieo cái consciousness về cái language nhiều lắm... Lúc ghi ra là một chuyện nhưng lúc ngồi ghi ra là lúc ý thức về ngôn ngữ nhiều nhất; nó chọn lọc để đưa vào bài hội thoại những cái được cho là nó hài lòng nhất...Hai đứa cùng construct cái bài đó thì đó chính là con đường học thuật. Mình thấy nó làm, mình đi vòng không thấy nó hỏi mình tức là nó đang làm tốt. Rõ ràng đưa lên thì nó perform tốt."

(Preparing and rehearsing roleplays developed the awareness about language very much. Writing down their turns for the roles was the time when they became aware of their use of language the most; they selected and decided what is best to put into their conversations. In pairs they constructed the conversations together, which I considered as a way of study. I saw them work, I walked around but I was not asked to help. This means they were working well. Definitely, their performances confirmed to me that they worked well).

In addition to the roleplays, Mr. Huy perceived that doing conversation analysis developed students' cross-cultural awareness. Analysing conversations created opportunities for students to work with others about their own way of thinking, using English, and solving problems. When asked about his overall perception of the designed intercultural content in the mid interview, he said:

“...When analysing conversations, during these moments, they compared what they thought, what they performed, and how they dealt with the problem to what they had listened to. I found that when they contrasted, they contrasted between how they solved problems...and what they learnt from the 
lesson...I mean they felt very interested when they solved problems differently from what they heard."

Generally, the use of the intercultural learning tasks was perceived by Mr. Huy as positive learning opportunities for students for both language and culture.

\section{Challenges of integrating intercultural teaching}

In Mr. Huy's opinion, intercultural teaching challenges teachers' time and expertise. Mr. Huy talked at length in the mid interview about time constraints. First, it takes time for teachers to become familiar with integrating culture especially in the early stage. Mr. Huy said:

"Sometimes I find the lessons quite long. For the first three lessons, because it's the first time, it took a lot of time to explain technical terms and get students familiar with the tasks in the worksheet...But I could do it ..for the later lessons, I could do it smoothly so I could save time."

Therefore, when asked about his feelings before, during, and after his intercultural teaching, Mr. Huy expressed in English:

"A little bit tired because first I have to encourage them to learn about culture besides language as well as listening and speaking skills. I spent more time talking to students about this.

After that..actually I feel very interested and happy. Why happy? When I see them perform the conversations in front of the class, students are eager to listen to their friends' performance."

As far as time is concerned, implementing the intercultural lessons within the current curriculum challenges the teacher's expertise. The extract below indicates the effort teachers have to make for teaching culture:

R: What kind of knowledge or expertise do you think teachers need in order to teach the designed lessons?

Mr. Huy: Because these lessons relate to culture, first they have to identify the language task. Second, identify the culture aspects that they will ask students to deal with, right? So they have to read about that... and they should have knowledge about that. Third, they can believe in using this kind of lesson in real life... It takes a lot of time. This will discourage teachers ...because in the lesson ... the teacher's book gives a lot about listening and speaking skills, not much about culture. So if teachers want to explore culture aspects they need to read more and learn more, so a lot of time.

Mr. Huy admitted the challenge of handling both language and intercultural tasks within his lessons as shown below: 
R: When we analyse conversations, is there anything particularly easy or challenging?

Mr. Huy : It's interesting but still, to me, a little bit challenging...challenging...For just one conversation but you have to analyse many different aspects like phrases, volume, stress, voices, context, and people's relationship. A lot of things at the same time, so sometimes I can't cover everything."

Finally, Mr. Huy perceived that intercultural teaching requires teachers' greater investment. In the final interview, he said:

\footnotetext{
"Honestly speaking, this intervention...is more work ...must have more work. I have to take some more time to prepare for lessons very carefully.

...Traditionally, I started lessons by focusing on the task, the roleplays, and the language students have to apply to complete their roles. Now, in addition to these, students have to compare, contrast in terms of culture, revising hypotheses; so it is longer and more work for teachers."
}

In short, for Mr. Huy, the challenge of intercultural teaching mainly concerns the expertise and effort to prepare and to implement lessons.

\section{Mr. Huy's attitudes towards adopting an intercultural orientation}

Despite the perceived challenges, Mr. Huy displayed positive attitudes towards adopting an intercultural stance. First, he expressed his willingness to share with colleagues his new understandings about teaching culture in the mid interview:

R: If you could tell other teachers about these steps, what could you tell them?

Mr. Huy: Yes, actually I want to inspire them about this model ... to apply to use. First, I will say about the general understandings, the importance of culture together with the language not only the language learning itself....; and after that I say how to do this.

Additionally, Mr. Huy made clear his openness for intercultural teaching. In the final interview when asked about his willingness, he confirmed:

“Surely I don't feel it's a burden... I must make this clear. There's no problem with more work to do.

...To me, it's an interesting approach I can apply into my teaching. ..I think. I don't have any constraint from my boss about applying this approach."

In sum, similar to Ms. Sen, Mr. Huy demonstrated positive attitudes and confidence in his new understanding about adopting an intercultural stance in his teaching.

\section{Mr. Huy's perception about the students' learning in the intercultural lessons}


Mr. Huy held consistently positive perceptions about his students' learning in postworkshop-one lessons and post-workshop-two lessons, which lasted from week five to week twelve. His main focus was students' participation in learning activities.

First, Mr. Huy emphasized his students' active participation. He provided signs of student interactions the in mid-interview:

R: How did your students respond to your teaching?

Mr. Huy: They engaged in the lesson, engaged in the performance. They gave feedback to friends' performances, answered my questions. That's good sign of engagement.

R: Were they active enough as you expected?

Mr. Huy: Most of the time yes....To compare with the last lessons, I see they actively participated in the activities.

More specifically:

R: What do you think about the roleplay tasks in the lesson?

Mr. Huy: I think yes. I gave them the task...and they sat together. They themselves created the conversation. During the time they worked together, they rehearsed...could learn about language. When they performed, they could think about intonation, the language, the words, and the contents too. Surely, I think they can develop their language.

He commented on the students' active participation in the intercultural tasks. In the final interview, he spoke about the aspects of the lessons he was most happy with:

I can find... they and I discover differences or similarities in terms of culture between the input conversations and their role-played conversations.

... I can tell you that they participated in the lessons very well. Again, good participation

... When I asked them to share, they did the pair work very well.

Moreover, Mr. Huy positively commented on the students' speaking:

R: What did you think about your students' roleplay performance?

Mr. Huy: most of them... were very good. They made very good roles as doctors, and patients. When you watch this video again ... they played the role as real real patient (raising tone)

$\mathbf{R}$ : What made them good? 
Mr. Huy: ...They completed roles... They showed their confidence, fluency to perform, and also the language use to give advice they could apply in the conversation.

In brief, the above extracts exemplify Mr. Huy's positive perceptions of his students' learning in the integrated lessons. In both language-focused content (roleplays) and intercultural content (e.g., comparing conversations), Mr. Huy saw students as active and interactive.

\subsubsection{Post-workshop-two focus group data}

Analysis of post-focus group data identified the following main themes:

1. Students' perceived language learning outcomes

2. Students' perceived intercultural learning outcomes

Each theme is detailed next.

\section{Students' perceived language learning outcomes}

Students perceived that their language learning progressed in two main aspects. The first aspect was their speaking ability, especially speaking fluency. When asked about what they learnt from the lessons, students explained that they became quicker than before in making English conversations. They said:

Hieu: thích tình huống vì mình đã react nhanh hơn, không cần suy nghĩ hơn, khả năng đóng vai sau 5 bài liên tục thì nhanh hơn, không cần phải ghi chi tiết ra từng câu, không còn học thuộc lòng ... bỏ qua giai đoạn soạn bài trên giấy. Hôm nay đi thi chỉ soạn bài bằng miệng.

... Mới đầu là ghi chi tiết ý, câu, sau rồi ghi ý chính, bữa nay là không cần ghi nữa ... vì khi giao tiếp thục tế không có ai đợi để mình soạn ý...Phản ứng nhanh hơn, biết đặt câu hỏi liền luôn, không suy nghĩ lâu.

My, Ngoc: Tụi em quen với đóng vai, chuẩn bị hội thoại nhanh hơn. Nhờ vậy mà bữa nay thi tụi em thiết kế hội thoại nhanh hơn. Chứ bình thường chuẩn bị lâu lắm...

Quyen: Nói tự nhiên không cần chuẩn bị trước.

(Hieu: (I) like roleplays because I reacted quicker, didn't need to think for long, my ability to play roles after five consecutive lessons got better, didn't need to write down each sentence in detail, no longer learnt conversations by heart...skipped composing conversations on paper. Today in the speaking exam, I only prepared (roles) orally. 
... At the start I used to write ideas in detail, then I wrote key points. Today I needn't write...because in communication no one waits for me to compose what to speak... Quicker reaction, knew to make questions immediately, didn't think for long.

My, Ngoc: We got familiar with playing roles, prepared conversations more quickly. Thanks to this, today in the exam we designed conversations more quickly. Normally took much longer...

Quyen: Speak naturally without preparation in advance.

The main improvements described in the above extracts include the students' reduction of time preparing for what to speak, quicker response in conversations, and more immediate language production and natural role interactions. These extracts also implied students' increased confidence in speaking as they stopped learning by heart and composing what to speak.

Second, students reflected on their participation in learning activities as interesting and useful experiences. When asked about what they liked most about the lessons, students referred to the use of scenarios and roleplays as follows:

Ly: Scenario

Ngoc, Hieu: scenarios, role play.

Hieu: I like scenarios most...

Ly: Em thấy việc dùng scenarios, đóng vai nó thú vị, nó thoải mái... Thầy cho bắt cặp với bạn lạ để cho mình quen kết bạn hoặc ..nói chung là làm nhóm, làm với người lạ. ...cho mình diễn, đóng vai tự tin trước đám đông.

Quyen: Cơ hội sáng tạo, sáng tạo ý tưởng, tưởng tượng.

(Ly: I found it interesting and comfortable to use scenarios and roleplays. The teacher asked us to pair up so that we could make friends...generally work in groups with new friends...for us to play roles to become confident in the crowd.

Quyen: opportunities to be creative, making ideas and imagination).

\section{Students' perceived intercultural learning outcomes}

The students maintained that the experience of the intercultural lessons resulted in their newly found awareness of aspects of intercultural communicative competence. First, they perceived that analysing conversations provided opportunities to examine their existing 
beliefs and develop cross-cultural understandings. When asked about the significance of making and revising hypotheses, My commented that:

My: Suy nghĩ chủ quan ban đầu của mình nó khác sau khi mình tìm hiểu những đoạn hội thoại đó ba lần... Về request, em nghĩ người ta sẽ nói thẳng luôn như ra lệnh, bắt buộc luôn ...Trong các tình huống phân tích thì người ta lại dùng Could you please, Would you mind, không có nói như ra mệnh lệnh...Ban đầu em nghĩ English speakers không có care how they sound. Sau khi học thì hiểu là thực ra họ cũng rất quan trọng vấn đề này như Á mình.

(My: My subjective thought at the start changed after I examined those conversations three times...Regarding English requests, I had thought that people would say frankly like giving commands, forcing...In the analysed situations, speakers used Could you please, Would you mind, not like giving commands...At first, I thought that English speakers didn't care how they sound, after this lesson, I realised that actually they consider this issue as important as Asians do).

Obviously, analysing aspects of conversations such as language structure and way of speaking led My to challenge her personal thoughts about English speakers' use of English. Similar to My, Ngoc saw a change in her thinking. She stated:

“Mình nhận ra sự thay đồi trong suy nghĩ của mình.

... Nhưng sau khi em nghe các bài hội thoại đó em nghĩ người nước nào cũng có cách thể hiện sự tôn trọng và lịch sự của người ta."

(I found my thought changed.

...but after I listened to those conversations, I thought that people in any country have their own way to express respect and politeness).

Unlike My and Ngoc, Hieu did not change her thinking. She said:

“Em thì không thay đổi suy nghĩ của mình... tức là em có suy nghĩ giống trong hội thoại trước khi em phân tích nó."

(I didn't change my thought... I mean I thought the same as the conversation before I analysed it).

As a result of doing conversation analysis, students critically reflected on their own beliefs in relation to their perceived new knowledge. Regardless of whether the outcome was either a change or confirmation of their beliefs, it was important that students developed the skills to learn about culture embedded in language by analysing language. 
Another aspect that emerged from the data is the students' awareness of cross-cultural pragmatic sensitivity. They demonstrated perceived gains in knowledge about the contextual appropriateness of language use, and an awareness of politeness in intercultural communication. For example, one of the students reflected on her gained knowledge of language use regarding making requests in English:

R: What should you pay attention to when you communicate in English with foreigners after you have learnt these lessons?

Ngoc: Qua học phần này thì còn biết được cái cụm từ nào là formal hay không để biết dùng cụm nào cho đúng trong tình huống, Chứ hồi nào đến giờ, tình huống nào thì em cũng nói có một kiểu/câu thôi, không quan tâm là môi trường nào... Bây giờ thì biết tình huống nào nên. Có những tình huống thân mật mà nói câu formal thi gượng gạo, xa cách.

(Ngoc: Finishing this course, I know which phrases are formal or not so as to use them correctly in communication situations. So far I have spoken the same way in any situation, not paying attention to the particular environment... Now I know which phrase to say in which situation. In informal contexts, if I say formal language, it sounds unnatural and distant).

Other students emphasized the role of politeness:

Hieu: Politeness rất quan trọng khi giao tiếp với người nước nào đi nữa chứ không nhất thiết người Anh...Với người lạ nên bắt đầu formal để gây thiện cảm, khi đã nói chuyện lâu một tí thì có thể informal hơn

Quyen:...Hiểu và biết là có những cái mình không nên nói ra.

(Hieu: Politeness is very important in communication with people of any country rather than British... Talking with new people, at the beginning, we can use formal language to create good impressions and informal language comes later.

Quyen: Understand and know what shouldn't be said).

With the same emphasis, another student explained how and why politeness can be practiced:

My: Em hiểu là ...trong những tình huống nhất định người ta chọn cách nói không trực tiếp để người nghe không khó chịu và dễ chấp nhận... Lúc yêu cầu người khác thì cái giọng của mình đừng bossy, hãy lịch sự.

(My: I understand that in certain situations, people choose to not say directly for the listeners not to feel uncomfortable, and so easy to accept... We shouldn't request people with bossy voice, be polite). 
Thus, appropriateness of language use and politeness were realized by students as important aspects of intercultural communication.

Finally, Mr. Huy's perception and the students' perception about their learning in the intercultural lessons were congruent with each other. Both highlighted students' positive engagement, fluent language production, and increased awareness about aspects of intercultural communicative competence, and intercultural communication.

In summary, in teaching, Mr. Huy closely followed the redesigned intercultural content in all of his lessons. In Mr. Huy's perception, culture received more central and regular attention in the intercultural-oriented lessons. More importantly, he believed that culture could become the primary goal of language lessons. Additionally, he considered the integrated intercultural teaching was useful for the students' intercultural awareness and independent learning ability. Although he was concerned about time issues, he was open to adopt an intercultural stance in future. He perceived the students' participation in the intercultural lessons as active and confident.

\subsubsection{Discussion}

\section{Mr. Huy's teaching practices}

In Phase Two, similar to Ms. Sen, Mr. Huy's teaching complied with the redesigned intercultural content. It reflected the following ICLT principles: value intercultural learning goals alongside linguistic and communicative goals; and mine the input for its cultural content.

- Value intercultural learning goals alongside linguistic and communicative goals

Mr. Huy's lessons focused on both language and intercultural content. In all lessons, besides teaching the textbook-based listening activities, Mr. Huy addressed all intercultural content: initiating hypotheses, roleplays, analysing, revising hypothesis, comparing, relating and reflecting tasks. Conversation analysis and roleplays seemed to be the main focus in all lessons as they were given more time than other parts. For other components, in two of the lessons, he asked the students to (1) create and examine hypotheses, reflect and share their reflections with each other (the third and the fifth lessons) and (2) give comments on the roleplay conversations (the first and the fifth lessons). He also explained how Vietnamese 
use additional particles as a lexical means to express politeness or friendliness (in the third lesson).

- Mine the input for its cultural content

According to Newton et al. (2010) and Newton (2016), for this principle, teachers make the most of diversity in classrooms, schools, and communities, especially learners' linguistic and cultural backgrounds with the other cultural contexts. However, in the current research context, all students speak the same mother tongue, Vietnamese, and most of them have little experience in travelling overseas and using English outside language classrooms.

The way Mr. Huy implemented the intercultural content evoked students' existing knowledge, experience, and motivation useful for learning. Therefore, his teaching can be considered as reflecting this principle. First, he usually created opportunities and allowed sufficient time for students to think about and discuss what they know and have experienced about the lesson topics, scenarios, and roleplays (in the first and the fifth lessons). His students had chances to relate the lessons' content and activities to their future working contexts such as in the first lesson. Additionally, Mr. Huy got students to reflect on their mother tongue and their own experience (e.g., in the third lesson). He asked students to comment and reflect on their English language used in their own and their classmates' roleplayed conversations (e.g., in the fifth lesson). Furthermore, what was special in his teaching was that he always motivated students. For instance, in all lessons, students practiced speaking with various partners. In the last lesson Mr. Huy used a video clip to teach vocabulary and let students talk outside in the open space. When guiding students to analyse conversations in the first and third lesson, he encouraged them to analyse conversations while in listening without using the conversations' transcriptions.

Adopting the view that reflection is important in intercultural learning (Byram, 1997; Liddicoat \& Scarino, 2013; Conway \& Richards, 2016), the above incidents in Mr. Huy's teaching can be considered as chances to involve students in reflections on language use and are therefore useful to for students' ICC. As McConachy $(2018$, p. 5) argues, "reflections on language use provides opportunities for coming to see language not just as a code but as a culturally interpreted form of social actions." What Mr. Huy did was similar to what the teachers in Skene (2014) did. In Skene's (2014) Australian context, three French language 
teachers asked students to reflect on their use of French in their performed French conversations which focused on language for buying and selling bread in French culture. Reflection enables students to learn something new and meaningful and construct knowing (cited in Conway \& Richards, 2016).

However, students could have been more involved in reflections in the first lesson if Mr. Huy had provided priming to encourage them. Mr. Huy could have done this while the students were doing the relating/reflecting tasks. Because a catalyst/stimulus is necessary for reflecting teachers' provision of relevant input/prompts is useful (Conway \& Richards, 2016). Given that in the early stage, students were unfamiliar with intercultural learning, Mr. Huy could have suggested that students think about situations in which they encountered something surprising or problematic and reflect against these situations. According to Liddicoat and Scarino $(2013$, p. 58), dissonant situations are starting points for reflection. Dissonance can demotivate students to engage with diverse others and therefore needs guidance.

\section{Mr. Huy's understandings}

A number of important changes can be seen in Mr. Huy's understandings and attitudes in Phase Two. First, he highlighted similarities and differences in how culture was treated in traditional and intercultural-oriented lessons. He came to realise that the interculturaloriented lessons addressed culture more explicitly and beyond teaching moral values. Second, he realised that culture can become the primary goal of language lessons. This point can be considered as an important shift in his perspective of teaching culture in comparison with Phase One when he believed that culture plays a peripheral role in language skill-based lessons. Third, Mr. Huy held a more positive attitude towards culture integration in Phase Two than in Phase One. He was more willing to adopt an intercultural stance and to share his understandings with other colleagues, while in Phase One he only considered teaching culture to vary classroom activities and to support his language teaching. These changes allow the conclusion that Mr. Huy has become more informed of and more open to an intercultural stance. 


\subsubsection{Case three: Mr. Sang}

\subsubsection{Observation data}

\section{The first intercultural lesson}

Mr. Sang began the lesson by using pictures to introduce the lesson's topic. He had the class discuss kinds of parties in Vietnam and similarities and differences between parties in Vietnam and Western countries.

Next, Mr. Sang showed and explained to the students the redesigned scenario (appendix 1.1). Similar to Ms. Sen's students, Mr. Sang's students gave lots of English and Vietnamese responses to this scenario. For example, "Can you help me to write a recommendation letter?"; "I was wondering if you could help me to write a recommendation letter for a student exchange program?" Mr. Sang asked the class to vote for the responses they agreed upon and identify the function of phrases used in these responses. The students answered that their responses functioned as making requests and asking for help. To have students form initial hypotheses, Mr. Sang asked "What's your belief about how native speakers request or ask for help?" Based on the students' answers, he wrote the hypothesis on the board as follows:

"I think that native speakers of English are both polite and straight forward when making request."

Mr. Sang said: "I want you to keep this preconception in mind; we will work on more situations so that you can see if your hypothesis is ok or not."

After that, Mr. Sang asked the class to read and choose from the redesigned roleplays (appendix 1.1). The students prepared for their chosen roleplay. Four pairs performed their roleplays in front of the class. Mr. Sang had the rest of the students analyse the intonation patterns and the grammar structures used in the roleplays to highlight how their classmates expressed politeness in their situations. The class ended as time was up.

At the beginning of the following class, Mr. Sang had students listen to the textbook conversations and complete listening activities. Next, Mr. Sang introduced the conversation used for modelling analysis (appendix 1.1). Unlike the other two teachers, before modelling how to analyse a conversation, Mr. Sang presented cultural information about New Zealand which was the context of the model conversation. For example, he showed the geographical 
position of New Zealand on the map, asking and telling the students information about its language, working hours, universities, and the weather. The students looked curious prior to listening to the model conversation. While analysing it, Mr. Sang explained the aspects involved in the analysis: conversation context, the speakers' social status, degree of imposition in request, (in)directness, and politeness. Moreover, he stressed that the students need to be aware of their own beliefs, values, attitudes, and pre-conceptions about the target speakers and culture in communication because English speakers' uses of phrases and manners are influenced by their culture. He added that conversation analysis helps students to realise their cultural pre-conceptions because they will recognise various aspects of conversations in addition to their content.

Mr. Sang then had students listen to and analyse the textbook conversations. The students concentrated on the analysing task. Mr. Sang and the whole class finally revised their hypothesis as follows:

"Vietnamese or American or New Zealand people are polite when they request but they have their own way to control politeness. This is up to their use of various phrases, language structure and intonation in various contexts."

The students compared the textbook conversations and their roleplayed conversations. The students looked confused. Therefore, Mr. Sang suggested that the students look for politeness expressions in the roleplayed conversations and compare them with those in the textbook conversations. There was no cross-cultural comparison because the students did not prepare Vietnamese conversations for roleplays.

Finally, Mr. Sang explained the relating and reflecting tasks. He then asked students to talk with classmates about their experiences that involved their use of English to make a request. Mr. Sang ended the lesson by reminding the students about the main tasks, especially the analysing task and the way politeness is handled in English requests.

\section{The third intercultural lesson}

As normal, Mr. Sang began the lesson by using pictures to introduce new words and the lesson's topic, online space, and language focus, agreement/disagreement. He asked questions about the way Vietnamese and Americans disagree in conversations and why they 
do so. He asked questions such as: How many ways do you express your disagreement? How do English speakers show disagreement? And why?

Mr. Sang showed the redesigned scenario (appendix 1.2). and asked the students to respond in Vietnamese and English. He asked questions such as:

Mr. Sang: How do you think Vietnamese express their disagreement?

Students: in our culture, if we disagree with one another especially their parents, we usually keep silent because we respect. We don't want to hurt people particularly parents because of relationship.

Mr. Sang: How do you think English speakers express their disagreement with one another?

Students: frank and direct.

He reminded everyone to pay attention to differences in the social context of these two languages. The students gave responses. Mr. Sang then had them explain their responses. Subsequently, the students made the following hypothesis:

"We think Americans, when they disagree, they usually express it frankly, directly, and strongly... they use strong stress and intonation."

He asked the students to explain their hypothesis as the following dialogue shows:

Mr. Sang: Why? What can be the reasons for those (being frank, direct, and strong) in their culture?

.... They have different values (raising tone)? What do they value in their culture?

Students: Individualism

Mr. Sang: Individualism means....? How can we talk to them without understanding their value? Individualism means that they value every single thinking, accent, action, and idea of every single person. This is contrast with our culture. What about our culture?

Students: Relationship, togetherness.

Mr. Sang also showed the students the lesson plan's pre-written hypothesis:

"I think Americans usually express their disagreement frankly when they have different or opposite opinions because they are individualistic."

Mr. Sang continued by discussing how expressing disagreements in each language is influenced by factors such as the uses of intonation and stress, vocabulary, non-verbal 
gestures, and cultural context. Mr. Sang told the students that they would revisit the hypotheses later in the lesson.

Similar to Mr. Huy, Mr. Sang pre-taught the words monthly, allowance, anonymous, and disposable before introducing and having students work on roleplays. He allowed plenty of time for the students to rehearse speaking. He invited two pairs to perform their roleplays in front of the class.

Mr. Sang then had students listen to the textbook conversations. He replaced the textbook listening activities with the conversation analysis task. He guided students to analyse conversations during their listening. Subsequently, he asked students to consider revising their initial hypothesis. However, most of them kept quiet. Mr. Sang then showed the prewritten revised hypothesis (appendix 1.2) and students agreed with it. At this point, Mr. Sang concluded that it is crucial to express disagreements politely in English communication. Next, Mr. Sang asked students to compare conversations. He worked with each pair. By the end of this task, as Mr. Huy did, Mr. Sang mentioned that Vietnamese often use additional mediating words such as "nha, nhá, nhé" to soften disagreements, although these words do not have real meaning.

For the relating/reflecting tasks, Mr. Sang encouraged students to think about English communication situations in their campus life in which they had disagreed with others. The students noted down their experience and shared their notes with each other. Mr. Sang worked individually with every pair at their seats and listened to some students' experiences.

At the end, Mr. Sang said to the whole class:

\footnotetext{
"We need to know how to say disagreement because we do it everyday. For communication in English, we need to follow some social and language rules to do it properly. Expressing disagreement politely is one way to persuade people as you protect your view and respect others' view in communication."
}

\section{The fifth intercultural lesson}

First, Mr. Sang used pictures to introduce the lesson topic (travelling) and language focus (apologising). Specifically, Mr. Sang had students discuss the advantages and disadvantages 
of travelling. He asked students to talk with friends about their travelling experiences such as the troubles they encountered and the activities they did.

Mr. Sang asked students to respond to the following scenario:

An English-speaking customer has booked for seat number 10 with Phuong Trang Company to travel to Ho Chi Minh city. Unfortunately, when he got on the coach at the station, seat 10 was sold to another passenger, and the coach was almost full. He got unhappy. As a staff of Phuong Trang Company, what would you say and how would you handle this situation?

Most of the students responded: "I really regret about that"; "I'm really sorry about the mistake."; and "I'm terribly sorry about that." Consequently, Mr. Sang told them to write their beliefs about how English speakers apologise in service situations. He wrote one of the students' hypotheses on the board as follows:

"I believe that most speakers of English apologise in a polite and direct manner. They use formal language to do so in service situations."

Next, Mr. Sang showed students the roleplays and got them to prepare for one roleplay of their choice. He left plenty of time for students to rehearse and perform their roleplays. He asked the class to comment on how apologies were made in the performances.

After that, Mr. Sang had students listen to and analyse textbook conversations. He instructed them to identify why the service providers in the conversations apologised, their attitudes and language of apology, and the attitudes of the customers at the beginning and end of each conversation.

For conversation comparison, Mr. Sang asked students to orally compare if the speakers in the textbook conversations used the same language phrases as in the students' roleplays to make and respond to an apology. Mr. Sang asked students to complete the comparison section in worksheet. Then, the students added changes to their initial hypotheses and agreed upon the following one:

"I think that most native speakers of English (in business situation) usually say sorry in a polite and honest way. I think they know their mistake and also give compensations to satisfy customers."

The class continued with relating and reflecting tasks. Mr. Sang asked students to follow the worksheet instructions for these tasks. He worked with each pair and encouraged pairs to 
share their answers without looking at what they wrote in their worksheet. From the students' speaking practices, Mr. Sang noted the following content on the board:

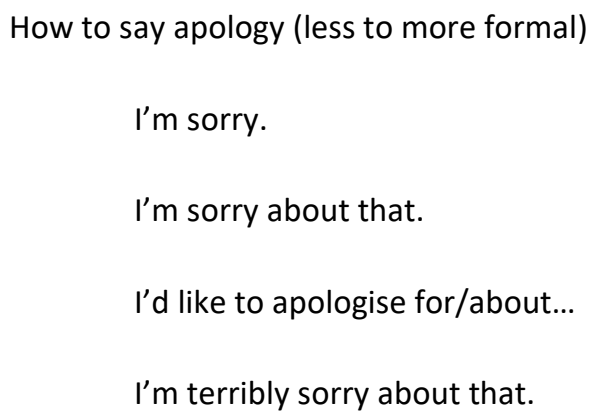

Finally, Mr. Sang summarised and ended the lesson. He said:

\begin{abstract}
"It is important to know how to say an apology because mistakes occur every day as well as in service situations. When you apologise to people about thing you did or said or annoyed or hurt them, it is important to say it right. Be polite and friendly to make the problem less severe."
\end{abstract}

\title{
5.3.3.2 Teacher interview data
}

The following themes arose from the mid and final interviews with Mr. Sang:

1. Value of the intercultural orientation

2. Challenges of teaching the intercultural lessons

3. Mr. Sang's attitudes towards adopting an intercultural orientation

4. Mr. Sang's perception of students' learning in the intercultural lessons

Each theme is detailed as follows:

\section{Value of the intercultural orientation}

When Mr. Sang was articulating his overall perception about the whole experience of participating in the research, he pointed out various values resulting from the integrated intercultural teaching.

First of all, Mr. Sang held the opinion that the integrated lesson design increased the amount of culture in language lessons more systematically. He remarked:

“Nó có tác dụng ở hai chỗ. Một chỗ là vẫn đề cập đến các chức năng ngôn ngữ .. là người ta sử dụng cái cấu trúc câu đó để làm cái gì. Thứ hai là, thêm cái cái phần phân tích... về yếu tố văn hóa.

...Thực ra trước đây thầy có làm nhưng không thường xuyên, tùy bài dạy có yếu tố văn hóa nhiều ít thôi. Không có nghĩ đến cái chuyện là có một qui trình như thế này". 
(This kind of lesson was effective in two places. On the one hand, it mentioned the language focused functions... people use the language structure for what function. On the other hand, it added the part about analysis... of cultural factors...Actually, previously I had done it like this but irregularly depending on if the lesson had more or less cultural content. I have not thought of such a teaching sequence).

He moreover noted as follows:

"The designed parts of the units are helpful and logical because they give students chances to compare their mother tongue and English language....raise their awareness uhm about the importance of culture or at least the cultural aspects that can affect communication ... I think that's very crucial for my students to be aware of these when they learn listening and speaking."

These thoughts indicate Mr. Sang's perception that the intercultural lessons addressed aspects of culture alongside language more consistently. By involving the students in comparing and analysing language, these lessons raised the students' cross-cultural awareness in using language and communication. In alignment with the above opinion, Mr. Sang noted the usefulness of the intercultural lessons in encouraging exploratory learning. As he said:

"I think using this kind of design with basic steps like hypothesizing, analysing, comparing, relating and reflecting is a kind of approach to help learners discover their own learning, and this is an effective way. Students are learners, so learners need to discover things by themselves...so that they can improve and build up their life-long learning skills."

Mr. Sang explained at length the usefulness of intercultural teaching on students' lifelong independent learning in relation to their intercultural ability as follows:

R: What can intercultural teaching help with developing students' intercultural ability?

Mr. Sang: Ít nhiều họ được trang bị một cách khác nữa để học listening và speaking, tự khai thác được bài nghe về mặt sử dụng ngôn ngữ, sử sụng ngôn ngữ và văn hóa có liên quan ra làm sao, liên quan tới mức nào, có liên quan hay không, tại sao; hỗ trợ cho việc tự học.

Cách học này giúp họ nhìn và hiều nhiều khía cạnh hơn, mở nhiều con đường hơn....họ sẽ tự phát hiện nhiều hơn, ờ không phải chỉ qua listening mà có thể qua movie trên thực tế. Họ liên tưởng đến yếu tố là tại sao người ta dùng cái câu này trong cuộc nói chuyện đó và tính tự nhiên nó tới mức nào. Như vậy cái này là do yếu tố văn hóa quyết định. Đó, như vậy là họ có khả năng liên tưởng nhanh hơn, lý do là họ đã ý thức trước rồi họ kết nối được các yếu tố văn hóa đã được đề cập trong các bài. 
Trên thức tế sau này, không phải trong lớp học,... cách thức mình giúp họ nhận biết, biết nhiều hơn ngoài phần nghe. .. tức là họ có cái chủ động của họ...Còn nếu không biết cách này thì khả năng họ liên tưởng nó ít."

(More or less students are equipped with an alternative to learn listening and speaking, can make use of listening tasks in terms of language use, how language use and culture relate to each other, and to what extent, if they relate or not, and why, supporting their self-learning.

This style of learning helps students to see and understand more aspects, open more ways to discover, uhm not limited to the listening tasks but in movies and in reality. Students relate to the reason why people say certain utterances in conversations and how natural they sound. These aspects are decided by culture. That's it. So they can link to these factors because they already have awareness about them through what they learnt in today's lessons.

In future, in reality, when they are no longer in the classroom ...this approach helps them to notice and know beyond the listening ...I mean they have their own way of being active...If they weren't aware of this approach, their ability to relate is limited).

Mr. Sang's clarification indicates that intercultural teaching enriches students' language learning experience and nourished students' long-term learning of culture. He emphasized that skills of recognising and relating culture in speech are important for students to develop because these skills enable students to learn more from the language while in communication.

In a similar vein, he valued the intercultural lessons in introducing to students the skills of noticing and adapting one's own beliefs. Mr. Sang recognized that the benefits of having the students be aware of and consider their hypotheses about the target language and culture go beyond language learning. He explained this in both English and Vietnamese in the midinterview, when asked about the aspect of the lesson he liked most:

"Hypothesis ...students become more aware or totally aware of cultural aspects...uhm actually it has been practical...It helps them overcome or adjust their behaviour, attitudes possibly about people around things around...

Tức là họ cần có đủ evidence thì họ mới có thể xác định được là cái hypothesis hay cái assumption ban đầu của họ là nó đúng hay là nó không đúng, còn nếu nó đúng thì đúng đến mức nào... Thì cái này dường như sinh viên không có để ý nhưng cái concept này lại cần cho họ trong việc học cao hơn sau này và trong cả cuộc sống của họ, đi làm chẳng hạn." 
(That means they need enough evidence, then they are able to identity if their initial hypothesis or assumption is right or not, if right, to what extent it is. Students don't usually pay attention to this concept, but it is necessary for them in future higher study and life).

According to Mr. Sang, the gap in the students' understanding is their limited realization about the importance of noticing and adapting their own beliefs.

In the final interview, Mr. Sang was asked if he could predict students' initial and revised hypotheses. In his response, he described how he guided students in this task, which shows his engagement in implementing intercultural content as an experienced teacher:

“Có thể có...lý do tại vì thầy phải xem bài đó trước ... cái phần nghe xong đó có yếu tố nào ... mới hay không,...khác hay không để mình có thể dự đoán trước phản hồi của sinh viên đến giai đoạn revise nó khác biệt nhiều hay không. Nếu sinh viên không phát hiện được cái điểm ở trong bài nghe sau khi nghe xong và sau khi phân tích hội thoại xong thì mình bổ sung cho họ thì họ có thể học được nhiều hơn ở phần bài nghe."

(Yes, possibly...the reason is that I had to examine the lesson in advance....the listening...to explore what cultural elements it has...new or not, similar or not, to anticipate how students will respond and how much they change their response in the revision stage. If students can't discover the cultural point(s) embedded in the listening after they listen to and analyse conversations, then I add this point to their knowledge then they learn more from the listening).

Mr. Sang also considered that intercultural teaching enriches teachers' choices of instructional methodology for teaching language skills, without replacing other approaches:

R: For the process of participating in this research, how do you perceive it?

Mr. Sang: This approach is one of the alternatives besides the approaches we are using to teach listening and speaking skills. (It) can be integrated to vary our approaches. This approach can be applied not only in listening and speaking but also reading and writing lessons depending on teachers.

Overall, in Mr. Sang's opinion, intercultural teaching added more culture to language learning on a more regular basis. Because of this, he considered that intercultural instruction contributed to students' cultural awareness, encouraged an exploratory learning style, and informed students' lifelong self-learning of culture.

\section{Challenges of teaching the intercultural lessons}

Mr. Sang considered the lack of culture-guided resources as the main challenge for intercultural teaching. In both interviews, Mr. Sang mentioned that a shortage of culture- 
focused teaching manuals and supplementary materials caused difficulty for teachers to address culture. Resource deficiency made lesson preparation time-consuming:

"It is the problem of manuals... Manuals help us to know what to focus on in the unit. For many units, manuals didn't sufficiently present cultural content. Only the manual for unit 12 provided the most notes about culture.

The time we spent on searching for manuals was rather much... I can find it a bit challenging that teachers need to collect and look for more other sources. Those intercultural tasks really need more time ... because we have to design tasks and certain scenarios clearly we must know to choose language resources, visual aids or others to supplement."

When he was asked about how he prepared the last intercultural lesson, he explained the reason why teachers need culture-focused teaching:

"I referred to the teaching manual when I prepared the slides for lesson $12 \mathrm{~A}$. It supported me with the suggestion about the cultural norms for making apology politely, using formal language when making apology...Language is of course influenced by culture, so the suggestion about cultural norms and language use for this unit was very interesting. This is an advantage of having manual because we don't have direct exposure to English environment.

...I also referred to the manual's suggestions for previous lessons but they were all about vocabulary not about any cultural norm related to the speech act nor its accompanied tone. ..Unit 12 identified the cultural norm in advance for me. I think the more notes on cultural norms the better for teachers. It guides teachers to prepare lessons. I did like this: I read the cultural suggestion, noted down the cultural norm, I listened to the conversations and noted the cultural elements in them, and then I made my lesson".

Clearly, using the note on cultural norms in the teacher's manual, Mr. Sang started to enrich culture in his lessons. It prompted Mr. Sang to recognise and address the cultural content embedded in the lesson. Mr. Sang's explanation reveals teachers' reliance on intercultural teaching resources. Additionally, it indicates the teachers' need for support especially in terms of cultural-norm-related knowledge to be able to prepare more culture-focused lessons.

\section{Mr. Sang's attitudes towards adopting an intercultural orientation}

The analysis of Mr. Sang's responses to the above challenges and the integrated intercultural teaching reveals his willingness to adopt intercultural teaching. 
First, Mr. Sang addressed the perceived challenge of time by pointing to the patience required for lesson preparation:

R: Mất thời gian như thế thì thầy có cảm giác là phiền hay nản quá không ..?

Mr. Sang: Không sao... cái đó là chuyện bình thường như soạn bài trước khi dạy. Nếu như mình hiểu được bài mình dạy càng nhiều, mình hiểu được sinh viên mình càng nhièu thì hai cái đó giúp cho mình... sử dụng một cái kiểu dạy đó, cho nên không sao, cái đó bình thường.

(R: Given that it is time-consuming, do you feel annoyed or demotivated?

Mr. Sang: Doesn't matter...That is normal as you prepare lessons before you teach. The more we understand the lessons and our students, the more it helps us to use that chosen teaching approach, so it doesn't matter, that's normal).

In addition to his patience in handling lesson preparation, Mr. Sang commented positively on the integrated intercultural teaching showing his welcoming attitude towards the innovation. The following extract reveals that he started from low awareness of the intercultural teaching which grew over the five lessons:

R: How did you feel before you taught these lessons?

Mr. Sang: I have no idea about making hypothesis. I know hypothesis but I have no idea about implementing teaching hypothesis in listening and speaking lessons.

R: And during the time you taught the lessons how did you feel?

Mr. Sang: I think it's very crucial and something that I need to apply whenever I have opportunities no matter what I teach.

Mr. Sang: After you have finished all three lessons, how do you feel?

Mr. Sang: I feel it's useful, effective and practical for students and... and ah another kind of approach that I can apply.

The reasons why he perceived the integrated intercultural teaching as "crucial" and "useful, effective, practical" were explained in the earlier section of his perceived values of the integration. Mr. Sang's positive attitude towards adopting intercultural teaching aligns with these earlier comments on the values of integrated intercultural lessons.

\section{Mr. Sang's perception of students' learning in the intercultural lessons}


Mr. Sang was asked about his students' learning while we were watching the recorded videos of the lessons. His opinions were given with respect to specific learning tasks. For some tasks, he viewed the students either as struggling or comfortably carrying them out.

First, regarding the roleplays, Mr. Sang recognised that his students had to make an effort to follow specific requirements of the roles they were asked to carry out. The speaking part of roleplays seemed taxing for them, causing them anxiety over their turn to perform as well as loss of attention during other friends' performances.

“Phần role play vẫn là cái gì đó họ phải struggle nhiều hơn...roleplay... họ phải làm theo cái yêu cầu. ...Mình không có biết chắc chắn được là tất cả các pairs thực sự rất thích cái scenario đó hay không. Các pairs không tập trung nhiều, không quan sát kỹ, lắng nghe như mình muốn tại vì còn đang bận suy nghĩ là cặp kết tiếp thầy sẽ gọi ai”.

(Roleplays seemed something they had to struggle much more with...roleplay...they had to follow its requirements... I didn't know for sure if all pairs were really interested in that scenario or not. Pairs didn't pay due attention, didn't observe carefully nor listened as I expected because they were busy thinking whom the teacher will call next).

Regarding the conversation analysing task, Mr. Sang expressed his uncertainty of the students' participation. He commented:

"Finding more about the listening conversations, finding out other features like the context of the conversation, and specific features relating to intonation, accent, volume, uhm ....this part of the design I am not quite sure about how much students can find out exactly... not sure about whether most of the students are confident enough to identify. I guess they may still select a more neutral answer."

This statement points to the fact that the analysing task includes various aspects of conversations for the students to examine. To Mr. Sang, students' self-confidence was not always obvious.

For the reflecting task, Mr. Sang considered that figuring out one's own lessons from his/her experience was challenging and time-consuming for students to achieve. Consequently, Mr. Sang decided to leave the reflecting task as homework to be revisited in the following lesson. Mr. Sang presented this in English:

R: How do you feel about the students' engagement in the reflecting task? 
Mr. Sang: Here, the students seemed more interested in listening, listening about each other's life than listening to the roleplays.

R: Uhm, so is it easy or challenging for your students to draw the lessons from their own stories by themselves?

Mr. Sang: Uh challenging. It should take a certain amount of time anyway. They cannot carry it out successfully at the first few times... I can set up relating and reflecting as a homework assignment for the next day.

In contrast, Mr. Sang found the students more independent with making and revising the hypothesis. He described the students' involvement in this task when he was asked to in the mid interview as follows:

“ Họ có đóng góp nhiều cho initiate hypothesis là một...họ tự ghi, tự suy nghĩ, coi họ lựa chọn hoặc thành lập cái hypothesis của họ thế nào,...để họ làm tự do chỗ đó, có khi họ cần discuss với kế bên... Mình không tự ghi hypothesis được, nó không phản ánh cái suy nghĩ của sinh viên về cái vấn đề... liên quan đến văn hóa".

(They contributed greatly to the initial hypothesis...they wrote by themselves, thought by themselves, seeing how they formed their own hypothesis... I let them work by themselves at that point... when they needed, they could discuss with students next to them. I shouldn't write the hypothesis myself because if I do so, this does not reflect the students' thinking about the culture-related problem).

And later in the final interview, he said:

“...I don't have any problem anyway guiding them to formulate hypothesis ...The only thing...is I need to give them enough time to formulate...I can manage the hypothesis quickly with my students".

Additionally, he commented that his students were improved and active in the listening part of the lessons. Mr. Sang remarked on their listening:

“Nghe đỡ hơn, có thấy nó nghe nhanh nhẹn hơn so với lúc đầu, phát hiện câu trả lời cho bài nghe nhanh chóng hơn".

(Listening better, I saw that they listened quicker than at the start, recognized the answers for the listening activity quicker).

Generally, Mr. Sang was certain about students' positive engagement in working on their hypotheses and the listening activities. In contrast, he doubted the students' active and independent participation in analysing the roleplays and self-reflection. 


\subsubsection{Post-workshop-two focus group data}

Similar to the case of Mr. Huy's students, Mr. Sang's students said they experienced both language and intercultural learning in these lessons. Two main themes were identified: (1) their perceived language learning outcomes and (2) their perceived intercultural learning outcomes.

\section{The students' perceived language learning outcomes}

The students perceived that they could learn various aspects of listening and speaking skills in the intercultural lessons. They mentioned both verbal and non-verbal components of speaking when they discussed what they think they learnt from the lessons. For example, Thinh perceived that he not only became more natural but also more confident and fluent in speaking:

Thinh: I now can make my conversation sound more natural having more appropriate structures used by natives.

...em chắc là em nói nhiều rồi, nói xuyên suốt,, nói miệt mài luôn

... em học cách nói trước nhiều người, confident

(... I am sure I spoke very much, spoke all the way through, spoke passionately and diligently

... I learnt how to speak in front of many people, confident).

Just like Thinh, Diem also perceived that she became more confident in speaking but moreover, described how she improved and changed. Diem said:

“Em học được cấu trúc mới... Lúc trước em dịch word by word... lúc trước muốn nói cái gì thì suy nghĩ tiếng Việt trước, thì hết giờ. Bây giờ thì mình cứ tập suy nghĩ tiếng Anh, từ từ em tập ...Em thấy tự tin hơn nhiều... em thấy em bình tình hơn.

(I learnt new language structures...previously I translated word by word...previously I used to think in Vietnamese before I say it in English. As a result, I run out of time. Now I keep on practicing thinking in English, I practiced this gradually...I found myself more confident and calmer).

The students added other aspects they learnt, apart from grammatical structures and pronunciation:

Thinh: chuyên sâu về phân tích... và cách trình bày ý kiến cuả mình. Học cách giao tiếp.

Nhu: cách phát biểu trước đám đông, thuyết trình, thể hiện gương mặt , cử chỉ 
Duy: Em học ngữ điệu tùy tình huống... cách bày tỏ cảm xúc của mình khi nói tiếng Anh

(Thinh: Further specialised in analysing....and how to express my opinion. Learn how to communicate.

Nhu: How to talk in front of the crowd, presenting, using facial expressions and gestures.

Duy: I learnt about intonation in context...how to express personal feelings when speaking English).

As can be seen, the students' reflections show their perceived gains in awareness about both verbal and non-verbal elements of English listening and speaking ability.

\section{The students' perceived intercultural learning outcomes}

The theme of the students' perceived intercultural learning outcomes was constructed based on the findings of their emerging awareness of aspects of ICC, and their learning interest.

First, the students showed an awareness of respect for others and politeness in communication. They also identified positive changes in themselves. In the following extracts, the students acknowledged what they learnt and described how they changed in handling associated disagreements, apologies, and giving advice:

R: Hoàn thành môn học này, theo em mình nên chú ý hơn tới yếu tố gì khi mình giao tiếng bằng tiếng Anh với người nước ngoài?

Thinh: Trong tình huống có bất đồng thì mình thể hiện tôn trong với người ta, mình nói là ý kiến của người ta không phải là sai nhưng có ý kiến khác tốt hơn.

Duyen: Lúc trước nếu làm sai điều gì thì chỉ nói đơn giản là "I am sorry". Ai hiểu thì hiểu không hiểu thôi làm biếng giải thích vì mình không sai với lương tâm mình. Giờ em nghĩ là khi muốn hai bên cũng vui vẻ thì mình nên có lời giải thích sau đó...Em thấy phân tích các bài hôi thoại chỉ cho em cách xin lỗi một cách hiêu quả ví dụ, xin lỗi có kèm biện pháp khắc phục.

Nhu: Lúc trước thường cho lời khuyên xong thì thôi, giờ cho lời khuyên còn nên cho lý do để giải thích nên mới thuyết phục người nghe.

(R: Completing this course, in your opinion, what should we pay more attention to when communicating in English with foreigners?

Thinh: If there is a disagreement, we show respect to the other speaker(s), we say that their opinion is not wrong but there are other better opinions.

Duyen: Previously, I simply said "I'm sorry" if I had done something wrong. I didn't mind if people understood me or not as long as I wasn't wrong with my conscience. Now, I think I should give 
explanation if I want both sides to be pleased... I found that conversation analyses taught me how to apologise effectively. For instance, I should include a compensation together with an apology.

Nhu: Previously, I merely gave advice, now I should also explain my advice to convince listeners).

In the above extracts, Thinh gave an example of how he would deal with disagreements. He considered respecting others' opinion to be important. Duyen and Nhu gave examples of how they adapted their thoughts and behaviours. The positive change is that now Duyen appears to consider both her own and others' feelings to be important. Thinh, Duyen, and Nhu all suggested communication strategies to maintain each other's respect, positive feelings, and effectiveness in communication.

The students' perceived positive change in seems clear in the case of Diem below. She elaborated at length a change in her personality:

“Em học được hai thứ quan trọng. Thứ nhất về văn hóa, phân tích những cấu trúc, những đoạn hội thoại thông qua đó em biết: nên chú ý coi người đó là nước nào...Điều này ảnh hưởng đến cách nói của mình khi mình nói tiếng Anh.

...Mặc dù mình không có ý xấu nhưng cách bộc lộ của mình có khi thô thiển. Lúc trước em chưa nói tiếng Anh tới mức lịch sự như bây giờ, bây giờ em thay đổi một chút về personality và cách nói chuyện hàng ngày

...Ảnh hưởng thứ hai của em đó là một phần nó làm tính tình em có những thay đổi đáng kể sau các bài học, về tính tình. Có những mặt mình nên suy nghĩ tích cực hơn, nữa là tiết chế lời nói dạ. .Tiếng Anh có những cái câu làm giảm nhẹ mức độ vấn đề hơn... Mỗi ngôn ngữ đều chú trọng tính lịch sự." (I learnt two important things. First, about culture, through analysing structures and conversations I see that I should pay attention to where that person comes from... this influences the way I talk to them in English.

...Although one does not want to be mean but the way he/she speaks may sound rude. Previously, I did not sound polite as I do now. Now, I have changed a bit in my personality and way of talking in daily communication.

...The second influence is that it changed my personality noticeably. There are things I should think more positively. In addition, (I) pay attention to my words...yeah. English has sentences that make problems less serious... Each language considers politeness important in its own way).

In the above reflection, Diem showed an awareness of adjusting her use of language and modifying her personality for the better. What is particularly interesting about Diem is that 
she seemed to make use of language learning to improve her personality and communicative ability at the same time. She recognised the relevance of what she learnt to how she developed.

Furthermore, the students expressed interest in intercultural learning. When they were asked What do you like about the intercultural-oriented lessons in general?, the students stated and explained their interest as follows:

Duyen: Em nghĩ, khâu làm hypothesis rât useful vì biết được lúc nào cũng phải hiểu mình trước... Em thích phần chia sẻ kinh nghiệm, nhớ lại trong tình huống đó mình đã dùng mẫu câu gì hay người ta đã dùng mẫu câu gì với mình ..còn rút ra những bài học nữa ... So sánh style giữa người Việt Nam và người nước ngoài. ..cả hai có giống có khác.

Duy: Em thích nghe, hiểu được thái độ của người ta thay vì nghe về thông tin

Diem: Em hiểu là hiểu được văn hóa thông qua tìm hiểu cấu trúc và từ vựng, địa vị xã hội và tuổi kể cả personality. Tất cả có ảnh hưởng đến cách mình giao tiếp.

(Duyen: I think, the process we make hypothesis was very useful because I learnt that I should always understand myself first...I like the part of sharing experience, recalling what sentences I said, what sentences other people said to me in a certain situation...(I) drew out lessons from it... Vietnamese and foreigners....have both similarities and differences.

Duy: I like listening. I listen to understand the speakers' attitude rather than to simply get information.

Diem: What I understand is that I can understand culture through examining sentence structure and vocabulary, social status, age, and even personality. These factors have influence on the way one communicates).

Duyen was aware of the importance of understanding about oneself and about others. Duy looked beyond listening for information, being aware of others' attitudes which is a nonverbal factor in communication. Diem recognised both language factors and multiple social factors embedded in communication interactions. Her response points to the fact that culture can be learnt through examining language. Altogether, these explanations touched upon aspects of savoir ${ }^{2}$ and savoir comprendre ${ }^{3}$ which are components of ICC in Byram's (1997) ICC model. Need further explanations here.

\footnotetext{
${ }^{2}$ knowledge

${ }^{3}$ skills of interpreting and relating
} 
In the following extracts, the students expressed their interest in the analysing task and highlighted the value of this task in language learning:

Thinh: Em thich nhất phân tích hội thoại. Đối với em chỉ riêng phần đó thôi đã hiểu ..ngữ điệu ngữ cảnh để giúp mình nói rồi.

Diem: Em nghĩ nhờ những bước phân tích đó mà làm cho việc nghe thú vị hơn...Khi phân tích từng bước từng bước hiểu sâu hơn thì bài nghe đó vô cùng giá trị...lúc trước học thì ít phân tích như vậy lắm. Lúc trước , khi thầy mở lên thì nghe, nghe được hoặc không. Không hiểu lắm đâm ra...không muốn dành thời gian cho nó vì không hiểu. Nhờ bước phân tích đó em hiểu nên cảm thấy việc nghe rất cần thiết.

(Thinh: I like analysing conversations very much. To me, this part itself already helps me to understand the speakers' intonation and speaking context to speak better.

Diem: I think thanks to the analysing steps, listening becomes more interesting... Analysing the listening step-by-step, I realised that the listening is very worthy...Previously, I was rarely taught to do like that. Previously, I listened whenever the teacher played the CD, I could or couldn't listen. As I could not understand what I listened to, I did not want to spend time on practicing listening. Thanks to analysing conversation, I understand it. So, I feel listening is very necessary).

Thinh was of the belief that conversation analyses contributed to his speaking ability. Diem found conversation analysis motivated her listening. The two students saw that the redesigned intercultural content enhanced their learning of language skills.

Mr. Sang's students' responses demonstrated their confidence in learning listening and speaking skills in his lessons. They, moreover, demonstrated interest in IcLL, showed an awareness of aspects of ICC, and perceived positive changes in themselves. While Mr. Sang doubted his students' independence and confidence in the analysing task, the student responses indicate that the analysing task seems to be the most useful and motivating component for them to participate.

In summary, Mr. Sang closely followed the redesigned intercultural content in his Phase Two teaching practices. However, similar to Mr. Huy, Mr. Sang's lessons seemed to focus more on conversation analysis than relating and reflecting skills. He created chances to raise the students' awareness of politeness and always made sure there was sufficient time for students to rehearse their roleplays. What was unique in his lessons was that (1) he explicitly explained the necessity of understanding one's hypothesis and considering revising 
it in communication; and (2) he often asked students to explain their responses and hypotheses and encouraged comments on the language used by students in their roleplays. Mr. Sang held the perception that the intercultural-oriented lessons addressed culture to a larger extent than normal lessons and enhanced the development of students' intercultural awareness and exploratory and life-long learning. He also noted the important role of intercultural instruction in developing various intercultural skills for students. He stated a willingness to apply intercultural teaching although he considered it to be challenged by teachers' limited teaching resources. He observed both students' independence and struggle in learning the intercultural-oriented lessons.

\subsubsection{Discussion}

\section{Mr. Sang's teaching practices}

Similar to the other two teachers. Mr. Sang taught all redesigned intercultural content in all observed lessons. In the data, the following iCLT principles were reflected in Mr. Sang's teaching: value intercultural learning goals alongside linguistic and communicative goals; and mine the input for its cultural content.

\section{- Value intercultural learning goals alongside linguistic and communicative goals}

Mr. Sang considered intercultural learning equally important as language learning in all three lessons. First, from the first to the fifth intercultural-oriented lessons, Mr. Sang addressed all the re-designed intercultural content alongside the compulsory listening activities. His persistent intention to enhance students' intercultural awareness and to enrich intercultural components was clearly displayed in all observed lessons. For example, early in the first lesson, he explicitly told the students, "I want you to keep this preconception in mind, we will work on more situations so that you can see if your hypothesis is ok or not." During this lesson, he provided cultural information about New Zealand, the context of the conversation on which he based a model of how to analyse a conversation. Early in the third lesson, he explicitly told the students to revisit their hypotheses later in the lesson. By the end of this lesson, he mentioned the use of additional mediating words in the Vietnamese language. In the last lesson, he and students explored the speakers' changes in attitudes in the listening. Seeing that his students needed help to carry on the intercultural tasks, Mr. Sang suggested that students pick up language phrases 
that express politeness and to comment on them (in the first lesson). He worked with individuals on the tasks (in the third and the fifth lessons). At the end of all lessons, Mr. Sang reminded the class about what communication aspects they should pay attention to from learning the focused speech act.

Students' limited language level or traditional learning style may demotivate teachers to address culture but for Mr. Sang, this is not the case. His persistence and being explicit in integrating culture alongside linguistic and communication goals probably resulted in positive impacts on his students' learning in the intercultural lessons.

\section{- Mine the input for its cultural content}

In the data, this principle was reflected to a larger extent in Mr. Sang's lessons than in the other two teachers' lessons.

In all lessons, Mr. Sang taught the intercultural content especially the conversation analysis and comparison. For example, in the first lesson, Mr. Sang explained the reasons for analysing conversations. His instructional activities to guide students' conversation analysis included (a) asking students to comment on the language used by them in their roleplays and (b) encouraging students to explain the responses they gave to the scenarios. Regarding the comparing task, Mr. Sang assisted students in completing this task. For instance, in the first lesson, when he found students confused, he suggested what they should compare. In the third lesson, he reminded students about how Vietnamese use additional mediating words to soften disagreements. After conversation analyses and comparisons in all lessons, he always had students revisit their hypotheses.

Hence, the way Mr. Sang guided students during the analysing and comparing tasks engaged students in a more student-centred learning style.

- Encourage an exploratory, experiential, comparative, and reflective approach to culture in which the learners (guided by the teacher) construct intercultural perspectives

Exploratory and reflective learning in which the students were able to construct intercultural perspectives was prominent in Mr. Sang's teaching. First, he explicitly explained the necessity of learning the redesigned intercultural content. For instance, in the first lesson, he stressed the importance of knowing one's own beliefs, values, and attitudes, 
and of conversation analysis. Second, he asked students to explain their initial and revised hypotheses. This allowed students to critically think about their intercultural perspectives. In all lessons, he taught students to recognise and consider revising their hypotheses. As mentioned in the previous analysis, this was the part he enjoyed teaching most and had no difficulty teaching it.

Moreover, regarding the relating and reflecting tasks, he explained these tasks (in the first lesson). In the third and final lessons, he monitored the whole class and worked individually with pairs on these tasks. Based on what the students shared with him and with each other, Mr. Sang wrote the final notes on the board (e.g., in the fifth lesson) and ended each of the lessons in a meaningful way by briefly summarizing the lesson's focused speech act and drawing lesson for communicating interculturally.

As can be seen, Mr. Sang implemented the re-designed intercultural content in a way that enhanced students' awareness of ICLL and ICC. His teaching also reveals his commitment in helping and motivating students to complete the redesigned learning tasks. The students' perception about their intercultural learning outcomes, as analysed earlier, appears to have resulted from this style of teaching.

\section{Mr. Sang's understandings}

In Phase Two, Mr. Sang's emerging understanding is strong in that he placed emphasis on developing students' aspects of ICC and on an explicit inclusion of intercultural instruction. First, in Mr. Sang's perception, the link between FL learning and culture clearly seems to be close. He believed that intercultural instruction in classes is practical for students. Specifically, he considered that regular integration of intercultural content enhanced students' (1) cross-cultural awareness, (2) intercultural learning especially, skills of noticing and relating culture, and understanding and adapting one's own beliefs, and (3) exploratory independent learning style. Second, Mr. Sang realised (1) the gap in his students' awareness of equipping themselves with the above-mentioned intercultural skills and (2) the relevance of integrating intercultural instruction. His realisations indicate that students should play a central role in their learning of culture in life. Furthermore, with the same concern for iCLT integration, Mr. Sang seemed to be realistic since he drew attention to the challenges such 
as the students' struggle with completing the intercultural learning tasks, and the teacher's limited time and resources for iCLT integration.

However, Mr. Sang's emerging understandings showed limitations. He perceived iCLT as an alternative to vary teachers' current teaching approaches (as analysed in his perception of the values of the integrated intercultural orientation) rather than being a more fundamental shift in stance.

\subsubsection{Cross-case analysis and discussion}

In the following cross-case analysis and discussion, I consider the aspects in which the three cases were similar, different, and contradictory to develop a finer-grained set of findings based on which I can draw conclusions in relation to the research questions which motivated this study.

The analysis synthesizes findings from each case and highlights three key findings. First, the case study teachers demonstrated a more systematic and principled engagement with culture. Second, they developed positive perceptions about iCLT while being aware of the challenges of iCLT. Third, they showed their improved understandings of iCLT.

\section{The teachers' adoption of iCLT}

First, the three case study teachers demonstrated a more systematic and principled engagement with culture. In all observed intercultural lessons after the first workshop, the three teachers' teaching complied with the redesigned lesson plans whose components aimed to promote intercultural learning through language learning. In the lessons after the second workshop, they continued to adopt the redesigned intercultural content in their classes. Their teaching practices reflected the following iCLT principles: addressing intercultural learning alongside language learning, mining the input for its cultural content, and encouraging an exploratory and reflective learning approach in which students construct intercultural perspectives. For example, all teachers taught students to consider their taken-for-granted hypotheses related to how English speakers deal with politeness and appropriateness in the lesson input (e.g., in requests, disagreements, and apologies). These incidents aligned with Byram's (1997) emphasis on knowledge of self and Witte's (2014) emphasis on raising awareness of stereotypes and taken-for-granted cultural assumptions. 
Such evidence showed their interest, commitment, and active participation in the research, given that they had to address the exam-based curriculum and mandatory textbook-based content in at the current university.

Second, despite using the same redesigned intercultural content, their teaching practices revealed their unique emphases in class. For example, Ms. Sen focused on the relating and reflecting tasks. Mr. Huy emphasized the value of students' lived experiences. Mr. Sang emphasized the importance of learning to discover and challenge one's cultural hypotheses. The process of adopting an intercultural stance led to the teachers' unique comments on the experience of teaching the intercultural lessons, in their reflections in the interviews. Ms. Sen said that this experience allowed her to reflect on her previous teaching of culture. Mr. Huy realised the way culture was addressed in traditional lessons and intercultural lessons. Mr. Sang recognised the value of intercultural learning in promoting students' longterm learning of culture. Such evidence shows that the teachers' adoption of an intercultural stance was a personal process despite using the same set of instructional materials.

\section{The teachers' perceptions of iCLT}

The three teachers demonstrated positive perceptions about the redesigned intercultural content in particular and iCLT in general after they participated in the workshops and taught the post-workshop lessons.

First, the teachers perceived that the redesigned intercultural teaching model increased the amount of ICLL in the lessons. In the data, the teachers perceived that the model created opportunities for students to learn intercultural skills. These opportunities are summarised in Table 19:

Table 19. Teachers' perceived opportunities for ICLL in the intercultural lessons

\begin{tabular}{lll}
\hline & Opportunities to & Perceived by \\
\hline - & challenge and critically reflect on one's own perspective & Ms. Sen and Mr. Sang \\
- develop cross-cultural awareness and independent thinking skills & Mr. Huy \\
- to analyse, compare, notice, adapt, and self-explore culture & Mr. Sang \\
\hline
\end{tabular}


The learning opportunities perceived by the teachers in Table 19 reflect diverse skills involved in ICC which according to Crozet and Liddicoat (1999) and Newton et al. (2010) are the skills of probing, reflecting, comparing, connecting, interacting, and experiential learning. In other words, adopting the redesigned intercultural teaching model fostered teachers' attention to students' ICC. According to Liddicoat (2002), Corbett (2003), Newton et al. (2010), and Newton (2016), explicit focus on culture and students' ICC is one of the key features of iCLT.

Second, the integrated intercultural lessons enhanced students' learning experiences. According to the teacher-interview data, Ms. Sen perceived that her students progressed from passive to more active during the post-workshop lessons. Mr. Huy considered his students as being active especially in these lessons. Mr. Sang perceived that his students were confident in some tasks but struggling in others. The teachers' perceptions of students' learning were reconfirmed by the student post-workshop-two focus group interviews which showed that all three focus groups perceived their participation in the lessons as positive learning experience in which their language learning and intercultural learning both improved.

Apart from the teachers' positive perceptions about the integrated iCLT, their perceived challenges for iCLT integration were also explored. In the data, both convergences and divergences were identified in the teachers' perceived challenges of iCLT. Ms. Sen explicitly emphasized teachers' limitations of intercultural knowledge and intercultural teaching skills, whereas both Mr. Huy and Mr. Sang emphasized time issues. Mr. Huy noted that intercultural lessons took a lot of time for teachers to identify cultural aspects and enrich their knowledge related to these aspects. Mr. Sang contended that intercultural lessons depended on teachers' knowledge about cultural norms which are not often provided in the main teaching materials and teaching manuals. In other words, according to the two male teachers, inadequacy of teaching manuals in the current context made intercultural lesson preparation time-consuming. In summary, the three teachers' major perceived challenges involved a lack of time and teaching materials for lesson preparation, and the need for teachers to develop their intercultural knowledge and intercultural teaching skills.

The challenges of time and teaching materials correspond with the teachers' perceived constraints found in Sercu et al. (2005), T. L. Nguyen (2013), D. C. Nguyen (2013), Gandana 
and Graham (2013), and Abdulrahman (2016). Importantly, the teachers in this current research seemed to regard teachers' intercultural knowledge and intercultural teaching skills as the most fundamental challenge. Aguilar (2008) makes a similar point when discussing the changing roles of teachers in interculturally-informed pedagogy:

"The best teacher will be neither the native nor the non-native speaker, but the person who can make students see the connections between their own and other cultures, as well as awaken their curiosity about difference and otherness" (p. 69).

\section{The teachers' improved understandings of iCLT}

The teachers' improved understandings of iCLT can be seen in their increased interest in adopting iCLT in their future teaching, their emphases on aspects of $\mathrm{iCLT}$, and their increased awareness of iCLT.

First, in the data, the three teachers expressed an increased interest in adopting iCLT in their future teaching. Although they all showed a positive attitude, the nuance of each teacher's attitude seemed to be unique. Ms. Sen said that she felt she became more responsible and committed to teaching culture. Mr. Huy said he wanted to inspire colleagues about the intercultural innovative teaching even though, in Phase One, he said that he only taught culture when he thought it enhanced students' language improvements. Mr. Sang said he would address the challenge of intercultural teaching through his commitment to lesson preparation. Altogether, these findings also show that the participant teachers have reached a more integrative view of teaching language and culture over the course of the intervention.

Second, the interview data showed unique features of each teacher in engaging with intercultural language teaching. Ms. Sen emphasized that teachers' intercultural knowledge and intercultural teaching skills are more crucial than teachers' being native or non-native. Mr. Huy emphasized that culture can become a primary goal in language lessons. He developed a more open attitude to integrating culture. These changes in Mr. Huy indicate that culture has gained a more valuable status rather than the peripheral status he perceived it to have in Phase One. Mr. Sang emphasized the need to address intercultural skills and the important role of explicit inclusion of intercultural instruction on students' inclass and life-long ICC development. 
Furthermore, through making sense of their teaching of the redesigned intercultural content, the case study teachers showed their growing awareness of iCLT. For instance, Ms. Sen reflected on her previous teaching of culture in the light of iCLT. Mr. Huy contrasted how he taught culture in traditional lessons and in intercultural lessons. Mr. Sang was aware of the role of explicit inclusion of teaching ICC on students' ICC development. Such teachers' growing awareness of iCLT is significant because, according to Borg (2006, as cited in Howard et al., 2016), teachers make decisions about practice as a consequence of their making sense of information that informs their work.

This study's findings of teachers' improvements in terms of applying, understandings and awareness about iCLT echo findings in studies that involved teachers in some forms of training on iCLT. Such studies include Lázár (2011), Mahoney (2015), Tolosa et al. (2018), Maijala (2018), and Dimas (2019). In Lázár (2011), in Hungarian context, the pre-service teachers were found to make conscious efforts to incorporate an intercultural dimension during their teaching. Lázár (2011, p. 124) considered the ICC training course, in which the teachers participated, as a powerful awareness raising function. In Mahoney (2015), the teachers perceived diverse values of ICLL and found IcLL complemented traditional teaching approaches to culture after they participated in the ICLL training course. Mahoney $(2015, \mathrm{p}$. 104) called the IcLL training course a professional development exercise for teachers. In New Zealand, Tolosa et al. (2018) found that the teacher participants shifted their view of teaching culture and focused more on culture practices after taking guided reflection alongside their teaching. Maijala (2018), in Finland, provided evidence which suggested that by involving teachers in reflecting and sharing experience, teachers could be prepared to face uncertainty in culture teaching. In Dimas (2019), the participating English teachers (professors) perceived that the adopted instructional design on ICC allowed them to fully develop language lessons and to balance textbook-based content and students' lived experience. Hence, the current study findings together with previous findings point to a positive impact of professional learning/training on teachers across contexts.

However, Byram (2015) points out that despite its importance, training does not always easily overcome teachers' pre-existing beliefs. This is the case found in Feryok and Oranje (2015). Feryok and Oranje (2015) introduced a case study teacher teaching German in a New Zealand school, to the use of a cultural portfolio. Feryok and Oranje (2015) analysed 
the teacher's reflection on her use of portfolios and found that the teacher conceptualised portfolios as a form of internal formal assessment instead of a means to address culture interculturally.

In summary, cross-case analysis identified no conflict but found that the intercultural teaching journey taken by each teacher was unique and personal. But common across these unique journeys, the teachers (1) addressed culture in a more systematic and principled manner in their classroom teaching practices, (2) held positive perceptions about the redesigned intercultural teaching model, (3) developed a more open attitude towards teaching culture in the light of iCLT principles, and (4) acquired an integrative view of and informed understandings about teaching culture. The three teachers became what Sercu et al. (2005, p. 10) described as "favorably disposed" teachers who see language and culture as equally important, display willingness to teach culture, and believe in the possibility of developing students' ICC in language teaching.

\subsection{Chapter conclusions and implications}

The focus of Phase Two was on the impact of two professional learning workshops, which introduced iCLT on the teachers' classroom teaching and emerging understandings, and students' learning. Its key findings include: (1) the teachers' systematic and principled adoption of iCLT; (2) the teachers' positive perceptions about iCLT; (3) and the teachers' acquisition of iCLT evident in their taking an integrative view of intercultural language teaching and in their gained understandings about iCLT, and (4) the students' positivelyperceived learning outcomes which included both language and intercultural outcomes.

To compare with findings in Phase One when there was an absence of attention to addressing the intercultural dimension in the teachers' teaching practices, Phase Two findings reveal two important insights. First, the case study teachers were able to implement/deliver intercultural-oriented lessons within the current curriculum. They were able to learn to teach interculturally, which was different from their classroom routines. The teachers' similarity and their unique emphases during the process of implementing the same intercultural materials, and their making sense of the experience of doing this reveal Prabhu's (1990) notion of teachers' sense of plausibility, defined as "teachers' subjective understanding of the teaching they do" (p. 172). Teachers' sense of plausibility is influenced 
by many factors including the teaching methods they use (Prabhu, 1990). However, as he argues, the teachers' sense of plausibility is important in that, with their sense of plausibility open to change, teachers are able to create a sense of involvement both for themselves and students in classrooms. Their teaching becomes "real" instead of mechanical implementation of teaching methods.

Moreover, the feasibility of the two models was confirmed. The first model was the PAR workshop cycles which involved the teachers working with iCLT content and implementing iCLT content in post-workshop teaching practices. The second model was the redesigned intercultural content which aimed to reflect iCLT principles in classrooms. Scholars (Lázár, 2011; Byram, 2015; Garrettrucks \& Osborn, 2016; Oranje \& Smith, 2018; Maijala, 2018) have argued that providing teachers with applied knowledge of developing ICC allows teachers to practice teaching culture with teachers' being favorably disposed towards iCLT. For instance, Maijala (2018, p. 1) maintains that "more attention should be paid to culture teaching methods in FL teacher education in order to move from the traditional, teacher-centred approach towards a new dynamic and learner-centred practice." This argument has been supported by the current study.

\subsection{Chapter summary}

This chapter has presented data from the case study teachers' post-workshop teaching practices and stated perceptions, and the student focus groups' perceptions of the learning experience of the intercultural-oriented lessons. Analyses used data from teachers' teaching observations, teachers' mid and final interviews, and post-focus groups.

Data analyses demonstrated that the teachers closely applied the redesigned intercultural teaching model and held positive perceptions about their teaching experience and students' learning. These key findings show the teachers' understandings and attitudes towards iCLT grew more positive as they became more familiar with it. Additionally, the students reported positively on their experience of the intercultural lessons. Phase Two findings allow the conclusion that designing and adopting a principled intercultural stance in the current university EFL programme is both feasible and positively affirmed by teachers. The implications drawn highlight the significance of professional learning opportunities that prepare in-service teachers to learn to teach interculturally within their existing context. 


\section{CHAPTER 6 CONCLUSIONS}

\subsection{Introduction}

This research examined the practices and perceptions of three case study teachers in relation to teaching culture in their EFL classes and students' perceptions of learning in their classes in order to answer the overall research question: What is the potential for fostering a more systematic engagement with culture and intercultural learning in EFL classes at a university in Vietnam?

In Chapter 1, I introduced the study including the context of English language teaching and learning in Vietnam, and my personal experience that motivated me to undertake this thesis. In Chapter 2, I reviewed and discussed the theoretical framework underpinning this current study, and scholarship on the teaching culture of teachers in Vietnam and beyond Vietnam. In Chapter 3, I discussed and justified the paradigm, research methods and approach used in this study and described the context in which data collection took place. Chapter 4 provided analyses and findings of the teachers' current teaching practices and perceptions related to the teaching and learning of culture in EFL classes. Chapter 5 provided analyses and findings that showed how the case study teachers progressed towards an intercultural stance in both their teaching practices and stated perceptions. Both Chapters 4 and 5 provided discussion and implications of the findings in the light of scholarship concerning an intercultural stance in FL education. This final chapter provides a summary of the main findings in relation to the research questions and highlights the study's significance. It also identifies limitations of the study and recommends areas for further research. Finally, the chapter ends with a concluding statement followed by a personal reflection.

\subsection{Summary of findings}

Phase One studied the current orientation to culture at the chosen university. It addressed RQ1: What are the current practices and understandings of the three case study Vietnamese tertiary EFL teachers in relation to teaching culture? The key findings, which reveal that the current orientation to culture had both constraints and affordances for adopting an intercultural stance at the current university, are: 
- In teaching practices, culture was peripherally addressed in the teachers' classrooms by focusing on cultural knowledge transmission and reliance on teachers' cultural knowledge and unplanned culture teaching moments.

- Regarding the teachers' beliefs and understandings around teaching culture, the teachers demonstrated static conceptualisations of culture, and lacked an awareness of intercultural language teaching and learning.

- The teachers showed points of positive alignment with an intercultural stance in their awareness of the value of and their interest in addressing culture (e.g., Ms. Sen and Mr. Sang) as well as at some points during their teaching practices when they valued sharing lived experience with students (e.g., Mr. Huy).

- According to the students, the current orientation to culture did not meet their intercultural learning needs.

Phase Two investigated the impact of professional development workshops on teachers' teaching practices and understandings of an intercultural stance. The aspects under examination included how the teachers implemented the iCLT lessons, how they made sense of the redesigned intercultural content, how they constructed knowledge about iCLT, their self-reported changes in awareness of $\mathrm{iCLT}$, and how they developed confidence in implementing iCLT lessons. Phase Two addressed RQ2: What was the impact of the two professional learning workshops which introduced intercultural language teaching on the classroom teaching practices and emerging understandings of the case study teachers? Its key findings are:

- In teaching practices, the teachers successfully implemented the redesigned intercultural content in lessons they taught after both workshops. The way each teacher implemented the intercultural lessons reflected iCLT principles, despite their different emphasis, and a more student-centred teaching style. The teachers did not extend the redesigned sample of intercultural content introduced to them, nor create their own intercultural lessons.

- Regarding the teachers' stated perceptions and emerging understandings, first, the teachers valued the way the lessons integrated language and culture. Second, their improved understandings about teaching culture were more in line with an intercultural stance than in Phase One. Third, the teachers expressed positive 
attitudes towards adopting an intercultural stance despite their perceived challenges and held positive views of the students' learning in the intercultural lessons.

- The students expressed positive views of the intercultural lessons and of the learning opportunities these lessons offered.

Altogether the thesis findings support Scarino's (2010, p. 324) distinction between two orientations to culture in FL education: the cultural orientation and the intercultural orientation. Specifically, Phase One's findings align with Scarino's (2010, p. 324) description of cultural orientation, which was "generally separate from and subordinate to the teaching of the language", "frequently comprised a generalised body of knowledge about the target country and its people", and "remained external to and separate from the students' own first language(s) and culture(s)", rather than an intercultural orientation. With regards to the teachers' perspectives, Phase One findings reveal what scholars term as the teachers' personal theories about teaching culture (Lázár, 2011, p. 124) and personal stories (Peiser \& Jones, 2014). Phase Two findings provide evidence of successful implementation and understanding of iCLT as well as enhanced understandings and attitudes towards iCLT by the teachers.

\subsection{Implications of the study}

Chapters 4 and 5 discussed the implications of the findings in each research phase. In this section, the implications of the study are discussed in a broader and holistic sense in order to highlight contributions this research makes.

Phase One findings informed the integration of iCLT in Phase Two by highlighting the relevance of adopting an intercultural stance into the current context. First, Phase One found that culture was treated as peripheral to the teachers' teaching practices and that the teachers were unaware of iCLT. These findings together with the marginalised status of culture in the Vietnamese EFL scholarship indicate the urgent need to address the intercultural dimension in the Vietnamese tertiary EFL context. This call to address the intercultural dimension of English language learning emerged in the last decade (T. M. H. Nguyen, 2007) and has been increasingly emphasized (Ho, 2011a, 2011b; T. L. Nguyen, 2013; Trinh, 2016). However, little research has suggested practical approaches or models that help to guide teachers to teach interculturally. As a result, Phase One findings highlight 
the need for professional learning approaches and models that can increase teachers' knowledge, expertise, confidence, and flexibility for implementing and preparing intercultural lessons, and reflecting on these.

In the same vein, Phase One findings indicate the necessity of professional support for the teachers to achieve their intercultural teaching goals. For example, Ms. Sen aimed at broadening students' worldviews, tolerance, and unselfishness alongside their language development. Therefore, she needs the expertise, which, according to Jin and Cortazzi (2017), is the ability to create tasks that involve students in analysing, understanding, and reflecting upon their own perspective. Mr. Huy emphasized students' linguistic proficiency. Mr. Sang considered students' language development to be more urgent than their intercultural competence. For students to achieve "fluency without foolishness" (Bennett, 1997, p. 20), both Mr. Huy and Mr. Sang would benefit from incorporating intercultural goals alongside language goals. This is because, according to Bennett (1997, p. 16), treating FL learning as a process of substituting words and rules to get the same meaning leads to learners being "fluent fools" who can speak well, but do not understand the social or philosophical content of the FL. Overall, Phase One findings provided analytical insights into the teachers' strengths and limitations which were addressed in Phase Two.

Phase Two findings show evidence of positive changes in the teachers' teaching practices, their stated perceptions, and emerging understandings (as detailed in Chapter 5). The findings of the two phases provide insights into how Vietnamese university EFL teachers make sense of teaching culture; how they were supported by professional learning to shift from a traditional to an intercultural stance; how they were willing to improve FL teaching quality and themselves from an intercultural perspective. These insights enable us to obtain a fuller understanding about the potential and challenges of adopting iCLT in a Vietnamese tertiary EFL context in reality as well as in similar EFL contexts. Understanding of teachers' perspectives promotes positive changes in schools because, according to Day (2002), Little (1992), and King and Newmann (2001), teachers play a key role in educational innovation and improvement and contribute to professional growth of colleagues and their professional community.

Although, the findings do not allow generalisations, it is possible to distil important provisional specifications that can be applied to similar contexts. First of all, the actual 
intercultural lesson model that reflects ICLL principles provided the teachers with a resource to design intercultural-oriented lessons. The redesigned intercultural content and procedures are summarised in Table 20:

Table 20. Procedure for IcLL

\begin{tabular}{|c|c|c|}
\hline Steps & IcLL & Students' activities \\
\hline \multirow[t]{4}{*}{1} & $\begin{array}{l}\text { Form initial } \\
\text { hypotheses }\end{array}$ & $\begin{array}{l}\text { Whole class discussion: Make hypotheses about cross-cultural } \\
\text { differences in directness and politeness }\end{array}$ \\
\hline & Speak & $\begin{array}{l}\text { Small groups: Rehearse and perform a role play which was } \\
\text { redesigned by the teacher based on the textbook-based } \\
\text { listening conversations }\end{array}$ \\
\hline & & $\begin{array}{l}\text { Whole class discussion: Discuss how each group managed } \\
\text { politeness }\end{array}$ \\
\hline & Listen & Listen to textbook conversations \\
\hline 2 & $\begin{array}{l}\text { Notice and } \\
\text { Compare }\end{array}$ & $\begin{array}{l}\text { Analyse textbook conversations (i.e., what and how } \\
\text { conversations were said, conversations' context, comparing } \\
\text { language styles) }\end{array}$ \\
\hline 3 & Reflect and relate & $\begin{array}{l}\text { Reflect on differences and relate to personal lives and } \\
\text { communication experience }\end{array}$ \\
\hline 4 & $\begin{array}{l}\text { Revise initial } \\
\text { hypotheses }\end{array}$ & Revise initial hypotheses \\
\hline
\end{tabular}

One of the lessons learnt from developing this lesson model is that for developing intercultural learning materials, teachers can approach existing teaching materials with a new mind-set. As can be seen from Table 20, instead of focusing only on aspects of language (i.e., listening for details and main ideas, and speaking for fluency), teachers can integrate intercultural learning in the ways that actually enhance communicative skill practice.

In the first step for IcLL, forming initial hypotheses (in Table 20), teachers can help students to think critically and discuss their cultural beliefs or assumptions related to the input. To do this, teachers prompt students to form an initial hypothesis or provide students with a hypothesis which usually reveals cultural prejudice(s) or a cultural generalisation. At this 
early stage, students discuss and explain the hypothesis to raise awareness of their existing cultural beliefs or assumptions.

In the second step, noticing and comparing, within the FL lessons, teachers can foster students' intercultural perspectives on language use by guiding them to be active interpreters of communication. Teachers, for this purpose, guide students to notice and analyse the cultural dimension of language use embedded in the conversations for listening. This includes students' exploration of language, conversation context, and cross-cultural comparison of communication styles. To explore language, students analyse features such as language phrases used to covey politeness, phrases that make the conversation go smoothly, speakers' use of volume, pauses, and stress and intonation and so on. For students' exploration of conversation context, teachers may use questions such as Where did the conversation take place? Who was involved? What was the social status of each speaker? The status difference of the speakers was high or medium or low? What was the level of familiarity between speakers? How well do they know each other? To compare language styles, students discuss their roleplayed conversation and mother tongue responses against the lesson input. According to Jin and Cortazzi (2017), the purpose of analysing the intercultural dimension is not just to encounter a range of cultures through texts to increase awareness of other cultural communities. Instead, Jin and Cortazzi (2017, p. 38) contend that students have chances to "explore, investigate, and interpret intercultural interactions; identify the stances and interpretations taken by interlocutors and the values they draw on; and identify sources of misunderstandings and intercultural conflict". This fosters flexibility, mindfulness, cultural adaptability, and even intercultural mediation (Jin \& Cortazzi, 2017).

Similarly, according to McConachy (2018, p. 91), "examination of language use in conversational transcripts or textbook dialogues allows learners to practice interpretation from a distanced perspective." McConachy (2018) argues that the paralinguistic dimensions of language use and the operationalisation of the socio-pragmatic dimensions of language use are not bounded by the relatively narrow concept of appropriateness. Instead, according to McConachy (2018), language use is social behaviours whose meanings are actively interpreted by individuals in interaction. McConachy (2018) suggests that teachers scaffold students' interpretation of language use which is embedded in the textbook-based 
conversation transcripts. This enables students to realise that culture is a constituent part of language use, and to understand the complexity of language use as a form of social behaviour (McConachy, 2018).

Because reflection on one's own culture and language is an important aspect of ICC (Byram, 2015; McConachy, 2018) and is emphasized in the intercultural orientation (Scarino, 2010), the next step in my redesigned model (i.e., relating and reflecting) requires teachers to guide students to relate and reflect on their own languages and cultures. Once students have gone through the analysing, comparing, and relating/reflecting steps, they consider revising their initial hypotheses.

Specifically, the reflecting task requires students to relate their cultural explorations in the previous step to their lived experience and to critically reflect upon differences. This step provides chances for students to share personal stories or communication situations that they have encountered and to discuss communication effectiveness and the lessons learnt from their personal communication experience in association with their new cultural findings. According to scholars such as Scarino (2010), Jackson (2011), McConachy and Liddicoat (2016), constant and deep reflections on the linguistic and cultural input enable students to decentre from their taken-for-granted linguistic and cultural perceptions. As a result, students are able to "consider their situatedness from the perspective of another" (Scarino, 2010, p. 324), "decentre from default perceptions", and "develop more sophisticated explanations for pragmatic interpretation" (McConachy \& Liddicoat, 2016, p. 17). Jackson (2011, p. 82) adds that learners become more aware of "how they and their fellow citizens conceptualise, understand, and experience" national identities and interactions, and how this awareness impacts upon their relations with others; become more mindful of stereotypes, and develop intercultural sensitivity.

Moreover, this current research's PAR cycle (which involved an initial workshop, postworkshop teaching, a subsequent workshop, and then post-workshop teaching) provides an effective in-context professional learning model for in-service teachers' professional development. The initial workshop involved components of (a) the teachers' reflection on their current teaching of culture, (b) awareness raising on the iCLT topic, (c) provision of theoretical knowledge and practical model(s) of intercultural-oriented lesson plans, and (d) the teachers' discussion of the introduced knowledge and instructional model. The 
subsequent workshop involved components of (a) the teachers' reflection on and sharing experiences of their intercultural teaching, and (b) the teachers working together to further develop or create their own intercultural lessons. The repeated cycle allows the teachers to develop interculturally from being guided to becoming more independent during postworkshop teaching practices. Through this model, the teachers were involved in a collective, active, reflective, and contextual learning process (Bergold \& Thomas, 2012) to construct their knowledge about and gradually acquire iCLT knowledge and skills during the research process (MacDonald, 2012).

As such, in terms of research methodology, this research can be considered as a systematic and comprehensive study that investigates teachers' perspectives on adopting an intercultural stance in the Vietnamese tertiary EFL context. It studied the case study teachers' classroom practices and beliefs before and after launching the professional learning workshops. The teachers were involved in the collaborative workshops in which the materials for intercultural language learning were developed in light of iCLT principles to suit the teachers' current teaching resources and context. The value of principles is that they are broad and abstract enough to allow the case study teachers to apply them in their unique ways. The case study teachers could benefit from discussing such materials and principles, implementing them in classrooms, and reflecting on their teaching. The findings showed that the case study teachers improved their understandings of and skills necessary for adopting an intercultural stance within their current context. The workshops in this research were shown to be effective in guiding teachers to understand what an intercultural orientation involves and implies, and to understand why it is valued. Therefore, with its contextual sensitivity, the design of this current study shows its contribution to the improvements of the case study teachers. In other words, this current study's research design was context-relevant to the participant teachers and reflected the teacher-centred approach to teachers' professional learning.

This research also enriches TPL scholarship by providing insights and evidence of the effectiveness of a particular approach to TPL focused on intercultural competence for teachers in the under-studied Vietnamese ELT context. To effectively enhance teachers' professional improvements in intercultural language teaching, TPL needs to provide teachers with opportunities to reflect on their own practice and understandings within a 
supportive community of practice. It also needs to provide opportunities for them to explore comprehensible versions of current research findings and theoretical understandings, and practical applications of these materials to teaching practice. Equally crucial, it needs to take into consideration teacher-related factors such as their teaching situations, existing teaching experiences and beliefs and current understanding about the topic under concern as well as their contextual constraints. This is a fine balancing act, but one which the current research sought to enact. The intercultural teaching workshop cycles (Phase Two) were designed with reference to a careful situation analysis (Phase One) and were rooted in the existing curriculum and textbook. Specifically, teachers' existing beliefs and understandings about key concepts (e.g., culture and teaching culture in EFL classrooms) were carefully explored in Phase One. This initial ethnographic exploration informed the workshop content and learning processes. It also allowed tracking of how each teacher shifted from his/her existing beliefs and understanding during the research as well as each teacher's unique trajectory of learning.

Considering the contextual constraints in which TPL takes place is also useful for understanding the degree to which teachers' professional improvement can be achieved and/or sustained. In the current research, the intercultural lessons were designed and implemented without ignoring the potential constraints for teachers' learning, i.e., the exam-oriented course, the linguistic-oriented coursebook, and the teachers' full teaching timetables, the lack of intercultural teaching resources, students' limited language proficiency, and big class size. Regarding the task of designing the intercultural model lessons, textbook analysis was conducted to identify and select the lessons in which intercultural content could be embedded but easily ignored by the teachers. In the last two intercultural lessons following the second workshop, the participants teachers were found to neither expand, revise nor create their own intercultural content. This was understandable because they were under pressure to prepare students for the final listening and speaking examination towards the end of the trimester. IC was not assessed in these examinations. Clearly, examination pressure can limit teachers' engagement with intercultural language teaching if IC is not assessed.

Given the insights presented above, it is my contention that, by providing teachers with appropriate support, it is feasible for teacher learning programs on intercultural language 
teaching to be organised within the teachers' natural work conditions which unavoidably involve contextual barriers. Taking teachers-related factors in their teaching situation into consideration rather than adopting a top-down model delivered by outside experts could help avoid teachers' resistance and allow their agency to inform research (Manara, 2014). This suggestion aligns with King and Newmann's (2011) principle that professional learning does not rely merely on outside experts and materials which are exclusive to teachers' daily natural working context. That means teachers are considered to be professionals who are responsible for improving themselves and actively engaged in this process instead of being passively trained (Manara, 2014). This implication is important for teachers, educator, teacher trainers, researchers and policy makers in Vietnam for improving TPL quality.

To recap, this section has highlighted the implications of the study in relation to the adoption of an intercultural stance in the tertiary EFL context. The development of intercultural learning materials based on iCLT principles and the development of in situ PAR professional learning model for teachers are crucial for successful adoption of an intercultural stance in the tertiary EFL context.

\subsection{Limitations and suggestions for further studies}

This section acknowledges limitations of the research and recommends areas for further research. This study has the following limitations. First, the research involved only a small group of tertiary EFL teachers at one university and so broad generalisations must be made with caution. Nonetheless, thick descriptions aimed at increasing this research's transferability to other similar contexts.

Second, the impacts of PAR professional learning on teachers' classroom practices and understandings in terms of intercultural language teaching was only investigated within a limited time frame of a fifteen-week semester. Involving the teachers in short learning workshops in one semester is not sufficient to support and convince the teachers to adopt a new way of handling the intercultural dimension sustainably. For example, the second workshop cycle provided chances for the case study teachers to co-work to create their own intercultural lesson plans which could be taught in the post-workshop-two lessons. However, the teachers agreed with each other to keep following my redesigned intercultural teaching model. This showed that the teachers were not ready to extend the 
introduced model to create their own intercultural-oriented lessons. Further research may extend this study's design to explore the teachers' expanding and creating the introduced intercultural teaching model in phase three. Further longitudinal research is necessary to explore the impacts of professional learning on in-service teachers' professional development for adopting an intercultural stance.

Third, data analysis was based on three main sources: classroom observations, teacher interviews, and focus groups. What the teachers said regarding this research topic in the two workshops was not used in data analysis. Future research is recommended to use this source of data together with other forms of teachers' critical reflection to gain insights into the teachers' perspectives.

Fourth, the redesigned intercultural-teaching model has limitations. According to Jin and Cortazzi (2017), developing students' ability to analyse intercultural communication requires an inclusion of a global variety of topics and situations. The redesigned materials for the intercultural lessons were based on the textbook-based input, which was the teachers' obligatory teaching material. The intercultural dimension of communication was explored only through a number of speech acts and instilled inauthentic dialogues written for listening practice. A more diverse range of sample situations were inevitably missed. Therefore, a more diverse range of language input is recommended in future research.

\subsection{Thesis conclusion and reflection on learning}

This study sought to understand the potential to seed an iCLT approach in a Vietnamese tertiary EFL context. It investigated the current and the intercultural orientations to culture in the teaching practices and stated perceptions of a small group of teachers, and in the students' experience of being taught by the teachers. The findings suggest a role for providing teachers with models for teachers' professional learning for promoting the adoption of an intercultural stance in the tertiary EFL context. Returning to the RQs posted at the beginning of this study, it is now possible to state that within a fundamentally-fixed curriculum, by adopting an intercultural stance, it is possible for language and intercultural learning goals to be synergistically addressed in EFL classrooms.

Conducting this project expanded my boundaries in FL didactics and personal maturity. First, I have realised the impact of a teacher being a researcher who wants to improve his/her 
teaching practices and professional development. I have come to realise that teachers play an important role in educational changes for the better. The teacher's daily contact with students and daily classroom observations bring him/her plenty of input about students. In addition to this, the EFL teacher has his/her own experience as a FL learner and user, which provides the teacher with very rich resources to understand the process of learning, using, and teaching the FL.

However, it is essential that teachers confidently move forwards to conducting research about the problematic issues to make positive changes in classes and schools. Without the teacher being a researcher, their impact on education is very limited. In my case, after I was able to narrow down the research problem in my classes, I came up with a set of assumptions to explain the teaching of culture in my context. I explored the literature with a strong interest. Many times, I felt that authors were communicating with me about my concern in my own teaching as if these scholars had been to my classes. I was enlightened by the scholarship and developed critical thinking on the research topic in relation to my own experience of learning, teaching and using a FL. This would never happen if I were not confident to embark on this PhD journey.

My initial expectation was that I could identify and implement some teaching techniques such as cultural assimilators, cultural simulation games, and roleplays to organise classroom activities in subjects at Vietnamese universities such as Culture of English-Speaking Countries. I also expected to quantify student improvements similarly to assessing the four macro language skills. However, what actually happened was that my perspectives and understandings around the research topic kept developing until when I discovered that FL teachers' perspectives and ability to foster students' intercultural learning are the first and foremost gap to be filled in the Vietnamese ELT context and scholarship. I decided to collaborate and share my new learning with my colleagues who do not usually have opportunities and time to examine the scholarship nor discuss with experts. Therefore, my colleagues, the three case study teachers were not the subjects but vital partners and contributors to this research.

Moreover, in doing this thesis I developed my professional identity, from a teacher to a teacher researcher. As a teacher, I am now more confident in terms of teaching culture. As a teacher researcher, I consider doing research as a part of my responsibility and a part of a 
wider debate in my discipline to support improvements in national education quality. With my determination to obtain insights about research in the area of Applied Linguistics, I have developed interest in qualitative research methodology, especially, the case study approach and thematic analysis method. Personally, as an EFL lecturer researcher, I am eager to conduct future research in intercultural language education which I did not have chances to do in this thesis.

Altogether, the above realisations made me positive that teacher researchers have a role to play in establishing an EFL educational environment in which teaching and research are more connected. 


\section{REFERENCES}

Abdulrahman, T., Usu, N. R., \& Tanipu, Z. (2016). Teachers' perspectives on the integration of culture and EFL. Journal of ELT Research, 1(2), 180-193.

Aguilar, M. J. C. (2008). Dealing with intercultural communicative competence in the foreign language classroom. In E. A. Soler \& M. P. S. Jordà (Eds.), Intercultural Language Use and Language Learning (pp. 59-78). Dordrecht: Springer.

Al-Amir, B. A.-H. (2017). Female teachers' perceptions of teaching culture in EFL classrooms at a Saudi University. 10(6), 28-26.

Alamri, W. A. (2018). Communicative Language Teaching: Possible Alternative Approaches to CLT and Teaching Contexts. English Language Teaching, 11(10), 132-138.

Anney. (2014). Ensuring the quality of the findings of qualitative research: Looking at trustworthiness criteria. Journal of Emerging Trends in Educational Research and Policy Studies (JETERAPS), 5(2), 272-281.

Arasaratnam, L. A., \& Doerfel, M. L. (2005). Intercultural communication competence: Identifying key components from multicultural perspectives. International Journal of Intercultural Relations, 29, 137-163.

Atkinson, D. (2002). Toward a sociocognitive approach to second language acquisition. The Modern Language Journal, 86(4), 525-545.

Aubrey, S. (2009). Creating a global cultural consciousness in a Japanese EFL classroom. English Language Teaching, 2(2), 119-131.

Baker, W. (2008). A critical examination of ELT in Thailand: The role of cultural awareness. RELC, 39(1), 131-146. DOI: 10.1177/0033688208091144

Baker, W. (2016). Culture and language in intercultural communication, English as a Lingua Franca and English language teaching: Points of convergence and conflict. In P. Holmes \& F. Dervin (Eds.), The cultural and intercultural dimensions of English as a lingua franca (pp. 70-89). Bristol: Multilingual Matters. 
Baldwin, J. R., Faulkner, S. L., \& Hecht, M. L. (2016). A moving target: The Illusive definition of culture. In J. R. Baldwin, S. L. Faulkner, M. L. Hecht, \& S. L. Lindsley (Eds.), Redefining culture: Perspectives across the disciplines (pp. 3-26). New Jersey: Lawrence Erlbaum Associates.

Baleghizadeh, S., \& Moghadam, M. S. (2013). An investigation of tensions between EFL teachers' beliefs and practices about teaching culture. Gist Education and Learning Research Journal, 7(Nov), 35-53.

Banafsheh, M. R., Khosravi, M., \& Saidi, M. (2016). In pursuit of intercultural communicative competence in EFL context: exploring Iranian English teachers' perceptions. The Journal of Applied Linguistics, 6(13), 65-83.

Barbour, R. (2007). Doing focus groups (U. Flick, Ed.). UK: Sage Publications.

Bartell, C. A. (2005). Cultivating high-quality teaching through induction and mentoring. California: Corwin Press.

Bassey, M. (1999). Case study research in educational settings. Buckingham. Philadelphia.

Bastos, M., \& Araújo e Sá. (2015). Pathways to teacher education for intercultural communicative competence: Teachers' perceptions. The Language Learning Journal, 43(2), 131-147.

Baxter, P., \& Jack, S. (2008). Qualitative case study methodology: Study design and implementation for novice researchers. The Qualitative Report, 13(4), 544-559.

Behrnda, V., \& Porzelt, S. (2012). Intercultural competence and training outcomes of students with experiences abroad. International Journal of Intercultural Relations, $36,213-223$.

Bennett, M. J. (1993). Toward ethnorelativism: A developmental model of intercultural sensitivity. In M. R. Paige (Ed.), Education for the intercultural experience (pp. 2171). Yarmouth, ME: Intercultural Press.

Bennett, M. J. (1997). How not to be a fluent fool: Understanding the cultural dimension of language. In A. E. Fantini \& J. C. Richards (Eds.), New ways in teaching culture (pp. 16-21). Alexandria. VA: TESOL. 
Bergold, J., \& Thomas, S. (2012). Participatory research methods: A methodological approach in motion. 13(1), Art 30.

Biebricher, C., East, M., Howard, J., \& Tolosa, C. (2019). Navigating intercultural language teaching in New Zealand classrooms. Cambridge Journal of Education, 1-17. https://doi.org/10.1080/0305764X.2019.1581137

Braun, V., \& Clarke, V. (2008). Using thematic analysis in psychology. Qualitative Research in Psychology, 3(2), 77-101.

Braun, V., \& Clarke, V. (2012). Thematic analysis. In H. Cooper, P. M. Camic, D. L. Long, A. T. Panter, D. Rindskopf, \& K. J. Sher (Eds.), APA handbook of research methods in psychology (Vol. 2, pp. 57-71). Retrieved from http://psycnet.apa.org/record/201123864-004

Braithwaite, R., Cockwill, S., O'Neill, M., \& Rebane, D. (2007). Insider participatory action research in disadvantaged post-industrial areas: The experiences of community members as they become community based action researchers. Action research, 5(1), 61-74.

Burrell, G., \& Morgan, G. (1985). Sociological paradigm and organisational analysis: Elements of the sociology of corporate life. Farnham: Routledge.

Byram, M. (1997). Teaching and assessing intercultural communicative competence. Clevedon: Multilingual Matters.

Byram, M. (2008). From foreign language education to education for intercultural citizenship: Essays and reflections. Clevedon: Multilingual Matters.

Byram, M. (2009). Intercultural competence in foreign languages: The intercultural speaker and the pedagogy of foreign language education. In D. K. Deardorff (Ed.), The SAGE handbook of intercultural competence (pp. 321-332). Thousand Oaks, USA: Sage Publications.

Byram, M. (2015). Culture in foreign language learning - The implications for teachers and teacher training. In Wai Meng Chan, S. K. Bhatt, M. Nagami, \& I. Walker (Eds.), 
Culture and foreign language education: Insights from research and implications for the practice (pp. 37-58). Boston/Berlin: De Gruyter.

Byram, M., Gribkova, B., \& Starkey, H. (2002). Developing the intercultural dimension in language teaching: A practical introduction for teachers. Retrieved from http://discovery.ucl.ac.uk/1562524/1/Starkey_InterculturalDimensionByram.pdf

Chang, B.-M. (2011). The roles of English language education in Asian context. Journal of Pan-Pacific Association of Applied Linguistics, 15(1), 191-206.

Chao, T.-C. (2016). A preliminary study of Taiwanese NNETS' self-assessment of intercultural communicative competence in English language teaching. Taiwan Journal of TESOL, 13(1), 71-103.

Chau, H. (2018). Towards the integration of culture into teaching English in upper secondary schools: Teachers' concerns and expectations. Hue University Journal of Science: Social Sciences and Humanities, 127(6B), 121-134.

Chau, H., \& Truong, V. (2018). Developing intercultural competence for upper secondary students: Perspectives and practice. National Conference Proceedings-Nghiên Cứu Liên Ngành về Ngôn Ngũ̃ và Giảng Dạy Ngôn Ngữ Lần Thứ III (Interdisciplinary Research on Language Teaching III), 227-239. Hue College of Foreign Languages-Hue University, Vietnam: Hue College of Foreign Languages-Hue University.

Chau, H., \& Truong, V. (2019). Integrating culture into EFL teaching behind classroom doors: A case study of upper secondary teachers in Vietnam. VNU Journal of Foreign Studies, 35(1), 55-67.

Cheewasukthaworn, K., \& Suwanarak, K. (2017). Exploring Thai EFL teachers' perceptions of how intercultural communicative competence is important for their students. PASAA, 54(July-December), 177-204.

Chen, G. M. (2014). Intercultural communication competence: Summary of 30-year research and directions for future study. In Intercultural Communication Competence: Conceptualization and its Development in Cultural Contexts and Interactions (pp. 1440). UK: Cambridge Scholars. 
Chen, G. M. (2017). Issues in the conceptualization of intercultural communication competence. In L. Chen (Ed.), Intercultural communication (pp. 349-368). Germany: De Gruyter Mouton.

Chen, Y. Y., Shek, D. T. L., \& Bu, F.-F. (2011). Applications of interpretive and constructionist research methods in adolescent research: philosophy, principles and examples. International Journal of Adolescent Medicine and Health, 23(2), 129-139. https://doi.org/10.1515/ijamh.2011.022

Cheng, C.-M. (2012). The influence of college EFL teachers' understandings of intercultural competence on their self-reported pedagogical practices in Taiwan. English Teaching: Practice and Critique, 11(1), 164-182.

Conway, C., \& Richards, H. (2016). 'Lunchtimes in New Zealand are cruel': Reflection as a tool for developing language learners' intercultural competence. The Language Learning Journal, 46(4), 371-383.

Corbett, J. (2003). An intercultural approach to English language teaching (Vol. 7). New York: Multilingual Matters.

Council of Europe. (2001). Common European framework of reference for languages: Learning, teaching, assessment. Retrieved from www.coe.int/lang-CEFR

Cowie, N. (2009). Observation. In J. Heigham \& R. A. Croker (Eds.), Qualitative research in applied linguistics: A practical introduction (pp. 165-181). New York: Macmillan Publishers.

Creswell, J. W. (2012). Educational research: Planning, conducting, and evaluating quantitative and qualitative research (4th ed.). Boston: Pearson.

Crozet, C., \& Liddicoat, A. J. (1999). The challenge of intercultural language teaching: Engaging with culture in the classroom. In B. L. Joseph, A. J. Liddicoat, \& C. Crozet (Eds.), Striving for the third place: Intercultural competence through language education (pp. 113-126). Melbourne: Language Australia.

Crozet, C., Liddicoat, A. J., \& Bianco, J. L. (1999). Intercultural competence: From language policy to language education. In J. L. Bianco, A. J. Liddicoat, \& C. Crozet (Eds.), 
Striving for the third place: Intercultural competence through language education (pp. 1-22). Melbourne: Language Australia.

Czura, A. (2016). Major field of study and student teachers' views on intercultural communicative competence. Language and Intercultural Communication, 16(1), 8398.

Dai, X., \& Chen, G. M. (2015). On interculturality and intercultural communication competence. China Media Research, 11(3), 100-113.

Damen, L. (2003). Closing the language and culture gap: An intercultural communicative perspective. In D. L. Lange \& M. R. Paige (Eds.), Culture as the core: Perspectives on culture in second language learning (pp. 71-88). USA: Information Age Publishing.

Day, C. (2002). Developing teachers: The challenges of lifelong learning. London: Routledge.

Deardorff, D. K. (2006). Identification and assessment of intercultural competence as a student outcome of internationalization. Journal of Studies in International Education, 10(3), 241-266.

Deardorff, D. K. (2008). Intercultural competence: A definition, model, and implications for education abroad. In V. Savicki (Ed), Developing intercultural competence and transformation: Theory, research, and application in international education, 32-52.

DeCapua, A., \& Wintergerst, A. C. (2016). Crossing cultures in the language classroom (2nd ed.). USA: University of Michigan Press.

Dellit, J. (2005). Getting started with intercultural language learning: A resource for schools. Melbourne: Asian Languages Professional Learning Project, Asia Education Foundation.

Dervin, F. (2010). Assessing intercultural competence in language learning and teaching: A critical review of current efforts. New approaches to assessment in higher education, 5, 155-172.

Dervin, F. (2016). Critical turns in language and intercultural communication pedagogy: The simple-complex continuum (simplexity) as a new perspective. In M. Dasli \& R. Díaz 
(Eds), The critical turn in language and intercultural communication pedagogy (pp. 8296). New York and London: Routledge.

Dervin, F., \& Liddicoat, A. J. (Eds.). (2013). Linguistics for intercultural education (Vol. 33). John Benjamins Publishing.

Dervin, F., Paatela-Nieminen, M., Kuoppala, K., \& Riitaoja, A. L. (2012). Multicultural education in Finland: Renewed intercultural competences to the rescue? International Journal of Multicultural Education, 14(3).

Díaz, A. (2013). Intercultural understanding and professional learning through critical engagement. Babel, 48(1), 12.

Díaz, R., \& Dasli, M. (2017). Tracing the "critical" trajectory of language and intercultural communication pedagogy. In M. Dasli \& R. Díaz (Eds.), The critical turn in language and intercultural communication pedagogy: Theory, research and practice (pp. 321). New York and London: Routledge.

Dimas, H. M. S. (2016). Integrating the intercultural communicative competence (ICC) in a foreign language Program: Faculty considerations upon leaving the haven of native speakership. English Language Teaching, 9(4), 1-10.

Dimas, H. M. S. (2019). Implementing an instructional design on intercultural communicative competence (ICC) with foreign language students aimed at joining the corporate world. English Language Teaching, Canadian Center of Science and Education, 12(3), 161-177.

Doan, N. B. (2014). Teaching the target culture in English teacher education programs: Issues of EIL in Vietnam. In R. Marlina \& R. A. Giri (Eds.), The pedagogy of English as an international language (pp. 79-93). Switzerland: Springer International Publishing.

Dörnyei, Z. (2007). Research methods in applied linguistics. Oxford: OUP.

Duff, P. A. (2012). Case study research in applied linguistics. New York and London: Routledge. 
Dytynyshyn, N., \& Collins, L. (2012). Culture and interculturality in the adult ESL context in urban Quebec: A case study. TESL Canada Journal, 30(1), 45-58.

East, M. (2012). Addressing the intercultural via task-based language teaching: Possibility or problem? Language and Intercultural Communication, 12(1), 56-73.

Edwards, R., \& Holland, J. (2013). What is qualitative interviewing? UK: Bloomsbury.

Estaji, M., \& Rahimi, A. (2018). Exploring teachers' perception of intercultural communicative competence and their practices for teaching culture in EFL classrooms. International Journal of Society, Culture \& Language, 6(2), 1-18.

Fantini, A. E. (2012). Multiple strategies for assessing intercultural communicative competence. In J. Jackson (Ed.), The Routledge handbook of language and intercultural communication (pp. 390-405). New York: Routledge.

Faulkner, S. L., Baldwin, J. R., Lindsley, S. L., \& Hecht, M. L. (2006). Layers of meaning: An analysis of definitions of culture. In J. R. Baldwin, S. L. Faulkner, M. L. Hecht, \& S. L. Lindsley (Eds.), Redefining culture: Perspectives across the disciplines (pp. 27-52). New Jersey: Lawrence Erlbaum Associates.

Félix-Brasdefer, C. J. (2017). The intercultural speaker abroad. In R. Giora \& M. Haugh (Eds.), Doing pragmatics interculturally: Cognitive, philosophical, and sociopragmatic perspective. Boston/Berlin: De Gruyter.

Feryok, A., \& Oranje, J. (2015). Adopting a cultural portfolio project in teaching German as a foreign language: Language teacher cognition as a dynamic system. The Modern Language Journal, 99(3), 546-564.

Gandana, I. (2015). Critical thinking, (inter)cultural awareness and pedagogical dilemmas: Stories of three university teachers in Indonesia. In Wei Meng Chan, S. K. Bhatt, M. Nagami, \& I. Walker (Eds.), Culture and foreign language education: Insights from research and implications for the practice (pp. 107-131). Boston/Berlin: De Gruyter.

Gandana, I., \& Graham, P. (2013). Professional identity, curriculum and teaching intercultural communication: An Indonesian case study. Language, Culture and Curriculum, 26(3), 229-246. 
Garrettrucks, P., \& Osborn, T. A. (2016). Intercultural competence in instructed language learning: Bridging theory and practice. Charlotte: Information Age Publishing.

Garrido, C., \& Álvarez, I. (2006). Language teacher education for intercultural understanding. European Journal of Teacher Education, 29(2), 163-179.

Gass, S. M., \& Mackey, A. (2000). Stimulated recall methodology in second language research. Mahwah, NJ, US: Lawrence Erlbaum Associates Publishers.

Gass, S. M., \& Mackey, A. (2016). Stimulated recall methodology in applied linguistics and L2 research. Taylor \& Francis.

Gee, J. P. (1990). Social linguistics and literacies: Ideology and discourses. New York: The Falmer Press.

Gerring, J. (2007). Case study research: Principles and practices. New York: CUP.

Gibbs, G. (2007). Analyzing qualitative data (U. Flick, Ed.). UK: Sage Publications.

Government. (2008). Resolution number 1400/QD-TTg: Approval of the Project of teaching and learning foreign languages in national educational system for the 2008-2020 period (QUYẾT ĐỊH Về việc phê duyệt Đề án "Dạy và học ngoại ngữ trong hệ thống giáo dục quốc dân giai đoạn 2008 - 2020"). Retrieved from http://vndoc.com/quyetdinh-so-1400-qd-ttg/download. 22 April 2019

Griffiths, R. L., Wolfeld, L., Armon, B. K., Rios, J., \& Liu, O. L. (2016). Assessing intercultural competence in higher education: Existing research and future directions [ETS Research Report No. RR-16-25]. Retrieved from Educational Testing Service website: http://dx.doi.org/10.1002/ ets2.12112

Gu, X. (2016). Assessment of intercultural communicative competence in FL education: A survey on EFL teachers' perception and practice in China. Language and Intercultural Communication, 16(2), 254-273.

Gu, X., Meng, M., \& Li, M. (2012). A survey on teachers' perception and practice of ICC assessment of University English learners in China. Intercultural Communication Studies, 21(1), 205-220. 
Guba, E. G. (1981). Criteria for assessing the trustworthiness of naturalistic inquiries. ECTJ, 29(2), 75-91.

Hall, E. T. (1977). Beyond culture. Garden city, New York: Doubleday.

Hall, S. (1997). The spectacle of the other. In S. Hall (Ed.), Representation: Cultural representations and signifying practices (pp. 22-29). London: Sage in association with the Open University.

Halualani, T. R., \& Nakayama, T. K. (2010). Critical intercultural communication studies: At a crossroads. In T. K. Nakayama \& T. R. Halualani (Eds.), The handbook of critical intercultural communication (pp. 1-16). USA, UK: Blackwell Publishing Ltd.

Han, X., \& Song, L. (2011). Teacher cognition of intercultural communicative competence in the Chinese ELT context. Intercultural Communication Studies, XX(1), 175-192.

Hecht, M. L., Baldwin, J. R., \& Faulkner, S. L. (2006). The (in)conclusion of the matter: Shifting signs and models of culture. In J. R. Baldwin, S. L. Faulkner, M. L. Hecht, \& S. L. Lindsley (Eds.), Redefining culture: Perspectives across the disciplines (pp. 53-73). New Jersey: Lawrence Erlbaum Associates.

Hepple, E., Alford, J., Henderson, D., Tangen, D., Hurwood, M., Alwi, A., ... Alwi, A. (2017). Developing intercultural learning in Australian pre-service teachers through participating in a short-term mobility program in Malaysia. Teaching and Teacher Education, 66, 273-281.

Herriott, R. E., \& Firestone, W. A. (1983). Multisite qualitative policy research: Optimizing description and generalizability. Educational Researcher, 12, 14-19. DOI: $10.3102 / 0013189 \times 012002014$

Ho, S. T. K. (2009). Addressing culture in EFL classrooms: The challenge of shifting from a traditional to an intercultural stance. Electronic Journal of Foreign Language Teaching, 6(1), 63-76.

Ho, S. T. K. (2011a). An intercultural perspective on teaching and learning in the Vietnamese EFL classroom. University of Sydney Papers in TESOL, 6, 43-69. 
Ho, S. T. K. (2011b). An investigation of intercultural teaching and learning in tertiary EFL classrooms in Vietnam (PhD thesis). Victoria University of Wellington, New Zealand.

Hoang, V. V. (2010). The current situation and issues of the teaching of English in Vietnam. 立命 館言語文化研究 (Ritsumei), 22(1), 1-12.

Hoff, H. E. (2014). A critical discussion of Byram's model of intercultural communicative competence in the light of Bildung theories. Intercultural Education, 25(6), 508-517.

Holliday, A. (2013). Understanding intercultural communication: Negotiating a grammar of culture. New York: Routledge.

Holliday, A. (2016). Studying culture. In Z. Hua (Ed.), Research methods in intercultural communication: A practical guide. (1st ed., pp. 23-36). UK: Wiley Blackwell.

Hood, M. (2009). Case study. In Qualitative research in applied linguistics (pp. 66-90). New York: Macmillan Publishers.

Houghton, S. (2010). Savoir se transformer: Knowing how to become. In Y. Tsai \& S. Houghton (Eds.), Becoming intercultural: Inside and outside the classroom (pp. 1994228). Newcastle upon Tyne: UK: Cambridge Scholars.

Houghton, S. (2013). Making intercultural communicative competence and identitydevelopment visible for assessment purposes in foreign language education. The Language Learning Journal, 41(3), 311-325.

House, J. (2008). What Is an 'Intercultural speaker'? In E. A. Soler \& M. P. S. Jordà (Eds.), Intercultural language use and language learning (pp. 7-12). Dordrecht: Springer.

Howard, J., Biebricher, C., Tolosa, C., Scott, A., \& East, M. (2016). Principles and beliefs behind teachers' existing intercultural language teaching practices. The New Zealand Language Teacher, 42(Dec), 31-43.

Howard, J., Tolosa, C., Biebricher, C., \& East, M. (2019). Shifting conceptualisations of foreign language teaching in New Zealand: Students' journeys towards developing intercultural capability. Language and Intercultural Communication, 1-15. DOI: $10.1080 / 14708477.2019 .1601201$ 
Hua, Z. (2016). Identifying research paradigms. In Z. Hua (Ed.), Research methods in intercultural communication: A practical guide (1st ed., pp. 3-21). Retrieved from https://onlinelibrary.wiley.com/doi/pdf/10.1002/9781119166283

Hua, Z. (2018). Exploring intercultural communication: Language in action (2nd ed.). Retrieved from https://www.taylorfrancis.com/books/9781315159010

Hwang, H. (2014). The influence of the ecological contexts of teacher education on South Korean teacher educators' professional development. Teaching and Teacher Education, 43, 1-14.

Jackson, J. (2011). Cultivating cosmopolitan, intercultural citizenship through critical reflection and international, experiential learning. Language and Intercultural Communication, 11(2), 80-96.

Jackson, J. (2014). Introduction to language and intercultural communication. New York: Routledge Publisher.

Jin, L., \& Cortazzi, M. (2017). Developing speaking for intercultural communicationtextbooks with critical and creative approaches. In H. P. Widodo, A. Wood, \& D. Gupta (Eds.), Asian English language classrooms: Where theory and practice meet. London: Routledge.

Johnson, R. B., \& Christensen, L. (2012). Educational research: Quantitative, qualitative, and mixed approaches (4th ed.). Thousand Oaks, California: Sage.

Kemmis, S., \& McTaggart, R. (2008). Participatory action research: Communicative action and the public sphere. In N. K. Dezin \& Y. S. Lincoln (Eds.), Strategies of qualitative inquiry (3rd ed., pp. 271-232). USA: Sage Publications.

Kennedy, J. (2016). Exploring opportunities for developing intercultural competence through intercultural communicative language teaching (ICLT): A case study in a Chinese as a foreign language classroom in a New Zealand high school (Master's thesis). Victoria University of Wellington, Wellington, New Zealand.

Kenny, T., \& Wada, T. (2009). Listening advantage 3. Kentucky, USA: Cengage Learning. 
Kenny, T., Wada, T., \& Sheils, C. (2010). Listening Advantage 3: Teacher's guide. Kentucky, USA: Heinle Cengage Learning.

King, M. B., \& Newmann, F. M. (2001). Building school capacity through professional development: Conceptual and empirical considerations. International Journal of Educational Management, 15(2), 86-94.

Kirkpatrick, A. (2012). English as an international language in Asia: Implications for language education. In A. Kirkpatrick \& R. Sussex (Eds.), English as an international language in Asia: Implications for language education (pp. 29-44). New York, London: Springer.

Kirkpatrick, A., Patkin, J., \& Jingjing, W. (2013). The multilingual teacher and the multicultural curriculum: An Asian example for intercultural communication in the new era. In F. Sharifian \& M. Jamarani (Eds.), Language and intercultural communication in the new era (pp. 277-299). New York: Routledge.

Kohler, M. (2015). Teachers as mediators in the foreign language classrooms. UK: Multilingual Matters.

Kramsch, C. (1993). Context and culture in language teaching. Oxford, UK: OUP.

Kramsch, C. (1998). Language and culture. Oxford, UK: OUP.

Kramsch, C. (2006). Culture in language teaching. In H. L. Andersen, K. Lund, \& K. Risager (Eds.), Culture in Language Learning (pp. 11-25). Denmark: Aarhus University Press.

Kramsch, C. (2013). Culture in foreign language teaching. Iranian Journal of Language Teaching Research, 1(1), 57-78.

Kramsch, C. (2014). Language and culture in second language learning. In F. Sharifian (Ed.), The Routledge handbook of language and culture (pp. 403-414). New York: Routledge.

Kramsch, C., \& Hua, Z. (2016). Language and culture in ELT. In G. Hall (Ed.), The Routledge handbook of English language teaching (pp. 38-50). London: Routledge.

Krefting, L. (1991). Rigor in qualitative research: The assessment of trustworthiness. The American Journal of Occupational Therapy, 45(3), 214-222. 
Kumaravadivelu, B. (2008). Cultural globalization and language education. New Haven and London: Yale University Press.

Kusumaningputri, R., \& Widodo, H. P. (2018). Promoting Indonesian university students' critical intercultural awareness in tertiary EAL classrooms: The use of digital photograph-mediated intercultural tasks. System, 72(Feb-2018), 49-61.

Kvale, S. (1996). Interviews: An Introduction to qualitative research interviewing. Thousand Oaks: Sage Publications.

Laopongharn, W., \& Sercombe, P. (2009). What relevance does intercultural communication have to language education in Thailand? ARECLS, 6, 59-83.

Lázár, li. (2011). Teachers' beliefs about integrating the development of intercultural communicative competence in language teaching. ForumSprache, 5(5), 13-127.

Le, H. T. (2013). ELT in Vietnam general and tertiary education from second language education perspectives. VNU Journal of Foreign Studies, 29(1), 65-71.

Le, V. C. (2015). Uncovering teachers' beliefs about intercultural language teaching: An example from Vietnam. The European Journal of Applied Linguistics and TEFL, 4(1), 83-103.

Li, C. (2017). Contemporary research in intercultural teaching in China: A critical review. In R. Hayo, D. Nunan, \& B. Zou (Eds.), Innovation in language learning and teaching: The case of China (pp. 289-306). London, UK: Macmillan Publishers.

Liddicoat, A. J. (2002). Static and dynamic views of culture and intercultural language acquisition. Babel, 36(3), 4-11.

Liddicoat, A. J. (2004). Reimagining culture in language teaching: Theory and practice. In B. Bartlett, F. Bryer, \& D. Roebuck (Eds.), Educating: Weaving research into practice (pp. 48-66). Brisbane: School of Language, Cognition and Special Education: Griffith University.

Liddicoat, A. J. (2005). Culture for language learning in Australian language-in-education policy. Australian Review of Applied Linguistics, 28(2), 28-43. 
Liddicoat, A. J. (2008). Pedagogical practice for integrating the intercultural in language teaching and learning. Japanese Studies, 28(3), 277-290.

Liddicoat, A. J. (2011). Language teaching and learning from an intercultural perspective. In Hinkel (Ed.), Handbook of research in second language teaching and learning (Vol. 2, pp. 837-855). New York: Routledge.

Liddicoat, A. J. (2014). Pragmatics and intercultural mediation in intercultural language learning. Intercultural Pragmatics, 11(2), 259-277.

Liddicoat, A. J. (2017). Interpretation and critical reflection in intercultural language learning: Consequences of a critical perspective for the teaching and learning of pragmatics. In M. Dasli \& R. Díaz (Eds.), The critical turn in language and intercultural communication pedagogy: Theory, research and practice (pp. 22-39). New York and London: Routledge Publisher.

Liddicoat, A. J., Papademetre, L., Scarino, A., \& Kohler, M. (2003). Report on intercultural language learning (pp. 1-153). Canberra, ACT: Commonwealth of Australia: Research Centre for Languages and Cultures Education at the University of South Australia and the School of Languages and Linguistics at Griffith University.

Liddicoat, A. J., \& Scarino, A. (2013). Languages, cultures, and the Intercultural. In Intercultural language teaching and learning (1st ed., pp. 11-46). Blackwell Publishing Ltd.

Lim, S., \& Keuk, C. N. (2018). A sociocultural analysis of Cambodian teachers' cognitions about cultural contents in an 'internationally imported' textbook In a tertiary English learning context. In H. P. Widodo, M. R. Perfecto, V. C. Le, \& A. Buripakdi (Eds.), Situating moral and cultural values in ELT material: The southeast Asian context (pp. 87-110). Switzerland: Springer.

Lincoln, Y. S., \& Guba, E. G. (1985). Naturalistic inquiry. Beverly Hill, Ca: Sage.

Little, J. W. (1992). Teacher development and educational policy. In M. Fullan \& A. Hargreaves (Eds.), Teacher development and educational change (pp. 170-193). London: The Falmer Press. 
Liu, F., \& Maitlis, S. (2010). Nonparticipant observation. In A. J. Mills, G. Durepos, \& E. Wiebe (Eds.), Encyclopedia of case study research (pp. 610-611). Retrieved from http://dx.doi.org/10.4135/9781412957397.n229

Liu, K. L. (2016). Exploring intercultural competence through an intercultural extracurricular activity in Taiwan. Journal of Language and Cultural Education, 4(1), 99-109.

Liu, S., Zala, V., \& Cynthia, G. (2015). Introducing intercultural communication: Global cultures and context (2nd ed.). UK: Sage.

Louis, M. R., \& Bartunek, J. M. (1992). Insider/outsider research teams: Collaboration across diverse perspectives. Journal of Management Inquiry, 1(2), 101-110.

Luk, J. (2012). Teachers' ambivalence in integrating culture with EFL teaching in Hong Kong. Language, Culture and Curriculum, 25(3), 249-264.

MacDonald, C. (2012). Understanding participatory action research: A qualitative research methodology option. Canadian Journal of Action Research, 13(2), 34-50.

Mackey, A., \& Gass, S. M. (2005). Second language research: Methodology and design. New Jersey: Routledge.

Mahoney, C. (2015). Exploring the intercultural in Australian community languages teaching. In Wei Meng Chan, S. K. Bhatt, M. Nagami, \& I. Walker (Eds.), Culture and foreign language education: Insights from research and implications for the practice (pp. 87106). Boston: De Gruyter.

Maijala, M. (2018). Culture teaching methods in foreign language education: Pre-service teachers' reported beliefs and practices. Innovation in Language Learning and Teaching, 1-18. https://doi.org/10.1080/17501229.2018.1509981

Manara, C. (2014). Intercultural dialogue on English language teaching: Multilingual teacher educator's narrative of professional learning. Cambridge Scholars Publishing.

Mangubhai, F., Marland, P., Dashwood, A., \& Son, J.-B. (2004). Teaching a foreign language: one teacher's practical theory. Teaching and Teacher Education, 20, 291-311.

Manoliu, M. N. (2012). A Communicative approach to language teaching-Origins and development. International Journal of Communication Research, 2(2), 138. 
Marczak, M. (2013). Communication and information technology in (intercultural) language teaching. Newcastle upon Tyne: Cambridge Scholars Publishing.

Marlina, R. (2014). The Pedagogy of English as an international language (EIL): More reflections and dialogues. In R. Marlina \& R. A. Giri (Eds.), The pedagogy of English as an international language: Perspectives from scholars, teachers, and students (pp. 119). Switzerland: Springer.

Maxell, J. A. (2013). Qualitative research design: An interactive approach (3rd ed.). USA: Sage.

McConachy, T. (2013). A place for pragmatics in intercultural teaching and learning. In D. Fred \& A. J. Liddicoat (Eds.), Linguistics for intercultural education (pp. 71-85). Amsterdam/Philadelphia: John Benjamins.

McConachy, T. (2018). Developing intercultural perspectives on language use: Exploring pragmatics and culture in foreign language learning. UK: Multilingual Matters.

McConachy, T., \& Liddicoat, A. J. (2016). Meta-pragmatic awareness and intercultural competence: The role of reflection and interpretation in intercultural mediation. In F. Dervin \& Z. Grozz (Eds.), Intercultural competence in education (pp. 13-30). London: Macmillan.

Merriam, S. B. (2001). Qualitative research and case study applications in education. San Francisco: Jossey-Bass.

Merriam, S. B., \& Tisdell, E. J. (2016). Qualitative research: A guide to design and implementation (4th ed.). USA: Jossey-Bass.

Moon, D. (2010). Critical reflection on culture and critical intercultural communication. In T. K. Nakayama \& T. R. Halualani (Eds.), The handbook of critical intercultural communication (pp. 34-52). USA, UK: Blackwell Publishing Ltd.

Moon, K., Brewer, T. D., Januchowski-Hartley, S. R., Adams, V. M., \& Blackman, D. A. (2016). A guideline to improve qualitative social science publishing in ecology and conservation journals. Ecology and Society, 21(3). Retrieved from http://dx.doi.org/10.5751/ ES-08663-210317 
Morita, L. (2013). Japanese university students' attitudes towards globalisation, intercultural contexts and English. World Journal of English Language, 3(4), 31-41.

Newton, J. (2016). Teaching English for intercultural Spoken communication. In W. A. Renandya \& H. P. Widodo (Eds.), English language teaching today: Linking theory and practice (pp. 161-177). Switzerland: Springer International Publishing.

Newton, J., Yates, E., Shearn, S., \& Nowitzki, W. (2010). Intercultural communicative language teaching: Implications for effective teaching and learning. Wellington: Ministry of Education.

Nguyen, L. (2015). Integrating pedagogy into intercultural teaching in a Vietnamese setting: From policy to the classroom. International Journal of Pedagogies and Learning, 9(2), $171-182$.

Nguyen, L., Harvey, S., \& Grant, L. (2016). What teachers say about addressing culture in their EFL teaching practices: The Vietnamese context. Intercultural Education, 27(2), 165-178.

Nguyen, T. (2017). Integrating culture into language teaching and learning: Learner outcomes. The Reading Matrix: An International Online Journal, 17(1), 145-155.

Nguyen, T. B. (2016). An investigation of Vietnamese EFL teachers' perceptions of intercultural competence and its application in high schools (PhD thesis). The University of Newcastle, Australia.

Nguyen, T. L. (2013). Integrating culture into Vietnamese university EFL teaching: A critical ethnographic study (PhD thesis). Auckland University of Technology, New Zealand.

Nguyen, T. M. H. (2007). Developing EFL learners' intercultural communicative competence: A gap to be filled? Asian EFL Journal, 21, 122-139.

Nowell, L. S., Norris, J. M., White, D. E., \& Moules, N. J. (2017). Thematic analysis: Striving to meet the trustworthiness criteria. International Journal of Qualitative Methods, 16, $1-13$.

Opfer, V. D., \& Pedder, D. (2011). Conceptualizing teacher professional learning. Review of educational research, 81(3), 376-407. 
Oranje, J. (2016). Intercultural communicative language teaching: Enhancing awareness and practice through cultural portfolio projects (PhD thesis). The University of Otago, New Zealand.

Oranje, J., \& Feryok, A. (2013). The role of culture in EAL students' lessons at a New Zealand primary school: A case study. New Zealand Studies in Applied Linguistics, 9(2), 5-20.

Oranje, J., \& Smith, L. F. (2018). Language teacher cognitions and intercultural language teaching: The New Zealand perspective. Language Teaching Research, 22(3), 310329.

Orlikowski, W. J., \& Baroudi, J. J. (1991). Studying information technology in organizations: research approaches and assumptions. Information Systems Research, 2(1), 1-28.

Patton, M. Q. (2002). Qualitative evaluation and research methods (3rd ed.). Thousand Oaks, CA: Sage.

Peiser, G., \& Jones, M. (2014). The influence of teachers' interests, personalities and life experiences in intercultural languages teaching. Teachers and Teaching, 20(3), 375390.

Peterson, B. (2004). Cultural intelligence: A guide to working with people from other cultures. Yarmouth, ME: Intercultural Press.

Pham, T. H. N. (2012). Cultural dimensions in intercultural communication \& implications for English language teaching. Tạp Chí Khoa Học Đại Học Huế (Science Journal of Hue University), 70(1), 171-180.

Phan, T. T. H. (2010). Factors affecting the motivation of Vietnamese technical English majors in their English studies (PhD thesis). The University of Otago, New Zealand.

Piątkowska, K. (2015). From cultural knowledge to intercultural communicative competence: changing perspectives on the role of culture in foreign language teaching. Intercultural Education, 26(5), 397-408.

Prabhu, N. S. (1990). There is no best method-Why? TESOL Quarterly, 24(2), 161-176.

Ragsdell, G. (2009). Participatory action research: A winning strategy for knowledge management. Journal of Knowledge Management, 13(6), 564-576. 
Rallis, S. F., \& Rossman, G. B. (2009). Ethics and trustworthiness. In J. Heigham \& R. A. Croker (Eds.), Qualitative research in applied linguistics: A practical introduction (pp. 263-287). New York: Macmillan Publishers.

RCLCE. (2007). Intercultural language teaching and learning in practice (ILTLP): Professional learning program. Retrieved from http://www.iltlp.unisa.edu.au/modules.html

Richards, K. (2009). Interviews. In J. Heigham \& R. A. Croker (Eds.), Qualitative research in applied linguistics: A practical introduction (pp. 182-199). New York: Macmillan.

Richards, L., \& Morse, J. M. (2013). Qualitative methods (3rd ed.). USA: Sage.

Riddiford, N., \& Newton, J. (2010). Workplace talk in action: An ESOL resource. Wellington: Victoria University of Wellington.

Risager, K. (2006). Language and culture: Global flows and local complexity. UK, USA, Canada: Multilingual Matters.

Risager, K. (2007). The intercultural competence of the world citizen. In Language and culture pedagogy: From a national to a transnational paradigm (pp. 222-239). Clevedon: Multilingual Matters.

Ruben, B. D. (1976). Assessing communication competency for intercultural adaptation. Group and Organization Studies, 1, 334-354.

Sahin, I., \& Yildirim, A. (2016). Transforming professional learning into practice. ELT journal, 70(3), 241-252.

Samovar, L. A., Porter, R. E., \& McDaniel, E. R. (2009). Communication between cultures. Canada: Cengage Learning.

Santoro. (2014). 'If I'm going to teach about the world, I need to know the world: Developing Australian pre-service teachers' intercultural competence through international trips. Race Ethnicity and Education, 17(3), 429-444.

Scarino, A. (2010). Assessing intercultural capability in learning languages: A renewed understanding of language, culture, learning, and the nature of assessment. The Modern Language Journal, 94(2), 324-329. 
Scollon, R., Scollon, S. W., \& Jones, R. H. (2012). Intercultural communication: A discourse approach (3rd ed.). Chichester, UK: John Wiley \& Sons.

Sercu, L. (2004). Assessing intercultural competence: A framework for systematic test development in foreign language education and beyond. Intercultural Education, 15(1), 73-89.

Sercu, L. (2006). The foreign language and intercultural competence teacher: The acquisition of a new professional identity. 17(1), 55-72.

Sercu, L. (2007). Foreign language teachers and intercultural competence: What keeps teachers from doing what they believe in? In M. J. Raya \& L. Sercu (Eds.), Challenges in teacher development: Learner autonomy and intercultural competence (pp. 6580). Frankfurt am Main: Peter Lang.

Sercu, L., Bandura, E., Castro, P., Davcheva, L., Laskaridou, C., Lundgren, U., ... Ryan, P. (2005). Foreign language teachers and intercultural competence. Clevedon: Multilingual Matters.

Sharifian, F. (2012). World Englishes, intercultural communication and requisite competences. In The Routledge handbook of language and intercultural communication (pp. 310-322). London, New York: Routledge.

Shohamy, E. (2006). Language policy: Hidden agendas and new approaches. New York, London: Routledge.

Sinicrope, C., Norris, J., \& Watanabe, Y. (2007). Understanding and assessing intercultural competence: A summary of theory, research, and practice (Technical report for the foreign language program evaluation project). Second Language Studies, 26(1), 1-58.

Siregar, F. L. (2016). In pursuit of intercultural communicative competence: an investigation into English language policy and practices at a private university in Indonesia (PhD thesis). Victoria University of Wellington, New Zealand.

Skene, C. (2014). Investigating reciprocal meaning-making as an element of intercultural language learning in the languages classroom. Babel, 48(2/3), 49-58. 
Sławecki, B. (2018). Paradigms in qualitative research. In M. Ciesielska \& D. Jemielniak (Eds.), Qualitative methodologies in organization studies (pp. 7-26). Retrieved from https://doi.org/10.1007/978-3-319-65217-7

Spencer-Oatey, H., \& Franklin, P. (2009). Intercultural interaction: A multidisciplinary approach to intercultural communication. UK: Palgrave Macmillan.

Spitzberg, B. H., \& Changnon, G. (2009). Conceptualizing intercultural competence. In D. K. Deardorff (Ed.), The Sage handbook of intercultural competence (pp. 2-52). UK: Sage.

Street, B. V. (1993). Culture is a verb: Anthropological aspects of language and culture process. In D. Graddol, L. Thompson, \& M. Byram (Eds.), Language and culture (pp. 23-43). London: Multilingual Matters.

Su, Y.-C. (2011). The effects of the cultural portfolio project on cultural and EFL learning in Taiwan's EFL college classes. Language Teaching Research, 15(2), 230-252.

Tekin, A. K., \& Kotaman, H. (2013). The epistemological perspectives on action research. Journal of Educational and Social Research, 3(1), 81-91.

Tesch, R. (1990). Qualitative research: Analysis types and software tools. Bristol, PA: Falmer Press.

Tian, J. (2013). Beliefs and practices regarding intercultural competence among Chinese teachers of English at a Chinese university (PhD thesis). George Mason University, Virginia, USA.

Ting-Toomey, S., \& Chung, L. S. (2005). Understanding intercultural communication. Los Angeles, CA: Roxbury Publishing Company.

Tolosa, C., Biebricher, C., East, M., \& Howard, J. (2018). Intercultural language teaching as a catalyst for teacher inquiry. Teaching and Teacher Education, 70(Feb), 227-235.

Ton, N. N. H., \& Pham, H. H. (2010). Vietnamese teachers' and students' perceptions of global English. Language Education in Asia, 1(1), 48-61.

Tran, T. P.T. (2014). Năng lực liên văn hóa trong giảng dạy và học ngoại ngữ: Nhìn từ lớp học (Intercultural competence in foreign language teaching and learning: A view from the classrooms). Cantho University Journal of Science, (30), 30-35. 
Tran, T. Q., \& Dang, H. V. (2014). Culture teaching in English language teaching: Teachers' beliefs and their classroom practices. Global Journal of Foreign Language Teaching, 4(2), 92-101.

Tran, T. Q., \& Duong, T. M. (2015). Intercultural language teaching: Rethinking the objectives of English language education in the Vietnamese context. English for Specific Purposes World, (46), 1-13.

Tran, T. Q., \& Seepho, S. (2014). Intercultural language teaching in the context of Vietnam: A gap to be filled. Research Scholar, 2(II), 27-38.

Tran, T. T. (2010). Enhancing graduate employability: Challenges facing higher education in Vietnam. The 14th UNESCO-APEID International Conference: Education for Human Resource Development, Bangkok, Thailand.

Trinh, T. T. H. (2014). Making a case for intercultural communicative competence teachers in Vietnamese English communicative teaching classrooms. Proceedings of the 7th International Conference on Educational Reform (ICER 2014), 114-122. Vietnam: Hue University.

Trinh, T. T. H. (2016). Achieving cultural competence in Vietnamese EFL classes: A case study from an intercultural communicative competence perspective (PhD thesis). University of Newcastle, Australia.

Trompenaars, F., \& Hampden-Turner, C. (1998). Riding the waves of culture. New York: McGraw-Hill.

Truong, B. L., \& Tran, T. L. (2014). Students' intercultural development through language learning in Vietnamese tertiary education: a case study on the use of film as an innovative approach. Language and Intercultural Communication, 14(2), 207-225.

Vo, P. Q. (2017). Rethinking intercultural communication competence in English language teaching: A gap between lecturers' perspectives and practices in Southeast Asian tertiary context. I-Manager's Journal on English Language Teaching, 7(1), 1-11.

Wahyudi, R. (2016). Intercultural competence: multi-dynamic, intersubjective, critical and interdisciplinary approaches. In F. Dervin \& Z. Gross (Eds.), Intercultural competence 
in education: Alternative approaches for different times (pp. 143-166). DOI: 10.1057/978-1-137-58733-6_8

Wang, Y. (2014). Views and attitudes of staff and students towards the significance of intercultural awareness in foreign language teaching and learning in an Australian university context (PhD thesis). Faculty of Education University of Tasmania, Australia.

Widodo, H. P., Wood, A., \& Gupta, D. (2017). Introduction: re-contextualizing English language teaching in Asia today. In H. P. Widodo, A. Wood, \& D. Gupta (Eds.), Asian English language classrooms: Where theory and practice meet (pp. 1-13). London: Routledge.

Willis, J. W. (2012). History and foundations of interpretivist research. In Foundations of qualitative research: Interpretive and critical approaches (pp. 95-146). Retrieved from https://dx.doi.org/10.4135/9781452230108.n4

Witte, A. (2014). Blending spaces: Mediating and assessing intercultural competence in the L2 classroom. Germany: Walter de Gruyter.

Wright, S. (2015). What is language? A response to Philippe van Parijs. Critical Review of International Social and Political Philosophy, 18(2), 113-130.

Yin, R. K. (2009). Case study research: Design and methods (4th ed.). USA: Sage.

Yin, R. K. (2012). Applications of case study research (3rd ed.). Thousand Oaks, CA: Sage.

Yoon, K.-E. (2007). Application of conversation analysis to teaching Korean language and culture. The Korean Language in America on JSTOR, 12, 126-144.

Young, T. J., \& Sachdev, I. (2011). Intercultural communicative competence: Exploring English language teachers' beliefs and practices. Language Awareness, 20(2), 81-98.

Zare, M. H., Nemati, F., \& Jafarian, K. (2015). Iranian EFL teachers' opinions about teaching culture in FL classroom. Science Journal (CSJ), 36(3), 1047-1067.

Zhou, Y. (2011). A study of Chinese university EFL teachers and their intercultural competence teaching (PhD thesis). University of Windsor, Ontario, Canada. 
This page is intentionally left blank 


\section{APPENDICES}

\section{Scenarios and roleplays}

\subsection{Scenario, roleplays and a conversation for modelling conversation analysis used in the first intercultural lesson}

Scenario

You are applying for a student exchange program offered by your university at a foreign university. You want your Vietnamese teacher to help with writing a recommendation letter in English for your application.

Q1: What will you say in Vietnamese with your Vietnamese teacher in this situation?

Q2: Imagine your teacher is an American, what would you say in this situation?

\section{Roleplays}

1. Your brother is turning 25 next Friday. You want to throw a surprise birthday party for him. You call the Recreational Center to request a room from $7 \mathrm{pm}$ to $10 \mathrm{pm}$. But the room is only available from $8 \mathrm{pm}$ to $10 \mathrm{pm}$. Call the center's service to check room availability and make your decision.

2. You requested a deluxe hall for your wedding Saturday, $23^{\text {rd }}$, afternoon. But the hotel put you in the grand ballroom Saturday, $16^{\text {th }}$, by mistake. You call the hotel staff to request the booking as you arranged.

3. You call the Springfield Community Center to request a change of booking for your monthly arts and crafts club meeting. You want a bigger room instead of the regular room that you have already booked because the next meeting involves party.

4. For an outdoor company event, you are calling the City of Nutley, Department of Parks and Recreation to reserve a barbecue area and the big picnic tables at Lake Park for the July 4th holiday. You will need the barbecue area all day Monday from 9am - 6pm. But the hotel only has got small tables. Finally, you agree to let your booking with smaller tables.

The conversation for modelling conversation analysis 
The following conversation took place in a workplace context in New Zealand. Read and analyse it, using the guided steps you were introduced in the lesson.

Tom and Greg have worked closely together for some time so know each other well. Greg is Tom's boss. Tom enters Greg's office to request a day's leave on Friday.

Tom: Can I just have a quick word?

Greg: Yeah sure, have a seat.

Tom: Great weather, eh?

Greg: $\mathrm{Mm}$,

Tom: Yeah, been a good week. Did you get away skiing at the weekend?

Greg: Yes we did... How can I help you?

Tom: I was just wondering if I could take Friday off and make it a long weekend.

Greg: Mm, I don't see any problem with that. You will have finished that report by then won't you.

\subsection{Scenario and roleplays used in the third intercultural lesson}

Scenario

Mai is a colleague in your office. She likes to take pictures, posts them on her facebook and checks face-book notifications all the time on her mobile phone. This takes her time from work. Therefore, your Office Head asks all people not to install any social network applications (including face-book, viber, skype, zalo...) on phone.

1. You don't agree with this idea as you don't usually check zalo during work and you need to have zalo on phone to keep in touch with friends and family.

Q1: What will you say in Vietnamese with your Head?

Q2: Imagine your Head is an American, what would you say in English with $\mathrm{him} /$ her?

2. You are not happy your Office Head's idea but you reluctantly agree.

Q1: What will you say in Vietnamese? 
Q2: What would you say in English?

\section{Roleplays}

You are interested in an online service (e.g., face-book) because it has some attractions (e.g., having your own online space, fighting boredom, expanding worldview, and making future job connections...) but your parent has some concerns about this (taking time from study, personal information safety, and unreal relationships...). You and your parent talk about this online service.

The pre-written revised hypothesis

"I see that the Americans in the conversation are willing to discuss about their disagreements with each other. They pay attention to the others' point of view instead of putting them down (e.g., "I see what you mean but..."). They use phrases to soften their disagreements and avoid conflicts ("I'm afraid...", "Oh yeah, sweetheart, Mmm...."). They also give reasons to support their opinion ("I think...", "to me...", "but I don't see..."). Understanding, and respecting other people's point of view, and politeness are emphasized. The speakers also show disagreement by reluctantly agreeing ("I can't disagree with anything you said here Mom")."

\subsection{Teachers' co-constructed scenario, roleplays used in the fifth intercultural lesson}

\section{Scenarios}

1. Two weeks ago, I bought a coach ticket for seat 4A. However, when I arrived at the coach station, this seat was sold to another passenger. If you were the ticket seller, what would you say and do? Imagine that if I were an American passenger, what would you say to me in English?

2. Have you ever been in the following situations?
a) Your booked transportation service picked you up at the wrong place;
b) The waiter/waitress brought you the food different from your order; and
c) You bought a product and recognised that it had a fault. 
3. An English-speaking customer has booked for seat number 10 with Phuong Trang Company to travel to Ho Chi Minh city. Unfortunately, when he got on the coach at the station, seat 10 was sold to another passenger, and the coach was almost full. He got unhappy. As a staff of Phuong Trang Company, what would you say and how would you handle this situation?

\section{Roleplays}

1. There was a couple who bought 2 tickets at the ticket counter for their trip. They thought they sat together but when looking at their boarding pass they found that they were not seated together. The husband was in $38 \mathrm{G}$ and his wife was in 44A. They came to you to tell you about their situation. As a staff member of the booking office, what would you say to the couple? what would you do to solve this problem?

2. A customer signed a contract to buy a car with your company. When he/she was done with his/her work. He/ she took the key to go home. When he/she went to the parking lot, space 7-G, he/she found that it was a red model, not the white compact that he/she asked for. Now he/ she comes back and talks to you about the situation. What do you say and do to solve the problem?

3. A customer bought something that was advertised $25 \%$ off yesterday. Today he looked at the receipt and found that he/she didn't get any discount as advertised. Now he/she brings the receipt back the store and talks to you- a manager of this store - about his /her situation. What do you do and say to handle this situation?

4. Ms. Baldwin is a Gold Guest member. She is staying in 1223 which is deluxe and beautiful room. The only thing that annoys her is the noise from the construction site. She comes to you- a receptionist on duty- to talk about this problem and wants you to move her to another suite. What would you say and do to handle this situation? 


\section{The sample intercultural lesson plan and worksheet}

\subsection{Lesson plan for the first intercultural lesson following the first workshop}

\section{UNIT 4 PARTIES}

\section{LESSON A: WHERE'S THE PARTY?}

\section{LESSON PLAN}

LEARNING OPPORTUNITIES:

In this lesson you will have the opportunity to:

- practice listening to short telephone conversations involving service requests, with a focus on listening to key information;

- explore the ways requests are made in English;

- and reflect on how politeness is managed in English and compare this with Vietnamese.

OBJECTIVES: By the end of the lesson, each student will have:

- developed awareness of paralinguistic strategies for managing politeness in English;

- identified, analysed, practiced, and critically reflected on a range of ways of making requests in English with a focus on how politeness is expressed in requests;

- identified useful/unfamiliar vocabulary or phrases from the lesson inputs, and put in place a plan to learn these items

- practiced listening for key information

SUCCESS CRITERIA 
- Accurately matched pictures and listening texts

- Identified up to five new words and phrases

\section{PREPARED RESOURCES}

1. Lesson plan

2. Worksheet

3. Handout

\begin{tabular}{|c|c|c|}
\hline Time & Learning skills & Classroom procedure \\
\hline & $\begin{array}{l}\text { Forming } \\
\text { hypotheses }\end{array}$ & $\begin{array}{l}\text { INTRODUCING TO NEW LESSON } \\
\text { 1. Introduction: T shows pictures about places for parties (e.g., hotel hall and restaurant) and kinds of party (e.g., } \\
\text { birthday party and wedding party) to introduce the lesson topic (party) and language focus (making requests). } \\
\text { 2. Initial hypotheses generation: } \\
\text { - T shows the following scenario: } \\
\text { You are applying for a student exchange program offered by your university and a foreign } \\
\text { university. You want your/Vietnamese teacher to help with writing a recommendation letter } \\
\text { in English for your application. } \\
\text { 1. What will you say in Vietnamese with your Vietnamese teacher in this situation? } \\
\text { 2. Imagine your teacher is an American, what would you say in this situation? } \\
\text { - T writes ss' responses (in Vietnamese and in English) on the board } \\
\text { - Thas ss generate initial hypotheses about how English speakers make requests }\end{array}$ \\
\hline
\end{tabular}




\begin{tabular}{|c|c|}
\hline & $\begin{array}{l}\text { - T writes their hypotheses on the board and has them vote for hypotheses } \\
\text { E.g.: "I think native speakers of English are usually direct/straight forward when making requests." } \\
\text { E.g.: "I think English speakers are more polite than Vietnamese speakers when they make requests" }\end{array}$ \\
\hline Roleplaying & $\begin{array}{l}\text { ROLE PLAY TASK } \\
\text { I. Pre-task: Vocabulary priming } \\
\text { - T uses pictures to pre-teach words and phrases: banquet hall, grand ballroom, barbecue, to reserve, have a } \\
\text { cancellation, to throw a surprise party. } \\
\text { II. During task } \\
\text { 1. Work arrangement } \\
\text { - T shows the four roleplays (see appendix 1.1) } \\
\text { - T divides the class into } 4 \text { groups and numbers them } 1 \text { to } 4 . \\
\text { - Each pair of ss in the same group is allocated with one roleplay. } \\
\text { 2. Individual work } \\
\text { - Thas ss read the assigned roleplay and write down appropriate responses for each role. } \\
\text { 3. Pair work } \\
\text { 3.1. Pair: Ss agree on appropriate responses in English for each role of their roleplay. } \\
\text { 3.2 Share: Each pair share and compare their conversation with the pair next to them. }\end{array}$ \\
\hline
\end{tabular}




\begin{tabular}{|c|c|}
\hline & $\begin{array}{l}\text { 3.3 Prepare to perform: Each pair rehearse their roleplay using the responses they have agreed upon. } \\
\text { 3.4. Performance: } T \text { invites one pair from each group to perform their scenario in front of class. }\end{array}$ \\
\hline Listening & $\begin{array}{l}\text { 4. Listening activity on page } 21 \\
\begin{array}{l}\text { - Ss listen to the four conversations of the listening activity on page } 21 \text {. } \\
\text { While listening, ss take notes and do Activity A and B, page } 21 \\
\text { - Ss compare their work with each other. } \\
\text { - T checks ss' work. }\end{array}\end{array}$ \\
\hline $\begin{array}{l}\text { Conversation } \\
\text { analysis }\end{array}$ & $\begin{array}{l}\text { III. Post Task: Focus on how to make requests in English } \\
\begin{array}{l}\text { 1. T's Modelling conversation analysis } \\
\text { - T introduces the model conversation (see appendix 1.1) } \\
\text { - Analysing the model conversation } \\
\text { - T asks ss questions such as: } \\
\text { - What do you notice about this conversation? What surprises you? What do you like/not like? } \\
\text { - T guides ss to analyse the model conversation in terms of: } \\
\text { - words/phrases used to make requests } \\
\text { - the intonation and stress } \\
\text { - degree of: Politeness, Indirectness, Effectiveness }\end{array}\end{array}$ \\
\hline Analysing & $\begin{array}{l}\text { 2. Ss' analysing textbook conversations } \\
\text { - Ss in pairs analyse the four the conversations' transcript of the talks they have listened to. }\end{array}$ \\
\hline
\end{tabular}




\begin{tabular}{|c|c|}
\hline Comparing & $\begin{array}{l}\text { 3. Comparing } \\
\text { 3.1. Conversation comparing } \\
\text { Pair work: Ss compare their English roleplayed conversation with the relevant textbook conversation they have } \\
\text { analysed: } \\
\text { - Words/phrases to make request } \\
\text { - Politeness } \\
\text { - Indirectness } \\
\text { - Effectiveness } \\
\text { 3.2 Cross cultural comparing } \\
\text { Pair work: } \\
\text { - Ss agree on how Vietnamese people would response in Vietnamese language for each role in the same } \\
\text { assigned scenario } \\
\text { - Ss share with the pair next to them. } \\
\text { Group work: } \\
\text { - Ss discuss: } \\
\text { - Does Vietnamese requesting style emphasize politeness and indirectness in the same way as English style? } \\
\text { - In what way are these two styles different? }\end{array}$ \\
\hline $\begin{array}{l}\text { Relating/ } \\
\text { reflecting }\end{array}$ & $\begin{array}{l}\text { 4. Relating and reflecting } \\
\text { Individual work: Ss think about their past experience in which they made requests or were requested in } \\
\text { English. } \\
\text { Pair-work: Ss discuss the following questions: } \\
\text { - What was the situation? } \\
\text { - Was the request in that situation polite and indirect or not? }\end{array}$ \\
\hline
\end{tabular}




\begin{tabular}{|c|c|}
\hline & $\begin{array}{l}\text { - How did you feel? Why? } \\
\text { - What can you learn from the experience above? }\end{array}$ \\
\hline $\begin{array}{l}\text { Revising } \\
\text { hypotheses }\end{array}$ & $\begin{array}{l}\text { 5. Revising hypotheses } \\
\text { 5.1 Ss draw a hypothesis based on analysing the conversations' transcript } \\
\text { 5.2 Ss revise their initial hypothesis } \\
\text { (E.g.: Native speakers of English are usually polite when making service requests. Some are more or less } \\
\text { direct than others. The degree of politeness or indirectness varies and is judged according to the phrases they } \\
\text { used to make requests, the intonation they said, and the context of speech.) } \\
\text { 5.3 Writing (optional): Homework } \\
\text { - Ss reflect on their learning in the lessons }\end{array}$ \\
\hline
\end{tabular}




\subsection{Worksheet for students}

\section{PART 1: STUDENTS' INITIAL HYPOTHESIS}

1. How do you think native speakers of English make requests?

2. Write down what you think.

\section{PART II: STUDENTS' ROLEPLAYED CONVERSATION}

1. Think about appropriate responses for each role and write them down.

2. With your partner, write down your own roleplayed conversation in English.

3. Think about appropriate responses in Vietnamese for each role and write them down.

\section{PART III: GUIDED STEPS}

\section{Analysing conversations}

1.1. Noticing what is said in the conversation: What phrases were used in the conversations?

\begin{tabular}{|c|l|l|l|}
\hline \multirow{2}{*}{ Conversations } & \multicolumn{3}{|c|}{ Phrases } \\
\cline { 2 - 4 } & To request/soften requests & $\begin{array}{c}\text { To make } \\
\text { conversations go } \\
\text { smoothly }\end{array}$ & $\begin{array}{l}\text { To agree/acknowledge each } \\
\text { other's comments. }\end{array}$ \\
\hline Sample Conv & $\begin{array}{l}\text { Can I have a quick word? } \\
\text { I was just wondering if I could... } \\
\text { You will have finished that report by } \\
\text { then won't you? }\end{array}$ & $\begin{array}{l}\text { Yeah sure, eh, Yeah } \\
\text { Did you get away at } \\
\text { the weekend? }\end{array}$ & $\begin{array}{l}\mathrm{Mm}, \\
\mathrm{Mm} \text {, I don't see any } \\
\text { problem with that }\end{array}$ \\
\hline Conv $\mathbf{1}$ & & & \\
\hline Conv 2 & & & \\
\hline Conv 3 & & & \\
\hline Conv $\mathbf{4}$ & & & \\
\hline
\end{tabular}


1.2. Noticing how the conversation was said: Look at the transcribed conversations and listen to them again to complete the table:

\begin{tabular}{|c|l|l|l|l|}
\hline Conversations & $\begin{array}{c}\text { Voice volume: } \\
\text { Loud or Soft? }\end{array}$ & $\begin{array}{c}\text { Which words were } \\
\text { stressed? }\end{array}$ & $\begin{array}{c}\text { Use of pause: } \\
\text { Yes or No? }\end{array}$ & $\begin{array}{c}\text { Intonation: } \\
\text { Falling or Raising or } \\
\text { both? }\end{array}$ \\
\hline Sample conv & & & & \\
\hline Conv 1 & & & & \\
\hline Conv 2 & & & & \\
\hline Conv 3 & & & & \\
\hline Conv 4 & & & & \\
\hline
\end{tabular}

\section{Evaluating and exploring}

2.1 With your partner, rate communication in terms of level of politeness, indirectness, and overall effectiveness and complete the table below with VERY or AVERAGE or NOT VERY and. Give evidence for your answer:

\begin{tabular}{|c|c|c|c|}
\hline Conversations & Polite & Indirect & Effective \\
\hline Model Conv (Tom and Greg) & VERY & VERY & VERY \\
\hline Conv 1 (speaker A) & & & \\
\hline Conv 2 (speaker B) & & & \\
\hline Conv 3 (speaker B) & & & \\
\hline Conv 4 (speaker B) & & & \\
\hline
\end{tabular}

2.2 With your partner, discuss each dimension of the conversation context and then fill in the table with HIGH or MEDIUM, or LOW: 
1. Where the conversation took place

2. Who was involved

3. What was the social status of each speaker
4. How well they know each other

5. How hard it is for the speaker to make his/her request successfully

\begin{tabular}{|c|l|l|l|}
\hline Conversations & $\begin{array}{l}\text { Status differences of } \\
\text { speakers/ (social } \\
\text { distance?) }\end{array}$ & $\begin{array}{l}\text { Level of familiarity of } \\
\text { speakers }\end{array}$ & $\begin{array}{l}\text { Level of difficulty (how hard it } \\
\text { is for speakers to achieve the } \\
\text { purpose of their requests) }\end{array}$ \\
\hline Model Conv & HIGH & MEDIUM & MIDIUM \\
\hline Conv 1 & & & \\
\hline Conv 2 & & & \\
\hline Conv 3 & & & \\
\hline Conv 4 & & & \\
\hline
\end{tabular}

\section{Comparing}

3.1 Look at your own roleplayed conversation and compare it with the relevant transcribed conversation.

a. What differences and similarities do you recognise between your own English conversation and the native English speakers' conversation?

b. What surprised you when you compare your own English conversation and the native English speakers' conversation?

3.2 Look at your Vietnamese responses in Part II. What is the style used in Vietnamese to make requests? Compare similarities and differences in communication style between Vietnamese and English. 


\section{Relating and Reflecting}

4.1 Think about your past experience in which you made request or were requested in English. Share with your partner about:

1. What was the situation?

2. Was that request in that situation polite and indirect or not?

3. How did you feel? Why?

4.2 What can you learn from the experience above? Write your answer in the following space:

\section{Revising hypotheses:}

5.1 How do you think native speakers of English make requests?

5.2 Write down what you think. 


\section{Textbook materials for the intercultural lessons following the workshops}

3.1 Textbook materials for the first intercultural lesson

Lesson 4A

\section{Parties}

\section{Lesson A Where's the party?}

\section{Warm-up}

A Connect the party spot on the left with a location on the right. Listen and check.
1 party room
a botel
2 backyard
b public park
3 bangoes hall
c privale home
4 picnic area
d restaurant

B What's your opinion about parties? Circle whether you agree (A) or disagree (D) with each sentence.
1 I like goirg to parties.
$A / D$
2 A good party has to have good food.
A/D
3 I prefer casual clothes to formal clathes when I go is parties.
$A / D$
4 An indoxe party is more fun than an outdocor cone.
5 I'm good at organizing parties
6 I can easily make new friends at parties.
$\mathrm{A} / \mathrm{D}$
AID

\section{Listening}

A Listen to the speakers talk about parties. Was each party formal or informal?

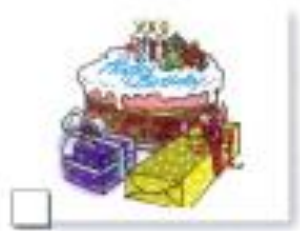

(1) a iomal

b informal

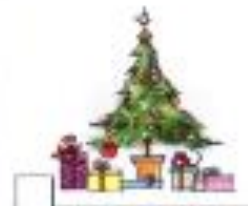

2 a tomal

b informal

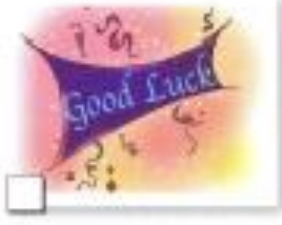

(3) a formal b informal

( 


\section{Further Listening}

A Four people are organizing parties. Where do they plan to have them? Match the place with the event.
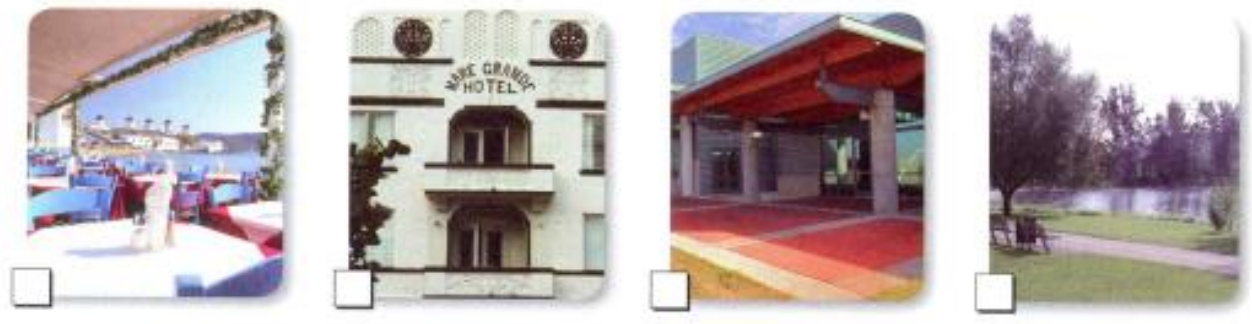

1 company event

2 wedding reception

3 birthday

4 club meeting

B Listen again. When will they have the event? Choose $\mathbf{a}$ or $\mathbf{b}$.
1 a Friday night $7-10$
3 a Sunday the 2 nd
b Friday night $8-10$
b Sunday the 7 th
2 a Saturday the 16th
4 a Monday 9-6
b Saturday the 23rd
b Saturday $9-6$

\section{Language Focus: Making requests}

- You can use Can // Will you / Could we / May / + verb to make requests.

Can thave a drink? Could we make a reservation?

Will you get me a menu? May I get some information?

$6 \mathrm{C}$ Listen again for the requests the callers make. Can they reserve the places they want? Circle yes $(\mathrm{Y})$ or no $(\mathrm{N})$ for each caller.
1 Caller 1
3 Caller 3
4 Caller $4 \quad Y / N$
2 Caller $2 \quad Y / N$

\section{Talk it Over}

With a partner, practice making and responding to friends' requests.

Can we have d patly al your house?

Will you pay for the food? 


\section{Further Listening}

1. A: Hey, thanks for calling the Old-Fashioned, DeepFried Factory! How can I help you?

B: My brother's turning 25 years old and we want to throw him a surprise party. Can I check availability for your party rooms on Friday night, the 6th?

A: You're in luck. We've just had a cancellation on that night, so it's open. The party room fits 25 people, and there's a great view of the river.

B: That's great. Put us down for 7:00 to 10:00 p.m.

A: Sorry, but it's available only from 8 to $10 \mathrm{pm}$. I'm afraid.

B: Aw, shucks ... mmmm ..., well, OK, yeah, I'll take it.

2. A: We specifically requested the deluxe hall with the crystal waterfall for the wedding Saturday afternoon.

B: I'm terribly sorry, there must have been some scheduling trouble with the hotel reservations office. We have you in the grand ballroom on that date.

A: I don't care who made the mistake, will you have what we reserved for Saturday the 23rd or not?

B: Well, yes, Mrs. Winthorp. We appreciate you as a customer, and we assure you that you will have the hall you requested on that date, Saturday the 16th.

A: Saturday the 23rd!

B: Yes, of course, as I said, Saturday the 23rd from 4:00 p.m.

\section{Audio Scripts}

3. A: Springfield Community Center this is Winona, can I help you?

B: Hi, Winona, this is Angela. What's up, girl?

A: Oh, not much. I guess you're calling about the monthly arts and crafts club meeting on the $2 n d$ ?

B: That's right, but not the 2 nd, the 7 th. Could we get - the bigger meeting room this time, instead of the regular small room? We're having kind of a party this time with snacks and soda.

A: Sure, Hon, we got you all set up for Sunday at ...

B: Sunday the 7 th big meeting room. Thanks so much. See ya!

4. A: City of Nutley, Department of Parks and Recreation.

B: Yes, this is Mrs. Spatafora with Balentine construction company. We're putting together an outdoor company event, and I was wondering, may 1 reserve a barbecue area and the big picnic tables at Lake Park for the July 4 th holiday weekend?

A: It's a bit late to call, isn't it?

B: Yes, so sorry. But we're not talking about the Monday holiday, here .... it's Saturday we had in mind. We need it all day, really, from $9: 00$ a.m. until 6:00 p.m. 


\subsection{Textbook materials for the third intercultural lesson}

\section{Lesson 7B}

\section{Lesson B My online space}

\section{Before You Lisłen}

A Read the sentences below and decide if the underlined word is a noun or a verb. Write $\mathbf{N}$ (noun) or $\mathbf{V}$ (verb) above each. Then listen and check your answers.

1 Sometimes a webpage says "enter your birthday," but I don't do it to protect my privacy.

2 I often do a search to find something quickly online.

3 I want to scan downloads to make sure they don't have viruses.

4 A good way to meet new people for business contacts is through online chat.

51 get a lot of spam mixed in my e-mail, and it's troublesome to check it all before I delete it.

B Read the statements below and circle a number to show your agreement. Rate each from $\mathbf{5}$ (strongly agree) to 1 (strongly disagree).
1 Computers help make new friends.
54321
2 Using computers makes you less social.
$54432 \quad 1$
3 Cyber friends are not real friends.
$\begin{array}{llllll}5 & 4 & 3 & 2 & 1\end{array}$
4 People you meet online are honest and kind.
$\begin{array}{lllll}5 & 4 & 3 & 2 & 1\end{array}$
5 It's wrong to suddenly end online friendships.
54321

\section{Extended Listening}

A Emily and her mother are talking about an online service. Number the topics they discuss in the order you hear them.

Protecting yourself

Fighting boredom

Expanding world view

Paying for the service

Taking time from homework

Making future job connections

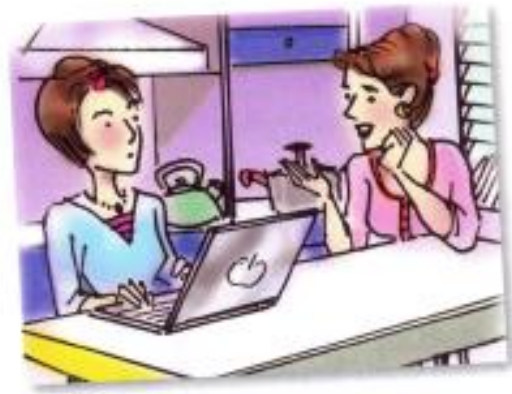

B Listen again to Emily's mother's concerns about the service. Decide if she believes the statements below are true $(\mathbf{T})$ or false $(\mathbf{F})$.
1 Stalkers attack people they meet online.
$\mathrm{T} / \mathrm{F}$
2 It's better to meet friends in the real world.
$\mathrm{T} / \mathrm{F}$
3 Going online is a great way to fight boredom.
$\mathrm{T} / \mathrm{F}$
4 Cyber friends don't feel responsibility to each other.
$T / F$
5 The idea of friendship is changing due to technology.
$\mathrm{T} / \mathrm{F}$ 


\section{Conversation Strategy: Agreeing and disagreeing}

- Here are some common phrases for agreeing:

lagree with you. You're right. That's right.

- Here are some common phrases for disagreeing:

I'm afraid I don'tagree. I don't think so, Idisagree. Wrong!

C Listen again and decide if Emily and her mother agree (A) or disagree (D) with each other on the following points.

1 The online service will expand Emily's world view. A/D

2 Online chatting is about using a machine, not interacting with people. A/D

3 Emily is old enough to try the online service. A/D

4 Real friends are more important than cyber friends. A/D

5 Chatting is going to take away from Emily's homework time. A/D

\section{Catch It! Word stress: Nouns or verbs?}

6 A Listen to the difference in pronunciation:

Examples: conTRAST ... CONtrast

The first word has stress on its last syllable. That makes it a verb. For homework you will compare and conTRAST two stories.

The second word has stress on the next-to-last syllable. That makes it a noun.

To make the photograph better, you should change the CONtrast.

B Listen to the following sentences, mark the stress, and decide if the word is a noun (N) or a verb (V).

\begin{tabular}{|c|c|c|}
\hline 1 research & $\mathrm{N} / \mathrm{V}$ & 5 present \\
\hline 2 contract & $\mathrm{N} / \mathrm{V}$ & 6 upset \\
\hline 3 address & $\mathrm{N} / \mathrm{V}$ & 7 protest \\
\hline 4 contest & $\mathrm{N} / \mathrm{V}$ & \\
\hline
\end{tabular}

\section{Try It Out!}

Read the opinions in Extending Listening C. Then write two of your own opinions about cyber friends. Share your opinions with a partner.

\section{Example:}
A: I think real friends are more important than cyber friends.
B: I disagree, I think cyber friends are real friends.

1

2 


\section{Extended Listening}

A: OK, Mom, here it is-the info about that online service I told you l'd like to join.

B: Oooh, very slick. "The world's number one site for personal connections." Sounds pretty cool, but...

A: Well, remember that membership is cheap, and I'm going to pay for it myself from my monthly allowance.

B: Yes, yes, that's right, I'm sure you will, sweetheart. I'm not arguing about money here...

A: I think that getting to know people is really gonna expand my world.

B: Yes, you're right. And you might make connections for your future career through some new friends.

A: I agree with you. This is a good chance!

B: But you must be aware that there are lots of strange people out in cyberspace too, so you need to be careful and protect yourself.

A: I hear you! Mom, you worry about me too much.

B: Hey, that's my job.

A: Oooh, yeah, what if I get some stalker following me around after dark? I could get attacked!

B: Uh, I don't think so. Ithink there's almost no chance of that happening. Keep in mind that all of this online chatting is anonymous. No one knows your name or face. What I worry about is that people might hurt you emotionally by the words they use or introduce you to ideas that are, well, the opposite of the values we taught you.

A: Mom, I'm a big girl. I CAN think for myself.

B: If you're so grown up, why do you need a computer to help you make friends? Every minute you spend with your nose to the computer screen is one minute that keeps you from the real world where you can interact with real people!

A: Oh, here we go...

B: Sweetheart, you're interacting with machines, not with people.

A: I'm afraid I don't agree. Mom. I'm using a machine as a tool to help me interact with people.

B: $\mathrm{Mmmm}$...

A: And computer communication helps to fight boredem!

B: Wrong! You see, right there, I don't like that. There are. a million other ways to fight boredom young lady. L uh, read a book. Oh, sorry, it's not high-tech enough you?

A: I am soooo not having this conversation anymore.

B: OK, OK, look, I'm sorry, I was wrong. I know you still read books.

A: All the time, thank you.

B: I guess what's really bothering me is the feeling that cyber friends, the friends you make online, are disposable.

A: What do you mean, "disposable"?

B: I mean, they're not like real friends that you take time to get to know. There's a big emotional investment in a real friendship. You're careful and kind with real friends. In the course of the friendship, you build up many shared experiences, experiences that strengthen the friendship. And, most of all, you don't end friendships easily. Do you see what l'm saying?

A: Yes, I see what you mean, but...

B: But I don't see it with this online service. What kind of experiences can you share with these people? And if you need a friend, are they going to be there for you? Yeah, these internet friendships start quickly, but they end quickly too. People just disappear online. They can act however they want.

A: But the idea of friendship IS changing with technology

B: I feel that cyber friends are a poor substitute for real friendships. To me, they're more a distraction-a game you can play on the computer. Yes, you might interact with someone and find that you like them, but I wouldn't call it friendship.

A: Ican't disagree with anything you've said here. Mom, I can't. I . . . l agree with you ... but I still want to try it.

B: - I know, Sweetie. You're right, you ARE a big girl, I gues: and I KNOW you can think for yourself, so go for it! Jus please be careful.

A: Thanks for the talk, Mom. On to my homework.

B: That reminds me! This online thing is going to take tims from your homework.

A: No, Idon't think so Mom, I promise! Look, you said tha it was $\mathrm{OK}$ and now... 


\subsection{Textbook materials for the fifth intercultural lesson}

Lesson $12 \mathrm{~A}$

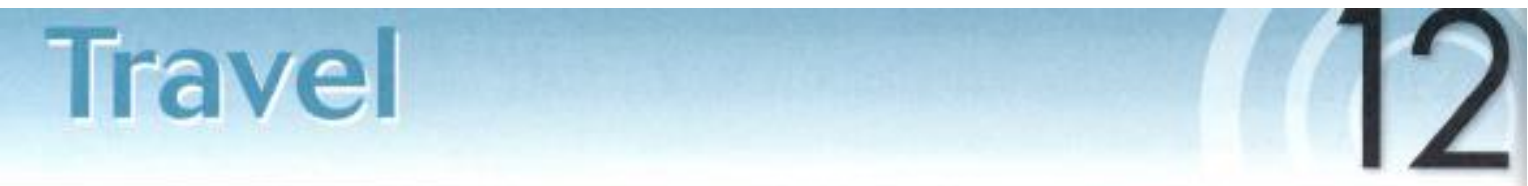

Lesson A We're terribly sorry about that problem...

\section{Warm-up}

A Look at the vocabulary words below and decide which aspect of travel each word is most closely related to.

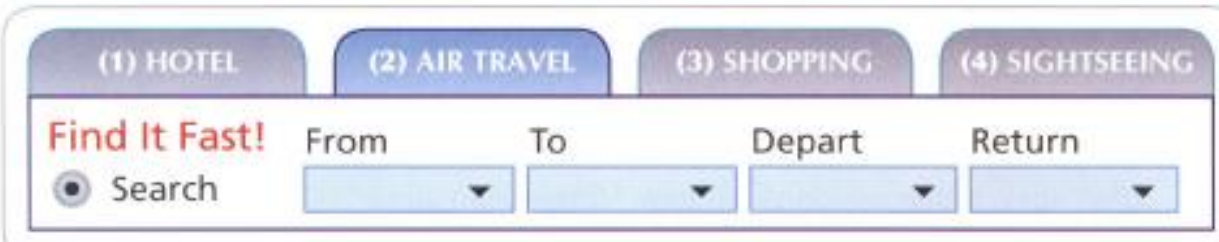

\begin{tabular}{|c|c|c|c|}
\hline $\mathbf{a}$ & souvenirs & f & mileage points \\
\hline & landmarks & $\mathrm{g}$ & museums \\
\hline & economy/business class & h & bargains \\
\hline & complimentary breakfast & i & deluxe suite \\
\hline & discounts & i & boarding pass \\
\hline
\end{tabular}

B Read the opinions about travel and decide if you agree (A) or disagree (D).

1 I prefer independent travel over a group tour.

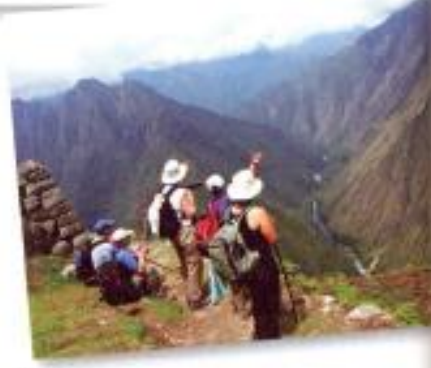

2 In a foreign country, you should always try the local food.

3 I like the challenge of using a foreign language when I travel.

4 When I visit landmarks, I take photos of myself in front of them.

A / D

A / D

\section{Listening}

A Listen to the speakers talk about different places. Where does each person decide to go?
1 a Fiji
b Hawaii
2 a Hong Kong
b Singapore
3 a London
b Paris
4 a Kenya
b Honduras

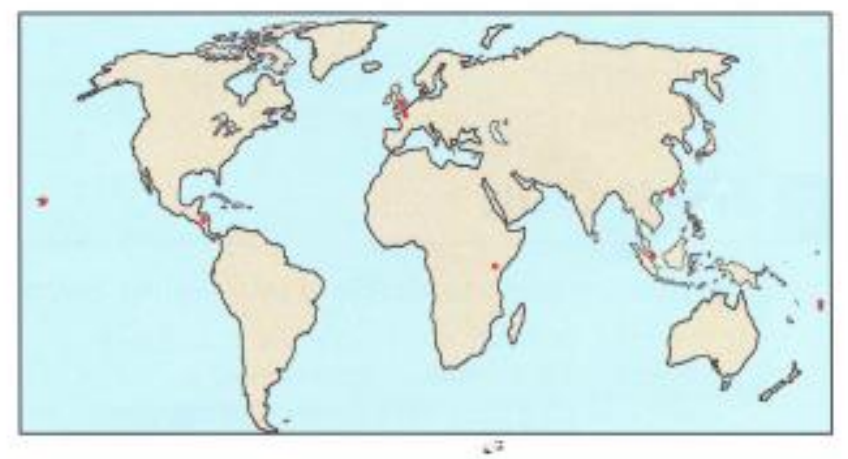


60 B Listen again. What's the main reason for going there?
1 a go diving
b go snorkeling
c relax on the beach
3 a visit museums and landmarks b practice speaking a language
c make new friends
2. a go shopping
b eat local food
c go swimming
4 a help build a school
b go sightseeing
c volunteer at a hospital

\section{Further Listening}

A Listen to the conversations. Where are the speakers? Number the locations in the order you hear them.
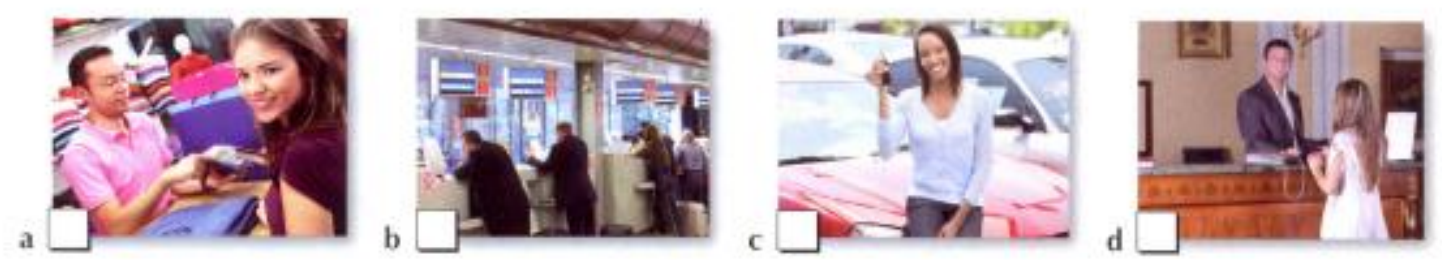

B Listen again. What are the customers complaining about?
1 a the seating
b mileage points
2 a the color
b the parking
3 a the style
c the food
c the price
b the discount
4 a the size
b the price
c the staff
c the location

\section{Language Focus: Apologizing}

- In service situations, workers use phrases like these to respond to customer complaints:

I'm terribly sorry. I'm very sorry about that.

lapologize. Id like to apologize for that.

C Listen again for the workers' apologies and decide whether the problem was fixed for the customer.
1 Yes/No
2 Yes/No
3 Yes/No
4 Yes/No

\section{Talk It Over}

Imagine different service situations (such as a restaurant, a bank, or a clothing store) and take turns making complaints and apologies with your partner.

Excuse me, 1 asked for sugar in my coffee.

I apologize. I'll get some for you in a sec. 


\section{Conversations' transcript for analysis}

\section{Extended Listening}

A: OK, Mom, here it is-the info about that online service I told you l'd like to join.

B: Oooh, very slick. "The world's number one site for personal connections." Sounds pretty cool, but ...

A: Well, remember that membership is cheap, and I'm going to pay for it myself from my monthly allowance

B: Yes, yes, that's right, I'm sure you will, sweetheart. I'm not arguing about money here...

A: I think that getting to know people is really gonna expand my world.

B: Yes, you're right. And you might make connections for your future career through some new friends.

A: I agree with you. This is a good chance!

B: But you must be aware that there are lots of strange people out in cyberspace too, so you need to be careful and protect yourself.

A: I hear you! Mom, you worry about me too much.

B: Hey, that's my job.

A: Oooh, yeah, what if I get some stalker following me around after dark? I could get attacked!

B: Uh, I don't think so. Ithink there's almost no chance of that happening. Keep in mind that all of this online chatting is anonymous. No one knows your name or face. What I worry about is that people might hurt you emotionally by the words they use or introduce you to ideas that are, well, the opposite of the values we taught you.

A: Mom, I'm a big girl. I CAN think for myself.

B: If you're so grown up, why do you need a computer to help you make friends? Every minute you spend with your nose to the computer screen is one minute that keeps you from the real world where you can interact with real people!

A: Oh, here we go...

B: Sweetheart, you're interacting with machines, not with people.

A: I'm afraid I don't agree. Mom. I'm using a machine as a tool to help me interact with people.

B: $\mathrm{Mmmm}$...

A: And computer communication helps to fight boredem!

B: Wrong! You see, right there, I don't like that. There are a million other ways to fight boredom young lady. L uh, read a book. Oh, sorry, it's not high-tech enough you?

A: I am soooo not having this conversation anymore.

B: OK, OK, look, I'm sorry, I was wrong. I know you still read books.

A: All the time, thank you.

B: I guess what's really bothering me is the feeling that cyber friends, the friends you make online, are disposable.

A: What do you mean, "disposable"?

B: I mean, they're not like real friends that you take time to get to know. There's a big emotional investment in a real friendship. You're careful and kind with real friends. In the course of the friendship, you build up many shared experiences, experiences that strengthen the friendship. And, most of all, you don't end friendships easily. Do you see what I'm saying?

A: Yes, I see what you mean, but ...

B: But I don't see it with this online service. What kind of experiences can you share with these people? And if you need a friend, are they going to be there for you? Yeah, these internet friendships start quickly, but they end quickly too. People just disappear online. They can act however they want.

A: But the idea of friendship IS changing with technology

B: I feel that cyber friends are a poor substitute for real friendships. To me, they're more a distraction-a game you can play on the computer. Yes, you might interact with someone and find that you like them, but I wouldn't call it friendship.

A: Ican't disagree with anything you've said here. Mom. I can't. I ... I agree with you . . . but I still want to try. it.

B: I know, Sweetie. You're right, you ARE a big girl, I gues: and I KNOW you can think for yourself, so go for it! Jus please be careful.

A: Thanks for the talk, Mom. On to my homework.

B: That reminds me! This online thing is going to take tim from your homework.

A: No, Idon't think so Mom, I promise! Look, you said tha it was $\mathrm{OK}$ and now... 


\section{Workshops}

\subsection{Presentation slides for the first workshop}

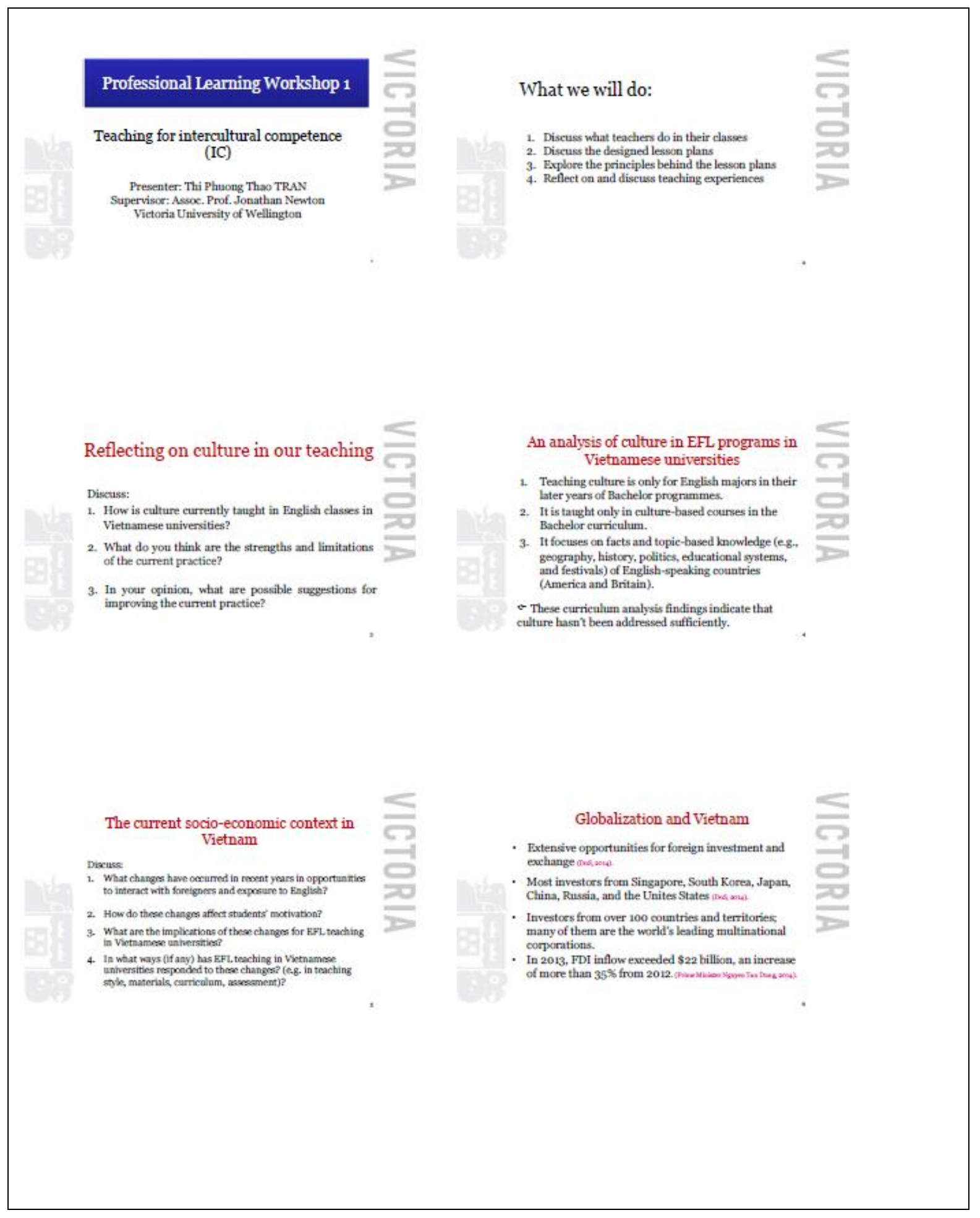


The employability of Vietnamese graduates

- Aspire to work in multicultural working contexts me

Think that intercultural dimensions of communication are important.

- Perceive their own ability to communicate across

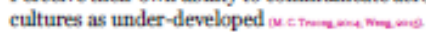

Roles of English in Asia and implications for teaching

Diecuss:

1. Does fluency in English guarantee success in communication among people coming from different countries? Why/why not?

International shifts in language teaching

and learning
focus on intercultural competence and global.

What language(s) do ASEAN nationals mostly use to communicate with counterparts from other ASEAN countries (e.g. in business, tourism, education)?

EEnglish has become the official working language in Asia motem monorot mindedness outcomes alongside linguistic and

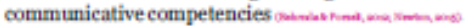

An example of pseudo communication

A post-listening activity from the textbook

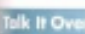

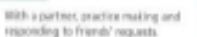

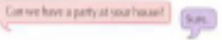

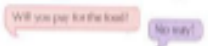

Redesigned activities to increase intercultural learning opportunities

Discuss:

What do you notice about the guided activities in the post-listening part of each lesson?

2. What steps do the activities follow?

3- What IC opportunities do these steps provide?

4. What learning outcomes do you think students can achieve from these opportunities?

5. What do you like/dislike about these activities? Why/why not? 
Steps

Step 1: Start with a hypothesis/preconception about the target culture 0es a cultual temothes)

Step 2: Analyze authentic input

1. What:

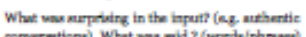

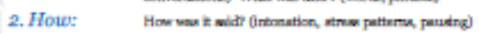

3. Evaluation: Seadenti imponviders of how polite/indinet the

4. Why: memeration max

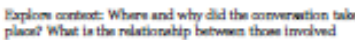

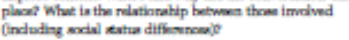

Step 3 Compar

Students own couversation $v$ s. authentic conversation.

Vietnamese style vs. English style.

Step 4: Relante and neflect

Students' own experienose, cultural sterootypes.. Step 5: Revise/ neform ulate/ ovefirm in itial hypothess

Note: Step 5 can follow erther step 2 or 4

\section{Principles behind the lesson plans} provide?

- Bxploring cultural in language ( $e$-g, the ways requests are made in English)

- Comparing with Vietnamese

- Relating this to their own experiences

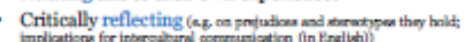

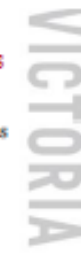

Discuss:

1. What do think are the underlying principles behind these activities?

\section{Intercultural competence:}

Intercultural awareness:

An understanding of similarities and differences between nother culture and one's own, noting that both cultures 
The intercultural communicative language teaching (iCLT)

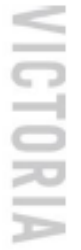

Aims of iCLT

Sensitivity to cultural differences.

- The importance of eulture in communication.

Culture not taught separately from language.

iCLT Principles 1. Make use of the social context of learning

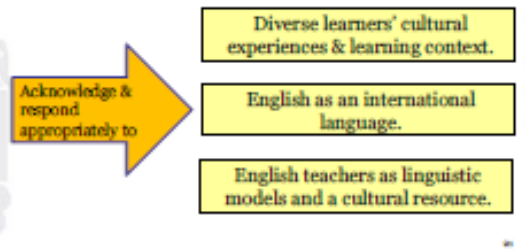

\section{Focus on intercultural learning objectives:}

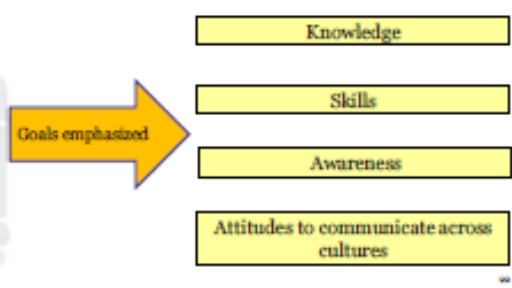

3. Adopt intercultural classroom practice

Tanguage and culture from the beginning.

Discuss:

1. In your opinion, what are the best points of iCLT? Why?

2. How does iCLT differ from traditional approaches?

3. What could be potential advantages and challenges that Vietnamese teachers may have when adogting

Exploratory and reflective approach to culture. this in tertiary EFL classes?

Explicit comparisons, \&

connections between languages and eultures. 


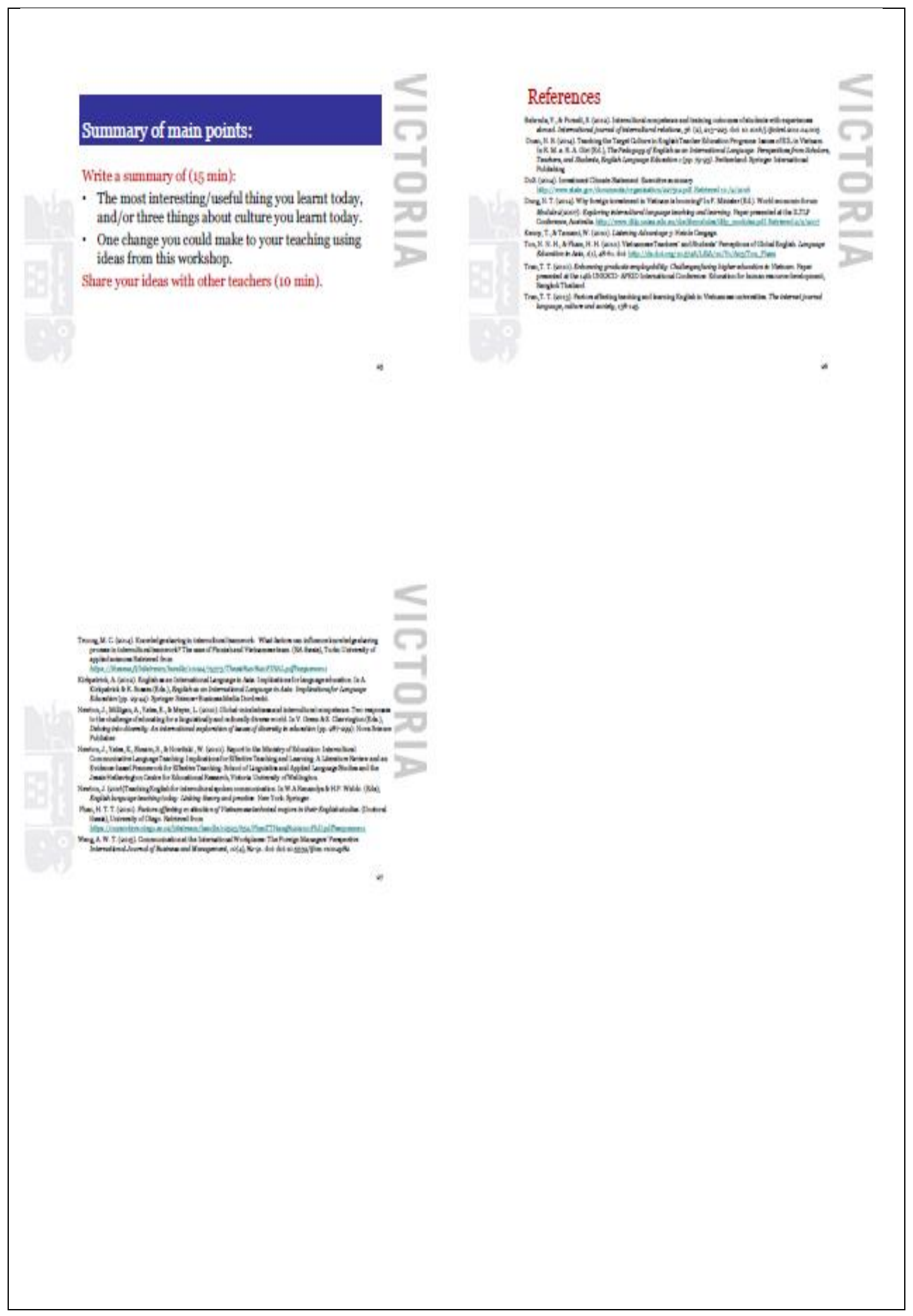




\subsection{Presentation slides for the second workshop}

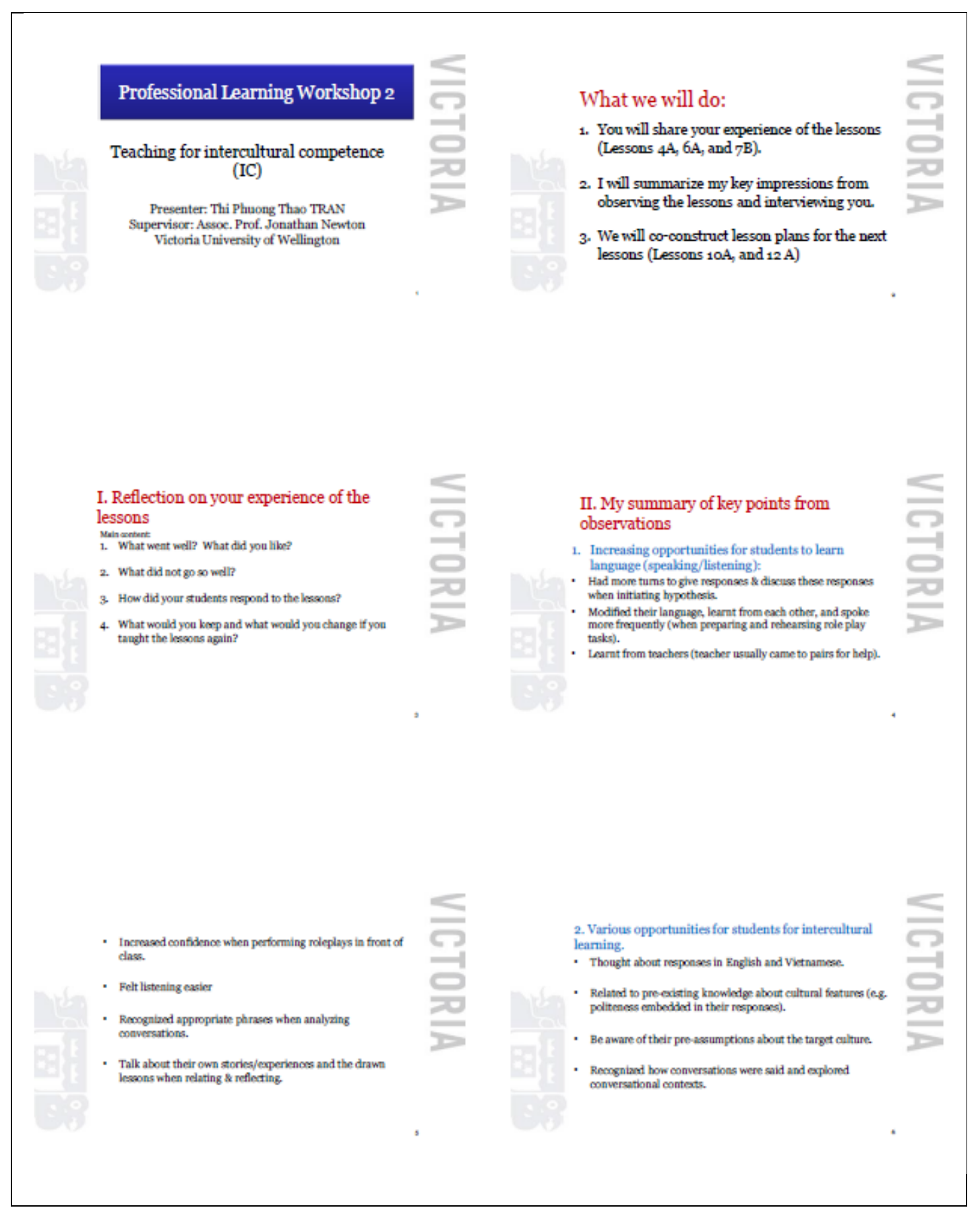


- Considered changing or kexping their hypothesia.

- Compered their own English \& native English comversa tons.

- Compared Vetnansese style and English atyle.

- Learnt from their refected leseons

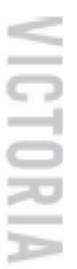

3. Students seemed to be more familiar with ANALYZING than COMPARING and REFLECTING:

Were not familiar with making Viennamese conversations in English dass.

- At first, it was not eagy for asudents to identify differenoss and similartites between Vhtnamsese and Englikh styles.

- Not always had time for sharing the drawn leseona.

4. Suggestions for improvements:

- To give instruetions for the REFL.ECTING AcP

- To do the designed staps more orally
III. Co-constructing lesson plans for next lessons

1. Lesson 10A: Further listening, page 51 Focused language strategy: giving advice

2. Lesson $12 \mathrm{~A}$ : Further listening, page 59

Focused language strategy: expressing apology
Expectations for designing lesson plans

- Evidence of using iCLT principles to design the lesson plans
Teachers' discussion and decisions

1. Discuss how you would teach the next lessons.

2. Discuss and make plans for the next lessons.

3- Arrange tasks for each of you during the interim between lessons 


\section{Observations}

\subsection{Observation protocol}

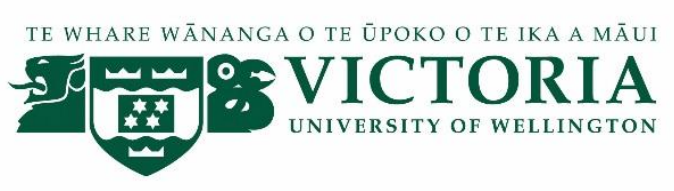

\section{OBSERVATION PROTOCOL}

Research Title:

INTEGRATING INTERCULTURAL LANGUAGE TEACHING INTO VIETNAMESE TERTIARY EFL CLASSES

This document identifies how observation, as a part of the project, is operationalized to ensure that intrusion is minimized and required data are obtained. All observations conducted in the research are for the purpose of understanding classroom teaching and learning processes and have no other purposes.

Statement of the observer's role: The researcher will take a non-participant role during observations. The researcher will not take any active participation in the classes observed. Her role is limited to observing and taking notes about the classroom processes including teacher's teaching and students' learning.

Observation approach

Since the research is exploratory in nature, the researcher takes a semi-structured approach to classroom observations. Observations collect data on a range of structured components in combination with unstructured components which happen during classroom practices.

Observation aims and objectives

Observations aim to obtain descriptive data about the current classroom teaching and learning processes from an intercultural language teaching perspective to triangulate with data collected from other methods (e.g., interviews, tests). 
Observation focus

Because observations aim at classroom processes, both teacher teaching practices and student learning will be observed. Observations on teacher teaching aim at exploring how teachers engage students in noticing, comparing, reflecting and interacting in terms of teaching and learning the speech acts in the selected units. This includes teacher' providing and guiding intercultural learning opportunities (e.g., teacher' implementation of lesson plans, uses of learning tasks and teaching materials, instructional methods, and teacher-student interactions).

Observations on students' learning involve evidence of students' engagement in intercultural learning opportunities (e.g., intercultural learning tasks), and classroom interactions. 
5.2 Classroom observation sheet

\section{OBSERVATION SHEET}

$$
\text { (Phase: ....) }
$$

1. OBSERVATION GOALS

2. GENERAL INFORMATION

\begin{tabular}{|c|c|c|c|c|c|}
\hline $\begin{array}{l}\text { 1. Research } \\
\text { context: }\end{array}$ & & & & & \\
\hline 2. Timing: & Week: & Date: & Time: & \multicolumn{2}{|c|}{ Observation number: } \\
\hline 3. Contents: & \multicolumn{2}{|c|}{ Unit title: } & \multicolumn{3}{|c|}{ Focused speech act of the unit: } \\
\hline 4. Class: & Major: & & Numbe & Students: & Room: \\
\hline \multicolumn{6}{|l|}{ 5. Teacher: } \\
\hline 6. Observer: & \multicolumn{5}{|c|}{ Tran Thi Phuong Thao } \\
\hline
\end{tabular}


3. OBSERVATION

\begin{tabular}{|l|c|c|c|c|}
\hline Time & Stages \& & Teacher teaching & Student learning & $\begin{array}{c}\text { Evidence of developing } \\
\text { skills of noticing comparing, } \\
\text { interacting and reflecting }\end{array}$ \\
\hline & main activities/tasks & & & \\
& & & & \\
& & & & \\
\end{tabular}




\section{SUMMARY}

1. Summary of how culture is taught

2. Summary of critical incidents and absence of incidents to teach culture in the lesson

3. Summary of points that need further clarification from teacher

4. General comments about the lesson 


\section{Written activity for students \\ WRITTEN ACTIVITY:}

DISCOURSE COMPLETION TEST FOR STUDENT PARTICIPANTS

Name: Email: Class:

Date:

Note: Before delivering this sheet to participants to provide their answers on, the researcher shows all the scenarios and questions on power point slides on the projector screen for everyone to read the scenarios and questions, provide explanation/clarification where necessary to make sure that everyone understands the situations and questions clearly.

Instruction: You are given the following role-play scenarios. Try to imagine yourself in the scenarios and respond to them as you would do in the real life.

Scenario 1: Requesting

You are typing up a three-page essay for your lecturer. It is due today. You have just finished the first paragraph when suddenly, your computer stops working. You see your flatmate, Emma (Australian) chatting online at the moment. You two are good friends. So you ask her to lend you her computer so that you can finish your work. It is important that you get her to agree to lend you the computer.

Question 1: Can you imagine yourself in this situation? Circle the score that best fits you.

1

Definitely NO
2 3
4 5

Definitely YES 
Question 2: How much pressure do you think your request might exert on your friend to say "Yes"?

Circle the score that best fits you.

1

Not at all
2

3
4

5

Very much

Question 3: Write what you will say in English here:

Question 4: Write what Vietnamese people usually say in Vietnamese in this situation here:

\section{Question 5:}

In your culture, does the choice to request vary according to your relationship $\quad$ YES NO with the speaker?

Give example or/and explanation:

\section{Question 6:}

In your culture, does the way you express your request change?

Give example or/and explanation: 


\section{Question 7:}

In your culture, does the choice to request vary according to topic?

Give example or/and explanation

\section{Question 8:}

In your culture, do you use more direct language with people you know well?

Give example or/and explanation:

\section{Question 9:}

What things do you consider when deciding what language to use in each case?

\section{Question 10:}

Does your choice of English vary if your flatmate is of other nationality (e.g.

Thai/Korean/Japanese)? Why?

Scenario 2: Complaining/Expressing concerns

Sara is the manager of a team within a government department. Rebbecca, Ella, Simon and Mary are all members of the team. The team has worked together for about one year. Sara has noticed an increasing number of writing errors in document produced by the team. Make your complaints. It is important that you make this act successfully. Scenario 3: Disagreeing 
You and Collum (American) are part of team of experts in a white collar, information technology (IT) organization. The team, which is largely made of men, has been brought together from several different sections of the company to work on a special project with a fixed time span. You do not agree with a proposal that David makes during the meeting because it demands a huge amount of financial investment. Express your disagreement. It is important that you soften the force of disagreement and show that you care about the feeling of the hearer.

Scenario 4: Giving advice

You and Min (Korean) are receptionists in a five-star hotel in city centre. Julie is not confident because she thinks she is not as beautiful as other people working in the reception team. Julie really wants to have some plastic surgery but she is afraid it is hurt and costly... You think Julie is already good looking and does not need any plastic surgery. Give your advice to her. It is important that Min will take your advice.

Scenario 5: Apologizing

Paweena (Thai) and you both work in a travel department. Paweena, branch manager, has higher status than you who is the policy manager in that area. Both of you have worked together for over a year. A member of your team (Minh) did not turn up for the recent meeting where she was expected to provide supporting material to Paweena. Paweena raises this with you. Express your apology. It is important that you your apology is effective and can re-establish a good relationship with Paweena.

\section{Remark}

Parts of this test are adopted from Nguyen \& Ho (2013), Malamed (2010), and Riddiford \& Newton (2010). 


\section{References}

Malamed, L. H. (2010). Disagreement: How to agree agreeably? In A. M. Flor \& E. U. Juan (Eds.), Speech act performance: Theoretical, empirical and methodological issues (pp. 199-215). Amsterdam: John Benjamins Publishing.

Nguyen, T. T. M., \& Ho, G. A. L. (2013). Request and politeness in Vietnamese as a native language Pragmatics, International Pragmatics Association, 23(4), 685-714.

Riddiford, N., \& Newton, J. (2010). Workplace talk in action: An ESOL resource. Victoria University of Wellington: Imprint Linguistics and Applied language studies. 


\section{Approval of Human Ethics Committee (VUW)}

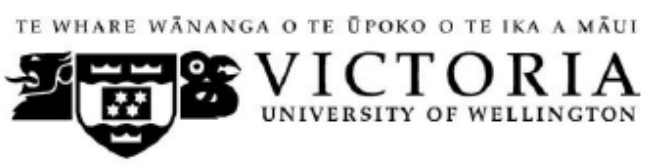

\section{MEMORANDUM}

Phone $\quad 0-4-4635480$

Email susan.corbett@vuw.ac.nz

\begin{tabular}{l|l}
\hline TO & Thi Phuong Thao Tran \\
\hline COPY TO & Dr Jonathan Newton \\
\hline FROM & AProf Susan Corbett, Convener, Human Ethics Committee \\
\hline \multicolumn{2}{|l}{} \\
\hline DATE & 12 October 2016 \\
\hline PAGES & 1 \\
\hline
\end{tabular}

SUBJECT

Ethics Approval: 23103

INTEGRATING INTERCULTURAL LANGUAGE TEACHING INTO

VIETNAMESE TERTIARY EFL CLASSES

Thank you for your application for ethical approval, which has now been considered by the Standing Committee of the Human Ethics Committee.

Your application has been approved from the above date and this approval continues until 31 May 2017. If your data collection is not completed by this date you should apply to the Human Ethics Committee for an extension to this approval.

Best wishes with the research.

Kind regards

Susan Corbett

Convener, Victoria University Human Ethics Committee 